\title{
Behind the Curtain: An Architectural Mise-en-Scène for Mise-en-Place
}

Natalie Petricca B.A.S

\section{A thesis submitted to the Faculty of Graduate \\ and Postdoctoral Affairs in partial fulfillment \\ of the requirements for the degree of}

\author{
Master of Architecture \\ in \\ Architecture

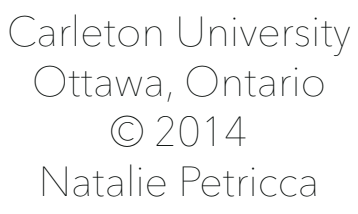




\section{ABSTRACT}

Behind the Curtain: An Architectural Mise-en-Scène for Mise-en-Place explores public spaces in the City of Ottawa with an interest in their theatrical potential. Utilizing historical precedents such as Greek and Elizabethan theatre traditions and scenographic devices, identified as frames, layers, point of view, choreography, lighting and viewer-viewed relationships, these "theatrical" civic moments are enhanced by the implementation of architectural elements with the intention to bring an awareness of their performative qualities.

In preparing the thesis project, the urban theatrical devices are further explored in the making of a neighbourhood-scaled intervention. This proposal is supported by a program - a Cultural Centre and Culinary Cooperative - which in itself contributes to interpersonal relationships analogous to the viewer-viewed aspects in theatre. This unique architectural programming also supports a community need - that of a social gathering space for local women from a traditional Italian community who generally remain isolated due to existing social dynamics and traditional gender roles. 


\section{ACKNOWLEDGMENTS}

To my parents, Claudene, Destin, Jaclyn and Jess. Thank you for your unending support.

To Yvan Cazabon. Thank you for your steadfast advice.

To my grandparents, the inspirations for this thesis. Mario and Teresa Zucchetto,

Ferdinando and Vincenza Petricca. Thank you for all you did that allowed me to get to this place in my life. 


\section{CONTENTS}

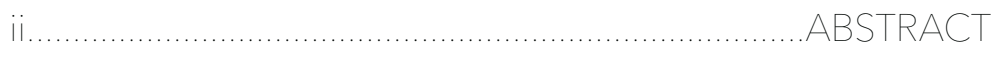

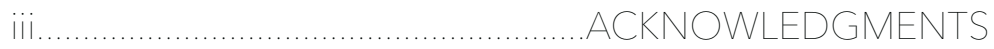

1 .........................................................

7 .................................... 1: (COMMUNITY) CENTRE

53 ...................................... 2: (TEACHING) CENTRE

75................................ 3: (ENTERTAINING) CENTRE

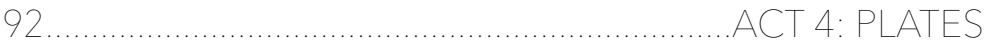

110

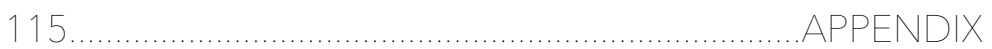

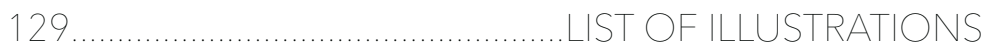

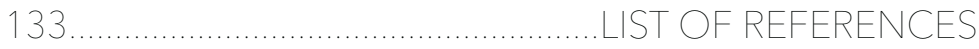




\section{INTRODUCTION}

\section{TERMS OF REFERENCE}

The mise-en-place of the proposed architecture provides the ingredients that allow for the mise-en-scène to occur.

Mise-en-place: A French phrase which means "putting in place", as in set up. It is used in professional kitchens to refer to organizing and arranging the ingredients (e.g., cuts of meat, relishes, sauces, par-cooked items, spices, freshly chopped vegetables, and other components) that a cook will require for the menu items that are expected to be prepared during a shift. ${ }^{1}$

Mise-en-scène: An expression used to describe the design aspects of a theatre or film production, which essentially means "visual theme" or "telling a story"-both in visually artful ways through storyboarding, cinematography and stage design, and in poetically artful ways through direction. Mise-en-scène has been called film criticism's "grand undefined term".?

In addition, within this thesis the following theatrical terms are used to draw parallels with architectural explorations:

\section{Theatrical Devices:}

Layering: The use of unique pieces of information in a specific sequence to provide information.

Framing: A border that encloses a scene in theatre to signify that what is being seen is a fragment of an experience and detached from reality. The most prominent example of a frame in theatre is the proscenium arch.

Choreography / Staging: A sequence of movement that is predetermined, either performed by an individual or by a group. In theatre this movement is staged by a choreographer or director, but in the proposed architecture can be scripted by providing views, change in levels, and partitions.

Point of View: The position from which the spectator observes the actor or the scene. This determines the spectators interpretation of the play.

Lighting: A specific arrangement and quality of illumination in order to facilitate relationships and to create desired effects.

Fourth Wall: The imaginary wall between the actors and audience in a traditional proscenium theatre. It is as if the audience is observing action separate from their reality through an invisible wall.

Sets: The collection of scenery and stage furniture that add information about where the play is taking place. 
Scrims: A piece of gauze cloth that is woven in such a way that when lit from behind is transparent and when lit from the front becomes opaque. It is used in theatre to mask actors or pieces of set in order the reveal them when desired.

Props: A portable object used by the actor to add information to the scene.

Backdrop: In traditional theatre, a painted cloth hung at the back of the stage to add information to the scene. In some theatre, the backdrop is a large built up set piece.

\section{Theatrical Results:}

Viewer / Viewed Relationship: The interchange between the viewer - spectator and the viewed-actor. Many factors such as point of view, lighting and sound influence this relationship.

Suspended Disbelief: A device used in theatre to encourage the audience to delay judgment on the implausibility of what is occurring. Only in a state of suspended disbelief can the audience engage with and believe a work of fiction.

Narrative Sequence: The order in which a series of connected events are told to an audience through words or images.

Temporality: Existing within or having some relationship with time.

Spatiality: Existing within or having some relationship with space and surroundings. 


\section{THE HISTORICAL THEATRE}

At the Acropolis in Athens, thought to be the place that theatre originated, the theatre was located at the end of the spectator's journey through the city. It was situated high on a mountain without walls or curtains, making the city of Athens the backdrop and its daily events the context in which the play was set. The actors and spectators entered through the same passageway, therefore symbolically equating them. In Greece, actors and spectators were equally lit, and the reaction of the spectators was equally important as the gestures and speeches of the actors. In this context the architecture created a container for the spectators and a frame for the setting of the city beyond.

Similarly, the Elizabethan theatre of the 17th century encouraged the audience to actively engage with the play to the point that they became quite loud, boisterous and unruly. As Western society changed and developed, theatre evolved to become enclosed buildings with specific architectural elements, setting a tradition of stage, auditorium, balconies, back stage and lobby distributed with varying relationships and this standard is continued into contemporary theatre. During the Elizabethan era, theatres started out as the work of craftsmen, not acclaimed architects, and housed any event that people would pay money to see. There was no social hierarchy to the seating, affording the opportunity for the social classes to intermingle. The stage was thrust out into the middle of the space, and the actor was raised above those standing on the floor in the area called "the pit". It was also during this period that gas lighting was invented.

Eventually, the audience was plunged into darkness and the actor fully lit, breaking the feedback loop between the actor, spectator and urban backdrop found in ancient Greece.

By the mid nineteenth century, going to the theatre became not only a cultural event, but also an indicator of social class. In Garnier's Paris Opera this became particularly apparent and became the first instance where attending the theatre to see and be seen, 
and to hear and be heard in the lobby became more important than the presentation in the auditorium. The lobby and its grand staircase became a stage of sorts, with the theatrical event blurring the lines between actor and spectator. This architecture of the spectacle however was disconnected from the city, while the Greek theatre was able to maintain a connection.

\section{THE URBAN THEATRE}

Most of the moments of theatrical potential occur in spaces where two conditions come together but do not meet - the courtyard in front of an office building or the alley between two buildings. On the scale of the city, these can be seen as joints, or as Marco Frascari describes in his essay, "The Tell-the-Tale Detail", the details:

\footnotetext{
....any architectural element defined as detail is always a joint. Details can be "material joints," as in the case of a capital, which is the connection between a column shaft and an architrave, or they can be "formal joints," as in the case of a porch, which is the connection between an interior and an exterior space. ${ }^{1}$
}

In the early research stages of this thesis, many of these spaces examined concepts and techniques of theatre, namely; the viewer-viewed relationship, layering, framing, lighting, point of view and staging/choreography. This analysis generated the proposals for a spatial and materal design meant to increase the theatricality of these spaces while identifying the architectural conditions within the city that lend themselves to a theatrical experience. These found urban spaces are seemingly ordinary yet have inherent performative qualities. Architectural elements and theatrical techniques could be implemented to reinforce this theatricality and to make it more apparent.

\section{SELECTING A SITE FOR THE THESIS PROJECT}

The analysis of urban theatricality informed the project site selection. It was necessary to examine an urban area's theatrical potential and to analyze it through a theatrical lens. Consequently, the community of Little Italy, and specifically the vacant site at Preston and Larch, was chosen for both its proximity to downtown and existing theatrical potential. When analyzing the community, two qualities stood out; the abundance of balconies 
and the extensive use of lighting. Respectively, balconies occur on the ground floor as most houses are elevated, resulting in a series of small staircases and balconies overlooking Preston Street. The balconies also vary greatly in size, but form a distinct visual rhythm, especially along the west side of the street. Much like the galleries in the Elizabethan theatres these balconies allow residents to view the "play" of Preston Street while remaining physically separate from it. Secondly, lighting is used extensively with varied qualities, intensities and scales. Illumination, though not apparent during the day, transforms the street at night. Large lights are used at each corner to illuminate the intersections, while smaller, more decorative lamp posts are used rhythmically every few meters to illuminate the sidewalk. In addition, many businesses leave their lights on at night, causing light to spill out of their largely glazed façades onto the sidewalk. These factors, make the site at Preston and Larch appropriate for an architectural intervention which utilizes theatrical relationships to promote education.

\section{THE PROPOSED ARCHITECTURE}

The community of Little Italy along Preston Street in Ottawa is largely populated by elderly Italian couples and ingrained with certain socio-cultural traditions and values. One tradition that is culturally accepted among senior Italians is that most retired men leave the home during the day to play cards and drink espresso with friends, while the women stay home minding the garden, performing household chores and preparing meals. Some of these women rely on their husbands for transportation, thus leaving them physically and socially isolated inside the home. Currently, similar centres for these women to go to congregate do not exist other than St. Anthony's Church at Gladstone and Rochester. Therefore, the program being brought to the area is a Cultural Centre and Culinary Cooperative. The tradition of making all your own food, including sauces, preserves, bread, pasta, wine and sweets is also part of traditional culture, and as a result the kitchen becomes the central gathering place of the home. Based on this, a public space where women can come together, cook and socialize is deemed desirable in 
the community. This common space could facilitate the passing-on of traditions by engaging a younger generation as well as other cultural groups. A garden and event space would also be incorporated so that people could learn where their food comes from while celebrating events and holidays as a community.

There is a strong connection between the act of assembling ingredients to create a meal and the expression of a narrative and action in space. Borrowed from the art of French cooking, the mise-en-place is an assembly of particular ingredients to create a dish and the creating of an action in space in theatre is referred to as the mise-en-scène. When examined in parallel, there are many connections that can be drawn between the two and a theatrical lens lends itself well to an exploration of a culinary centre. At the scale of the city, there are multiple moments of theatrical potential that can be examined and their qualities and characteristics applied to the architectural proposal. The miseen-place within the city identifies the inherent ingredients that can be emphasized and added to in order to create a moment with theatrical "potential", or the mise-en-scène.

This thesis aims to discover and construct theatrical moments within the actions of the "everyday". The architectural program of the Cultural Centre and Culinary Cooperative would therefore be defined with an emphasis on theatrical exchange. As theatre was first used to educate the masses on the laws of the city in ancient Greece, it is appropriate to use a theatrical lens to design a space for teaching.

Notes

1. Marco Frascari, "The Tell-the-Tale Detail." VIA 7: the building of architecture (Cambridge, Massachusetts: MIT Press, 1984) 
ACT 1: (COMMUNITY) CENTRE 


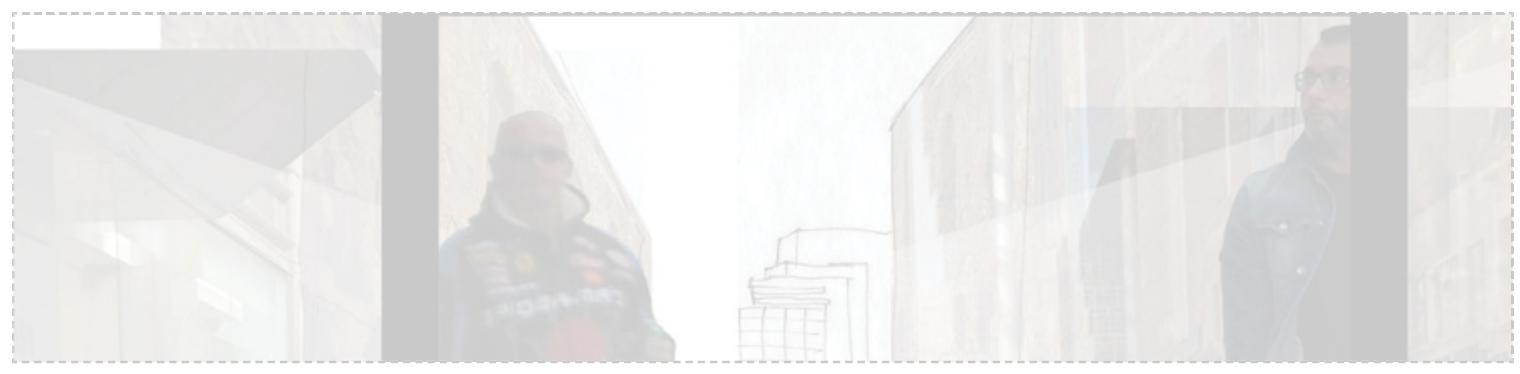

The characteristics imbued in the proposed architecture set up the potential for theatrical moments when actors and spectators are added. In theatre, Robert Le Page uses the technique of mise-en-scène to explore the interchange between the actor and the theatre space or architecture. He provides the actors with the resources to interact with and transform the mise-en-scène, therefore it is ever evolving and adapting to the actions of the actors. It has an inherent kinetic quality and this movement is what defines: the space it occupies. ${ }^{3}$

Set Direction: It is early morning in the springtime and the light is streaming in across the entrance in long narrow bands resembling a colonnade. When the artificial lighting comes on it is low over the cook tops and the rest of the space is day lit.
There is very little sound in the building, just the slight trickle of water from last night's rainfall running down the gutters in the back garden. The herbs growing on the green wall at the back are fragrant and enliven the building. 


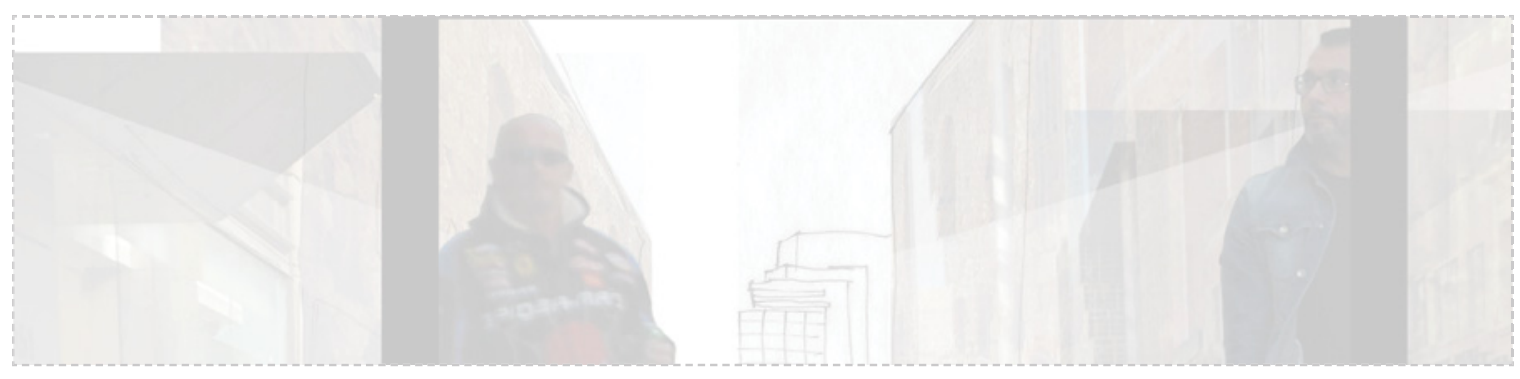

Le Page feels that human action is what gives meaning to space ${ }^{4}$ and within the proposed architecture it is the didactic actions that give the space richness. The architecture in this space is present in order to encourage this exchange. The actors and: spectators become components of the mise-en-place as their roles shift creating kinetic movement in the mise-en-scène, as Le Page described. The roles between actor and spectator are ever evolving and shifting as a person advances through the building and their ability to influence the mise-en-scène is dependent on what role they are playing at the time.

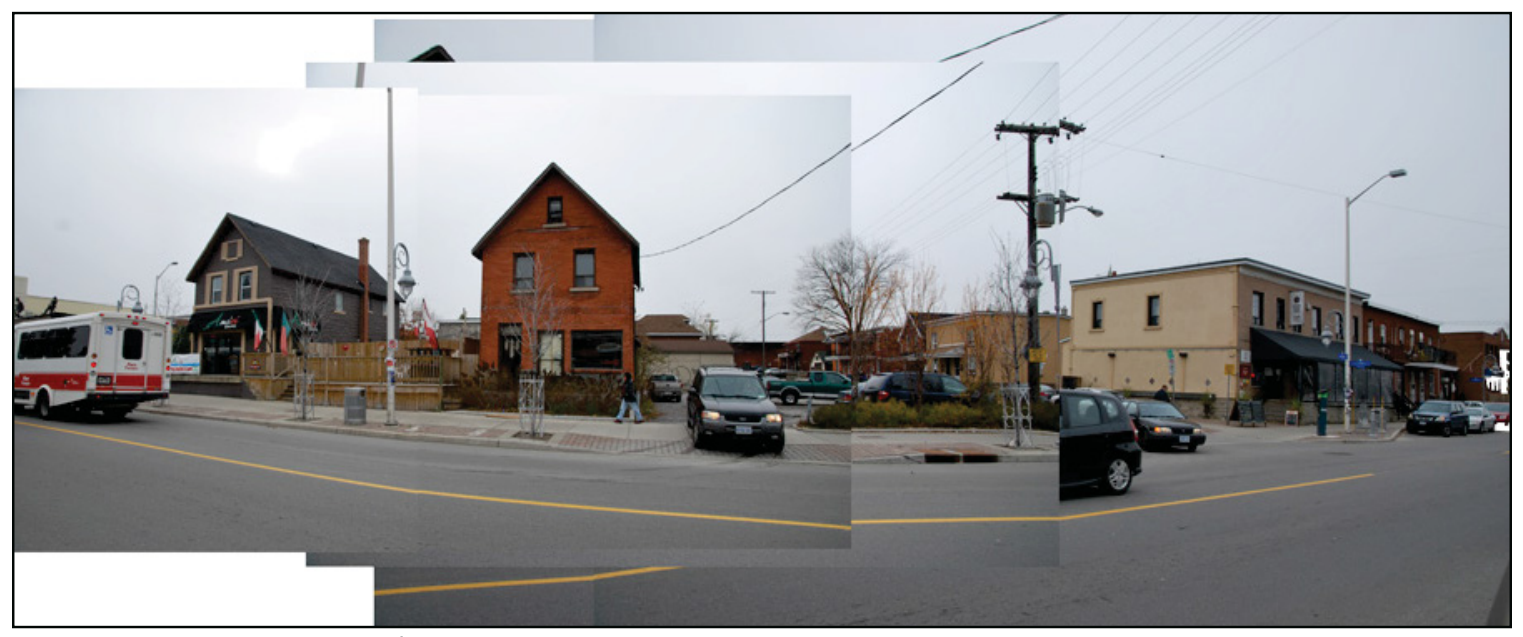

Figure 1: Existing Preston Elevation 

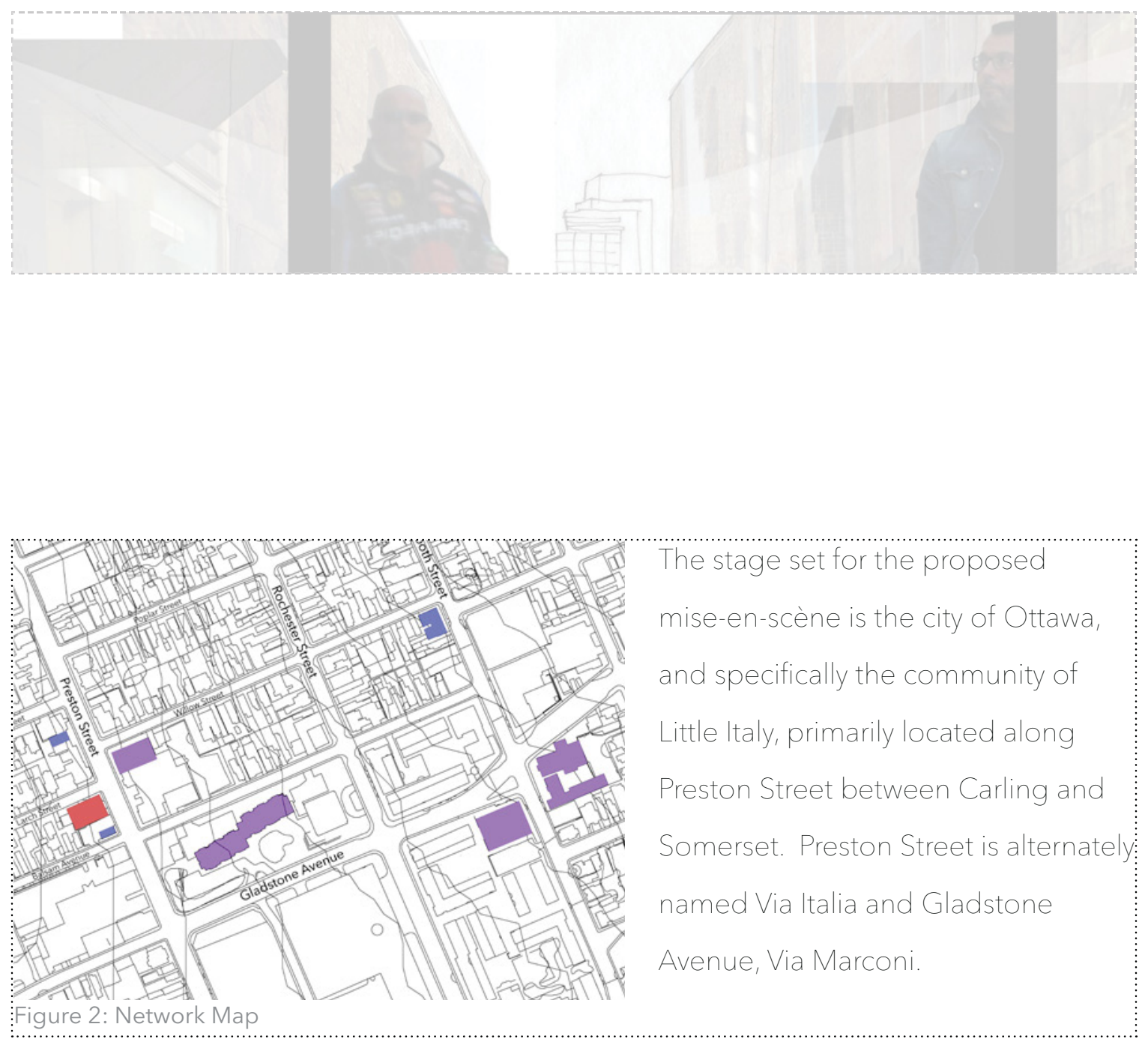

Maria walks from her home on Preston

Street just south of Somerset and enters through the glass structure off of Preston. She has a key, as do all the ladies belonging to the center, and she unlocks the door and lets herself in.

She is the first to arrive so she turns on all the lights. Just inside the front door she hangs her coat, puts on her apron and changes into indoor shoes.
Maria goes to her cooking station, unlocks it and puts her jars of tomato paste and puree on the counter. She pulls the ground veal, pork and an egg out of the fridge to bring it to room temperature.

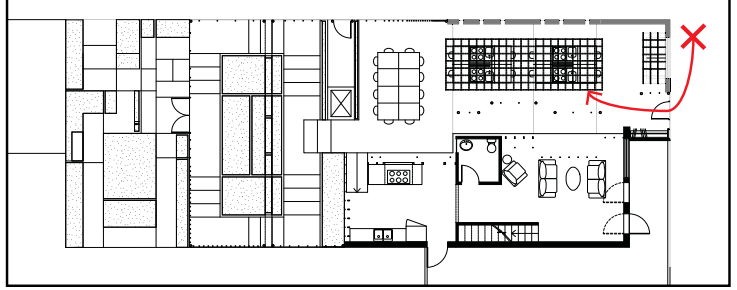




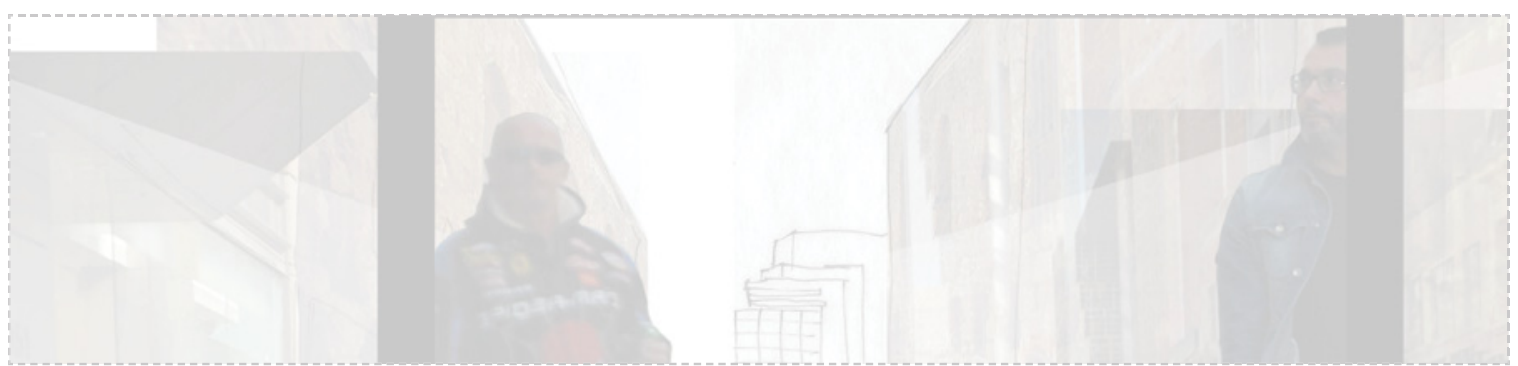

The area is mostly populated by restaurants and cafés, with small, single family dwellings along the streets running perpendicular. Most of the traffic in the area is vehicular along Preston, with very little traffic moving east-west, as the O-Train tracks lie to the west and consequently many of the streets are cul-de-sacs. Some pedestrian traffic does occur, but this is mostly people walking from their vehicle, parked on the road or in one of the various parking lots, to a restaurant for dinner. Thus, the area is mainly active at night, although additional activity can be observed to and from the cafés, government offices, or the yoga studio during the day, especially when good weather permits casual strolling.

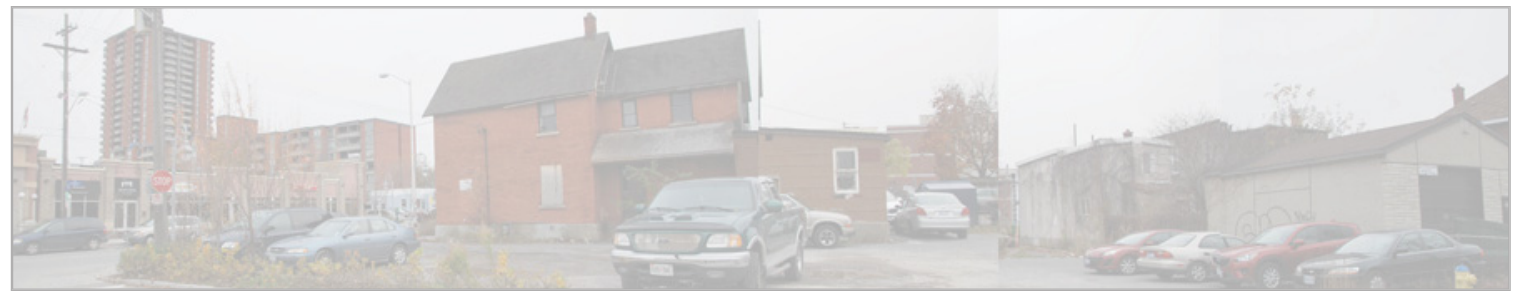




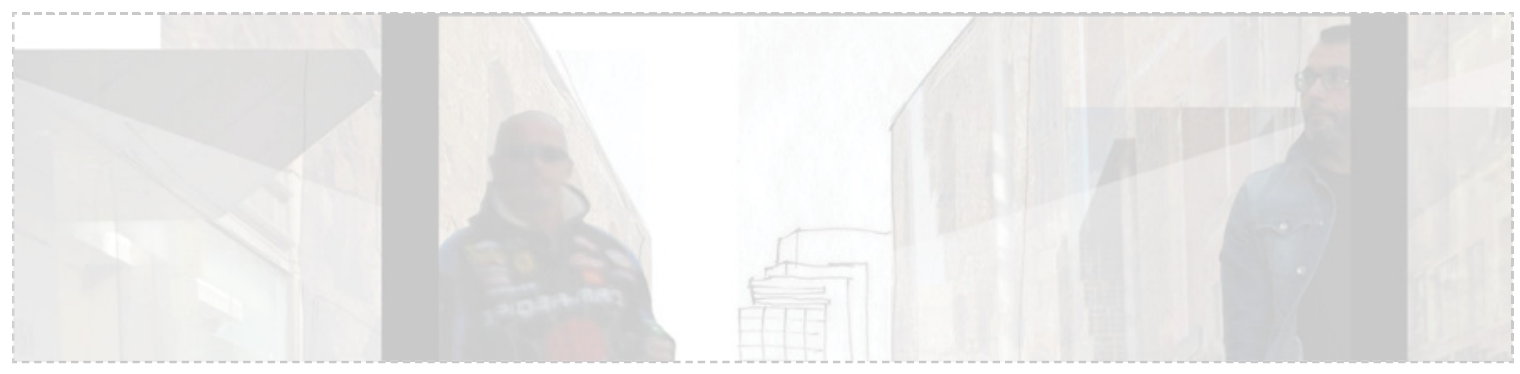

While the area is changing both physically, with new condo developments being constructed at Preston and Carling, and demographically, with an increasingly diverse population, many of the original Italian families have remained in the area, most being seniors. Their main areas to congregate in the community are St. Anthony's Catholic Church on Gladstone, the Italian Canadian Community Centre at the Gladstone Terrace, and Sala San Marco, but otherwise there are no spaces designated for this function.

The Italian culture is still very much present in Little Italy, and there are certain social dynamics that are very prevalent between men and women.

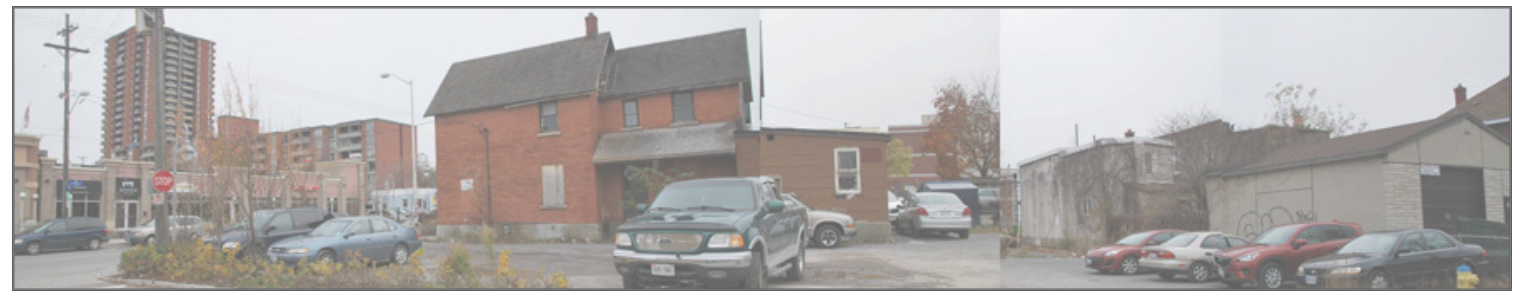




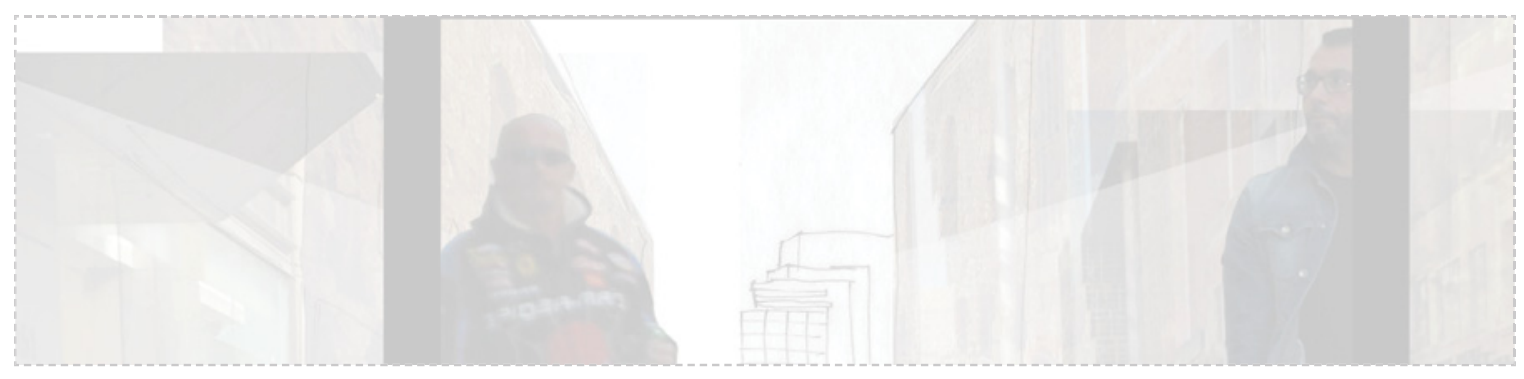

During the day, the men who are retired usually socialize; playing cards, watching the soccer game and drinking espresso with their friends at the local bars or cafés. Contrastingly, most women stay at home to cook, clean and generally look after the household. These women remain isolated, with some of them reliant on their husbands for transportation. What is missing in the community is a place for the women to congregate and perform tasks they enjoy. Among the senior population there is evident: pride in growing and making what you eat and drink. This includes everything from vegetables and herbs grown in the garden, to preserves, bread, pasta, sauces, and wine.

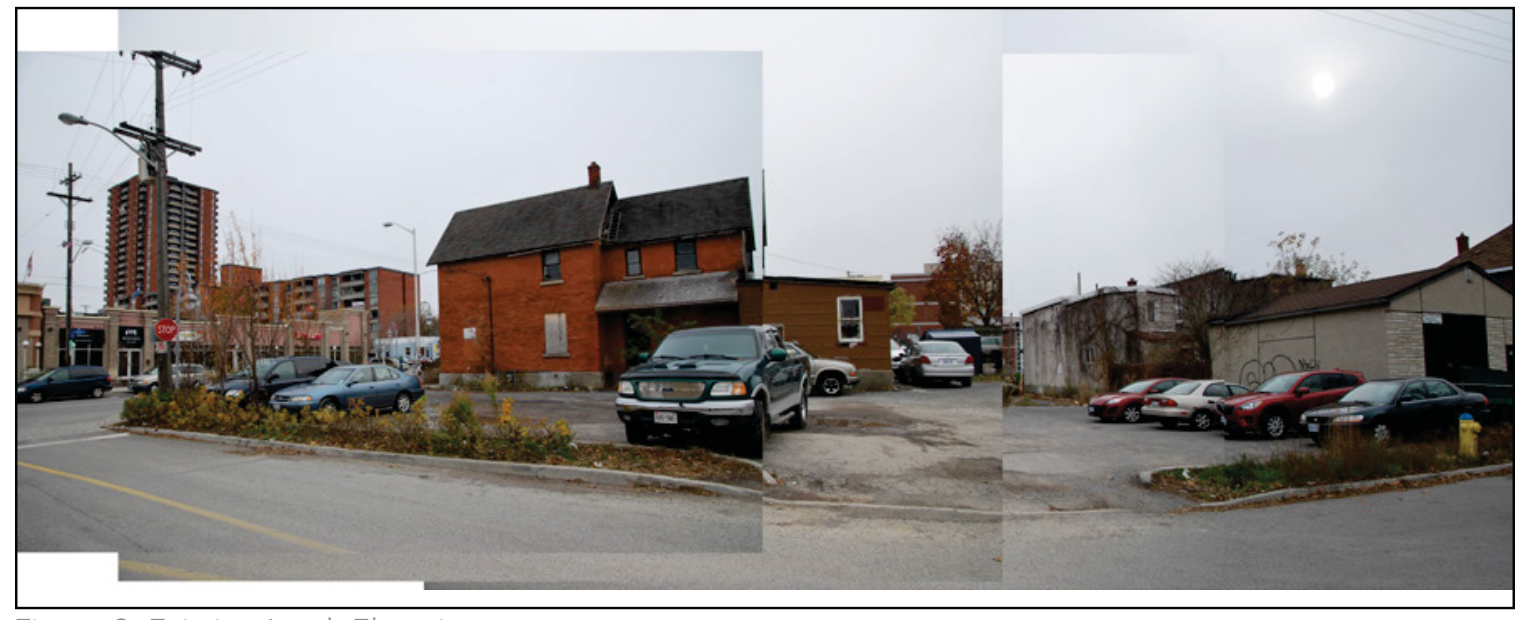

Figure 3: Existing Larch Elevation 


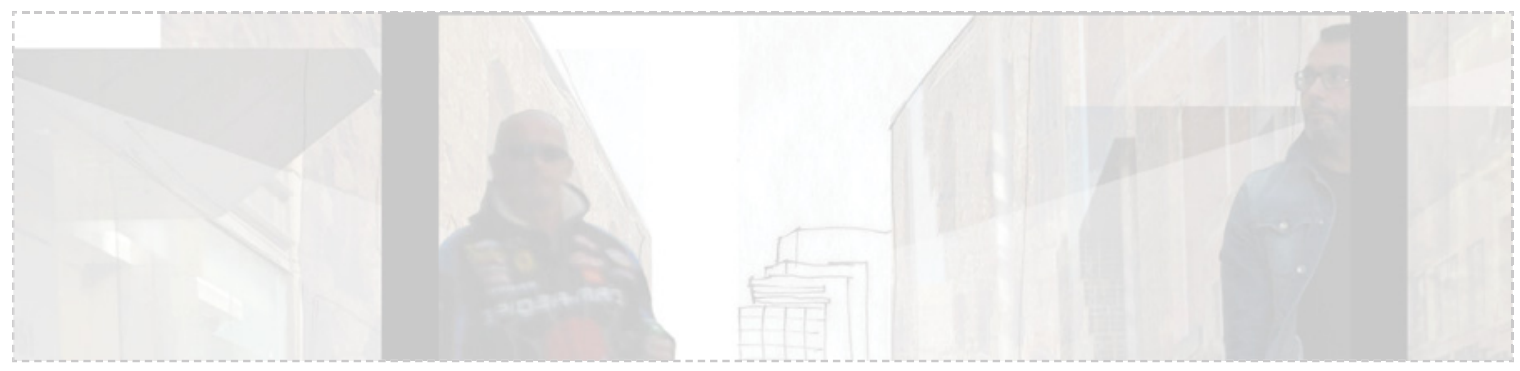

There is also a tradition of gathering with family and friends, congregating around the kitchen while the host is cooking and then sharing a meal together. The sharing and savouring of food and wine is very much ingrained in the Italian culture, therefore there is a strong emphasis on food in the area, although there are few locations serving unprocessed varieties. The identification of both lighting and the use of balconies along Preston Street as ingredients of the mise-en-place allows for a mise-en-scène of theatrical moments.

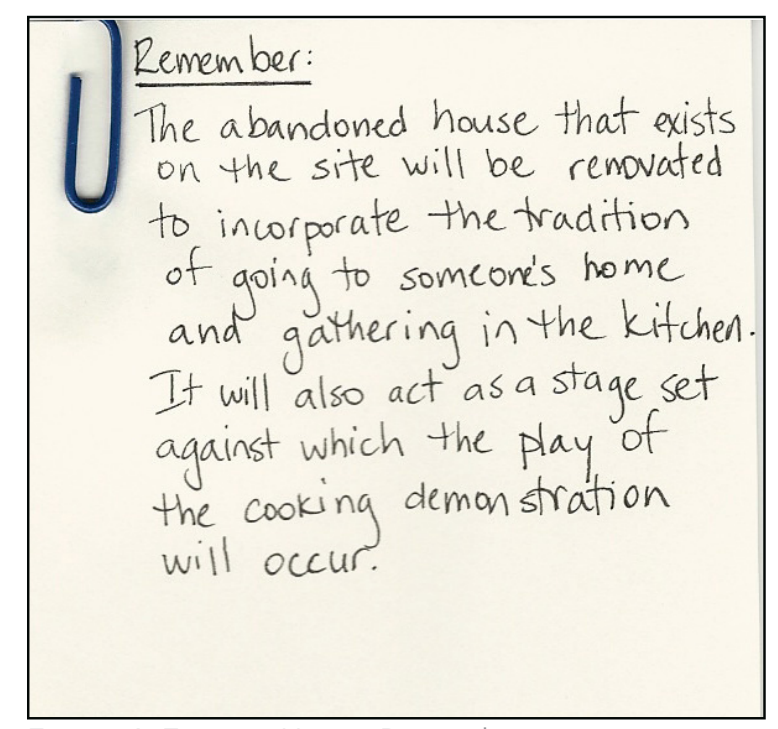

Figure 4: Existing House Reminder 


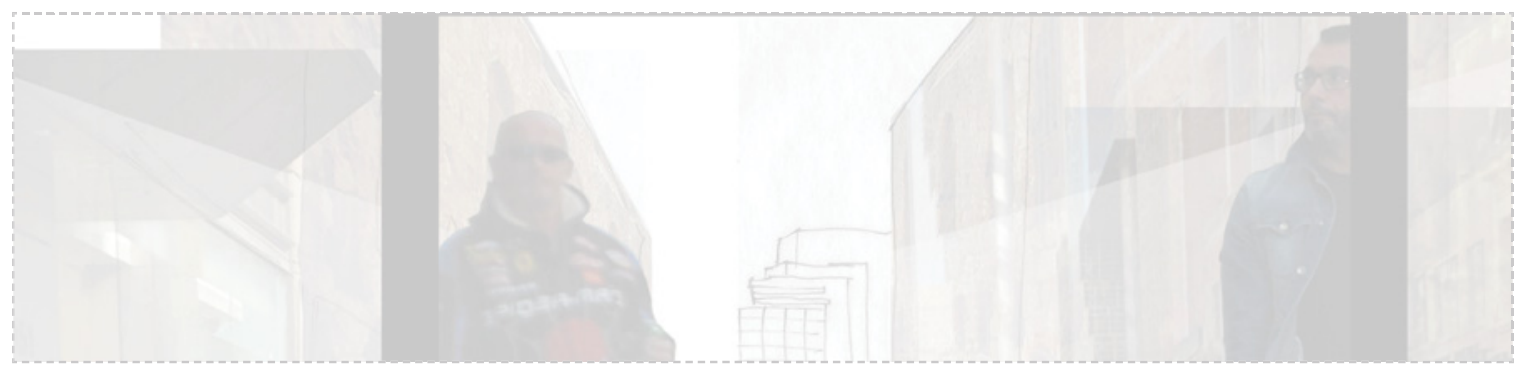

Instead of the women staying at home and completing their daily tasks in isolation, the proposed community kitchen and garden would allow them to cook in the company of friends, and to remain socially active. It would become a didactic space for passing on traditions to the younger generation. The centre would serve as a social space outside the home in which women will undertake larger communal cooking projects than they could individually. While not its primary function, the space also has an inherent flexibility in order to allow secondary activities such as women bringing their grandchildren for the afternoon or bring their children to help harvest the garden in the fall. As the older generations pass away, their skills, knowledge and traditions, for the most part, are being lost with them.

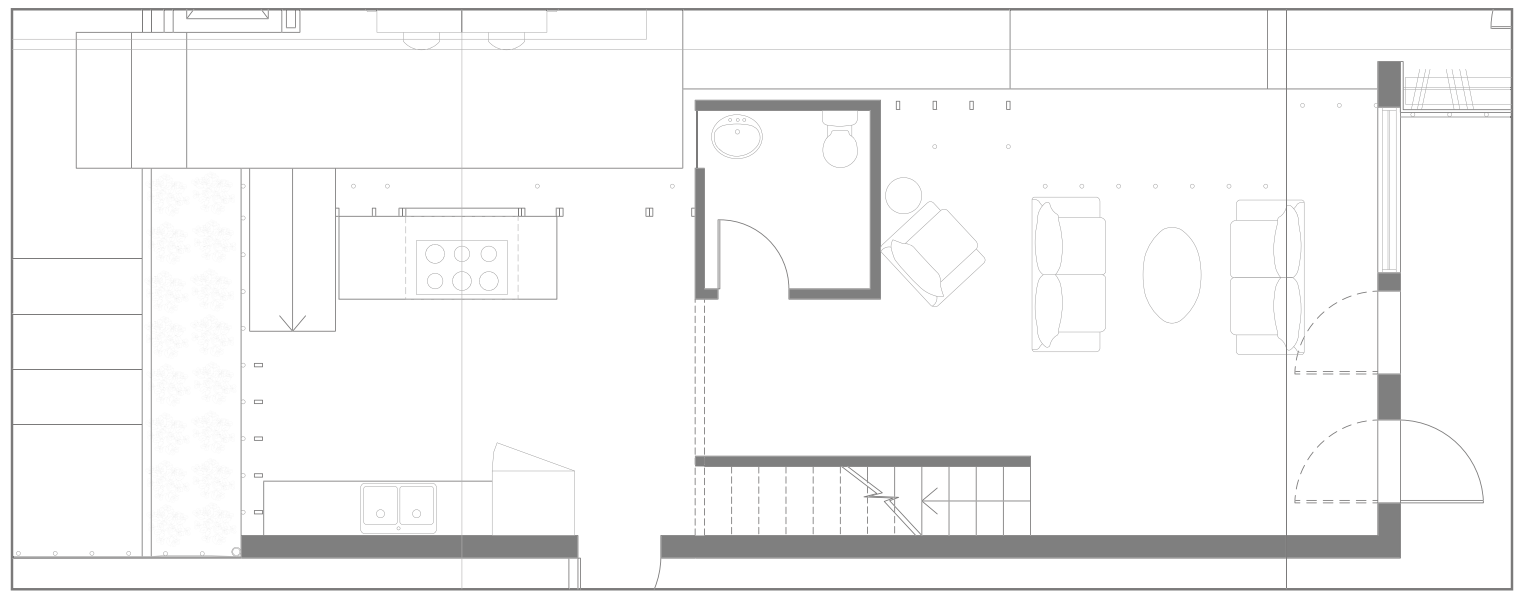

For full scale drawings please see page 92 


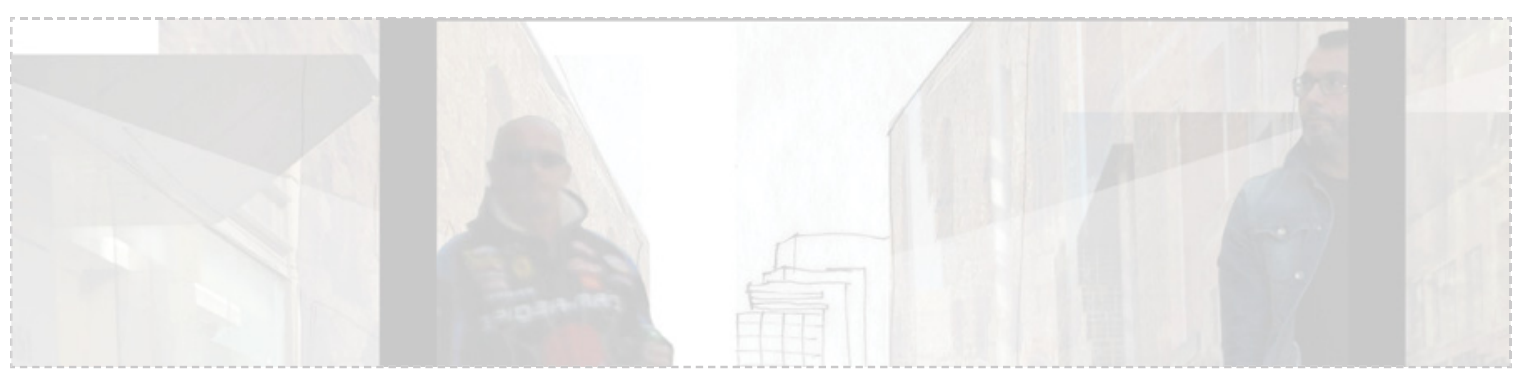

For this reason, one component of the building's programming allows for teaching and disseminating traditions and recipes. Visitors to the centre would learn how to plant a garden, when to plant certain vegetables, how to tend the garden and when and how to: harvest. During the day, the space would function as a community kitchen and teaching space, and at night could host various events and celebrations. It will be a space that will serve the community as its first objective, and present social and cultural relationships in a theatrical way.

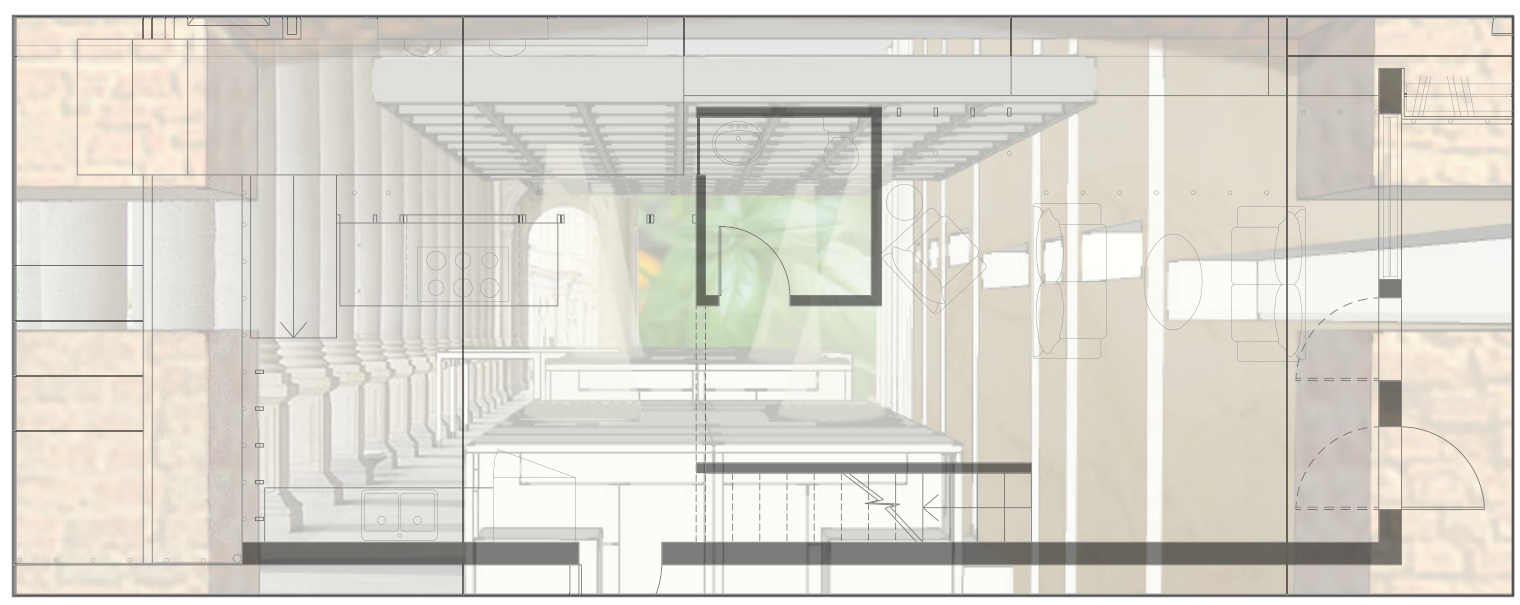




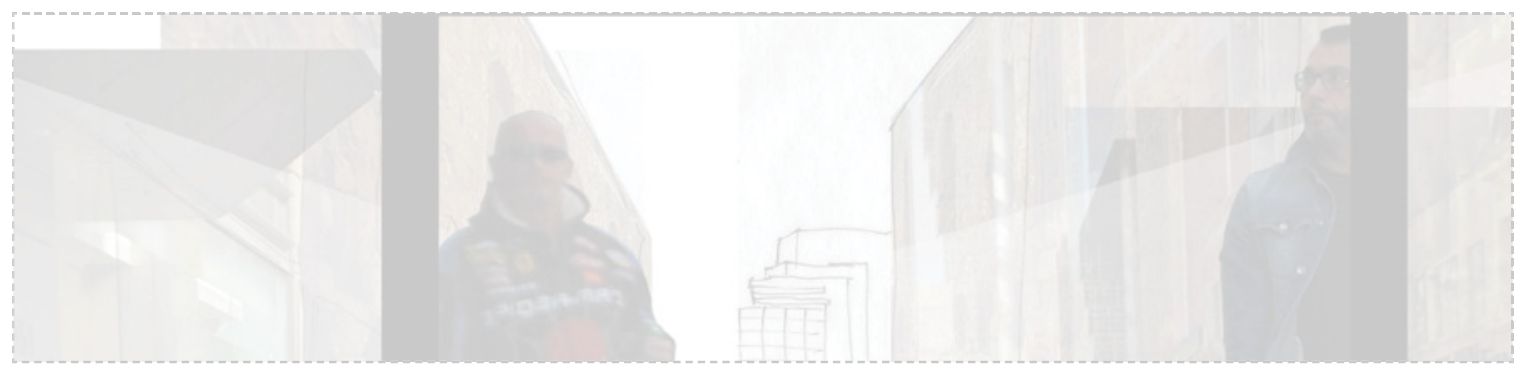

Three analogous conditions shared by theatre and the proposed architecture include; arrival, gathering and focus. Arrival in contemporary theatre is typically through the foyer or atrium, but in the Greek theatre this journey occurred through the city and terminated at the theatre. In this way, the city acted as a preparation for arrival to the spectacle.
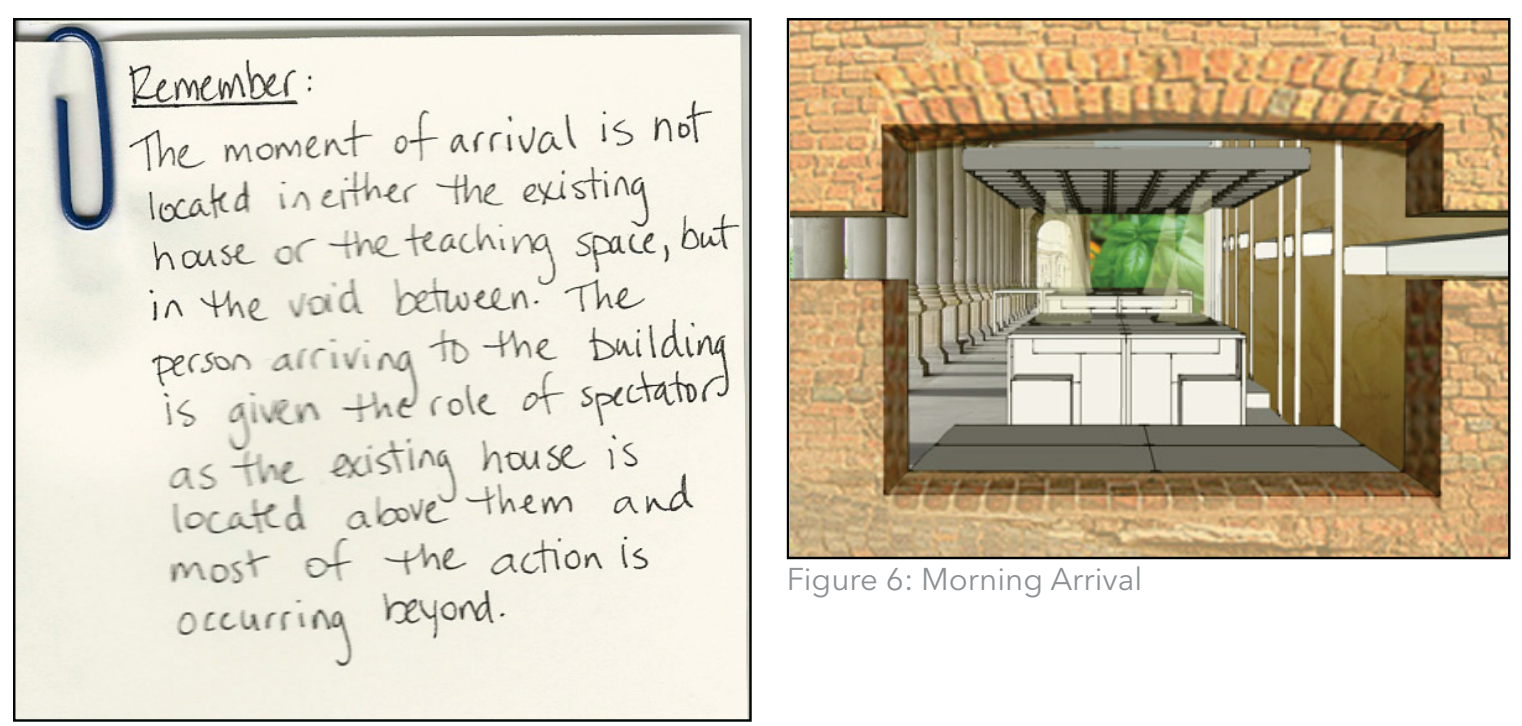

Figure 6: Morning Arrival

Figure 5: Arrival Reminder 


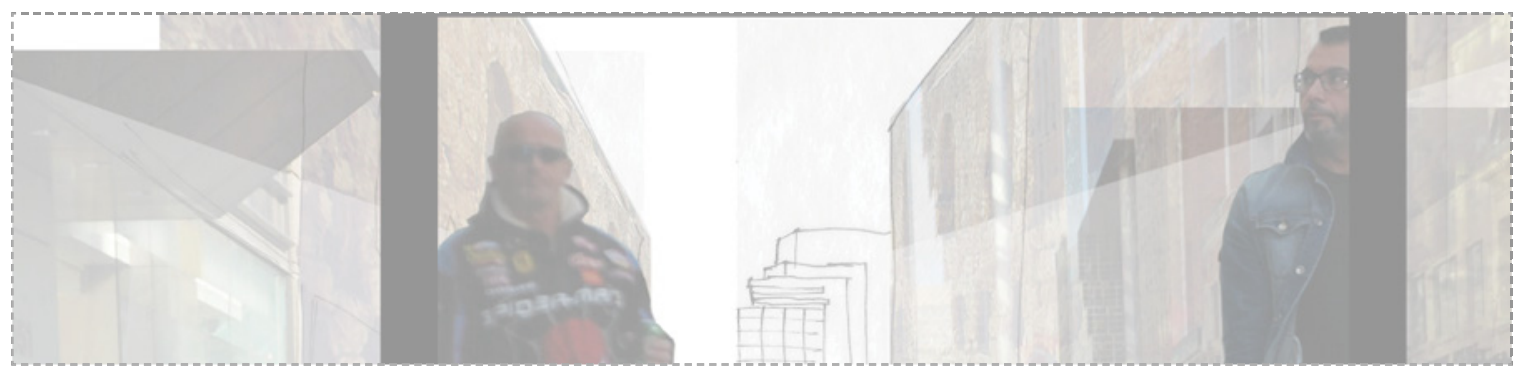

Similarly, arrival and access are also discussed by Peter Brook in his Immediate

Theatre. ${ }^{5}$ The performance is accessed architecturally from two separate passages,

the stage door and the foyer, both of which allow easy transitions to the world of the

stage. The performance cannot be considered complete until it is performed in front

of an audience, making them an essential component. ${ }^{6}$ The actor must establish a

relationship with the audience so that they are willing to engage with the performance and take on an active role in the play?

Teresa arrives out of breath as Maria is putting down her things. She has some items that need to get into the refrigerator right away so she quickly removes her shoes, moves over to her station and then goes back to remove her coat and get her apron. Maria sees Teresa across the room and she goes over to chat. They decide to make an espresso, sit down and catch up before

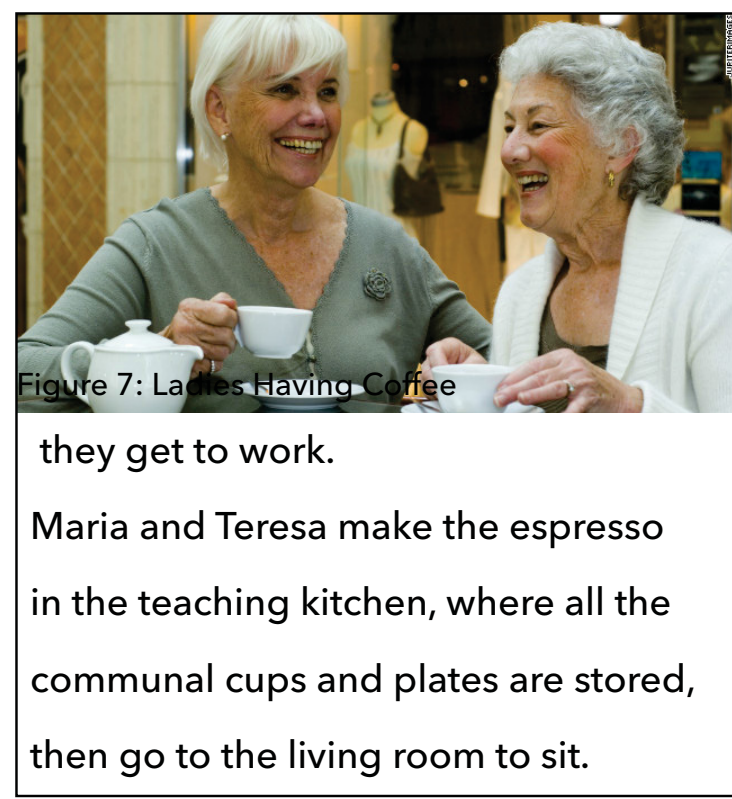




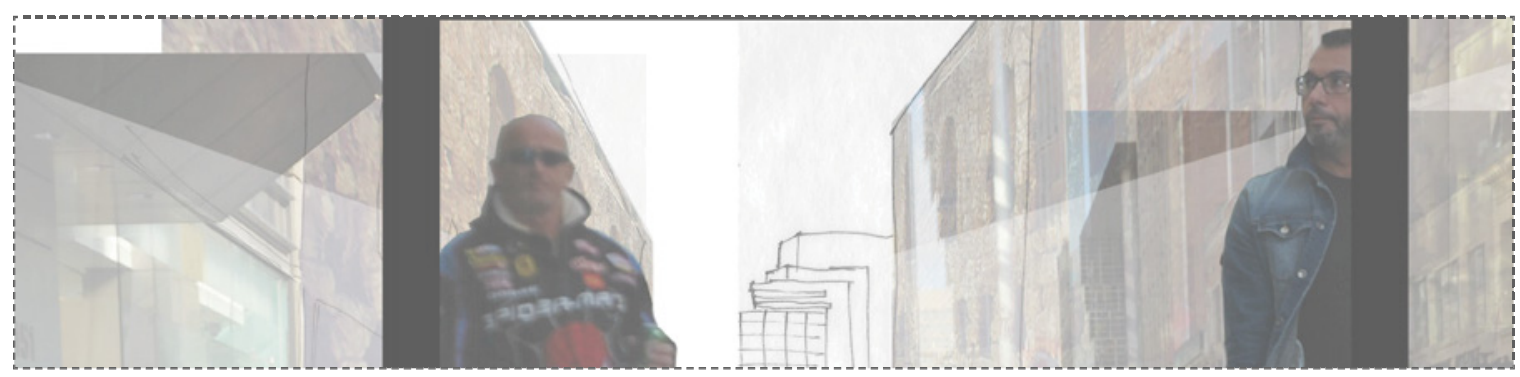

In the Greek theatre, arrival occurred on the part of the spectator through the parodos, at the end of their journey through the city. The parodos was the space between the skene, the architectural backdrop and the auditorium, the seating for the spectators. As the spectators took their seats and the actors filed onto the stage, the daytime and outdoor setting of the theatre allowed for both the actors and spectators to observe the acting of each other and even more importantly, the spectators to see each other. The spectators, having been previously equated to the actors upon entering the orchestra, assumed the responsibility, both implicitly and by the scripting of the play, to react and engage with the happenings of the theatre; ${ }^{8}$ to yell out, throw objects at the stage, and to stomp on the wooden benches.?

They are recalling the Christmases of their childhoods:

MARIA: I never remember a Christmas tree in my mother's house. I don't remember it.

TERESA: We had a Christmas tree. MARIA: Well as I said, they didn't go for it the old folks. They didn't go for it. What they believed in was that at 12 o'clock at night they went to church.
MARIA: They celebrated mass and after that they'd come home. We'd have some sausage and things like that at the church and then the next day we had a big dinner with the family. Our fathers and mothers, they were from a different world.

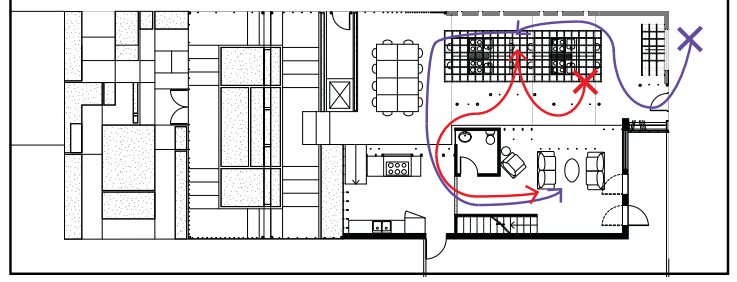




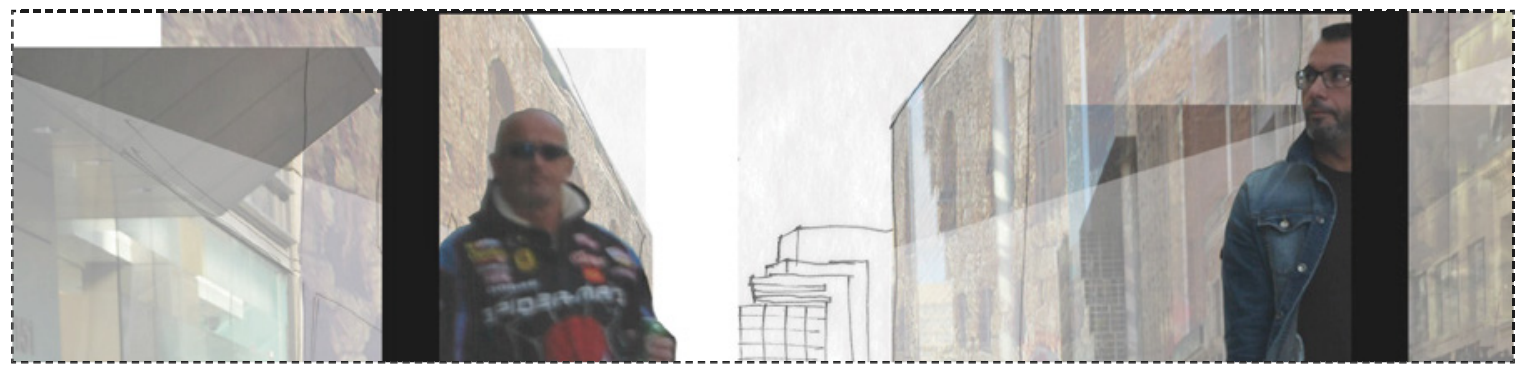

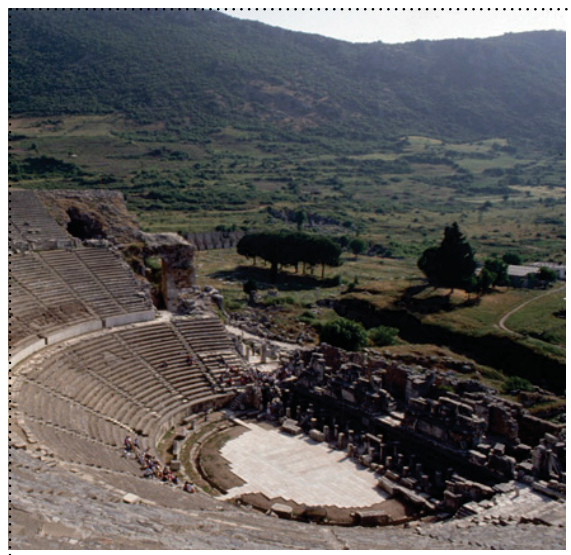

Figure 8: Ancient Greek Theatre
The reactions of the audience became part of the staging, making each performance unique. The actors and spectators had very similar relationships with one another as they both saw each other fully lit. The only difference between them was that the spectator saw the actor in the round at all times as the amphitheater surrounded the orchestra, whereas the actor was almost fully surrounded by the spectators
MARIA: They were different. They brought us up...as long as we ate and were healthy that's all that counted.

They couldn't afford to send us to school. They didn't have that kind of money. So they did what they had to do to survive. Thank God my mother and father...they reached to see us all get married and get settled up nice, families and that's it.
TERESA: My mother used to wash clothes by hand with the washboard... scrub them. And then we had no stove, no gas stove...we had a coal stove, which she used to heat up, put a big pot on top of it, with the Clorax, whatever you had, put it in there and boil your clothes and let them come white. 


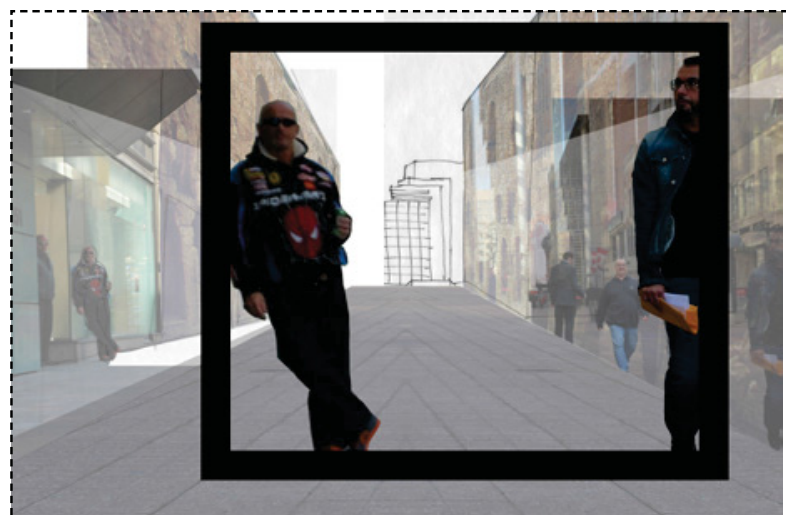

Figure 9: Viewer-Viewed: Sparks Street
Viewer-Viewed: Sparks Street examines

the relationships of spectator and actor, point of view, and choreography within the city borrowing from traditions of Greek theatre. The spectator is elevated in the centre of the street and the actors move along the faces of the surrounding buildings.

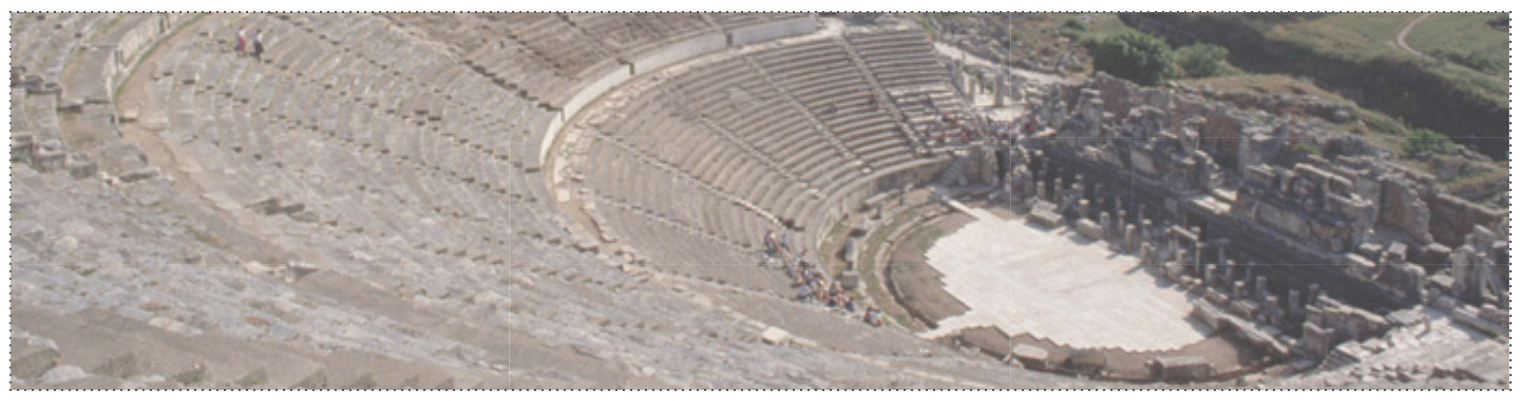

\section{You can just imagine nine children with all those diapers and clothes} and things like that, our poor mothers worked. ${ }^{10}$

When Lucy enters, the ladies go over to the "balcony" to chat with her.

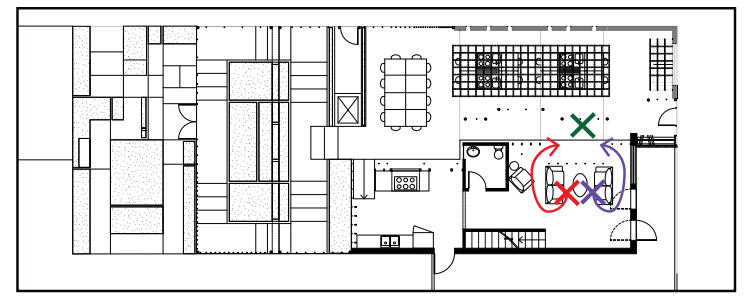


The architecture becomes like the skene of the Greek theatre, as it is the place from which the actors exit and enter while creating a background and context to their performance. For this reason, the images of the Greek skene are overlaid in order to emphasize the spatiality. The spectators are always raised above the actors in Greek theatre and thus always view them from above, allowing mutual participation in the play and constant interaction. This relationship allows multiple plays to occur at the same time, with actors and spectators shifting roles as they cross the street north and south. The choreography encourages people to exit buildings as actors and seamlessly transition into the role of spectator as they move and pause in the raised centre of the street.

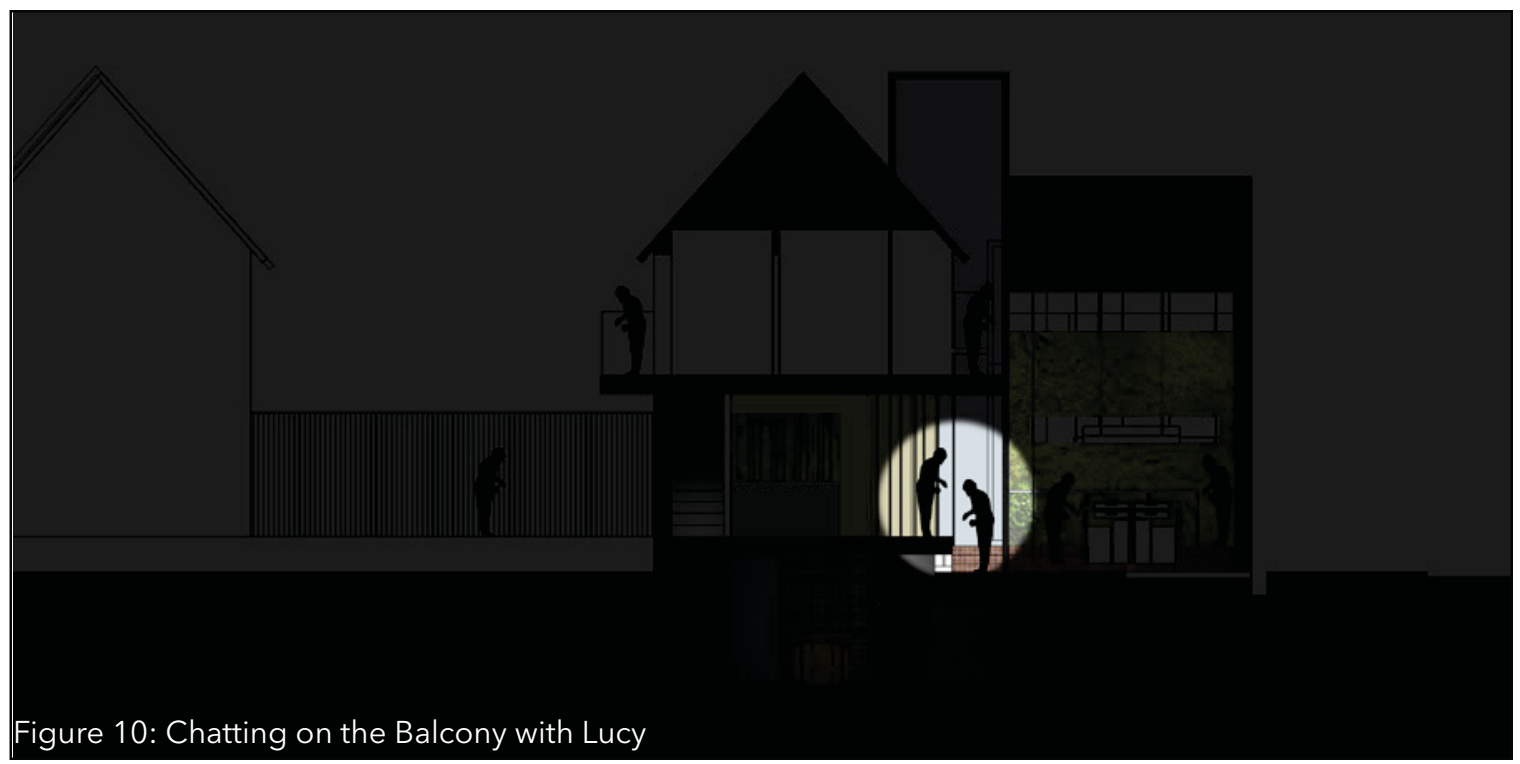


The spectators here appear larger than life and are framed, reversing the common relationship between spectator and actor. Traditionally, the actor is given the most importance and is always considered in the foreground while the role of the spectator is secondary, and in the background. The actor is generally presented in the proscenium arch for the viewer, but in this case that role is reversed and the spectator is framed with the actors moving past in the background. The use of people twice, both as actor and spectator, emphasizes the duality of people's roles as they move through the city.

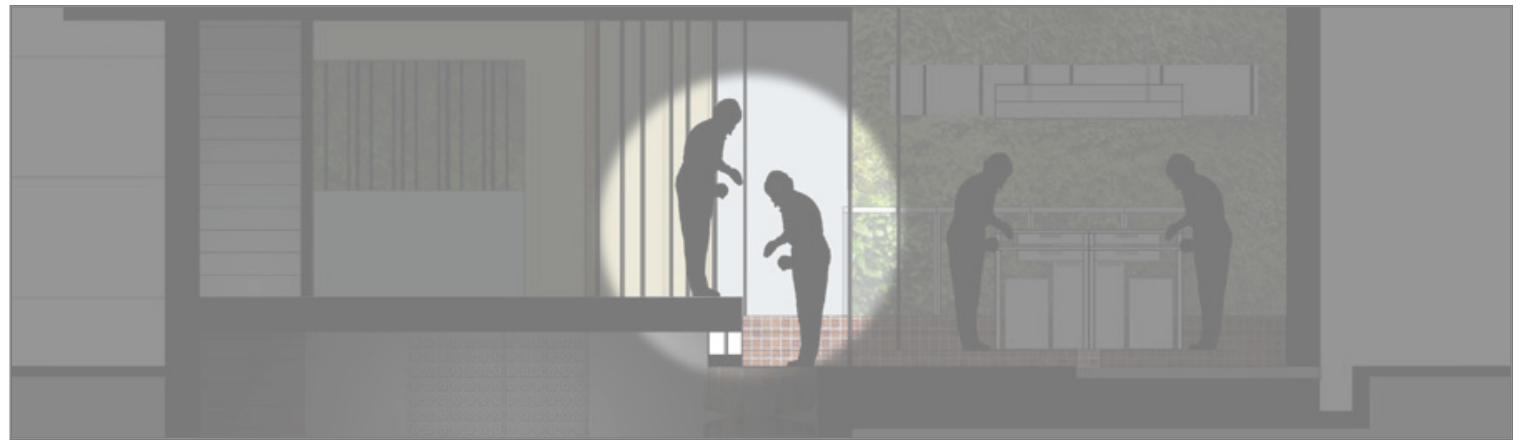




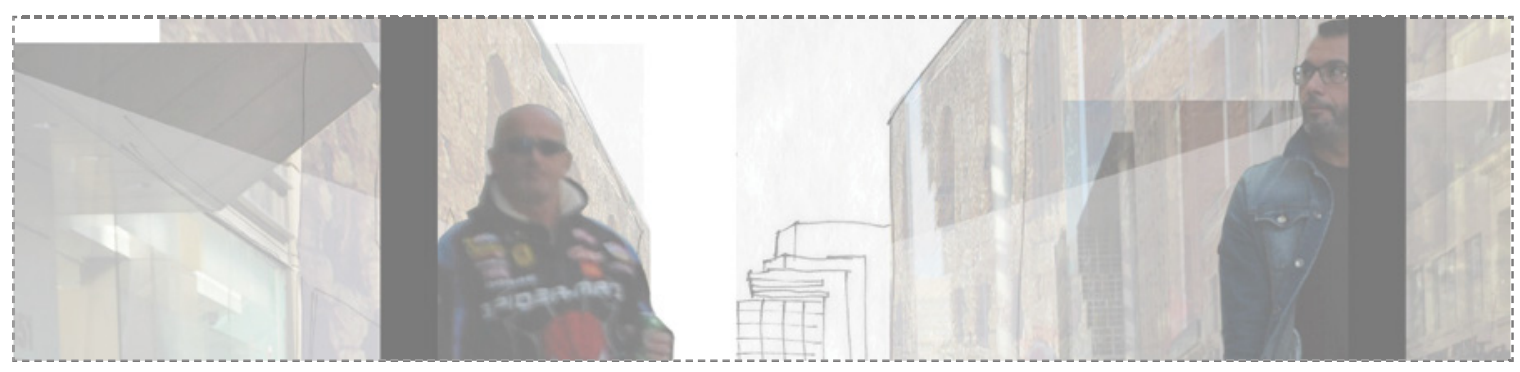

In comparison, Antonin Artaud also imagines a theatre where the actor and spectator are equated and the fourth wall is broken down. The stage is replaced with, "a kind of single site, without partition or barrier of any kind, which will itself become the theatre of the action".11 The spectators are seated in the centre of the room and the action that takes place surrounds them.

Tony arrives, rings the doorbell at the front door, and one of the ladies lets him in. He is delivering flour. He has been here many times before so he knows to wipe his shoes and then proceed between the screens of the liminal space which frames views for him of both the cooking area and existing house. He puts it on the counter of the teaching kitchen and the ladies will do what they need with it.
Set Direction: The sun has shifted and the existing house is casting shadows on most of the addition. The vertical herb gardens are fragrant and the smell of espresso is in the air. There are many parallel conversations occurring and the sounds of sauces simmering and water boiling are perceptible.

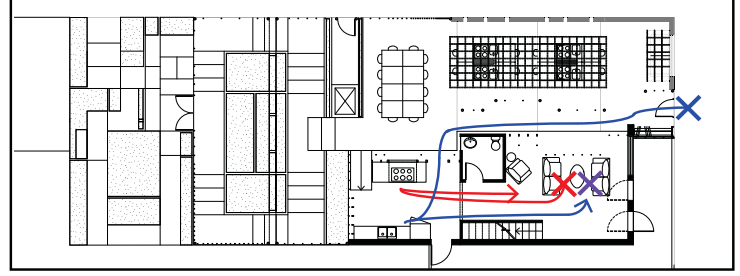




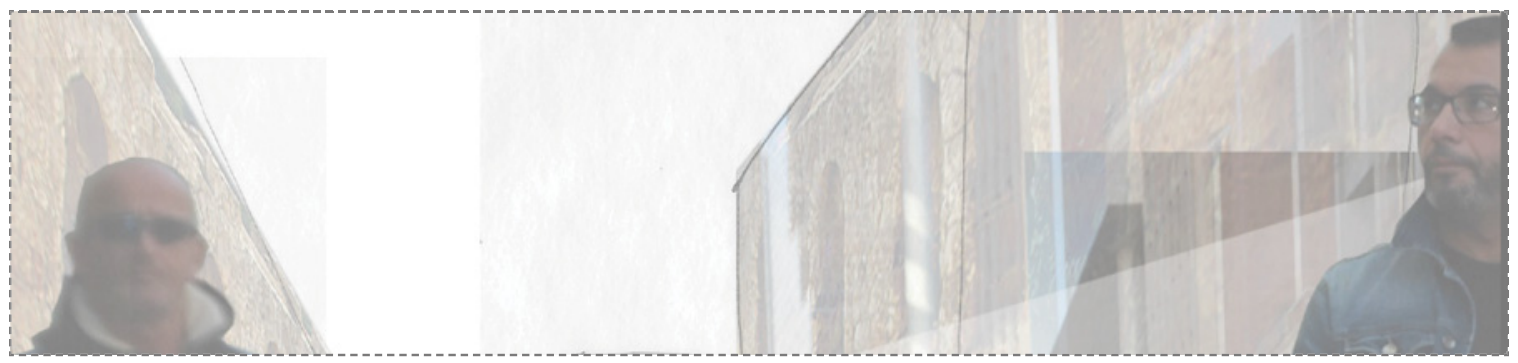

They are encouraged to physically engage in order to participate and understand the play and move around the centre area to get the best view. Artaud saw this as the method of breaking down the fourth wall, the barrier between spectator and actor. ${ }^{12}$ The play that occurs in this space is not predetermined and is created around subjects, events or known works. ${ }^{13}$
MARIA: Eh, Tony! How are you doing? Do you want an espresso? TONY: Good morning Maria. Good morning Teresa. Sure I'Il have a fast one. I have a few more deliveries today.
Maria proceeds to the kitchen and makes Tony an espresso then joins them in the living room and they chat for a while.

Teresa is in the midst of telling Tony about the Italian culture they left many years ago.

TERESA: We call it dolce far niente. It means the sweetness of doing nothing. We are masters of it. Dolce far niente.

MARIA: Non si parla così in Italiano. Si parla con i gesti. 

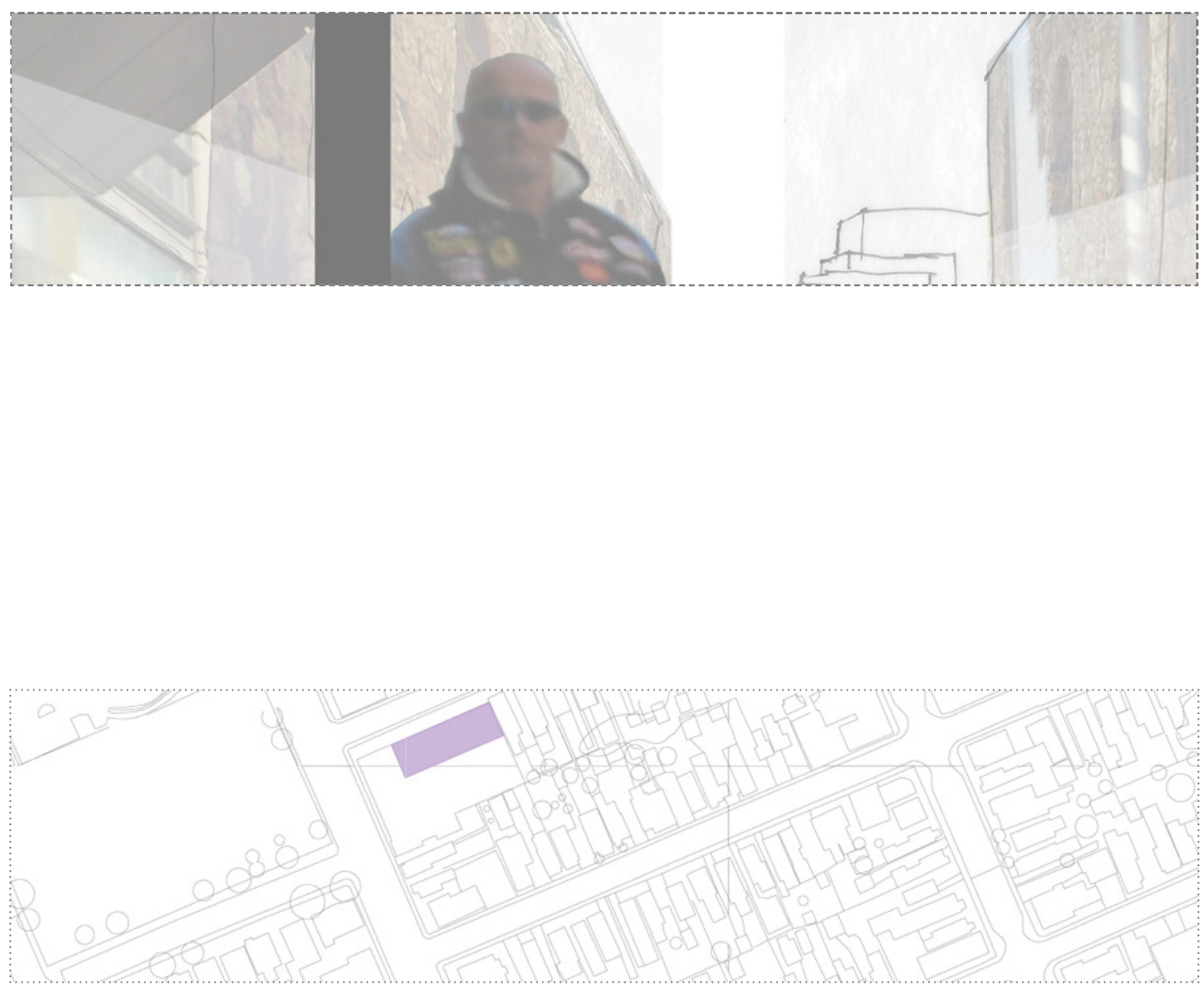

MARIA: Si può parlare tutte le lingue movendo le mani.

TERESA: You can't learn Italian just like this [moving her hands]. You don't speak the language just with your mouth, you speak with you hands, i gesti. ${ }^{14}$
TONY: (Laughing in Italian accent and waving his hands) Ok, ok! I have many more deliveries to do today so I will have to say Ciao! Grazie for the espresso! See you next week. 

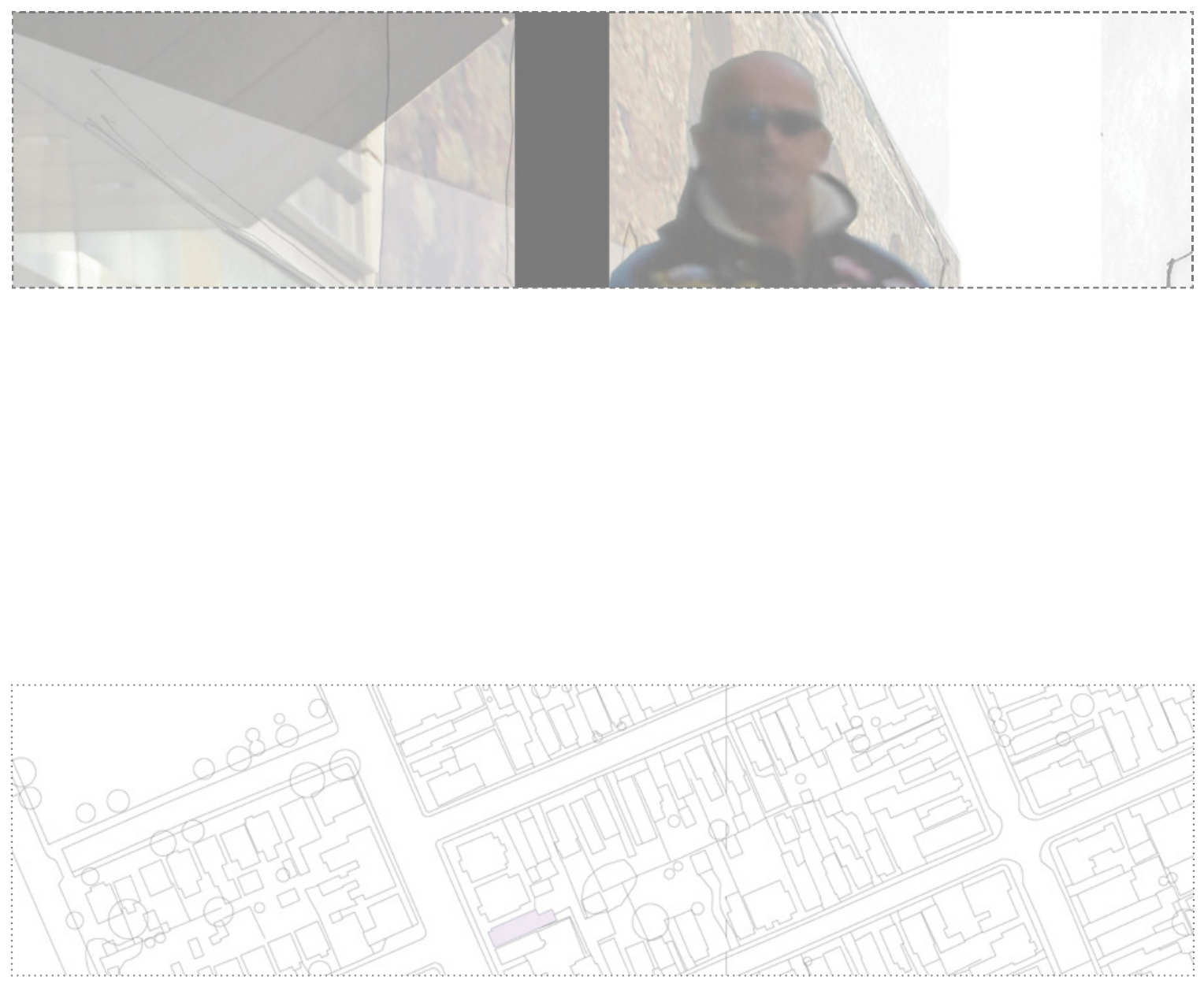

He exits the way he came in. They decide to begin their tasks and on her way back to her station, Maria pauses at the vertical herb wall to collect some basil. Teresa returns to her station and begins assembling the cookies her grandchildren love. She should have just enough time to get them into the oven before Maria comes over to make pasta. Maria returns to her station, and begins preparing her sauce.

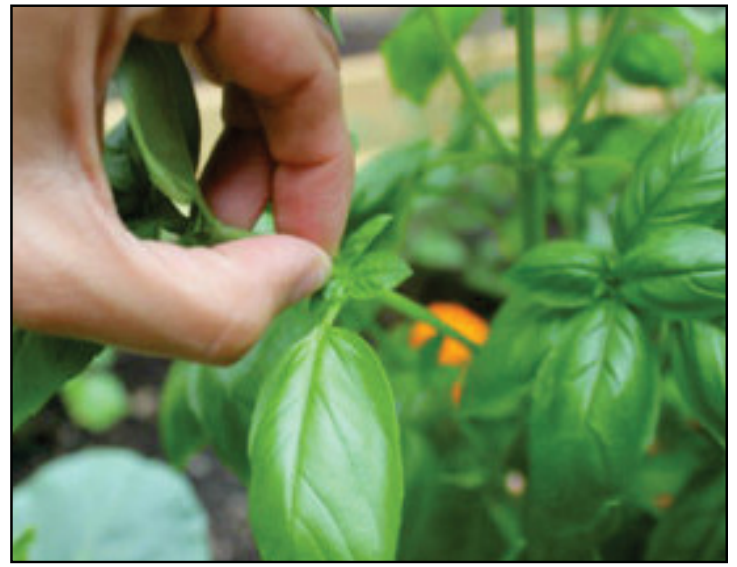

Figure 11: Hand Picking Basil

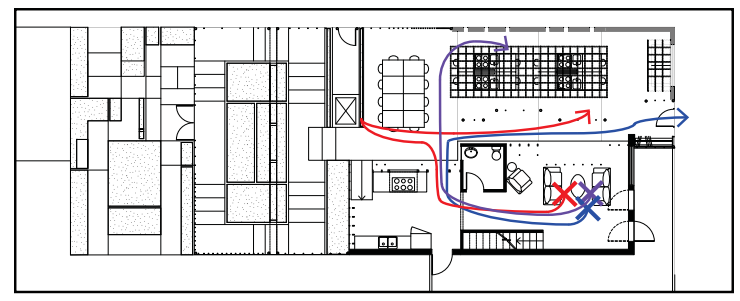



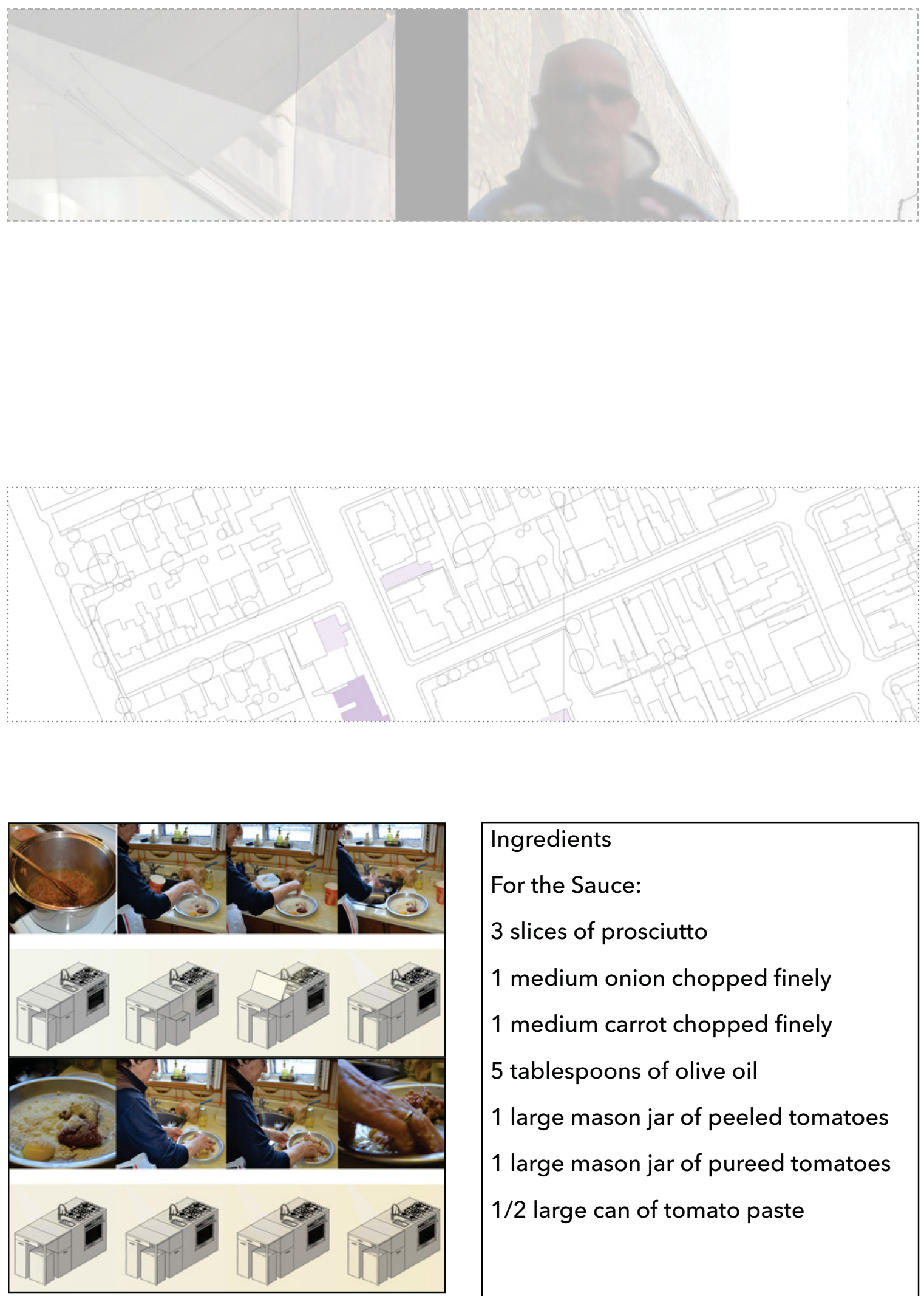

Ingredients

For the Sauce:

3 slices of prosciutto

1 medium onion chopped finely

1 medium carrot chopped finely

5 tablespoons of olive oil

1 large mason jar of peeled tomatoes

1 large mason jar of pureed tomatoes

$1 / 2$ large can of tomato paste

Figure 12: Cooking Station Manipulation 1 

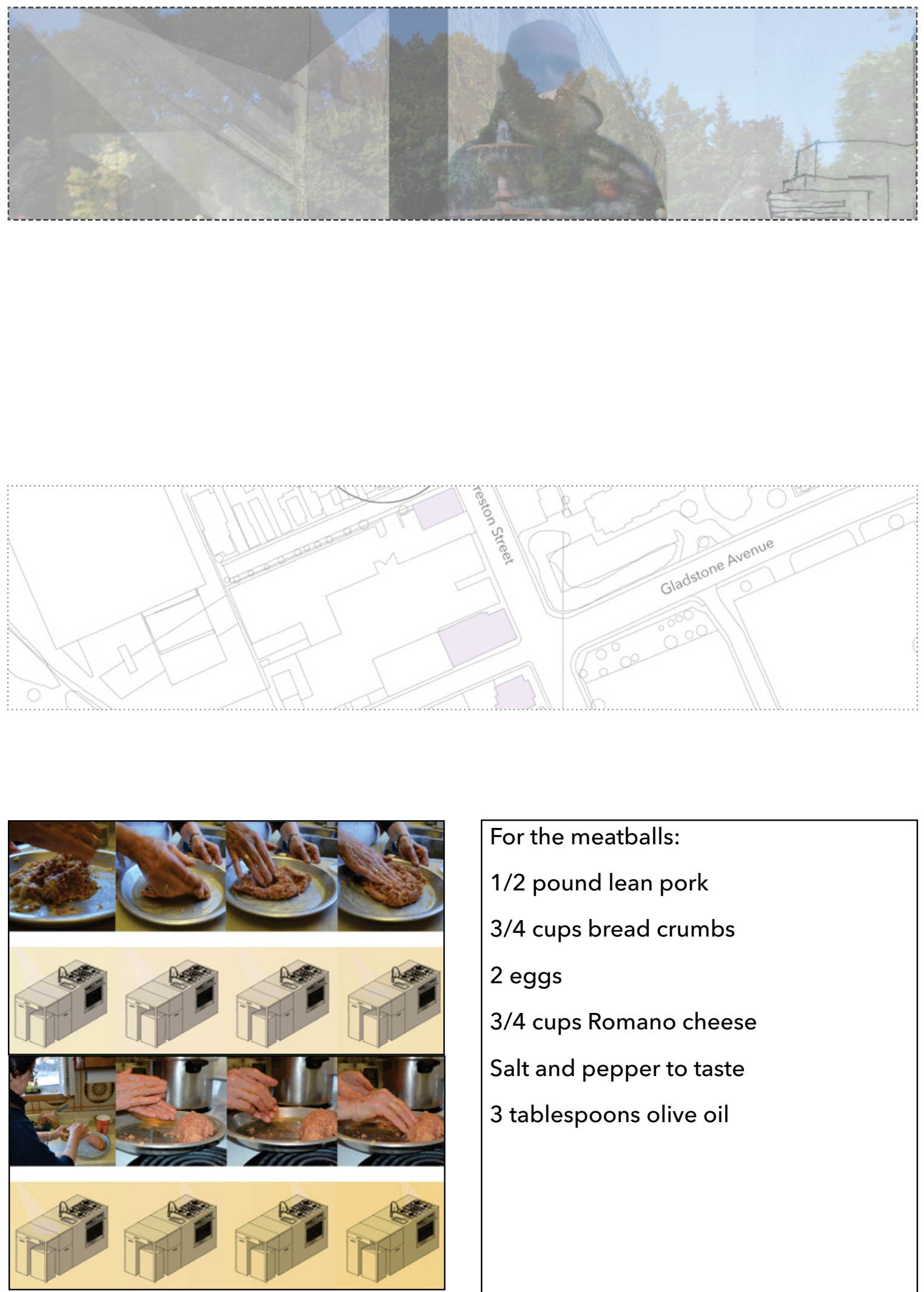

For the meatballs:

$1 / 2$ pound lean pork

3/4 cups bread crumbs

2 eggs

3/4 cups Romano cheese

Salt and pepper to taste

3 tablespoons olive oil

Figure 13: Cooking Station Manipulation 2 

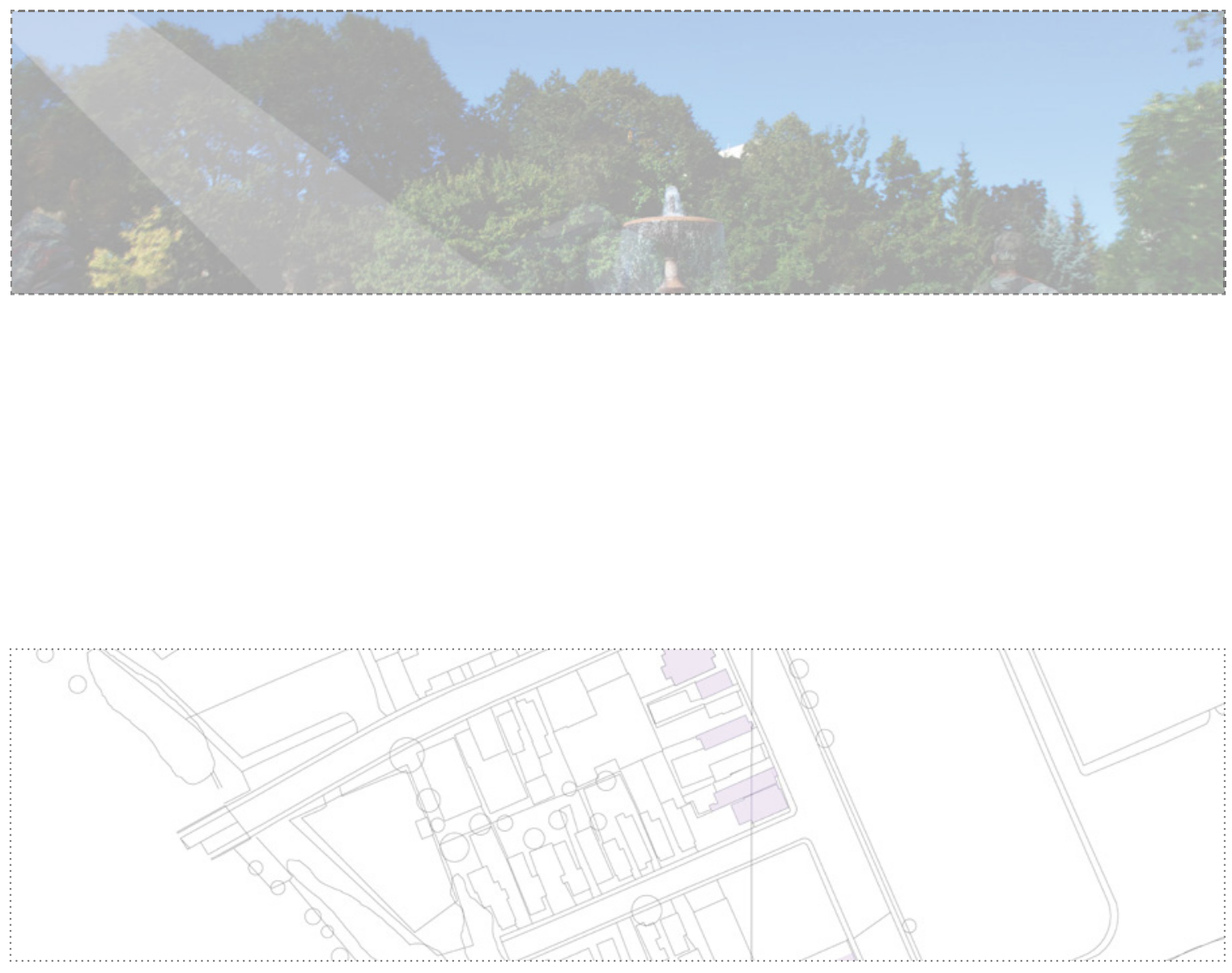

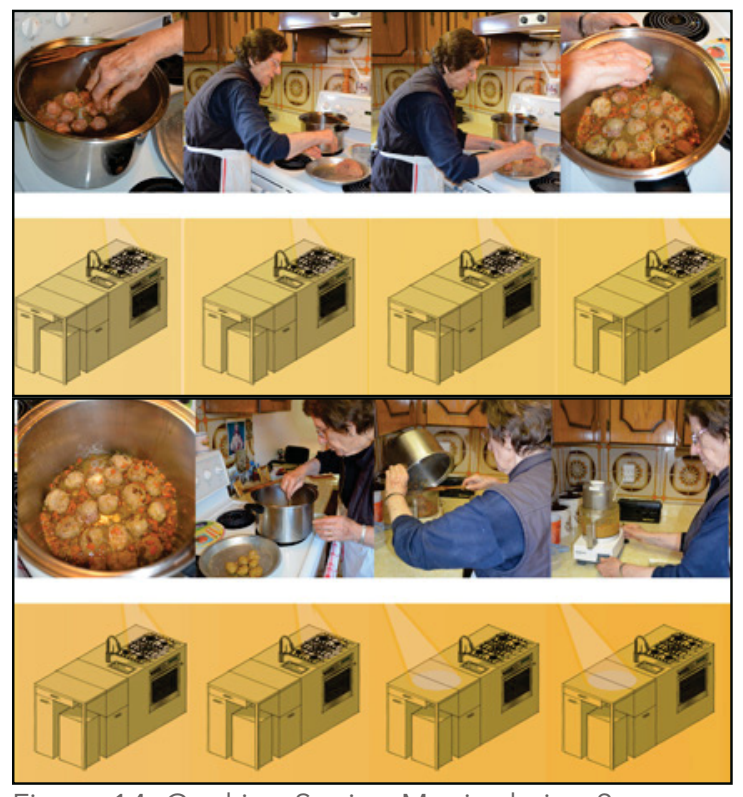

Figure 14: Cooking Station Manipulation 3
Method:

In a large pot, cook prosciutto in 5 tablespoons olive oil until browned. Add chopped onion, carrot and a few tablespoons of water to the prosciutto and cook over low-medium heat for about 1 - 1.5 hours, or until the onions are translucent and everything is cooked through. You have now made a sofrito. 

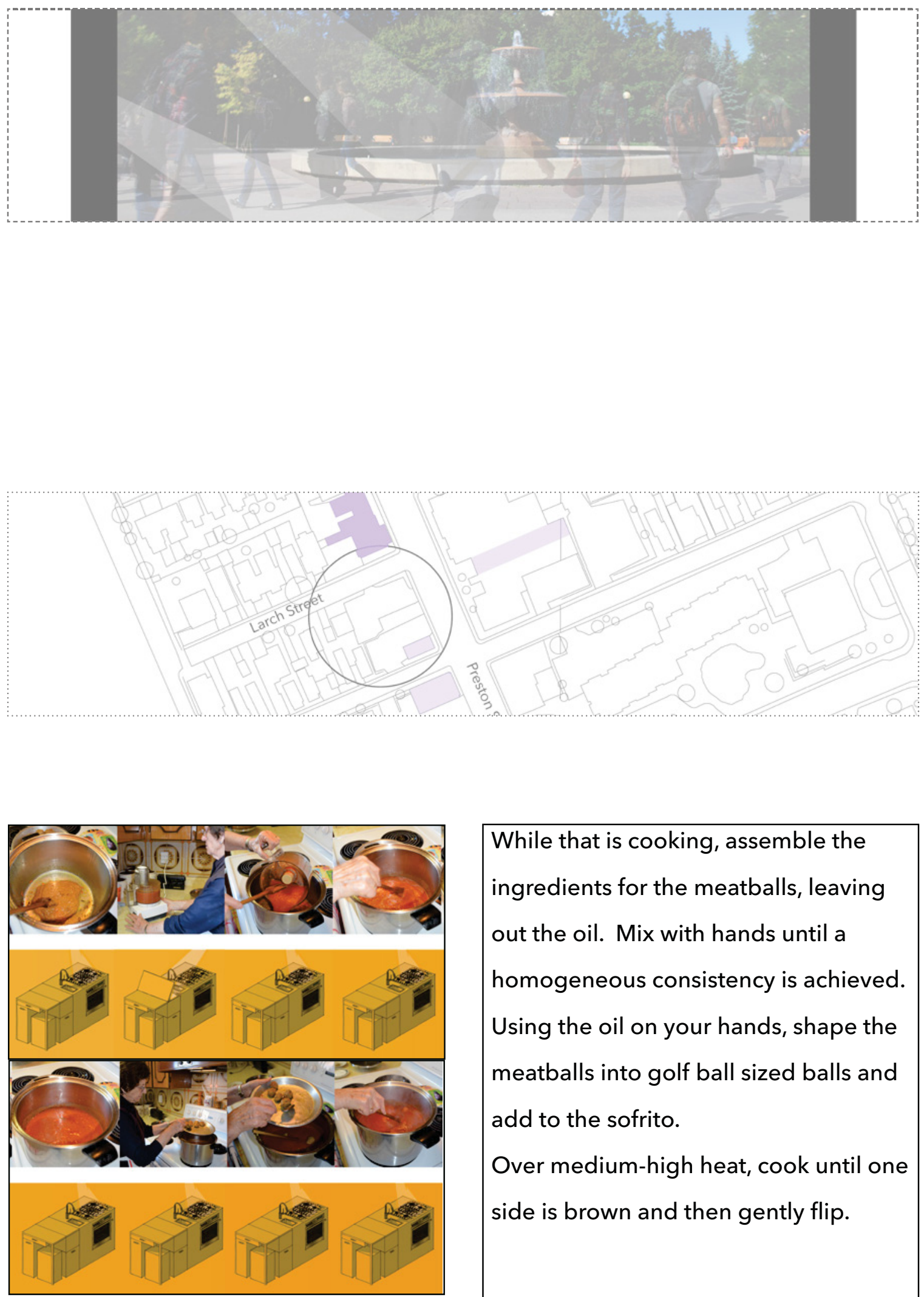

While that is cooking, assemble the ingredients for the meatballs, leaving out the oil. Mix with hands until a homogeneous consistency is achieved. Using the oil on your hands, shape the meatballs into golf ball sized balls and add to the sofrito.

Over medium-high heat, cook until one side is brown and then gently flip.

Figure 15: Cooking Station Manipulation 4 

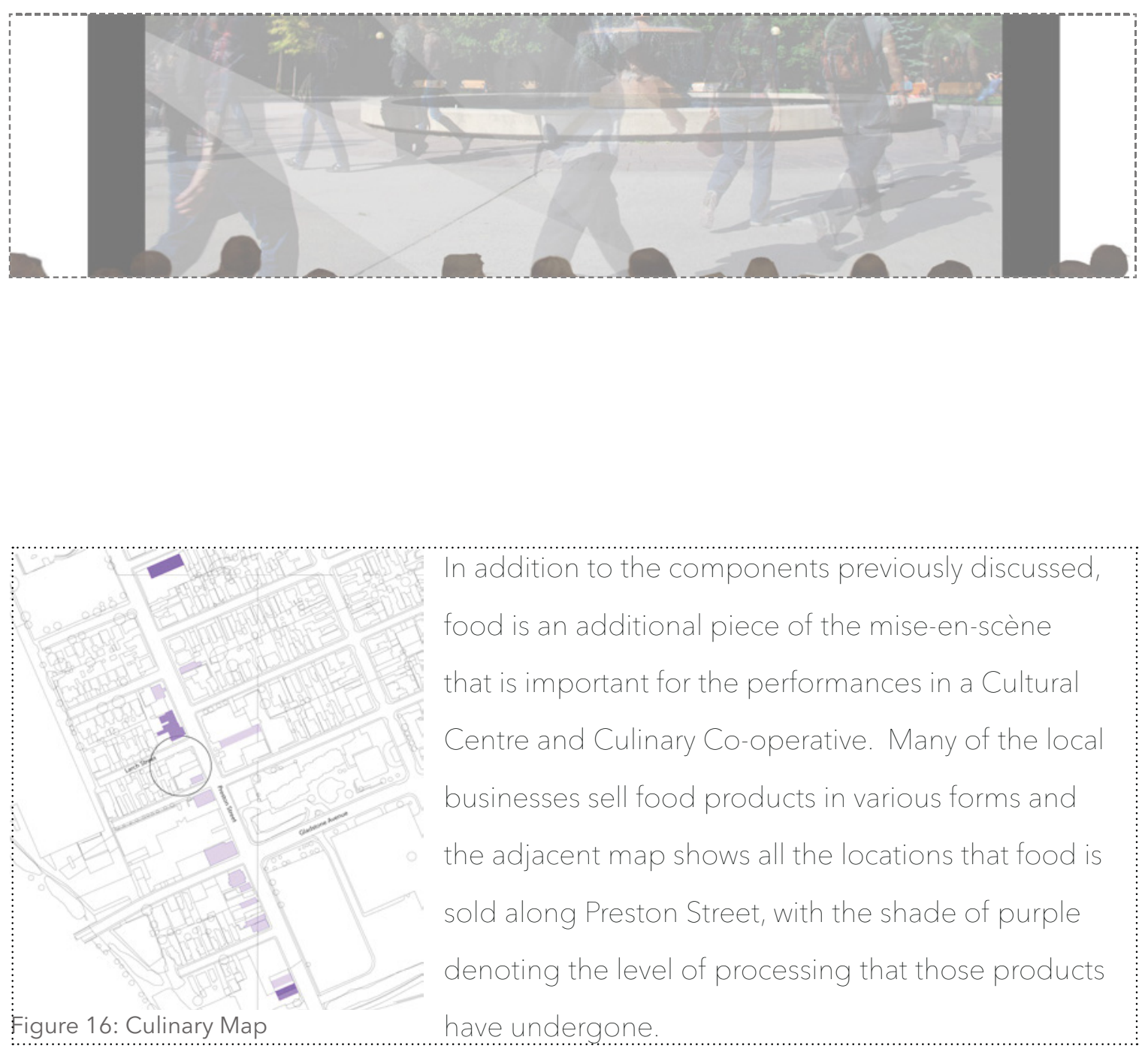

Once both sides are browned, remove from sofrito and set aside. Pulse sofrito in the food processor until blended and then add back to the pot.

Process peeled tomatoes and also add to the pot. Add jar of puree and tomato paste. Add some water to the empty jars and add to the sauce until it is fairly liquid, about the consistency of a thin smoothie.
Do not add too much water as sauce will get looser as it gets warmer. Cook over medium heat until it comes to a boil and then add in the meatballs. Taste for seasoning and then let simmer on low for about an hour and a half. Occasionally stir the sauce to make sure the meatballs are not sticking to the bottom. 


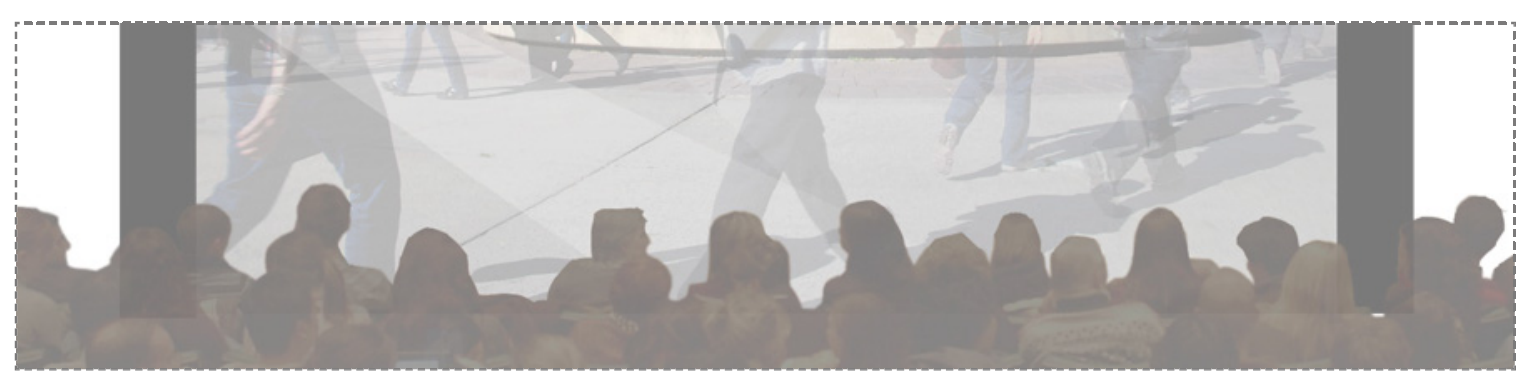

The darkest purple demonstrates the businesses that sell unprocessed products such as coffee beans at Bridgehead or fresh meats and cheeses at Nicastro, and the lightest purple highlights the various restaurants in the area. Residents moving about Preston Street making food purchases create the choreography in the area.

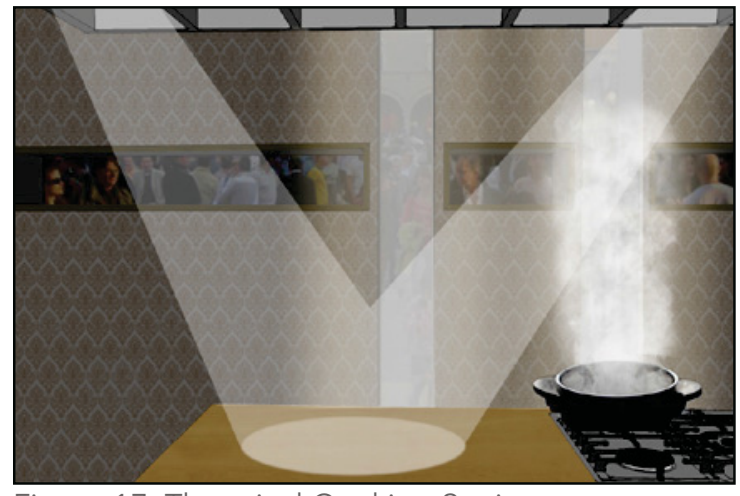

Figure 17: Theatrical Cooking Station

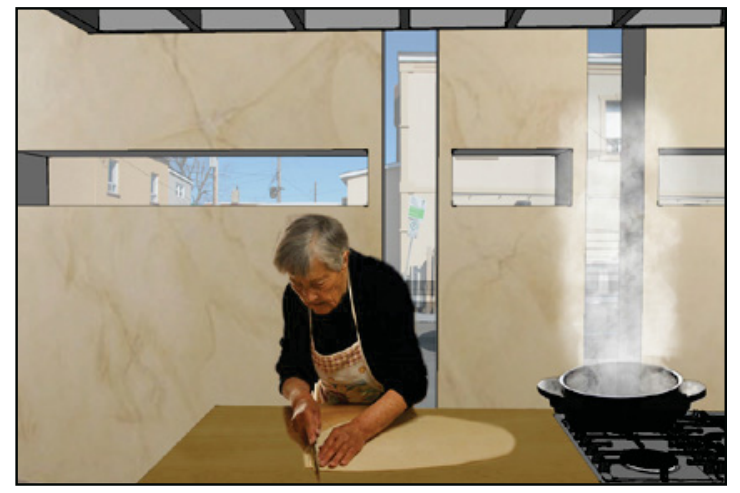

Figure 18: Day-to-Day Cooking Station 


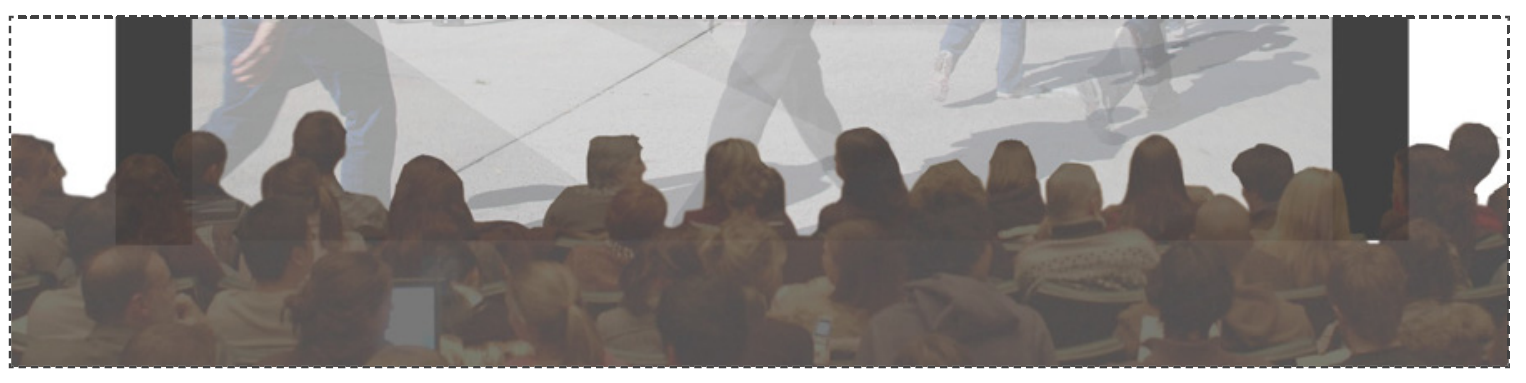

Choreography is an element of mise-en-scene of the proposed architecture that is explored in the discussion of Greek theatre. Upon approaching the Greek theatre, there: was a distinct feeling of compression as one moved through the parodos, which served as the sole entrance and exit for both the spectator and actor ${ }^{15}$, thereby equating them in the realm of the theatre. This compression occurred between the architecture of the auditorium and the skene, the backdrop for the play and change rooms for the actors.

The station is fully equipped with all the tools and ingredients Maria needs to make her sauce. It has various compartments that pull and fold out and the cook top, a sink and an oven are for her and the lady opposite to share. She has a perfect view from the centre of her station out towards Larch Street and she can watch the people passing by as she cooks.

\section{REMEMBER:}

At the centre of each station facing Larch street, a $20 \mathrm{~cm}$. wide vertical window allows narrow views to the street. There is a horizontal band of windows located at approximally eye height and mimicking the change oflevel of the floor.

Figure 19: Views Reminder 


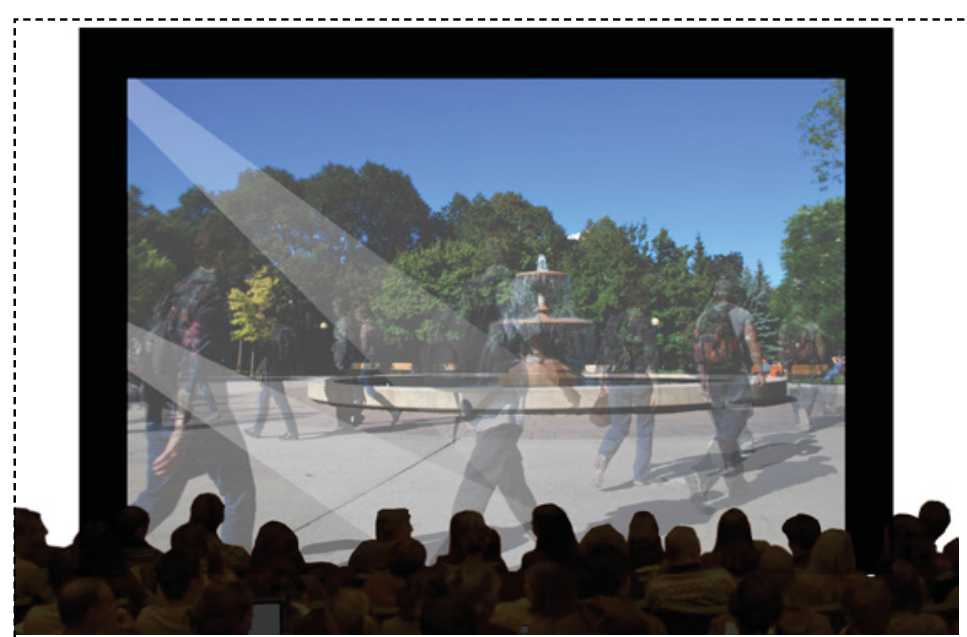

Figure 20: Choreography: Confederation Park

Compression occurs sectionally as well, as the theatre was traditionally located at the highest elevation and at the end of the strategically choreographed passage through the city. Upon reaching the climax of the orchestra, the grade flattened, allowing the spectator to take a breath in the vast auditorium before them. The staging of the compression and subsequent release onto the orchestra prepared the spectator for the experience of the play, asking them to shed what preconceptions they had brought with them and to begin afresh.

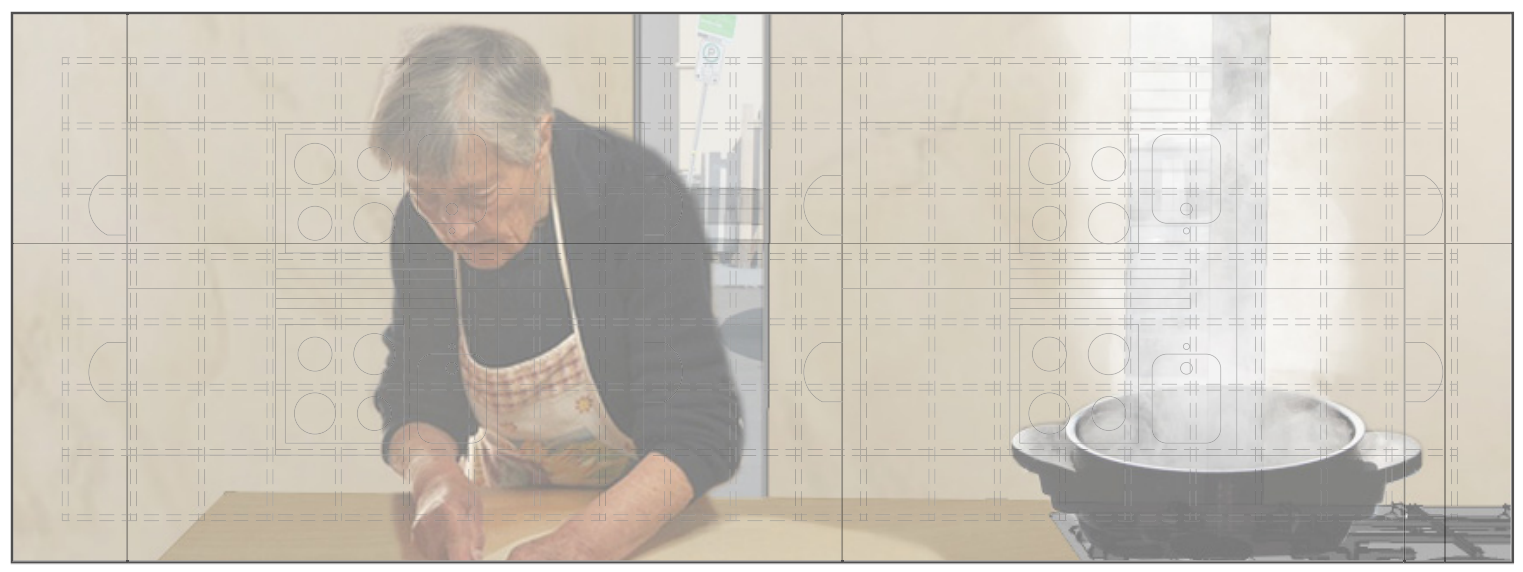


Choreography: Confederation Park studies the viewer-viewed relationship, choreography, lighting and temporality. Confederation Park is a unique site with some of the highest concentrations of foot traffic in the city with most people using it as a shortcut to get to their final destination. The unique choreography is determined by delineated paved paths that give form to desire lines running through the site and the fountain that is located at the node where all of these paths converge. The existing "architecture" of the site is the dictator of this choreography which people are inclined to participate in.

If the architecture of the skene was not present, the effect of the release would be lost and the staging of the preparation would not be effective. It also served to selectively block the panoramic view of the city and strategically frame what was useful or necessary for the scene. It maintained the relationship with the context of the city, but elevated the spectators and the actors to the level of the play.

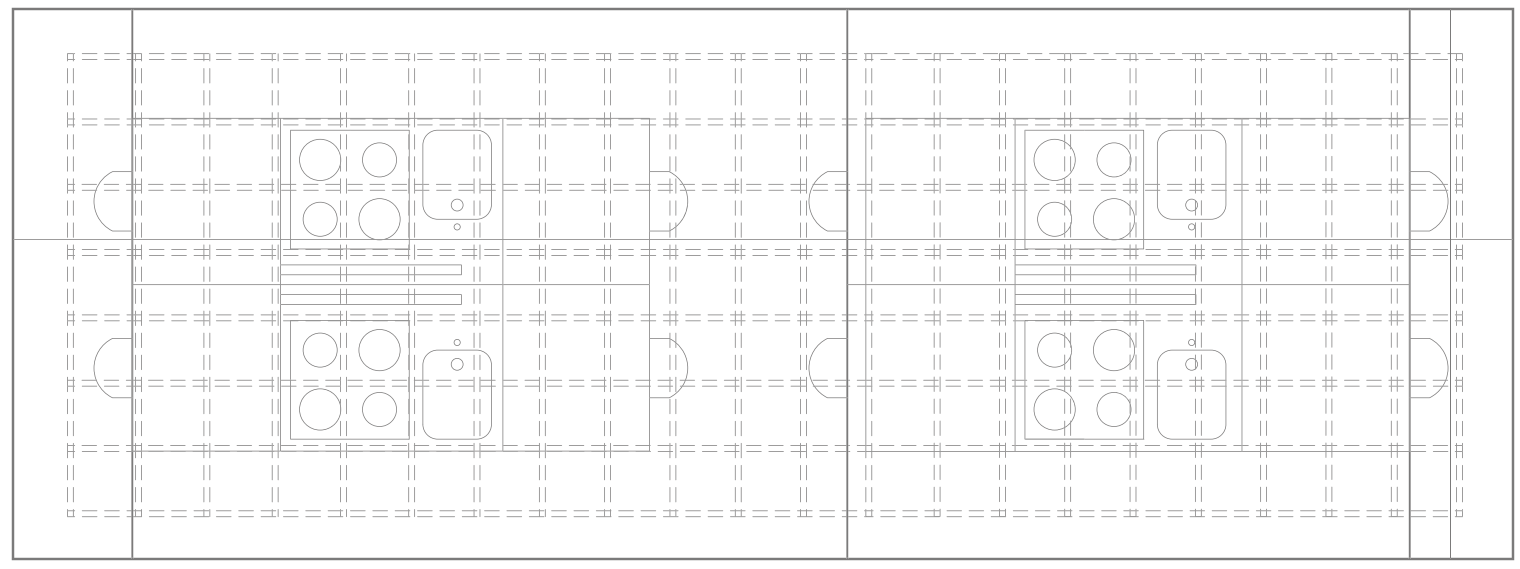


The actors in this illustration are walking through the park and past or around the fountain. The choreography of their movement is shown through time by overlapping sequential images taken from the same perspective. Each image is given equal importance, emphasizing that no one moment is more significant than another in this choreography. The scene is shown from the point of view of the spectator in a traditional theatre setting and they are shown as smaller and in darkness, as they would appear to the actor.
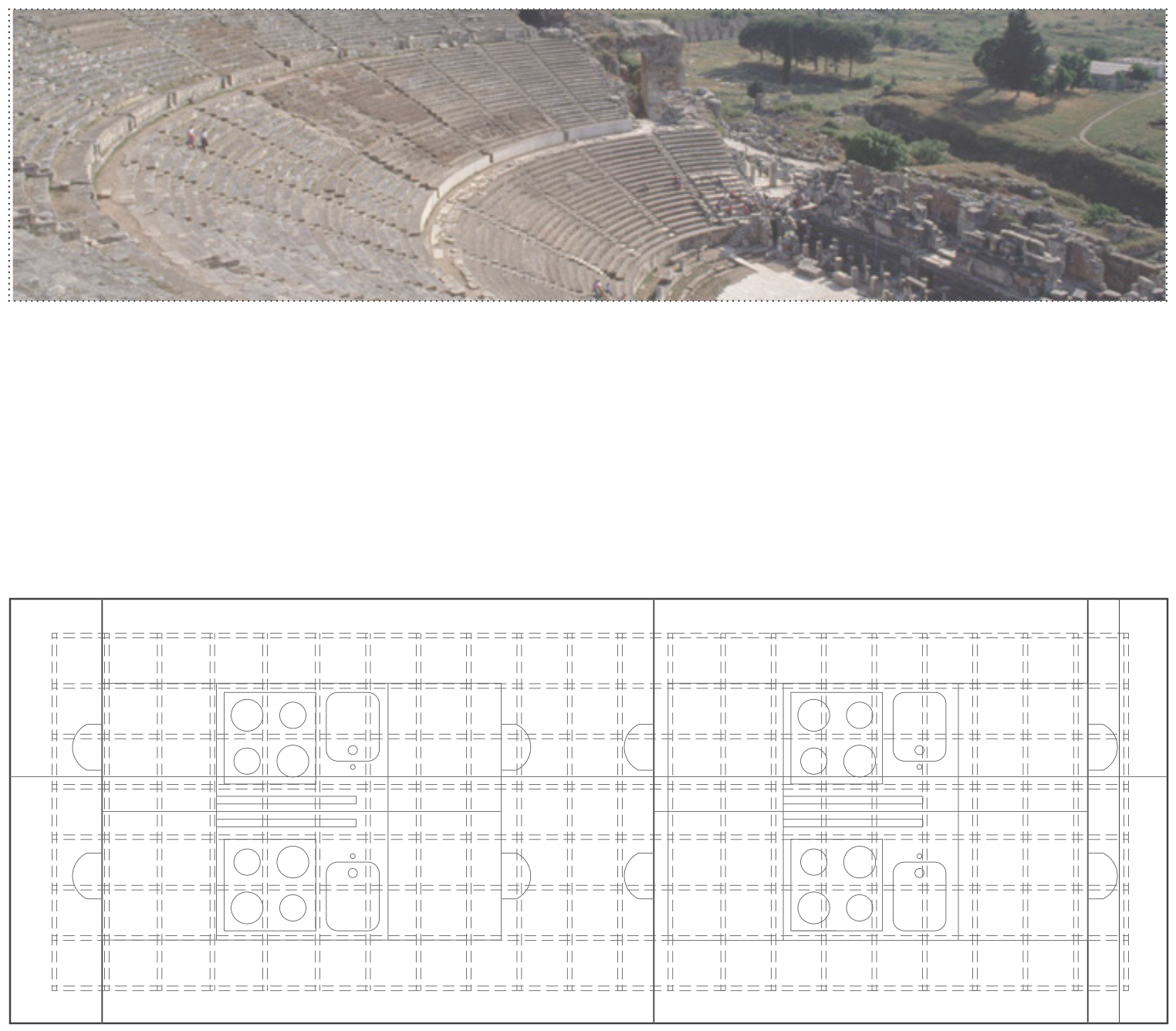
The use of artificial light is suggested although in reality the scene is day lit. The shadows created are dramatized by their overlapping and overlaying in the process of creating the collage. The scene in the park is contained within a frame, reminding the viewer that what they are observing is temporal and a separation from reality. The spectator sits outside of the drawn frame, but is still contained within the picture frame from our point of view.

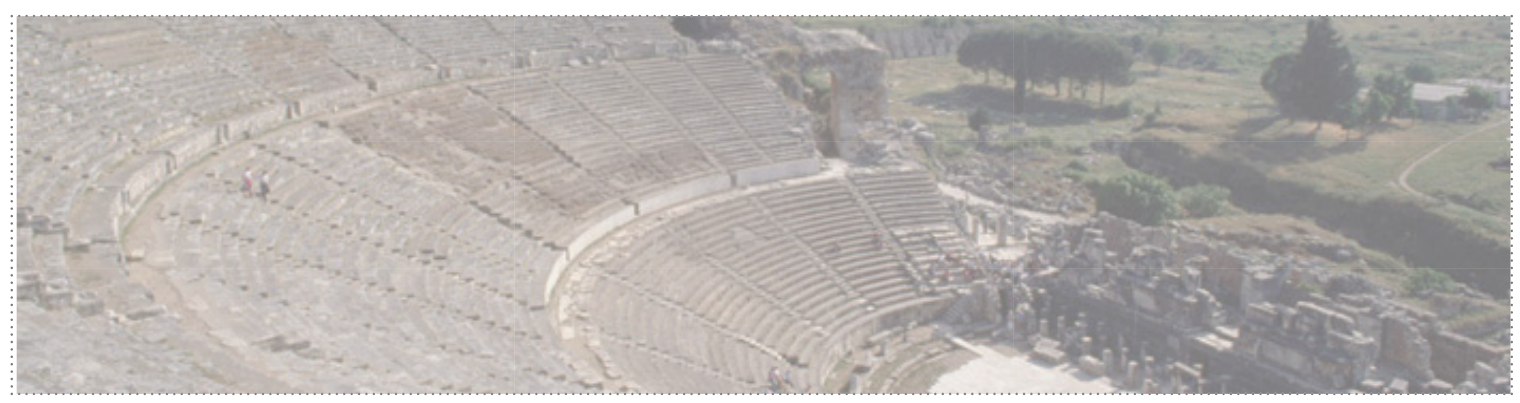

Because Maria's children are grown and have moved out, she cooks with Teresa and they share what they produce.

Today is the day of the week that they make pasta.

Teresa's cookies are finished baking and she pulls them out and sets them aside on racks to cool. 

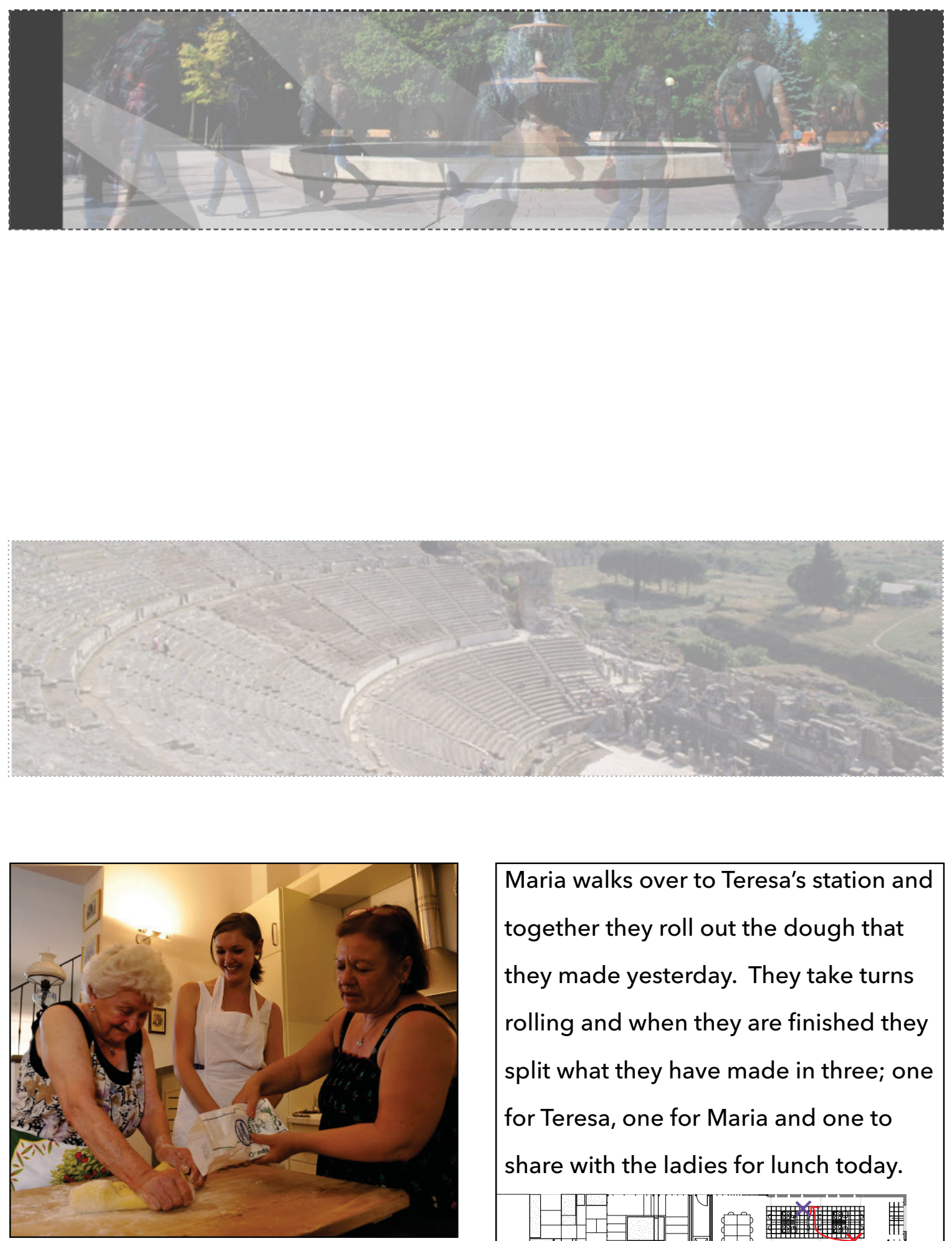

Maria walks over to Teresa's station and together they roll out the dough that they made yesterday. They take turns rolling and when they are finished they split what they have made in three; one for Teresa, one for Maria and one to share with the ladies for lunch today.

Figure 21: Women Making Pasta

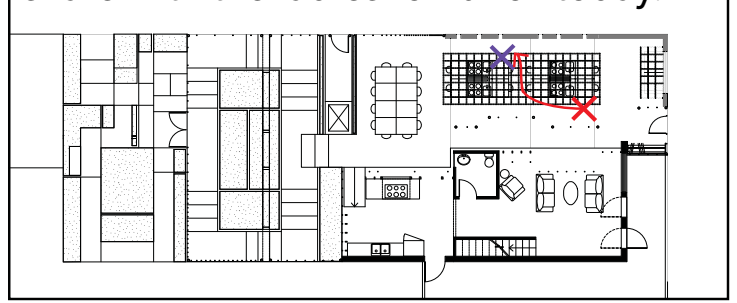



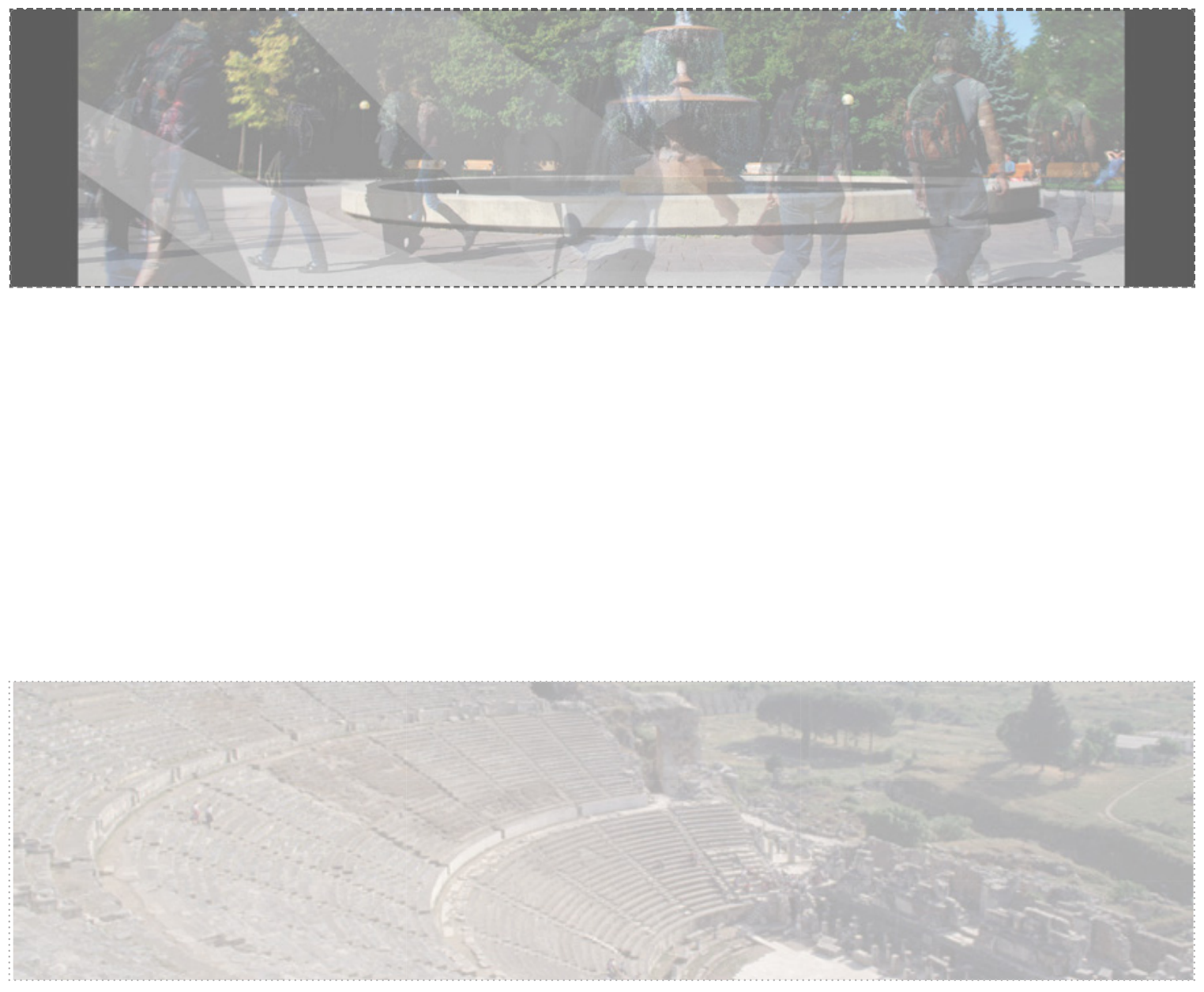

MARIA: When you first get married you're really not much of a cook. I watched my mother make sauce, I watched my mother-in-law, I got a lot from my mother-in-law, a lot from family. If you notice, the towel never leaves my hands because I keep wiping all the time...this is what my mother-in-law taught me.
MARIA: You take a few spoonfuls of tomato and you throw [the meatballs] in [the pot] because the meatballs remain very soft, not like some of the meatballs you eat sometimes when you're invited somewhere. You eat a meatball and they're as hard as can be. If you throw them at the wall the wall will crack. [pulling out a jar of pepper sauce] I get it from my sisters. 

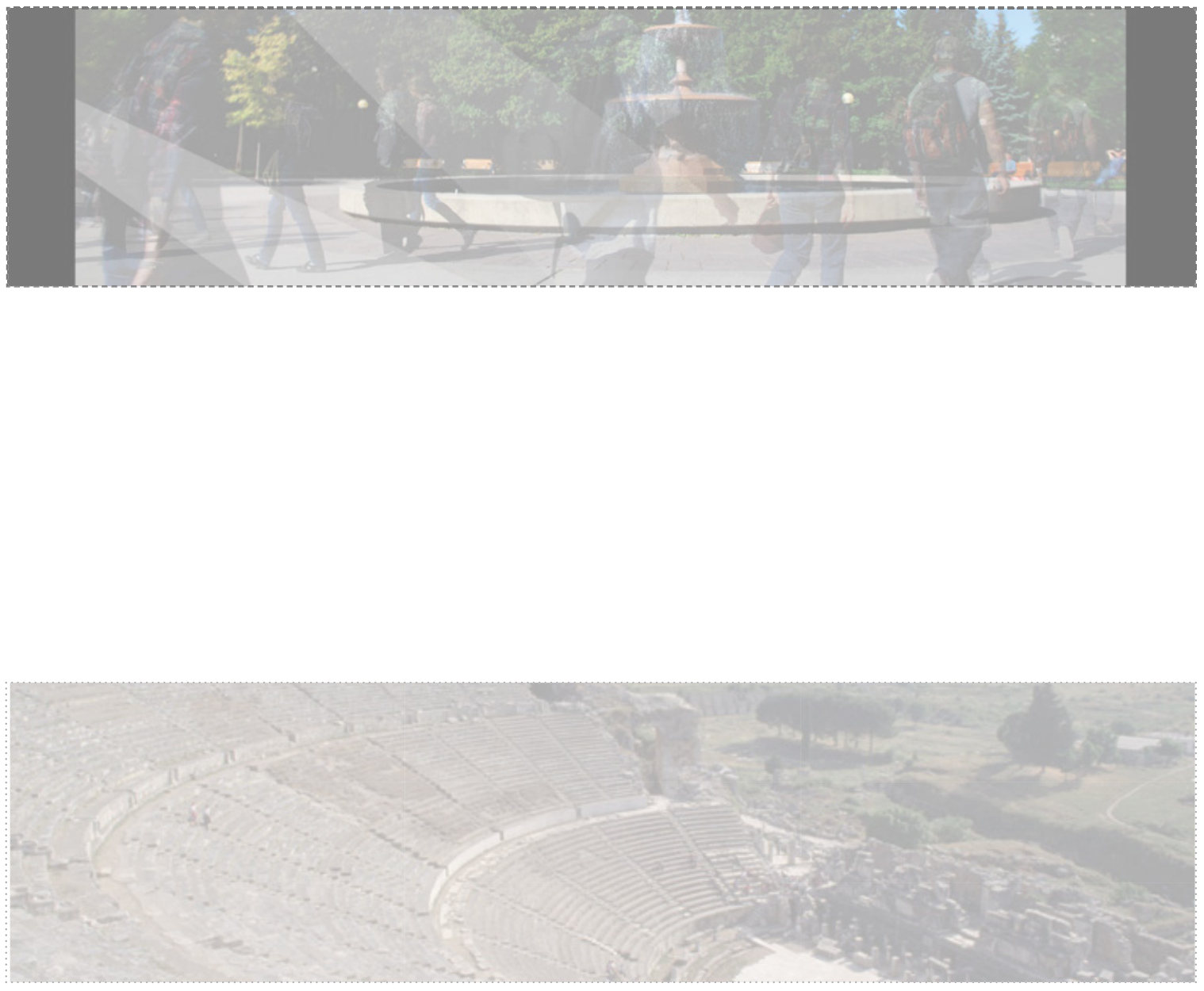

MARIA: They have a garden which they grow [the peppers] in. They give me enough to make a jar for about four years. ${ }^{17}$

Teresa takes out a large pot, fills it with water, and brings it to a boil.

She adds in the pasta and after a couple minutes removes it from the water, drains it and sets it aside.
While that is happening, Maria goes to the kitchen, collects some plates and cutlery, and sets a place at the table for each lady that is cooking today.

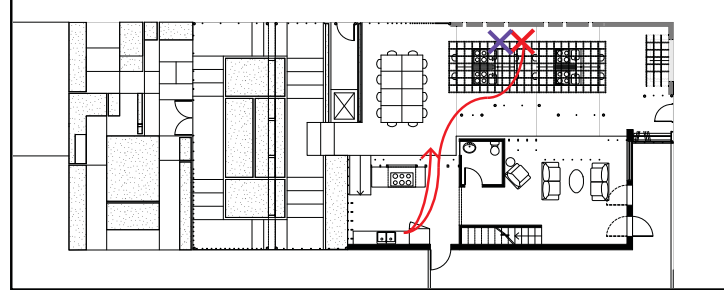



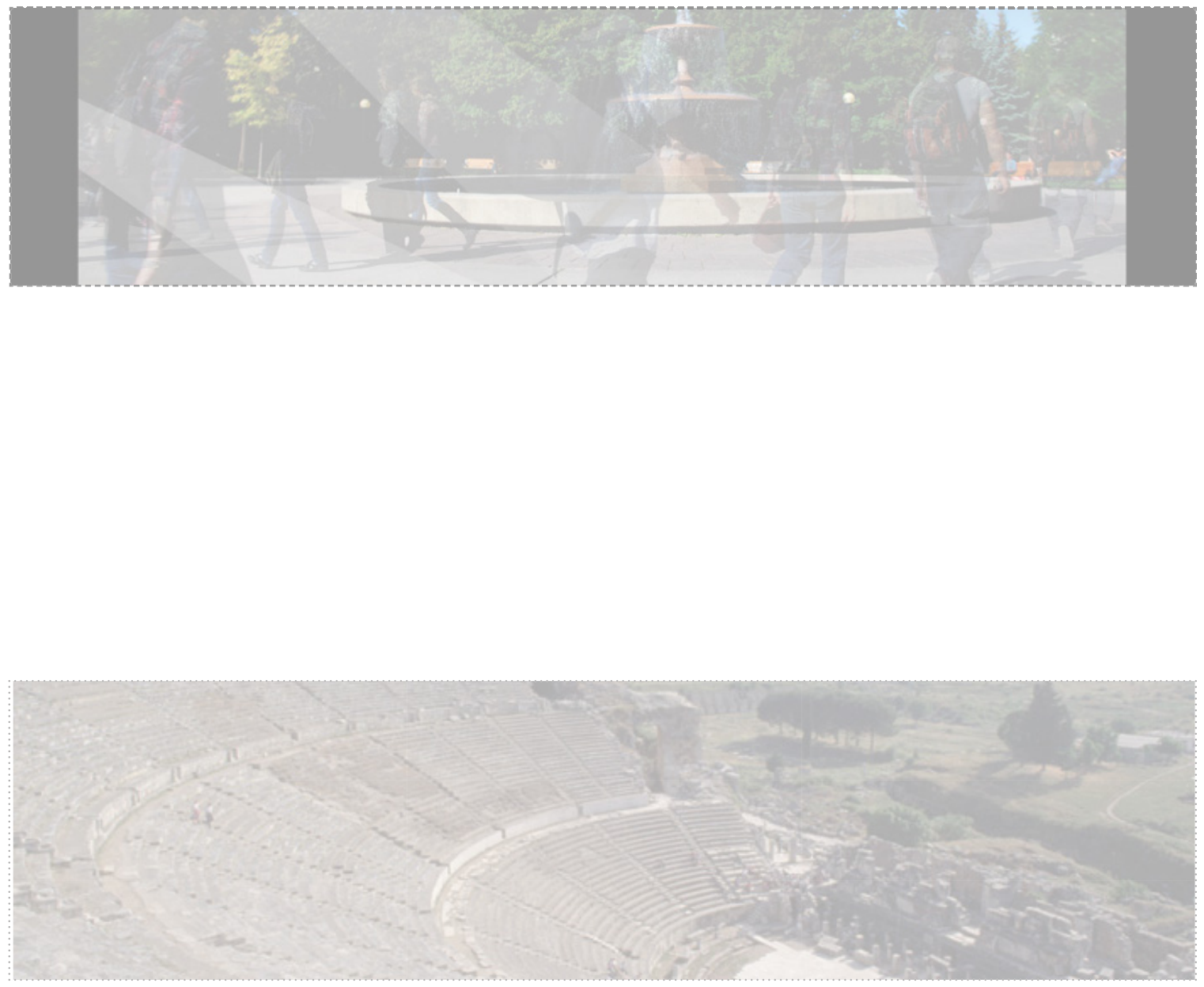

Set Direction: The table located at the back near the vertical herb garden is the communal table where the ladies gather to share a meal. The table is made up of eight smaller ones, each equipped with a stool.
The light has shifted again and is lighting up the table through the openings between and within the green walls. From a seated position at the table, one can see through the green wall into the garden at the rear. 

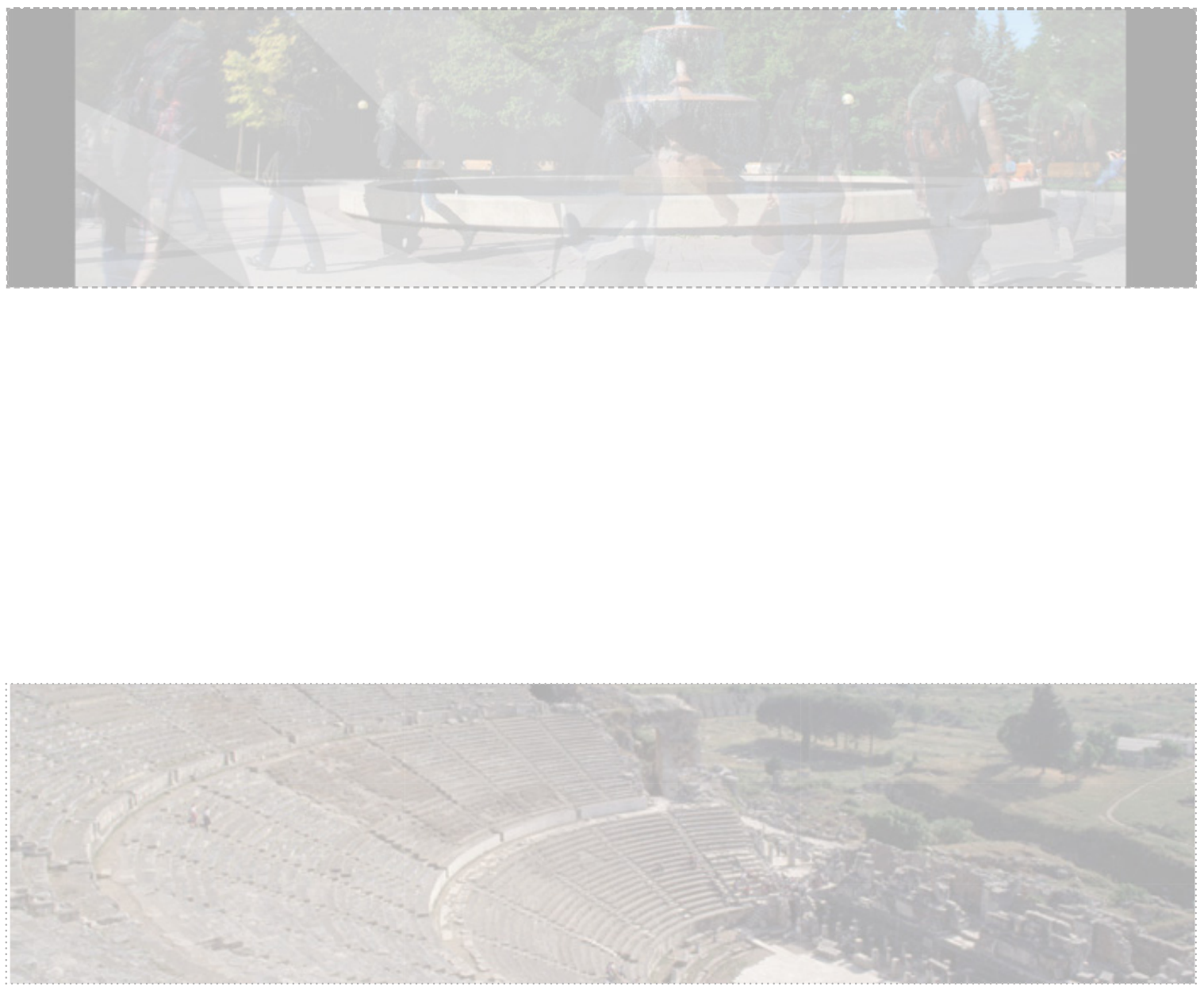

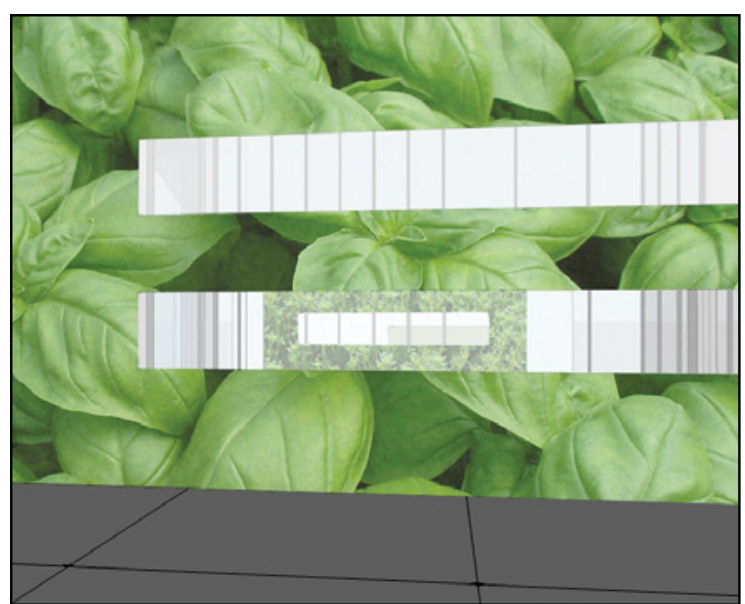

Figure 22: Vertical Herb Gardens

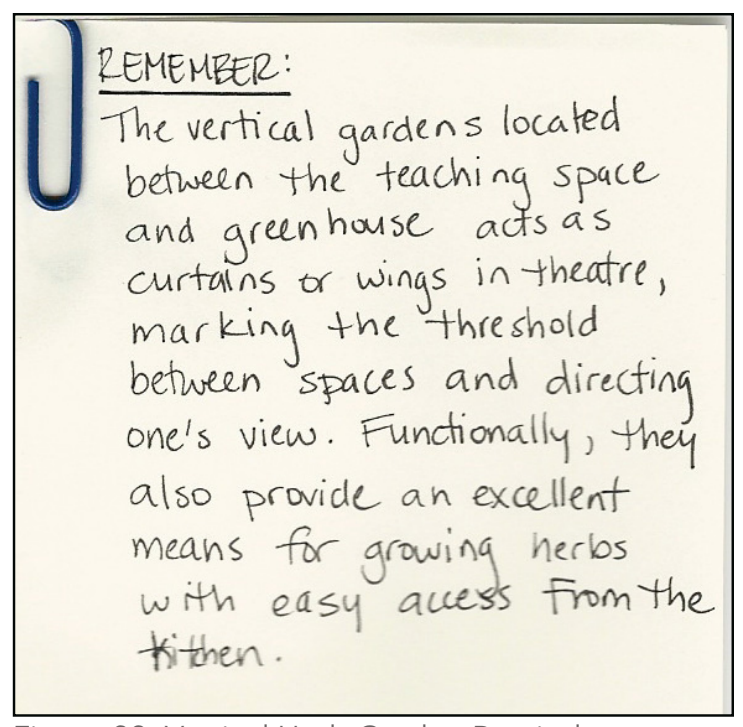

Figure 23: Vertical Herb Garden Reminder 

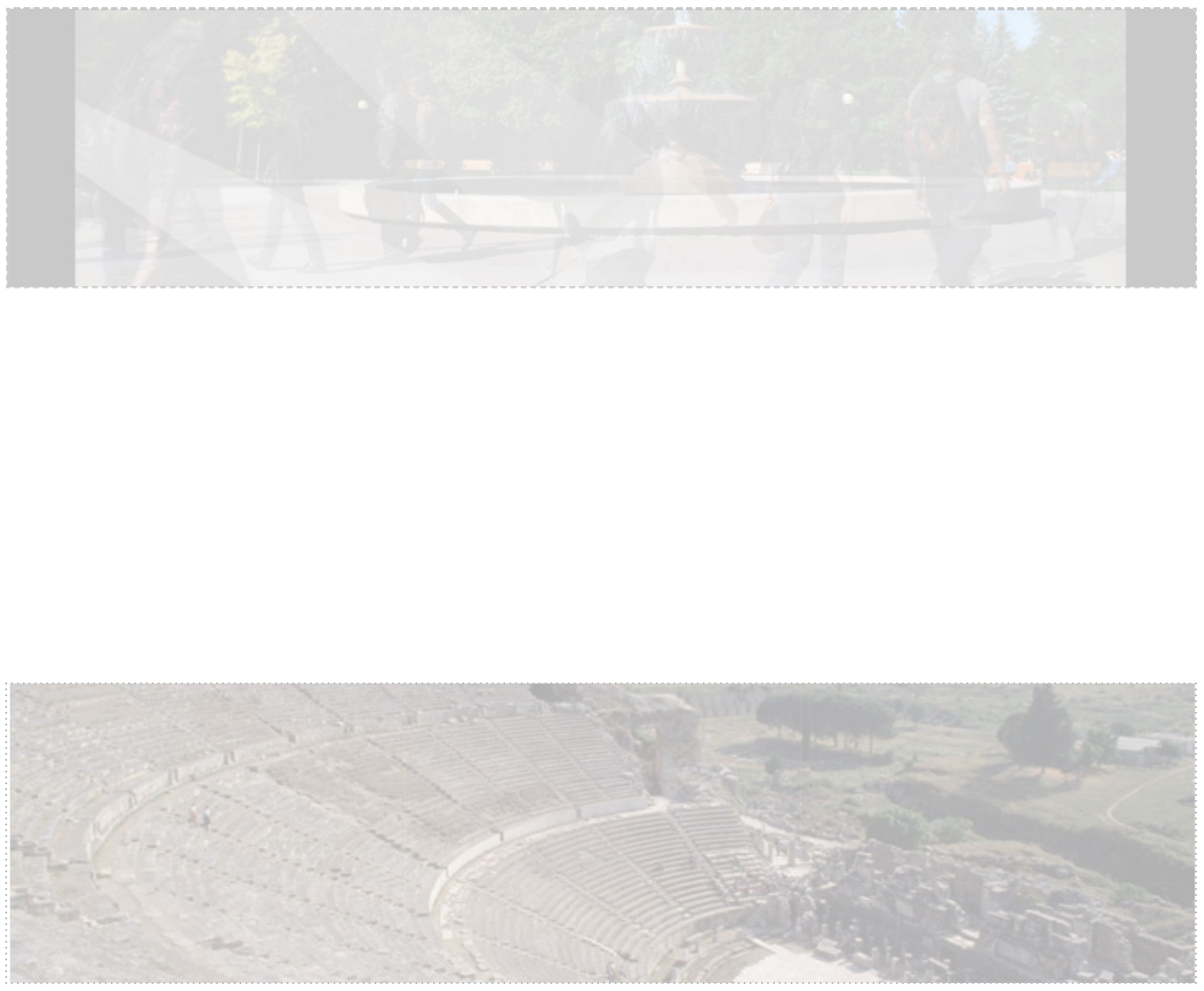

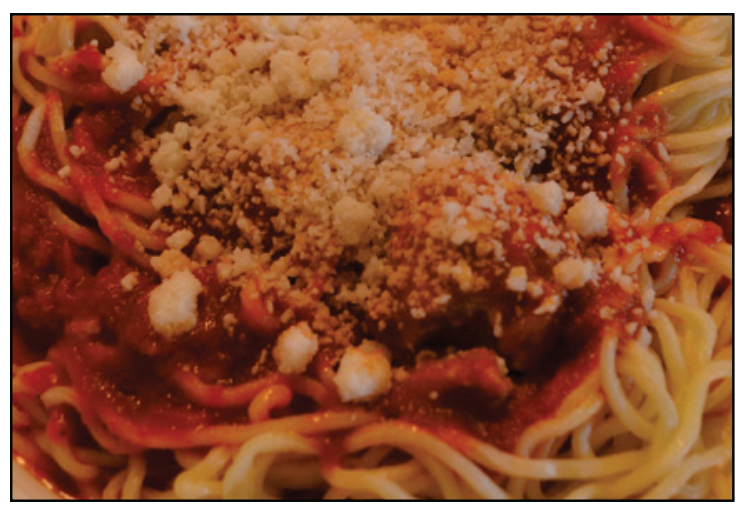

Figure 24: Pasta
Maria proceeds back to her station where the sauce is finished cooking, brings it to Teresa's and together they put out the pasta. All the ladies gather around the large table and enjoy lunch while taking in the garden at the back.

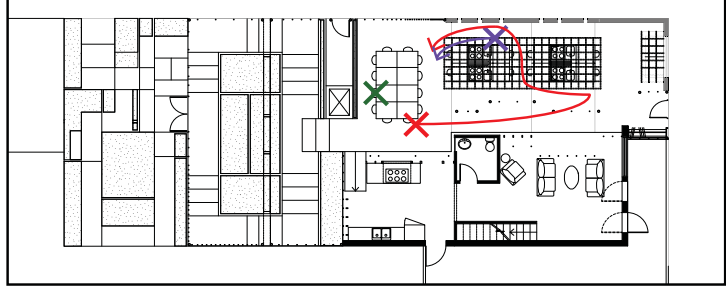



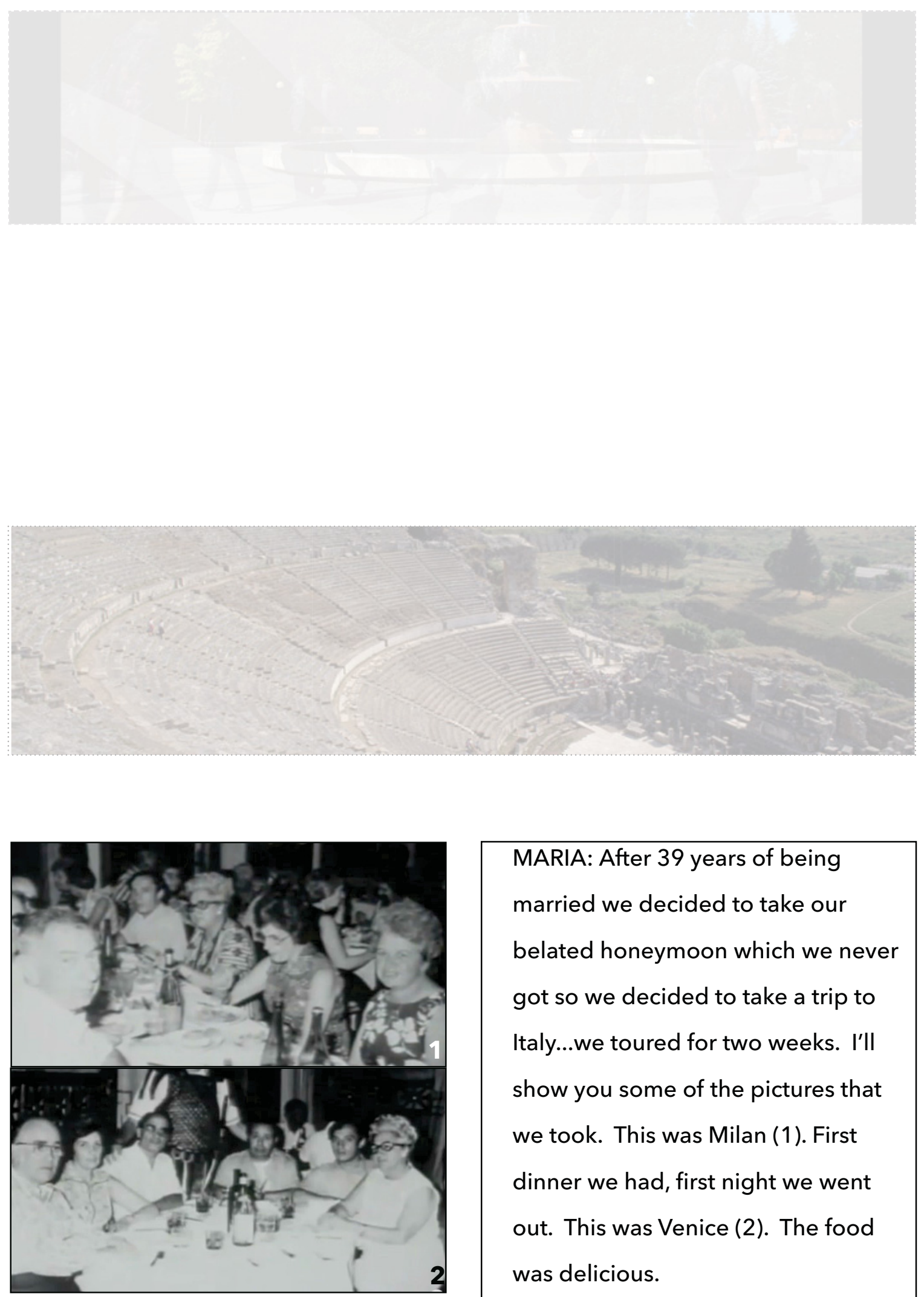

MARIA: After 39 years of being married we decided to take our belated honeymoon which we never got so we decided to take a trip to Italy...we toured for two weeks. I'Il show you some of the pictures that we took. This was Milan (1). First dinner we had, first night we went out. This was Venice (2). The food was delicious. 

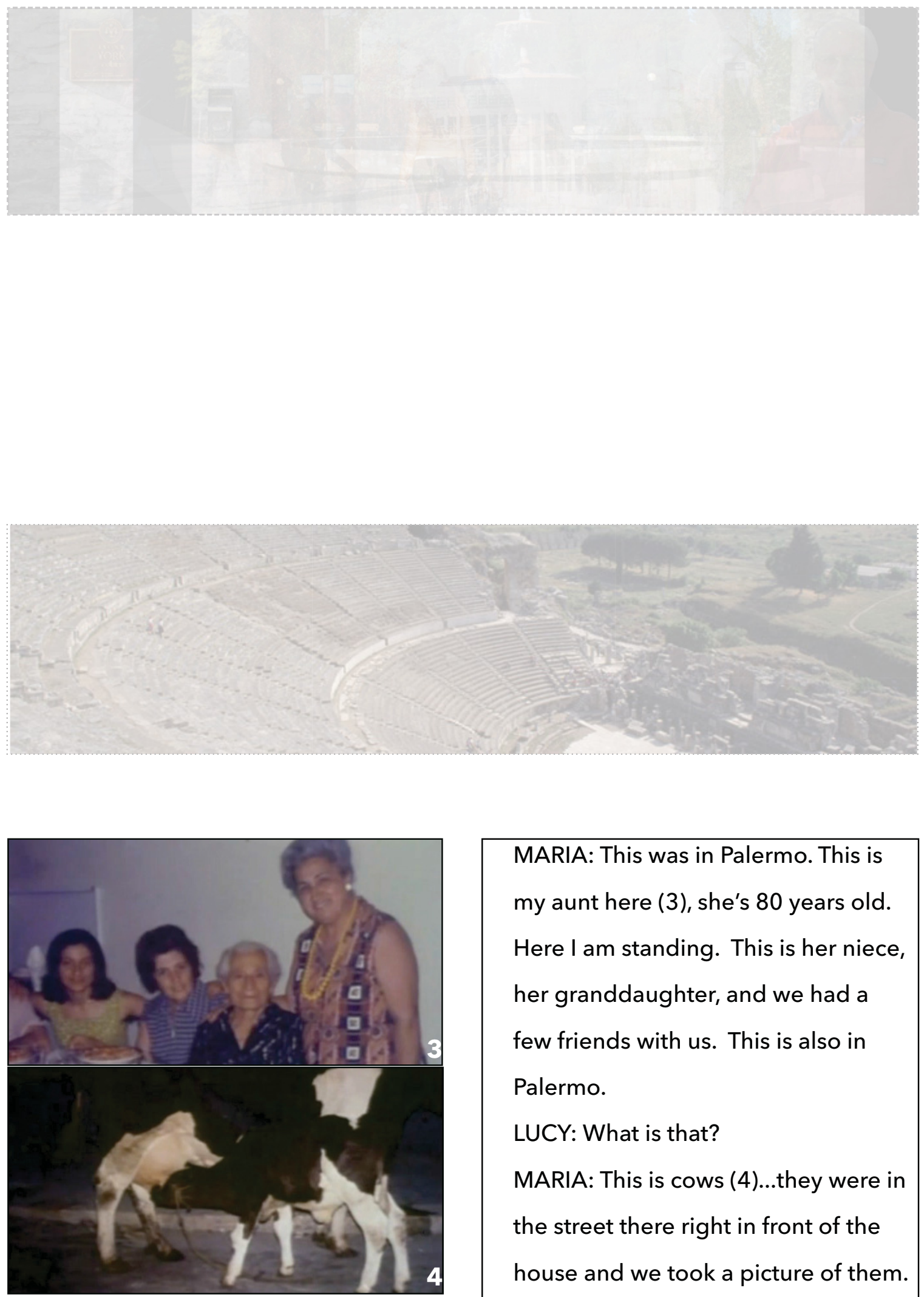

MARIA: This was in Palermo. This is my aunt here (3), she's 80 years old. Here I am standing. This is her niece, her granddaughter, and we had a few friends with us. This is also in Palermo.

LUCY: What is that?

MARIA: This is cows (4)...they were in the street there right in front of the house and we took a picture of them. 

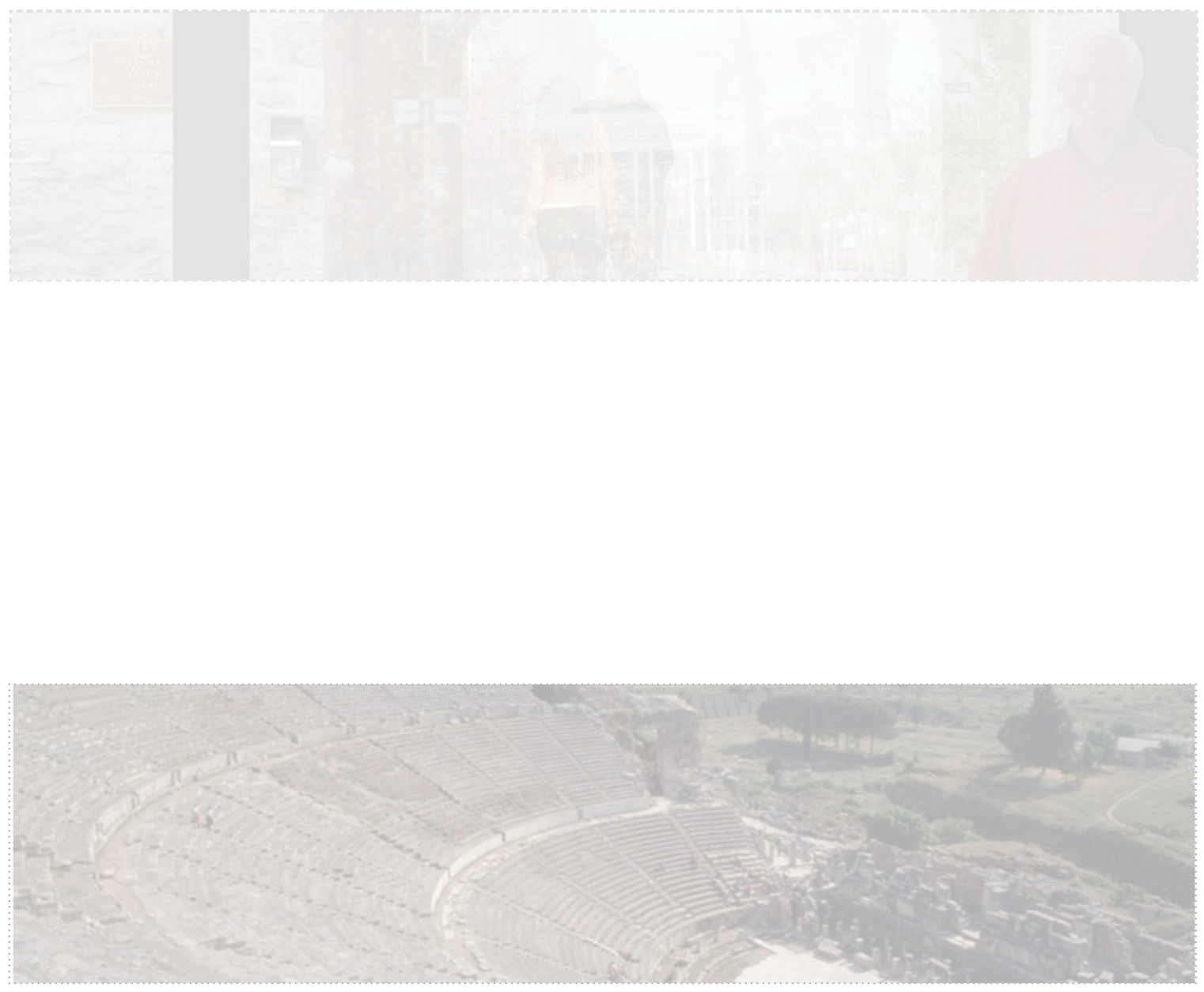

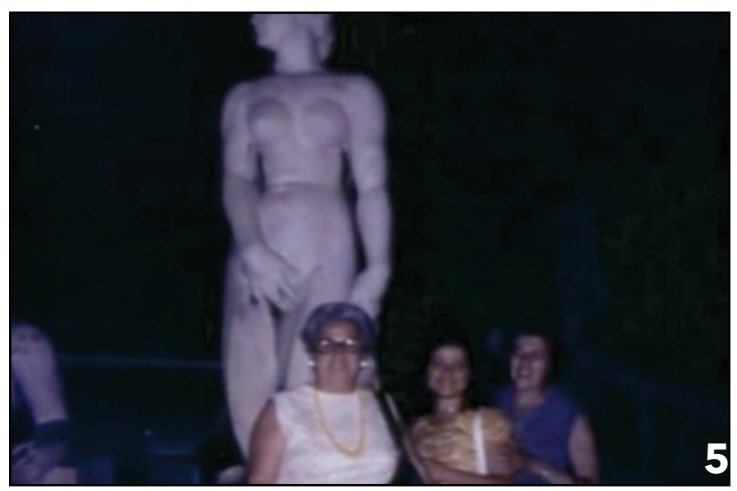

Figure 27: "Italianamerica" Video Stills 3
MARIA: We thought it was nice. And this was in Palermo (5), they called it Pallazo di Vergogna, the piazza of shame.

LUCY: The shameful plaza. Why was it called Pallazo di Vergogna? MARIA: Well because there were all these naked statues and I thought they were just great. 

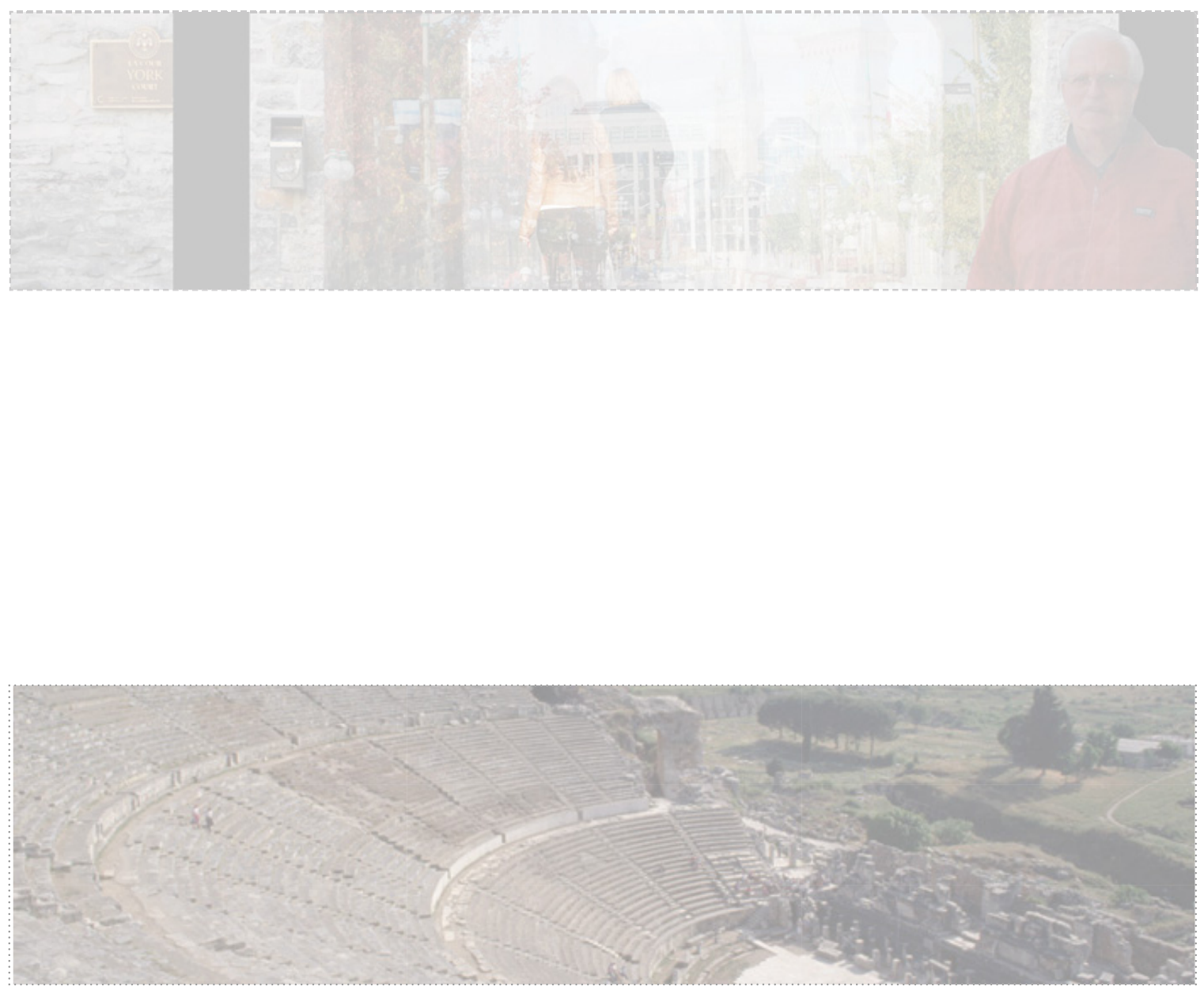

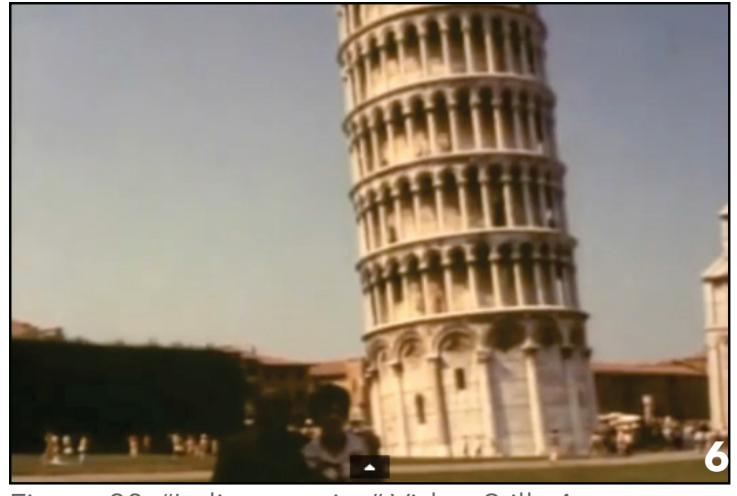

Figure 28: "Italianamerica" Video Stills 4
TERESA: You thought they were great?

MARIA: And the statues were beautiful.

And this was the leaning... LUCY: Leaning Tower of Pisa (6)... MARIA: Anything we saw we took a picture of... ${ }^{18}$ 

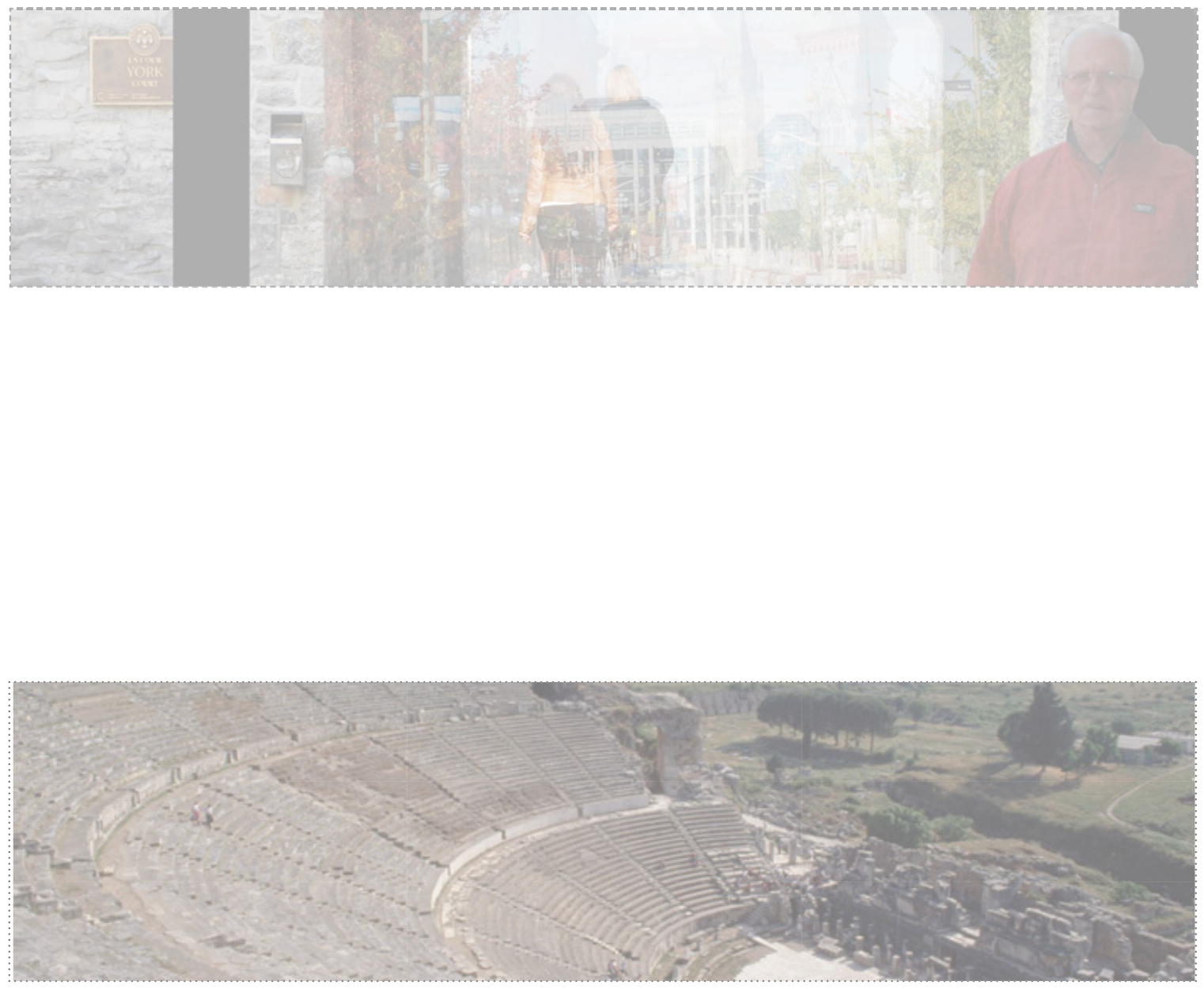

After lunch the ladies wash the dishes in the kitchen, make espresso and proceed to the living room to enjoy their coffee and rest a bit. Some go out on the balcony and get some fresh air, while others relax on the couches. Some of them even close their eyes for 10 minutes.
Teresa packages the cookies in containers and leaves them on the counter at her station and begins gathering the tools she needs for the pasta-making class she'll be teaching later on.

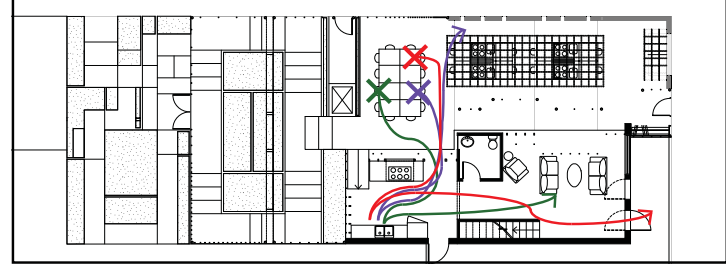



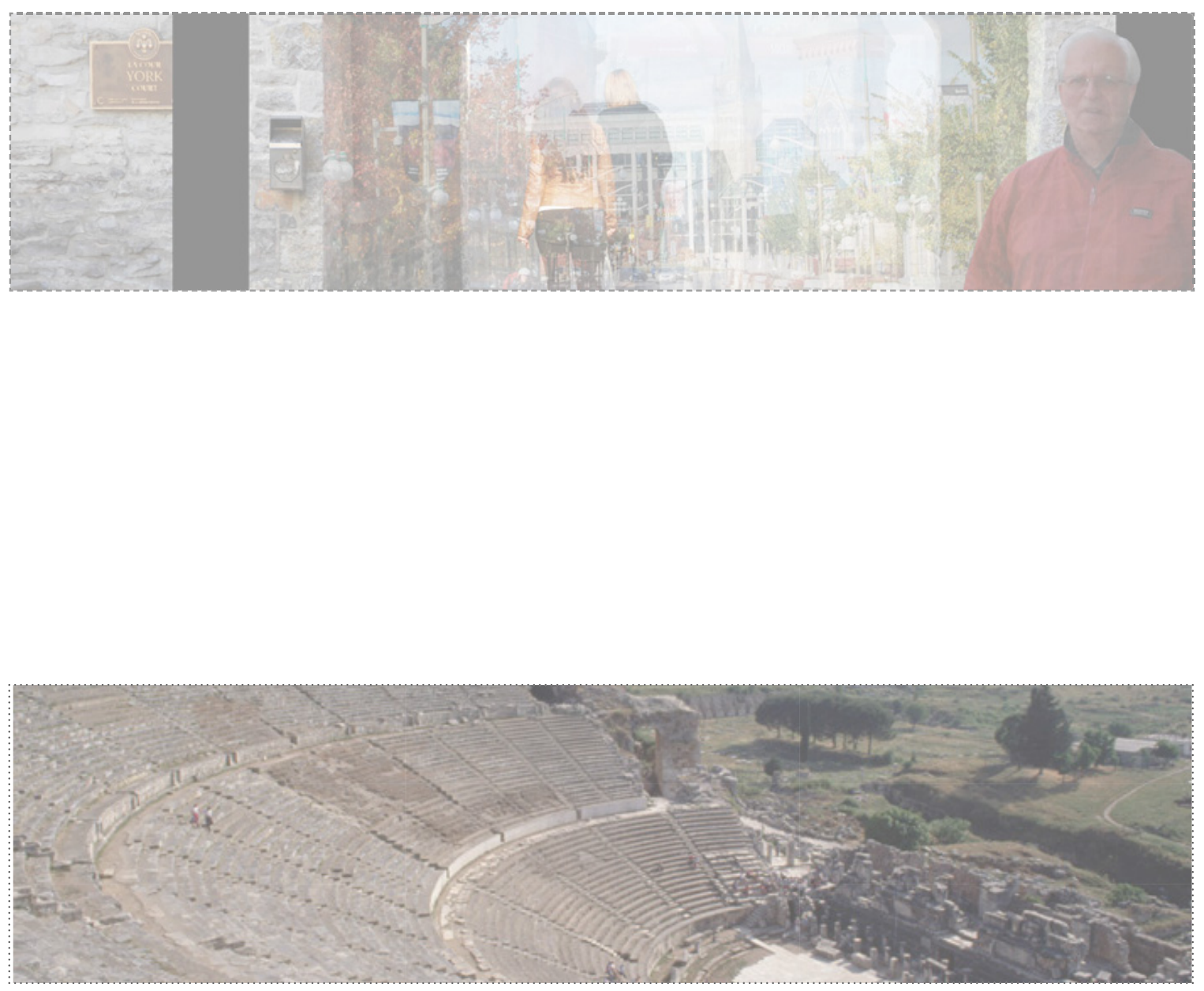

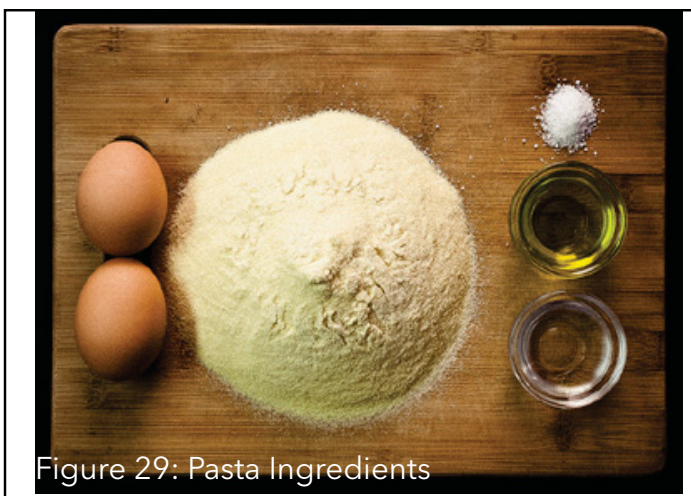

Set Direction: All the equipment for classes is located within the teaching kitchen. The tables that the ladies just used for eating are used as individual stations in the cooking classes. Teresa makes her way to the kitchen and takes out eight pasta machines and attaches each to a table. She then places a large bag of flour, four dozen eggs and a bowl of water in the middle of all the tables with two sets of measuring cups. Each station also receives a bowl for making the pasta and a bowl for garbage.

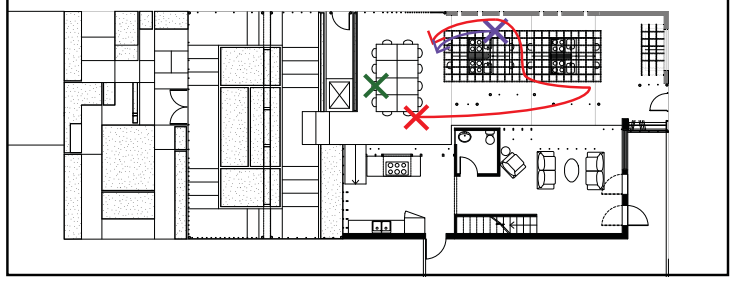



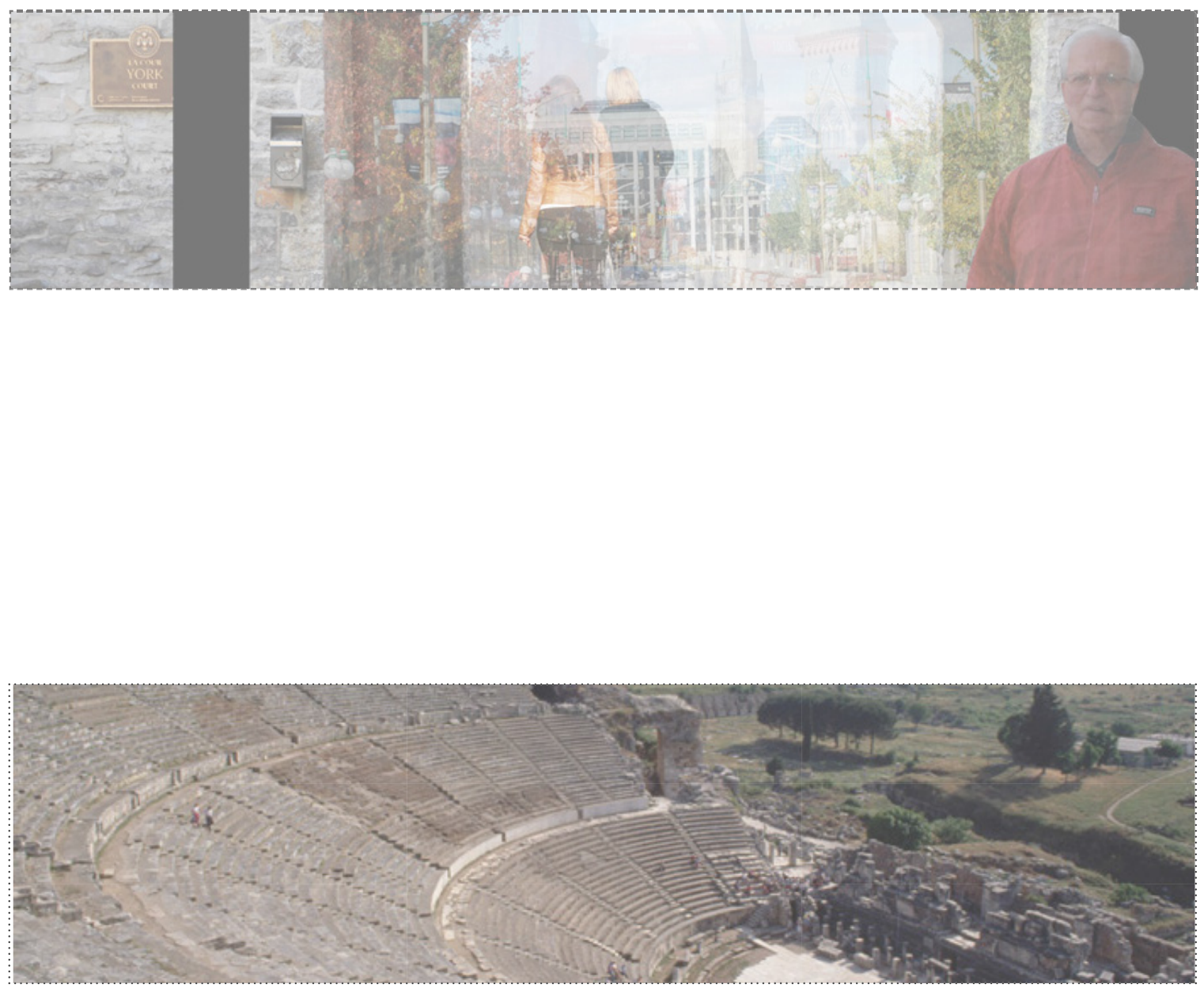

Maria packs up her belongings, locks her station and makes her way to the door. She removes her apron and hangs it, leaves her indoor shoes on the shoe rack and puts on her coat.

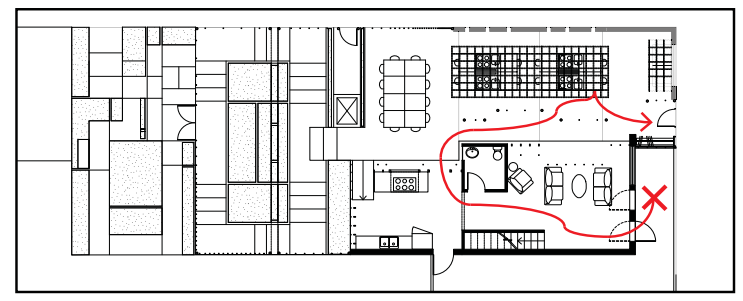




\section{Notes}

1. Prosper, Montagné, Larousse Gastronomique, ed: Jennifer Harvey Lang (New York: Crown, 1988).

2. Brian Henderson, "The Long Take," in Movies and Methods: An Anthology, ed. Bill Nichols (Berkeley: University of California Press, 1976), 315

3. Aleksandar Saša Dundjerović, The Theatricality of Robert Lepage (Montreal: McGill-Queen's UP, 2007) 98

4. $\quad$ lbid, 99

5. Peter Brook, The Empty Space (New York: Atheneum, 1968) 111.

6. $\quad$ bid, 142 .

7. $\quad$ bid, 143 .

8. Peter D. Arnott, Public and Performance in the Greek Theatre (London: Routledge, 1989) 11.

9. Ibid, 6 .

10. Italianamerica. Dir. Martine Scorsese. Perf. Charlie Scorsese and Catherine Scorsese. National Communications Foundation, 1974. Film. YouTube. 12 Aug. 2008. Web. 20 Feb. 2014. <http:// www.youtube.com/watch?v=2tzKAlLb4iM>.

11. Antonin Artaud, "The Theatre of Cruelty (First Manifesto)," Antonin Artaud, Selected Writings (New York: Farrar, Straus and Giroux, 1976) 248.

12. $\quad$ bid, 248 .

13. Ibid, 250

14. Eat Pray Love. Dir. Ryan Murphy. Perf. Julia Roberts and Javier Bardem. Sony, 2010.

15. James Turney Allen, Greek Theatre of the Fifth Century before Christ (New York: Haskell House, 1966) 2.

16. Ibid, 1

17. Italianamerica. Dir. Martine Scorsese. Perf. Charlie Scorsese and Catherine Scorsese. National Communications Foundation, 1974. Film. YouTube. 12 Aug. 2008. Web. 20 Feb. 2014. <http:// www. youtube. com/watch? $=2$ tzKAlLb4iM>.

18. Italianamerica. Dir. Martine Scorsese. Perf. Charlie Scorsese and Catherine Scorsese. National Communications Foundation, 1974. Film. YouTube. 12 Aug. 2008. Web. 20 Feb. 2014. < http:// www.youtube.com/watch?v=2tzKAlLb4iM>. 
ACT 2: (TEACHING) CENTRE 
Within traditional theatre, many tools are used to support the narrative of a play. Sets, scrims and props are among the most useful elements to set the stage for the actors. Similarly, in our daily experience of the city, we are constantly receiving information, signs and spatial relationships which helps us to locate ourselves and allows us to collectively participate in the city.

From the perspective of the spectator in the Greek theatre, the play was always staged in: a series of layers with the actor in the foreground, skene in the middle ground, and the city framed in the background. The elevated point of view of each spectator allowed for a linear and layered relationship to occur.

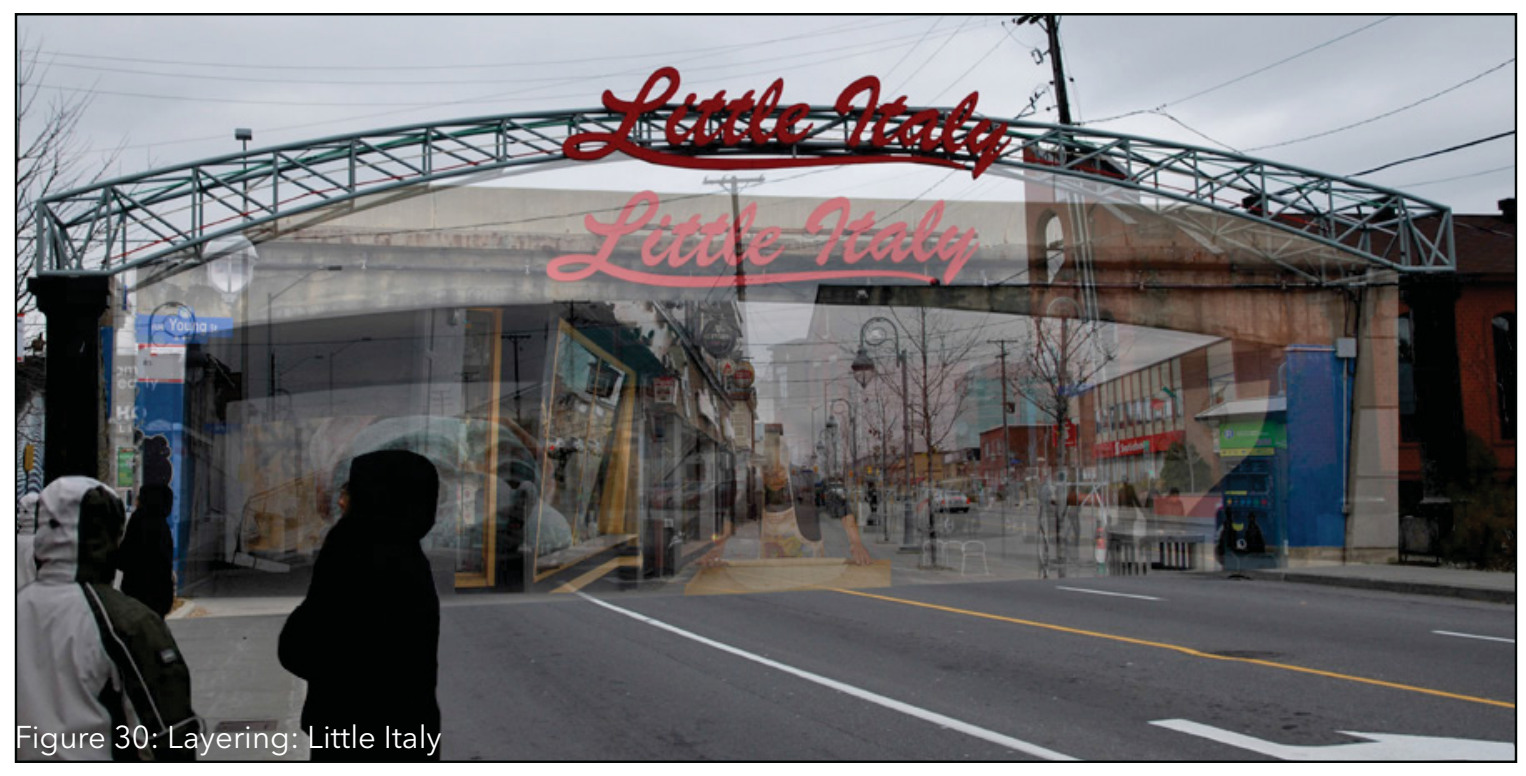




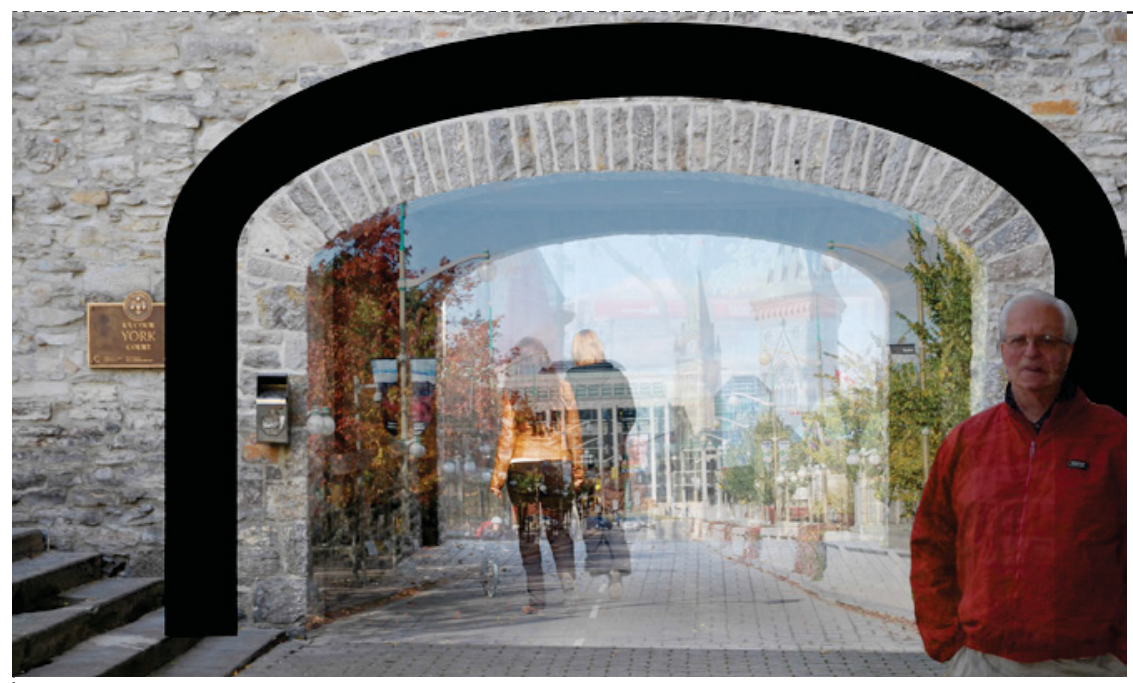

Figure 31: Layering: The Courtyards

To the spectator, the city was always framed by the theatre's architecture, providing strategic views beyond the scene. The actor often had his back to the city, but could be seen through the frames in the skene, and at brief moments through the compressive space between the skene and the auditorium along the parodos. In each of these scenarios, it was the architecture that acted as the vehicle for these methods of viewing

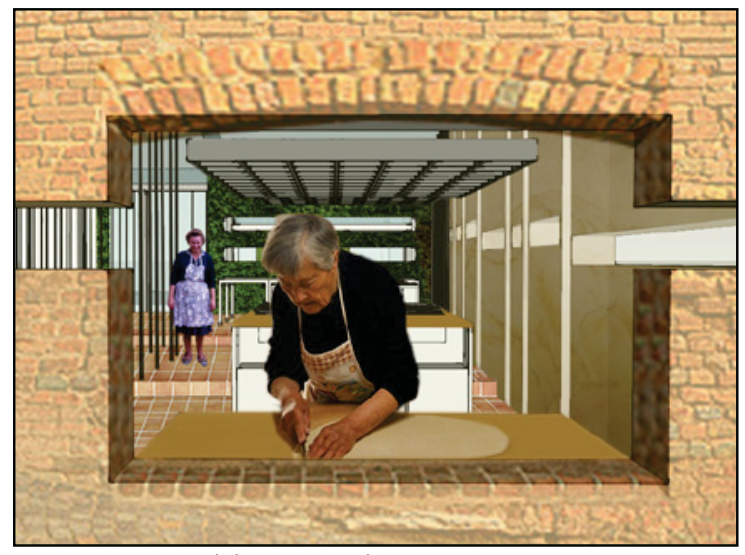

Figure 32: Midday Arrival
Chloe is attending a session on making pasta from scratch. She was instructed to approach the front door and ring the bell for someone to let her in.

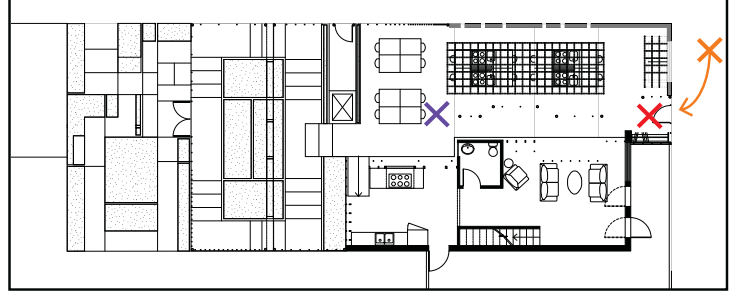


Layering: The Courtyards explores the techniques of layering, framing, and suspended disbelief. A layered view of Ottawa is achieved by incorporating different images and architectural elements to suggest a more unified and layered whole. The layers act much like scrims of the stage, each containing different spatial information and when one is added or removed the setting or context within which the play is understood is modified. Each layer or scrim is contained within the proscenium arch, the frame through which the spectators view the play.
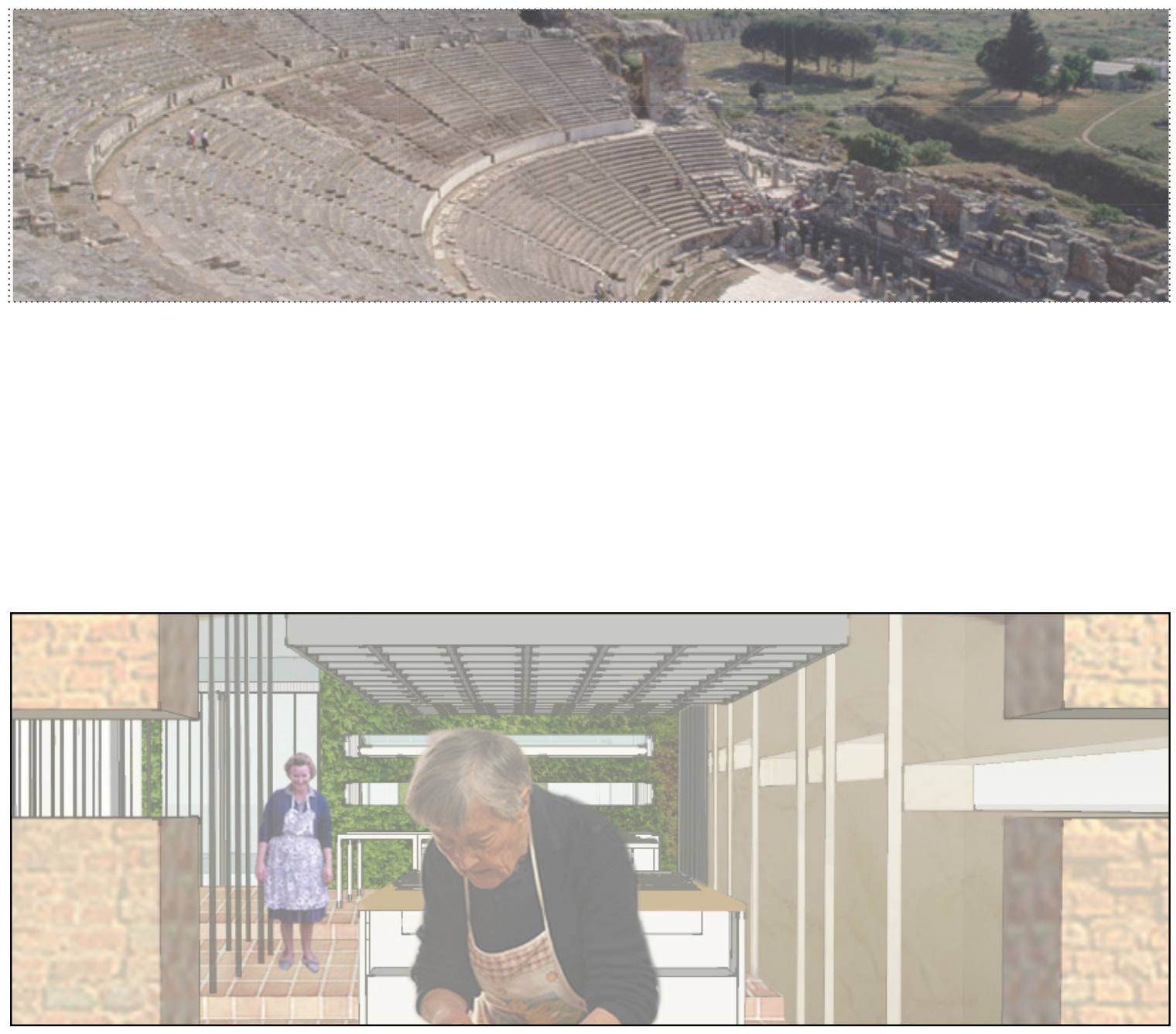
While some acting can happen in front of this arch, the setting of the play is contained within it. It is a constant reminder that what the spectators are witnessing is a fragment of reality and is being framed from a specific view. In the Greek theatre, the city in the background, the skene and the actors are each layers of context within the play. The city is the ultimate setting of the play, as it is understood that the audience and actors all ultimately belong to the city and are players within the activities of daily life. The skene acts as the mediator between the reality of the city and the fantastical display of the theatre.

In terms of the contemporary theatrical mise-en-scène, Peter Brook interprets aspects of the experience of theatre from the Greeks to conceive his Holy Theatre as the "InvisibleMade-Visible". The stage was the space where the invisible could appear and take a deep hold on the senses. ${ }^{1}$ The function of the spectator in this theatre was difficult to define, as the spectator was seen as there but not there, necessary but not necessary. ${ }^{2}$

Chloe is admitted by an older lady and remembers from the instructions to remove her shoes and coat.

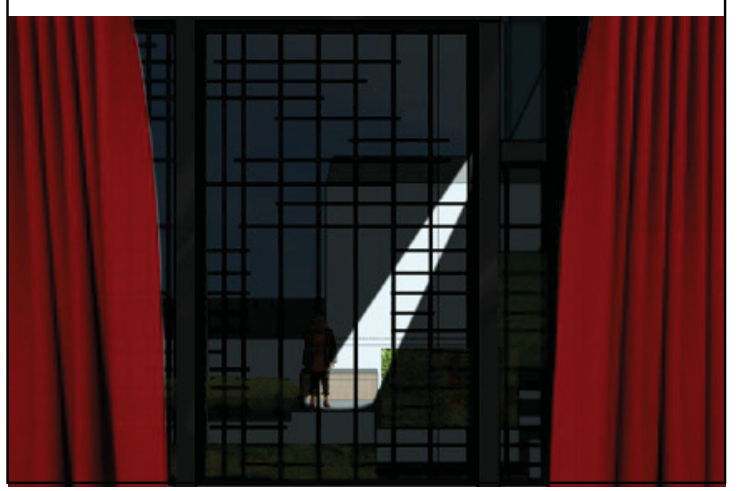

Figure 33: Theatrical View to Garden
She is met by her instructor, Teresa, and is led to the back of the space, looking out on the greenhouse.

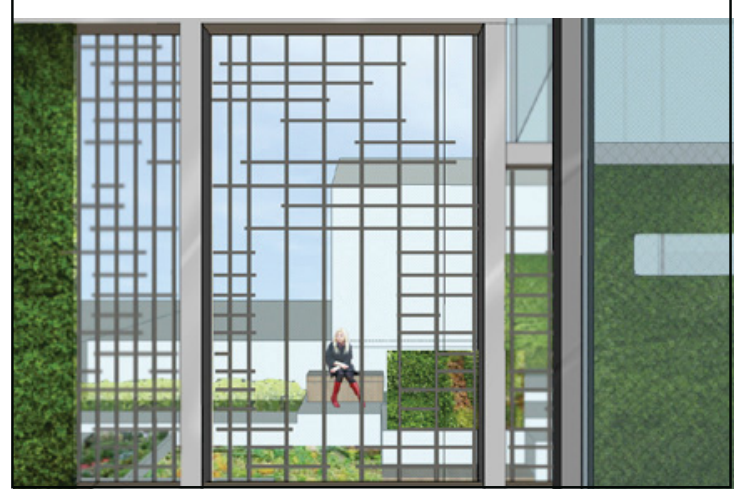

Figure 34: Day-to-Day View to Garden 
The architecture frames the city and is also used as the backdrop for the actors, who enact the lives of common people and play out dramatized versions of every day occurrences. The actors are the human connection through which the spectators understand the play's narrative with which they can most closely relate.

It was possible that the invisible could be made visible through the presence of the performer and this presence could reveal certain relationships that would not normally have existed. ${ }^{3}$ The actor and spectator had to exist simultaneously in the same space in order for the Holy Theatre to come to fruition.

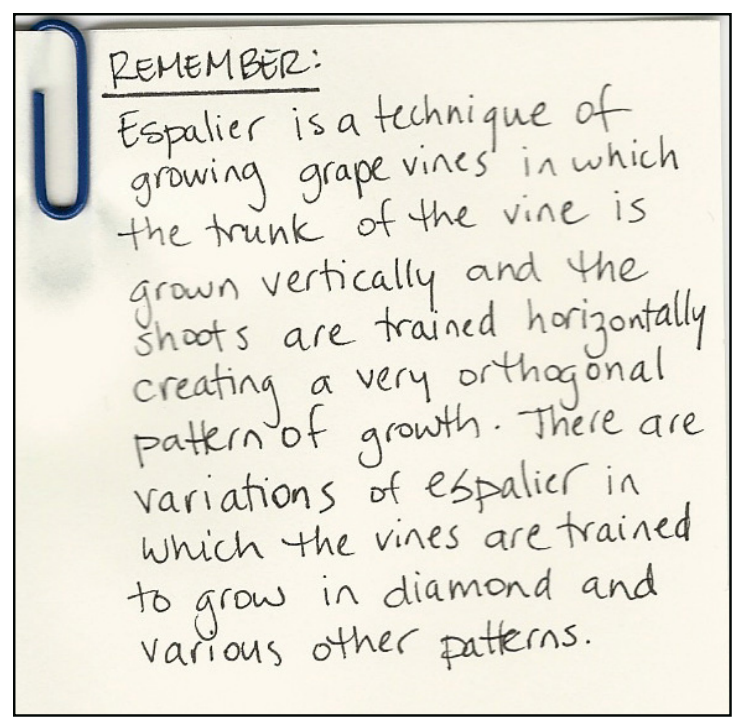

Figure 35: Espalier Reminder
The greenhouse has four levels of planting beds with stairs descending around the outside. The back garden beyond appears to be stepped with planting beds interspersed and meets grade at Larch.

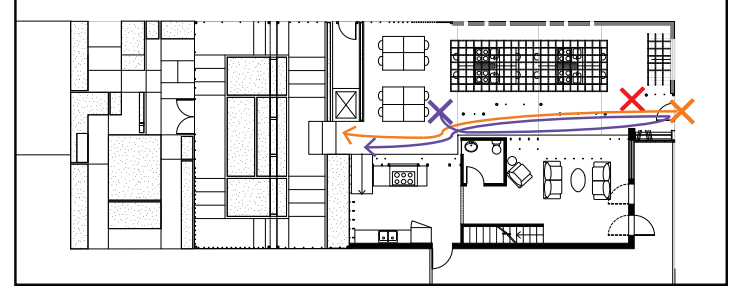




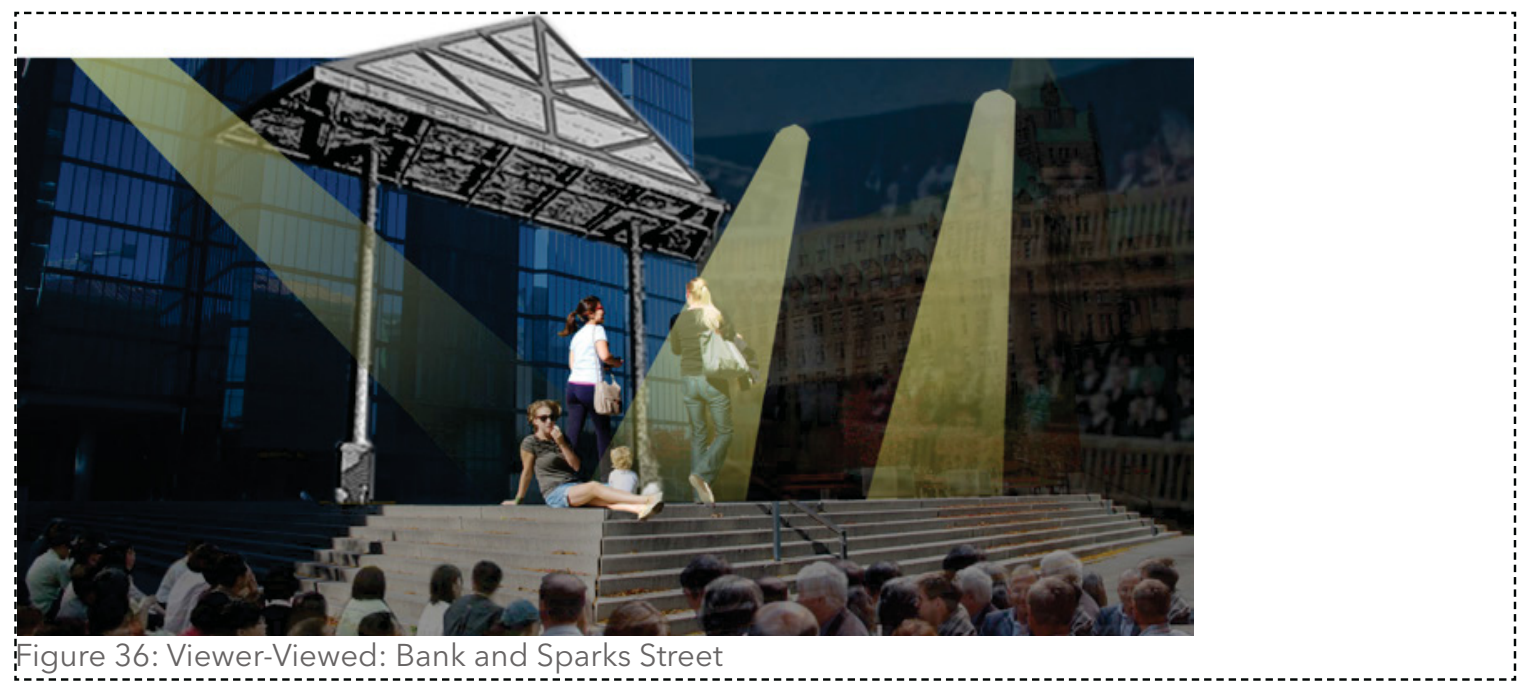

While Brook's Holy Theatre was conceived out of rendering the invisible visible,

Elizabethan theatre exposed social and political themes to the pleasures of its audiences. In addition, Elizabethan theatre aimed to remove sinful behaviour from the city of London. Before this, plays occurred mainly on makeshift stages in empty halls. ${ }^{4}$ When formal theatres were first built, they were used for anything for which people would pay money. This included diverse entertainment ranging from animalbaiting to cockfights to jousting. The spectacle of Elizabethan theatre traditionally had six fundamental characteristics; conventional constructions by craftsmen, a scale that corresponded to the found spaces previously used as theatres, a form that was recognizably classic, fake finishes such as "marble" columns, a crowded audience and a focus that was primarily delineated through pure geometry. ${ }^{5}$

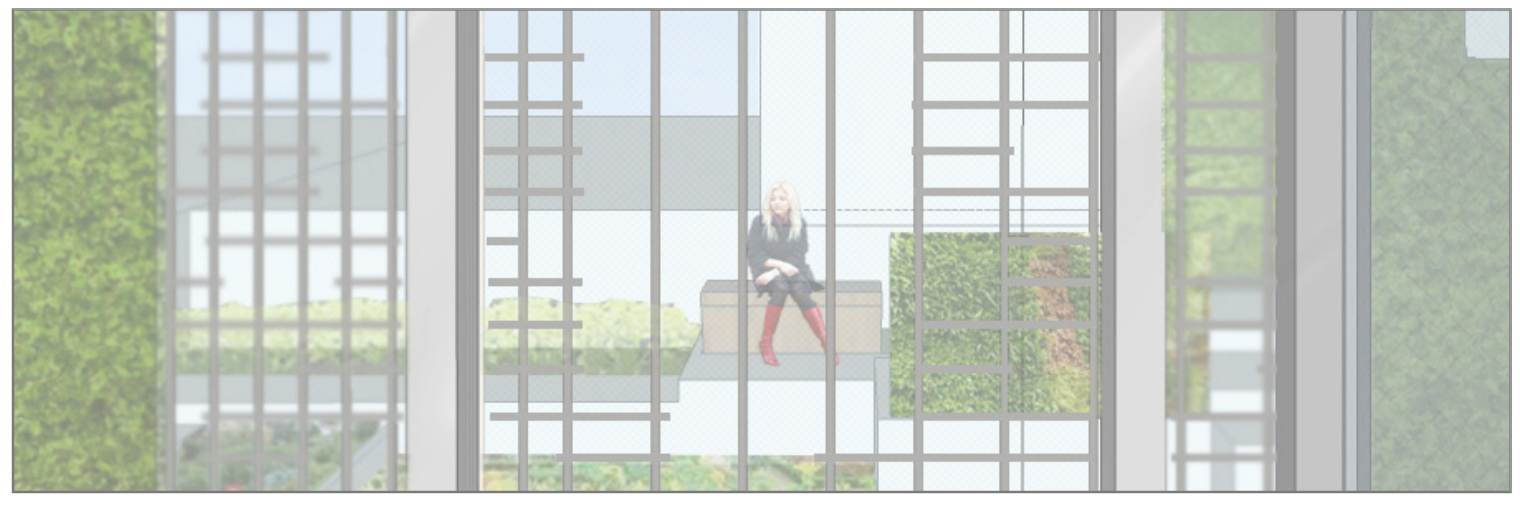


Viewer-Viewed: Bank and Sparks Street examines the viewer-viewed relationship, lighting, setting and point of view. The plaza at Bank and Sparks suggests the qualities: of an Elizabethan theatre with the raised platform acting as a thrust stage for the city, making the "actors" on the stage visible "in the round". In the Elizabethan theatre, part of the audience views the actors from below as the stage is raised within the pit, while others view the play from galleries above and around. For this reason, the actors are shown larger than life, as they would have appeared to those viewing them from below.

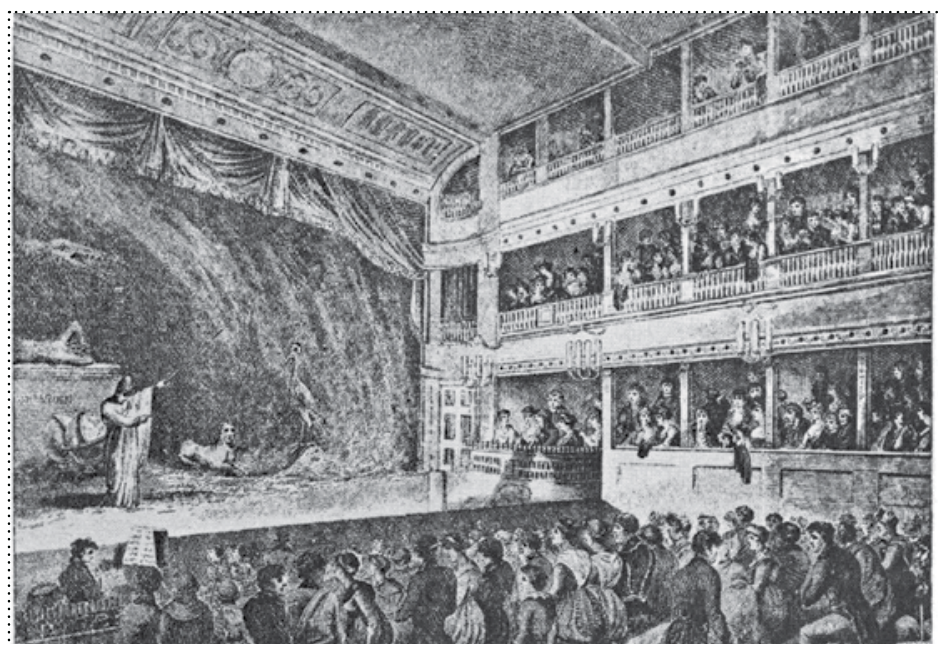

The trestle stage formed a platform in the centre of a flat open area called the pit, containing standing room only

Figure 37: Elizabethan Theatre

Maria's husband is picking her up today because she has a lot to carry. When he arrives she goes out to the car and they go home.

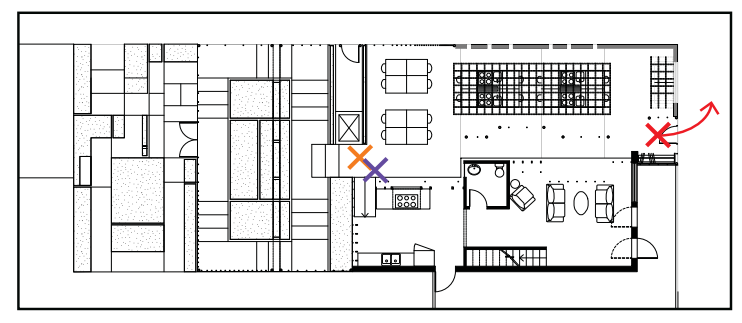


The existing architecture helps to provide a "balcony" quality for people in the offices surrounding this plaza acting as spectators to those occupying the plaza below. The Bank of Canada building acts as the tiring house, with a projecting roof attached and supported by posts. The setting in Elizabethan theatre was generally described in sign posts, but in this case the setting of the city is expressed through reflection of Parliament on the glass façade. The scene is artificially lit, with the actors being within the bounds of the light and the spectators receding back into darkness.

The actor was therefore thrust out into the middle of the audience, bringing the attention of the spectators mainly to the actor, as opposed to the scenery. ${ }^{6}$ Both the stage and the structure behind it, named the tiring house, were potentially dismountable. Three levels of galleries surrounded the pit on three sides, and were each: roofed, facing an unroofed centre.? The face of the tiring house contained two large doors and a shallow gallery draped with a figured curtain. Many stages had a projecting roof located overhead, usually supported by posts, but in some instances cantilevered from the structure.

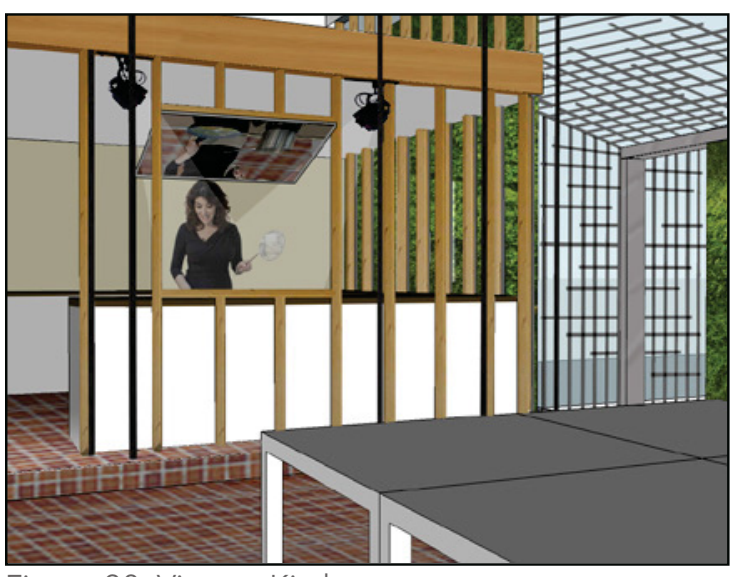

Figure 38: View to Kitchen
Set Direction: From their stations, the students can see into the teaching kitchen where the island is perfectly framed for them. An angled mirror is located above the cook top so that the students can observe how Teresa's hands handle the dough. Each student has an equal opportunity at a view. 


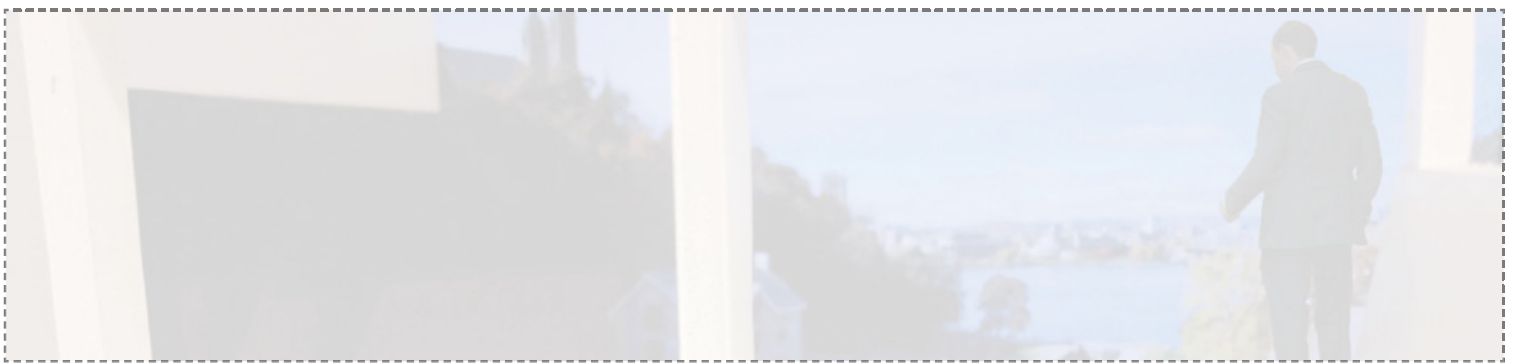

Musicians were contained within the gallery, unlike in the Greek theatre where they were: at the level of the actors. Place and setting was referenced through sign boards and text: rather than imagery or backdrops.? There was very little hierarchy in terms of seating and tickets were purchased for the pit and the galleries alike. People were able to purchase tickets for whichever location they could afford, and the galleries slowly became more "lower class" as unsavoury activities could occur in the shadows. As productions became more elaborate, ticket prices began to increase, making even the cheapest tickets unaffordable to the working class. Thus, the size of theatres grew, allowing for more "cheap" tickets to be sold and to increase attendance rates. ${ }^{10}$

CHLOE: Teresa, before the class gets started I'd like to use the washroom and get some air. Is there anywhere I can go without going back out to Preston? TERESA: Sure, if you want some air as well, l'd suggest going upstairs to use the washroom. It'll be the first door on your right.
If you continue down the hall, there will be a balcony on your right. Teresa proceeds to the island to set up her ingredients and make sure everything is properly visible through the mirror. More students ring the doorbell and she makes her way over to greet them. 


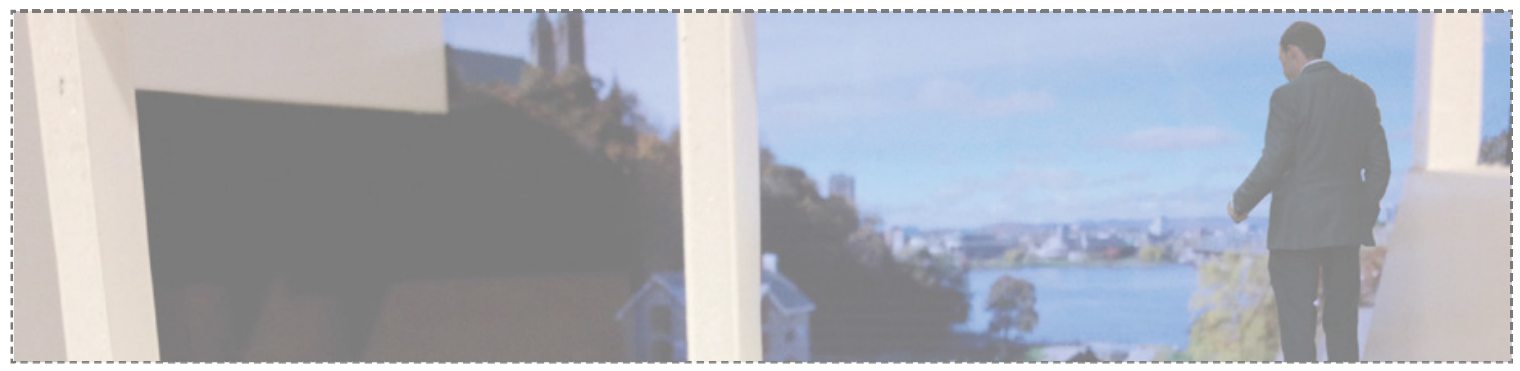

As the larger theatres became increasingly difficult to travel to, smaller theatres called patent houses began appearing in the centre of London, bringing theatre back to the urban experience. The laws were strict on what types of productions were allowed to encourage attendance at the larger theatres, and because of this performance types such as musicals and pantomime were born satisfying the new laws. Due to the Puritan movement, theatres were outlawed from 1642 - 1660, and when the ban was lifted, royal tennis courts were generally repurposed into theatres. ${ }^{11}$ This resulted in a change to the configurations and proportions of the Elizabethan theatre and was also the same time that scenic theatre began to emerge, introducing devices such as layering and framing.

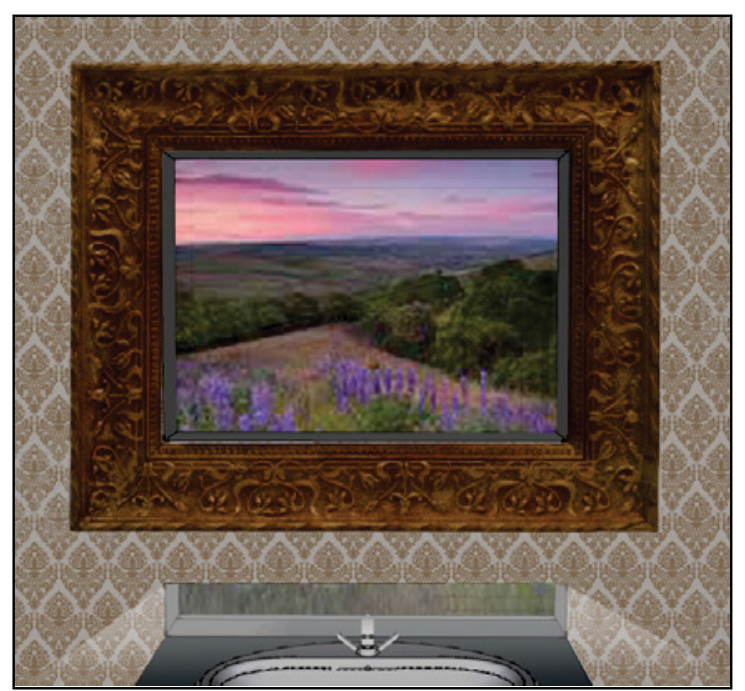

Figure 39: Theatrical Washroom Detail
Chloe proceeds upstairs and uses the washroom. As she washes her hands, she realizes that instead of a mirror, there is a perfectly framed view across the teaching space below and out the glazing opposite her. There is also a small slit of glass behind the tap, perfectly framing her hands as she washes them. 


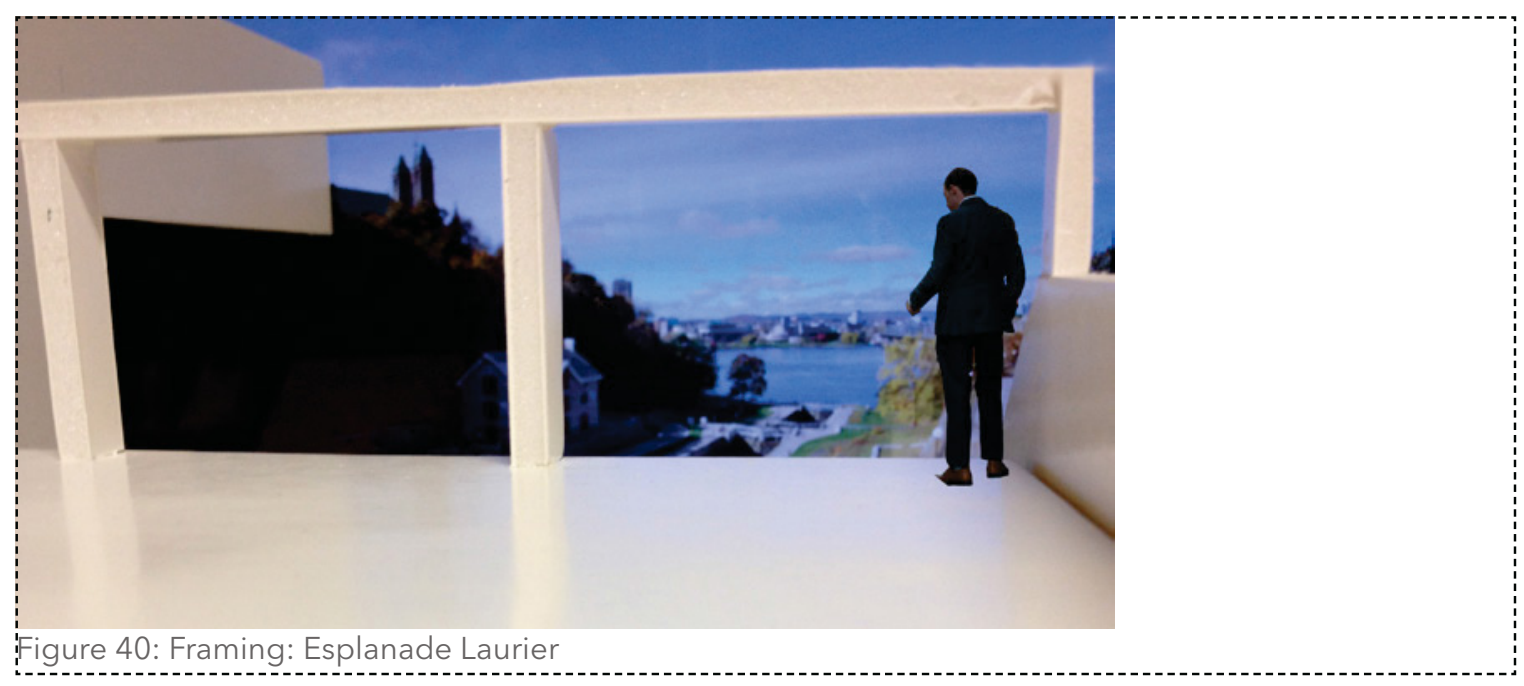

An additional ingredient in the mise-en-scene of theatre is framing. It is a tool utilized by many of the arts in order to encourage the viewer to observe something from a particular point of view. The human body naturally does this by isolating certain aspects of images in order to formulate a perception of a scene or image. ${ }^{13}$ The frame is used in cinema as a vehicle for creating an impression of a virtual totality that can only be realized through body-brain achievement. ${ }^{14}$ In "New Philosophy for New Media", Mark Hansen discusses and gives examples of new digital art practices.

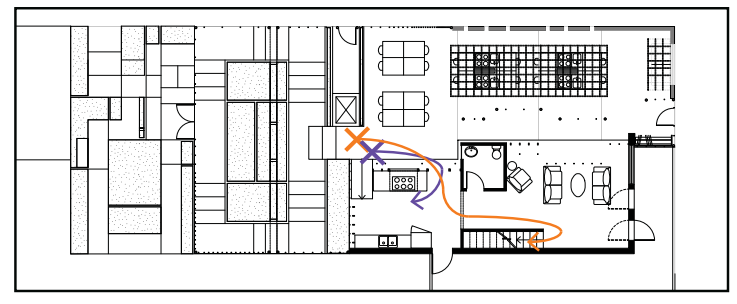


Framing: Esplanade Laurier studies choreography, framing, viewer-viewed relationships and point of view. The staircase at Bank and Laurier creates a stage on which the actions and sounds of those descending, ascending and pausing at the top of the stair are amplified and put on display for the people moving along the streets or pausing in the plaza below. The people on the stair might not realize that they are on display and the people below may not be aware of the people on the stair. By framing the moment at which people come down, face their "audience," and begin their descent, it makes the actors aware that they are on stage and frames their view of the city. This device also frames them for their spectators, and brings attention to the fact that they are on display.
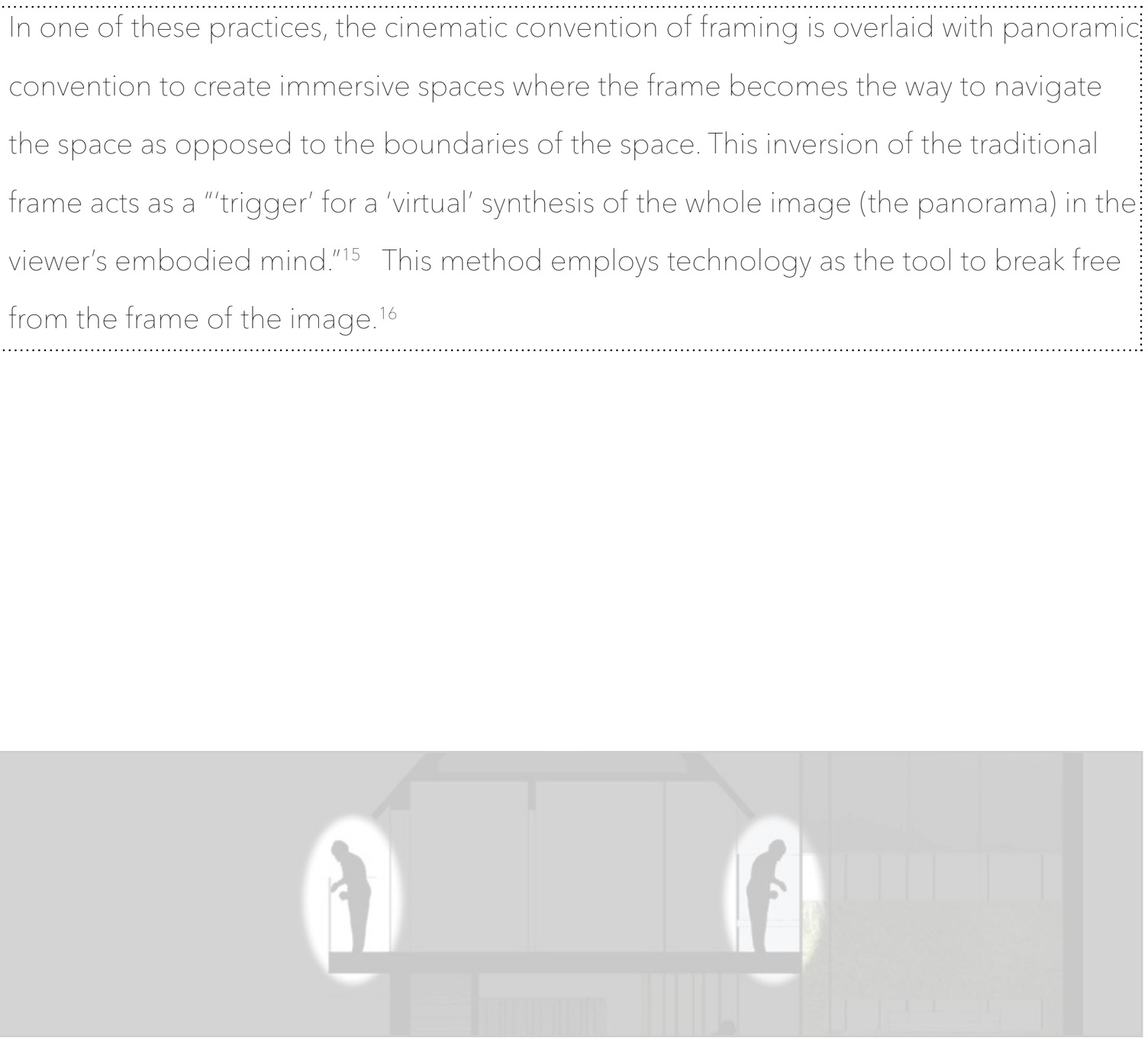
The depth of the frame over the stair would be $60 \mathrm{~cm}$, the dimension required for an average person to fully inhabit it. By placing a full height wall with framed openings along the north side of the stair, the selected openings highlight the actors as they descend, giving the spectators snapshots of their movement. This provides the actors with portholes through which they can view the city.

Framing is not only a convention of art, but is also used in the relaying of information.

It always requires a frame and originates in the "transpatial meaning-constituting and actualizing capacity of (human) embodiment."17 In other words, the meaning that is interpreted by the audience is influenced by the actions of three players; the writer, who provides the text, the actor who contributes expression and the set designer who designs a setting for these actions to occur.

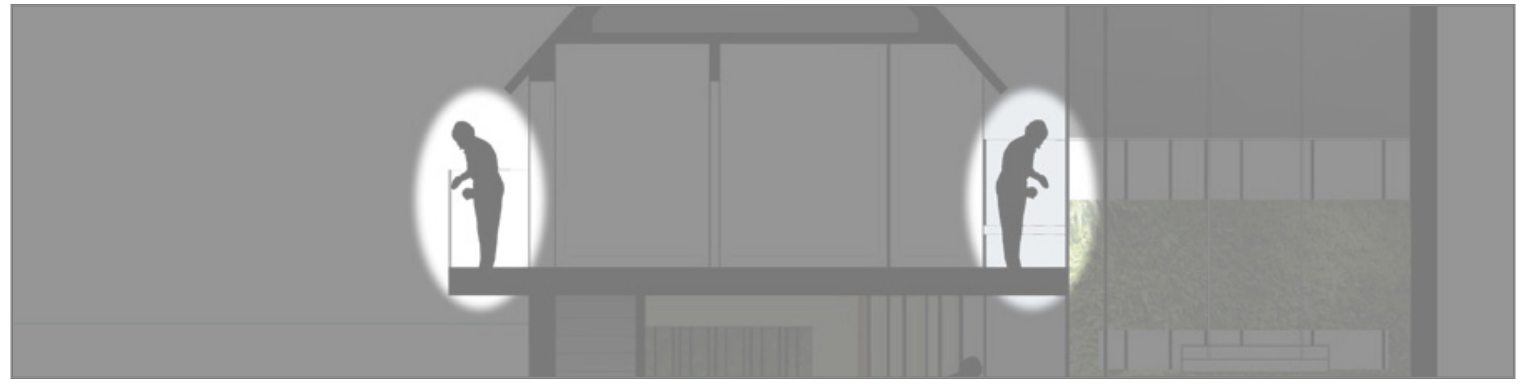


The entire body of the actor is rarely framed and most openings are placed at moments when the actor's body connects with the architecture, such as a hand sliding down the banister and feet walking down the stairs. If the spectator becomes interested in the movements in the openings, they would be able to move around the wall to fully engage and receive the performance.
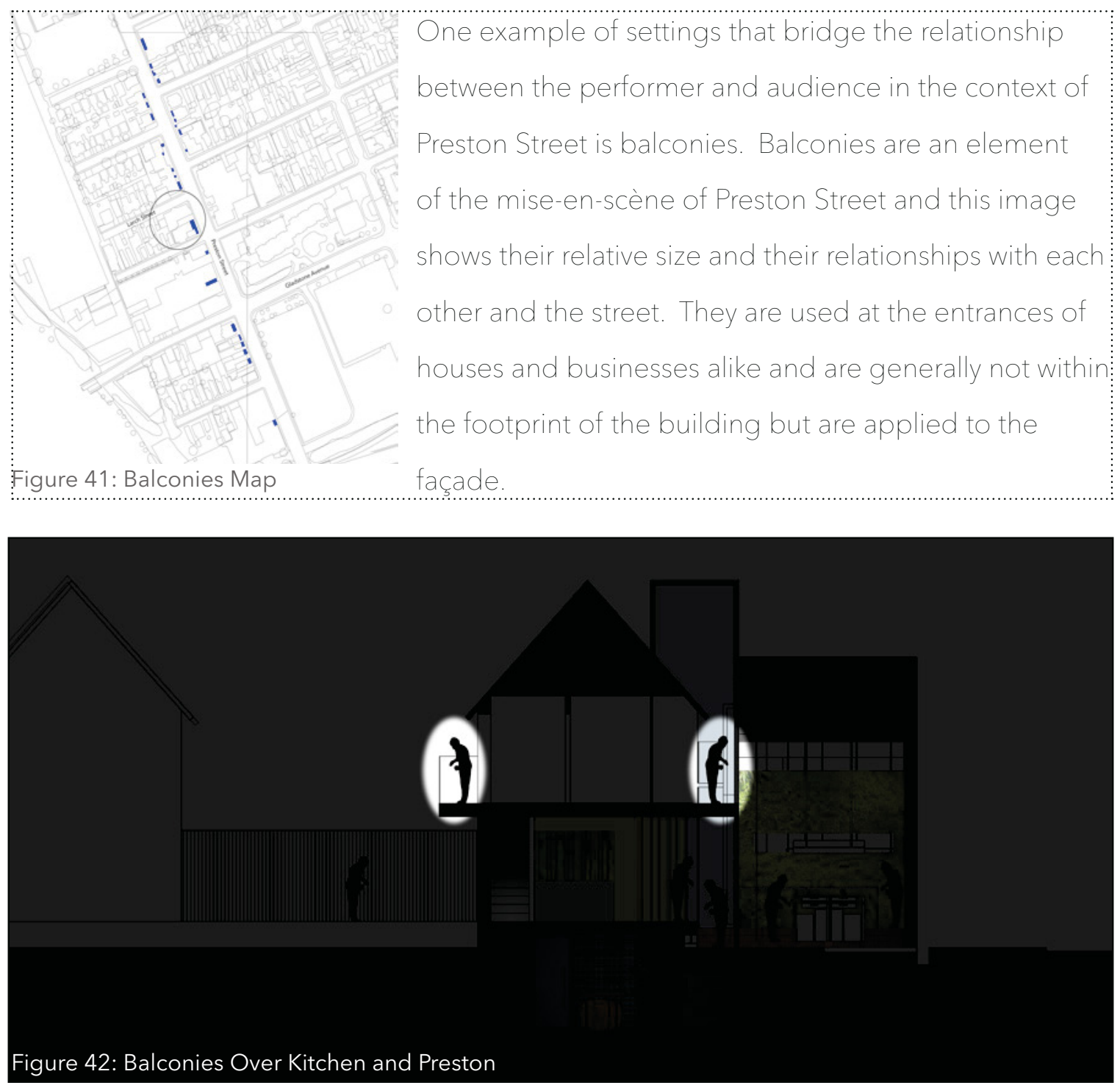


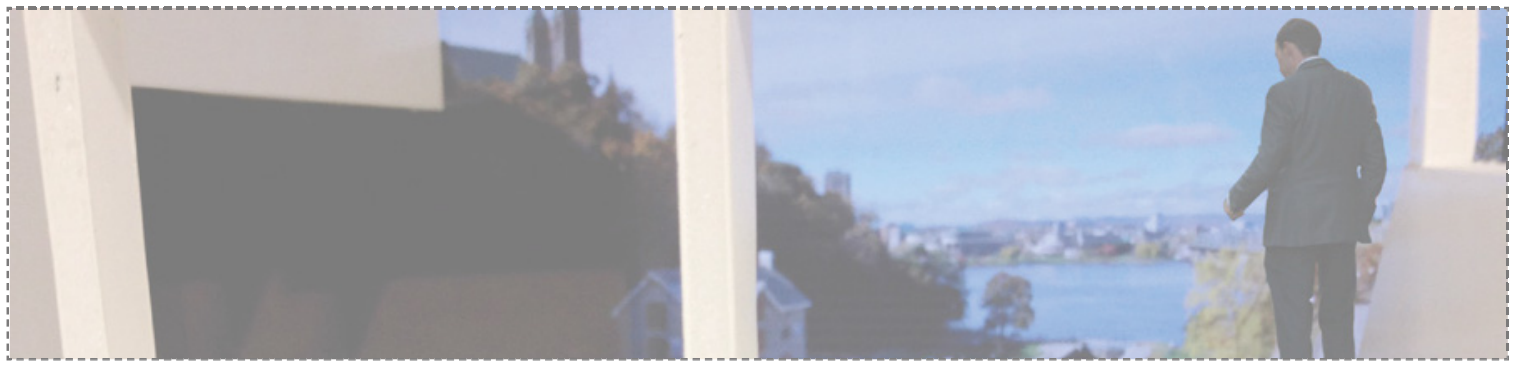

They are located about one meter above street level and provide an excellent viewing platform for spectators to observe actors on the street. Balconies are most consistent along the western side of Preston Street, with very few on the eastern side. They act as both viewing platforms and as moments of transition from private to public; for example from being a spectator to becoming an actor participating in the "play" of Preston Street:

She moves out onto the balcony. It is small, but just enough to detach her from what is going on in the building and allows her to spy on what is happening below. As she comes back inside, she realizes that opposite is another balcony, this one looking out over the kitchen. She goes out onto that balcony and on half of it is able to peer from behind the screen without being noticed. If she steps to the side she is fully visible for those below.

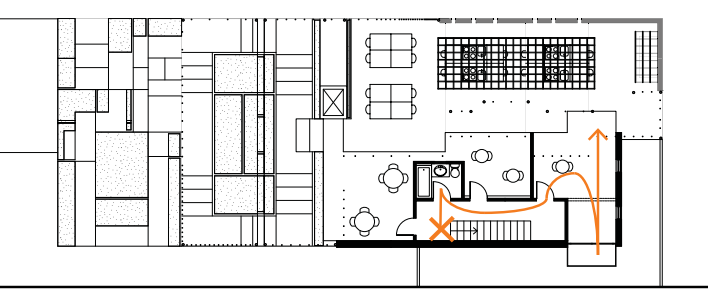



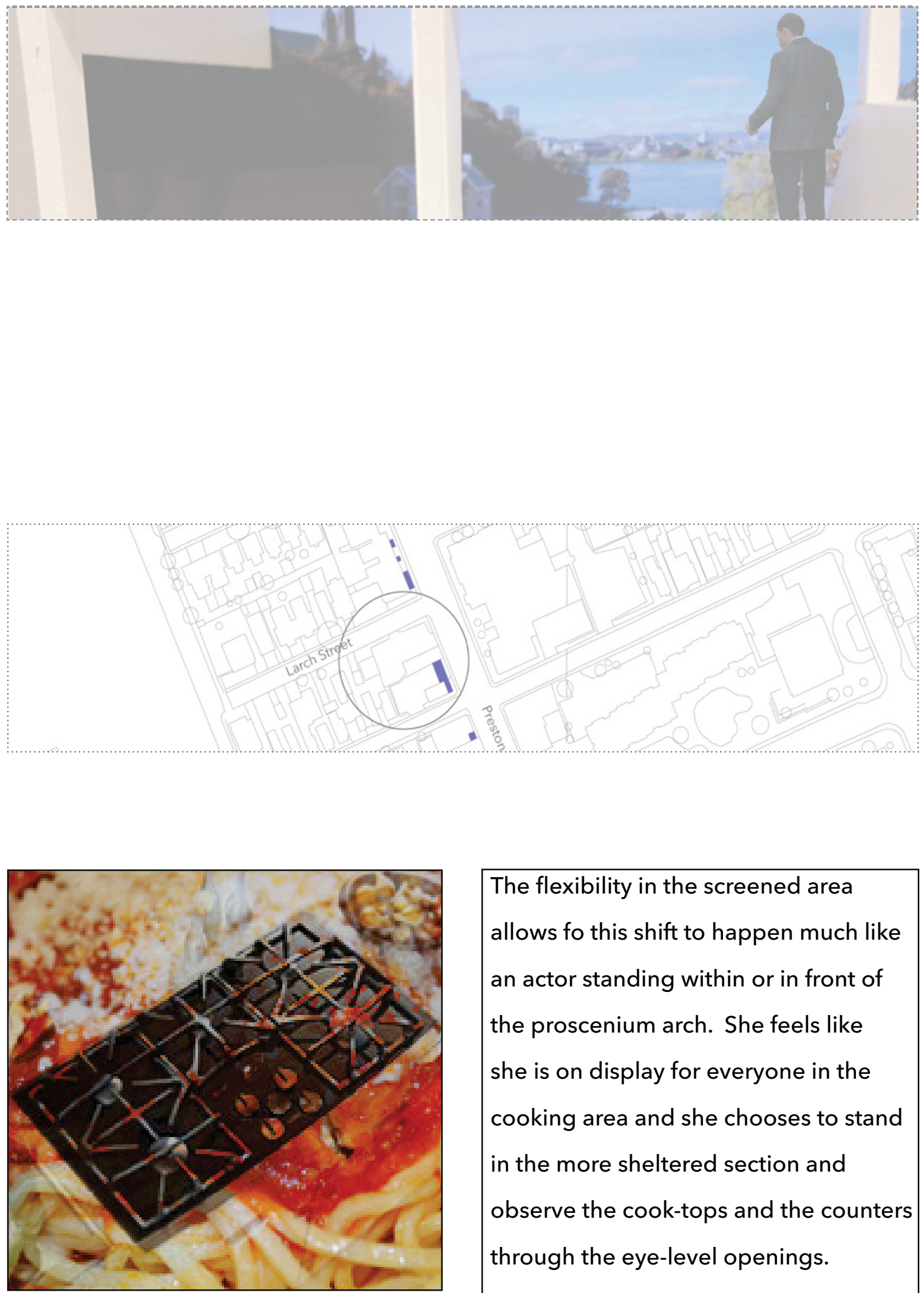

The flexibility in the screened area allows fo this shift to happen much like an actor standing within or in front of the proscenium arch. She feels like she is on display for everyone in the cooking area and she chooses to stand in the more sheltered section and observe the cook-tops and the counters through the eye-level openings. 


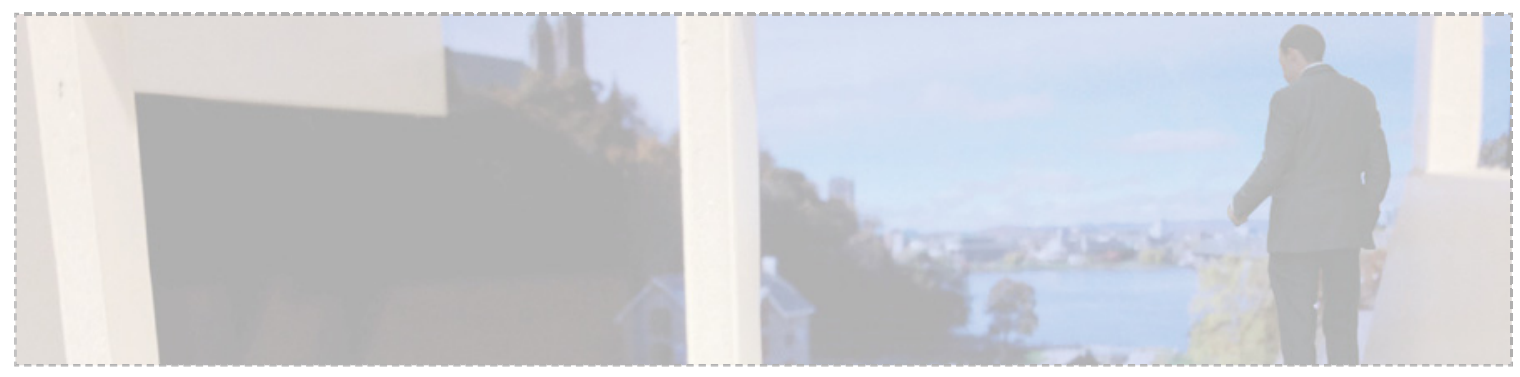

Gathering is an action performed mainly by spectators at the theatre, before and after the main event. In the proposed architecture, however, this is extended to the inhabitants-performers as well as the visitors-spectators. Theatre brings people together before the play starts, at the intermission and after the play. During those times, people are free to wander, mingle, and watch others.

It appears as if the ladies below are preparing their dinners to take home. Chloe returns downstairs and more people have arrived for the class, both women and men, of all different backgrounds and ages. They each take a seat at their station. At the station next to Chloe, Lucy is also attending the class. They begin talking, and they arrive on the topic of making wine.
REMEMBER:

The sensory division between actors and spectators is broken and gathering can ocar between the two. The sense of gathering would be present between the ladies who belong to the centre as there is a tradition of gathering with food in the Halian culture. Gathering would be heightened as members of the community come and learn from these women.

Figure 44: Gathering Reminder 


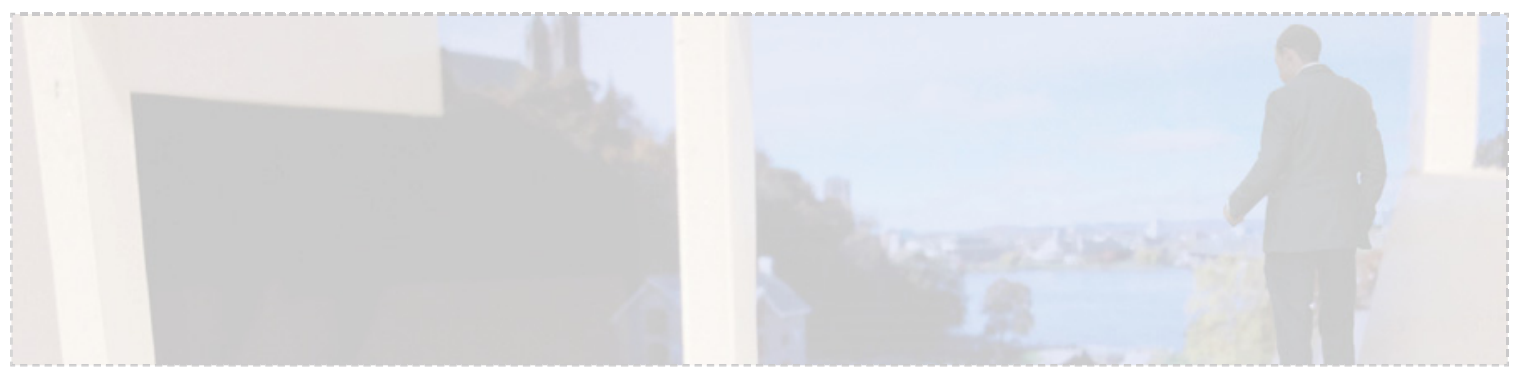

By contrast, in earlier times the invention of gas lighting and the ability to plunge the audience into darkness during a performance caused theatre to move away from being an event of gathering or community to a more individual experience. In contrast to Greek theatre, the actors could no longer see the spectators and the spectators could no longer see each other. The proposed architecture would have the inherent flexibility to create both of these scenarios as necessary in order to encourage exchange between the inhabitants-performers and visitors-spectators

\footnotetext{
Lucy beings to tell Chloe about how her father used to make wine.

LUCY: Years ago they didn't have such things as cellars. You used to buy the grapes and squeeze the juice in a room there and put the barrels in one of the bedrooms...in the boarder's bedrooms and make the wine ferment.
}

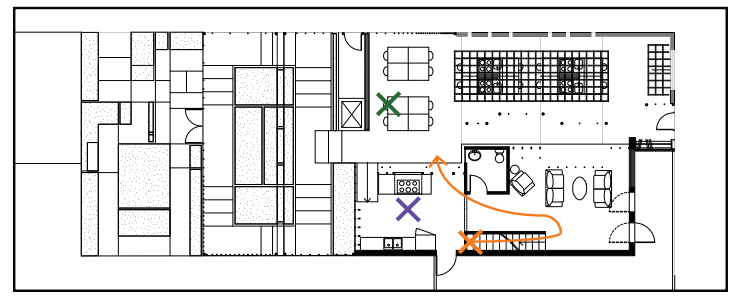




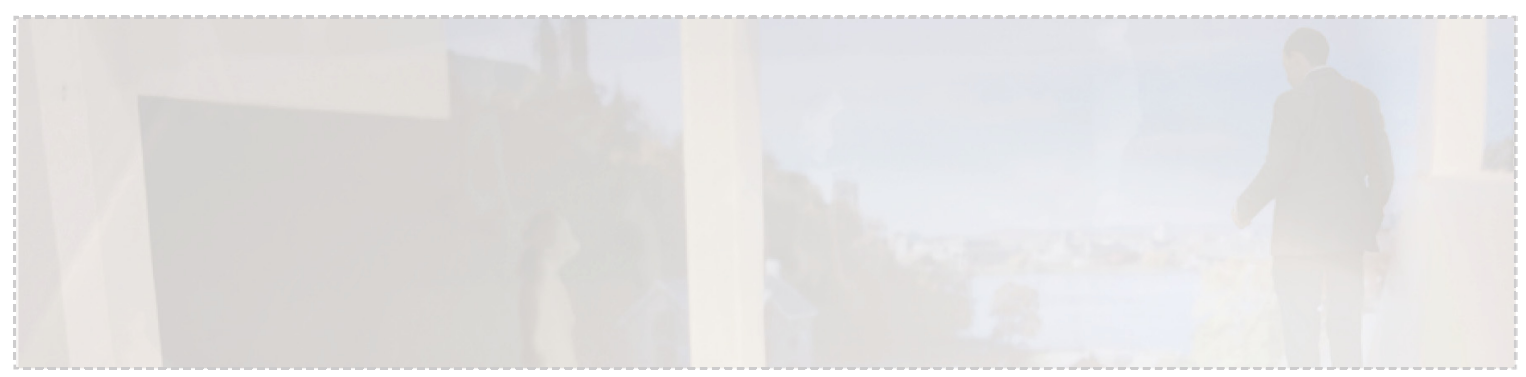

CHLOE: You used to make wine where?

LUCY: In the house...in the room with the boarders and all. We used to make the wine, put two or three barrels, make it ferment. We used to get some wine out of it...very good. The smell of that wine used to get us at night time.
LUCY: You know what wine is, that smell when it starts to ferment? A lot of people used to do that. They used to make their own wine. It was cheaper to them. They couldn't go buy wine or at that time they didn't have gallons of wine like they do today from California or things like that. 


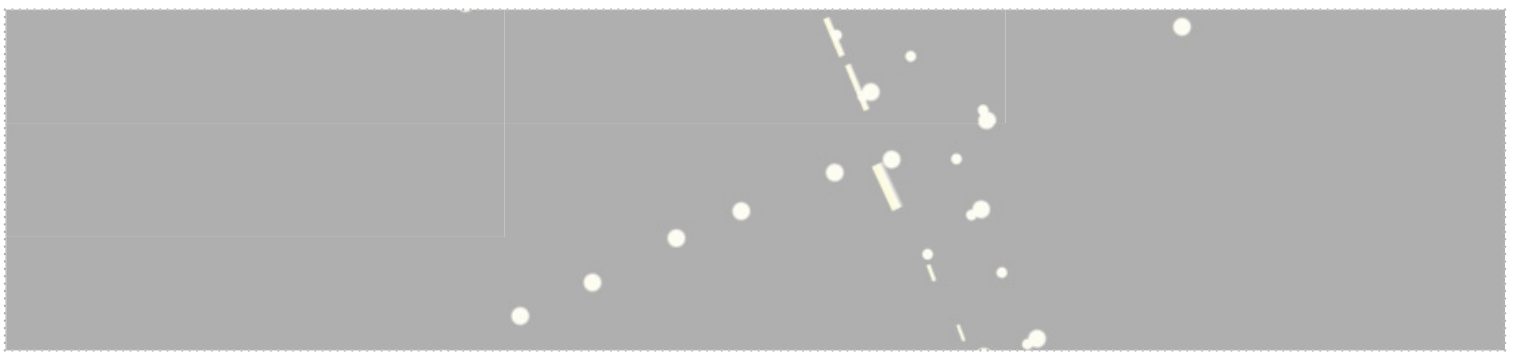

LUCY: They used to make their own wine, and it was pretty good wine too. The only thing there was that they didn't have the facilities of cleaning it up the way they should have. You can just imagine what it looked like. In the kitchen, all these boxes of grapes piled up.
LUCY: Then of course you used to pick it out, take it, bring it downstairs, you used to put it in this barrel that was sawed in half, put on a pair of black boots and start mashing it, walking around on the grapes. Then of course when it was mashed very good, [my father]used to take it out and put it in this, in Italian we say nu'stringiture, to strain it, real tight. ${ }^{18}$ 


\section{Notes}

1. Peter Brook, The Empty Space (New York: Atheneum, 1968) 47.

2. $\quad$ bid, 57

3. Ibid, 58

4. Donald C. Mullin, The Development of the Playhouse; a Survey of Theatre Architecture from the Renaissance to the Present (Berkeley: University of California, 1970) 32.

5. Iain Mackintosh, Architecture, Actor, and Audience (London: Routledge, 1993) 9.

6. Donald C. Mullin, The Development of the Playhouse; a Survey of Theatre Architecture from the Renaissance to the Present (Berkeley: University of California, 1970) 68.

7. Ibid, 34

8. $\quad$ bid, 35

9. Ibid, 38

10. Ibid, 62 .

11. Iain Mackintosh, Architecture, Actor, and Audience (London: Routledge, 1993) 16.

12. Donald C. Mullin, The Development of the Playhouse; a Survey of Theatre Architecture from the Renaissance to the Present (Berkeley: University of California, 1970) 63.

13. Mark B. N. Hansen, New Philosophy for New Media (Cambridge, MA: MIT, 2006) 6.

14. Ibid, 70

15. Ibid, 49

16. Ibid, 53 .

17. $\quad$ bid, 84

18. Italianamerica. Dir. Martine Scorsese. Perf. Charlie Scorsese and Catherine Scorsese. National Communications Foundation, 1974. Film. YouTube. 12 Aug. 2008. Web. 20 Feb. 2014. <http:// www.youtube.com/watch? $v=2$ tzKAILb4iM>. 
ACT 3: (ENTERTAINING) CENTRE 
An additional experience of the spectators in the theatre is focus. This occurs when the
house lights go down, the space goes silent and the lights come up on the scene on
stage. Attention is given to the activities on the stage and the spectators must engage
that spectators are no longer concerned about the reactions of those surrounding them,
but are rather more interested in what is occurring on the stage. Methods in theatre of

Teresa makes her way up to the kitchen and begins the demonstration. Once it has concluded, she comes down and each student attempts the recipe on their own. The door bell rings, Teresa proceeds over and lets in the people renting the space for the wine tasting event.

Tom is in charge of setting up the spaces for the event, including placing table cloths on each of the tables throughout the space, setting up chairs and making sure the wine is chilled.

REMEMBER:

In the proposed architecture, focus comes in learning about food. There is attention paid to cooking, the passing on of traditions and the absorption of knowledge. The space is designed to explore different methods of observing and engaging. Attention may be brought to a scene when atimer dings, the smell of fresh bread is in the air, a video screen comes down or hands fouch Fresh dough.

Figure 45: Focus Reminder 


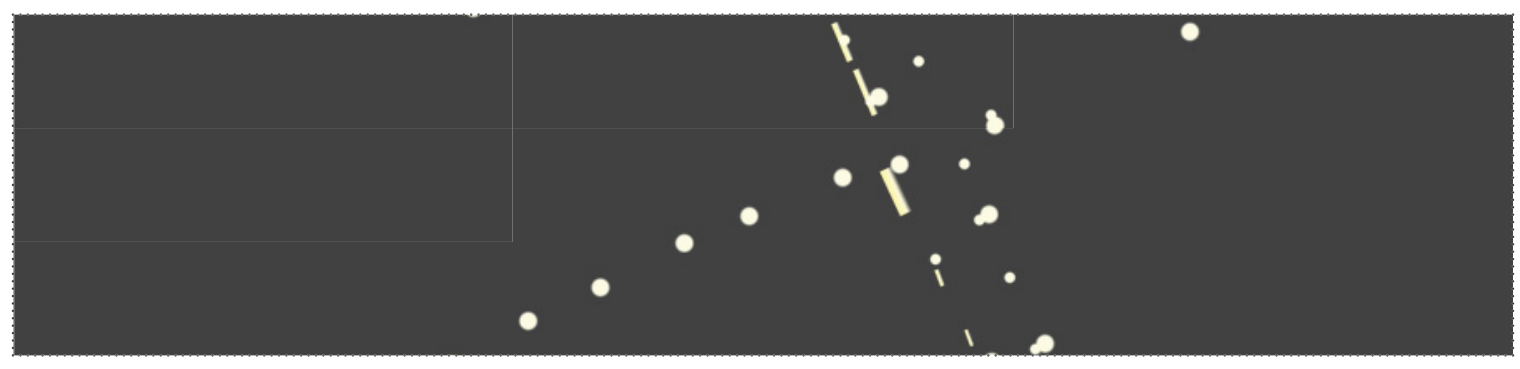

There will be stations for various wines around the building and a cooking demonstration in the teaching kitchen. Once the students have satisfactorily completed the recipe, they are asked to clean up their station, return their pasta machine to the kitchen, and then are allowed to leave. They all file back to the front door, put on their coats and depart.
It is almost dinner time and all the students have left for the day. Teresa is the last one in the building. She ensures the space is clean because the wine tasting event will be using the same tables her class did.

Tom goes upstairs to begin setting up the three rooms; a red wine room, a white wine room and a sparkling wine room. 

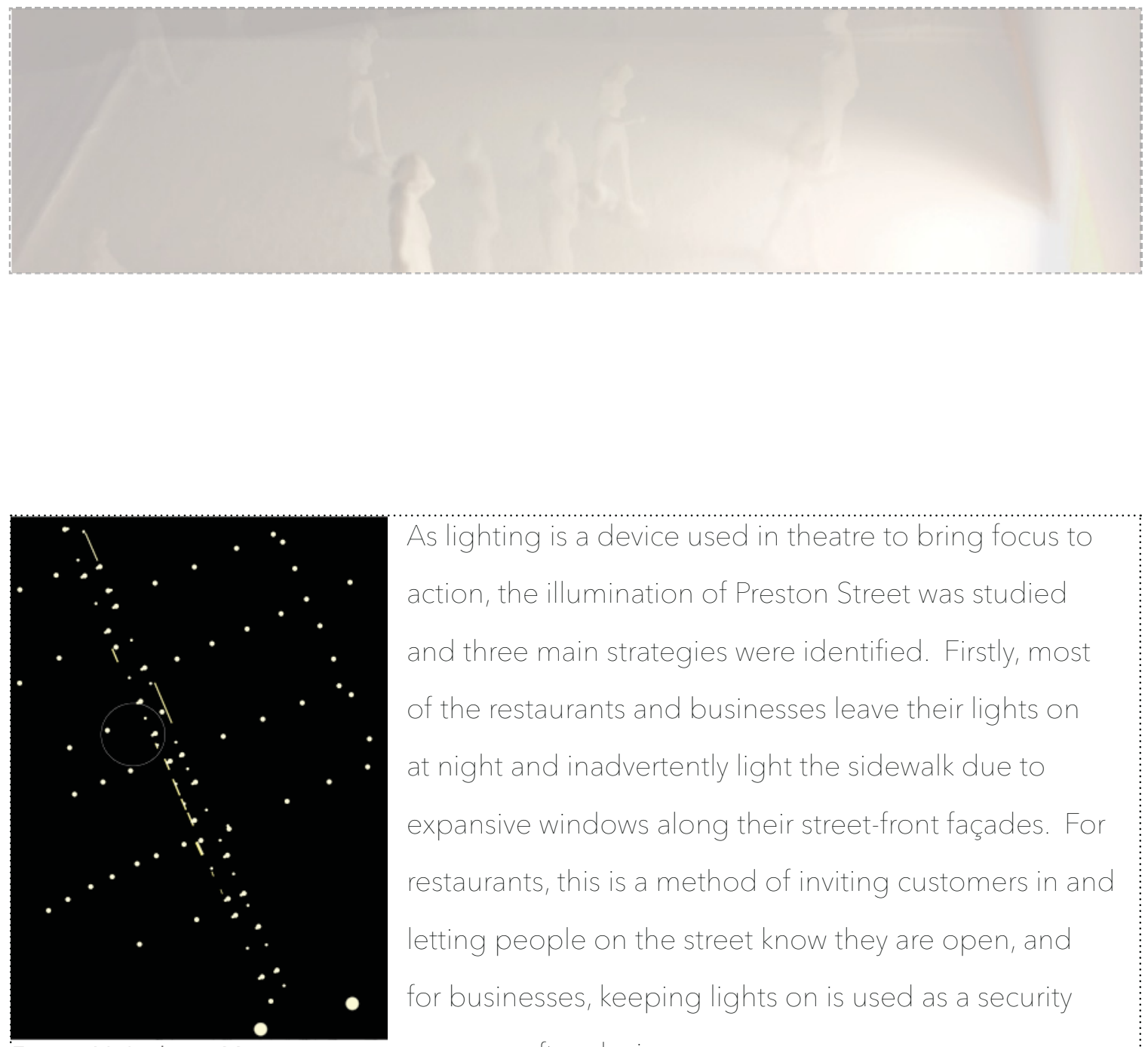

As lighting is a device used in theatre to bring focus to action, the illumination of Preston Street was studied and three main strategies were identified. Firstly, most of the restaurants and businesses leave their lights on at night and inadvertently light the sidewalk due to expansive windows along their street-front façades. For restaurants, this is a method of inviting customers in and letting people on the street know they are open, and for businesses, keeping lights on is used as a security

Figure 46: Lighting Map measure after closing.

Set Direction: The sun has set and
there is a glow coming from the glass
structure. From the outside window
there are glimpses of what is happening
inside.

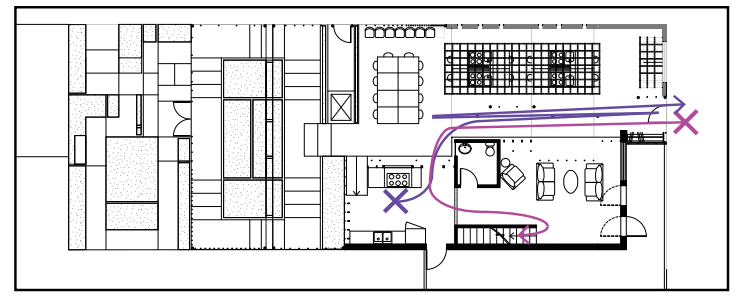




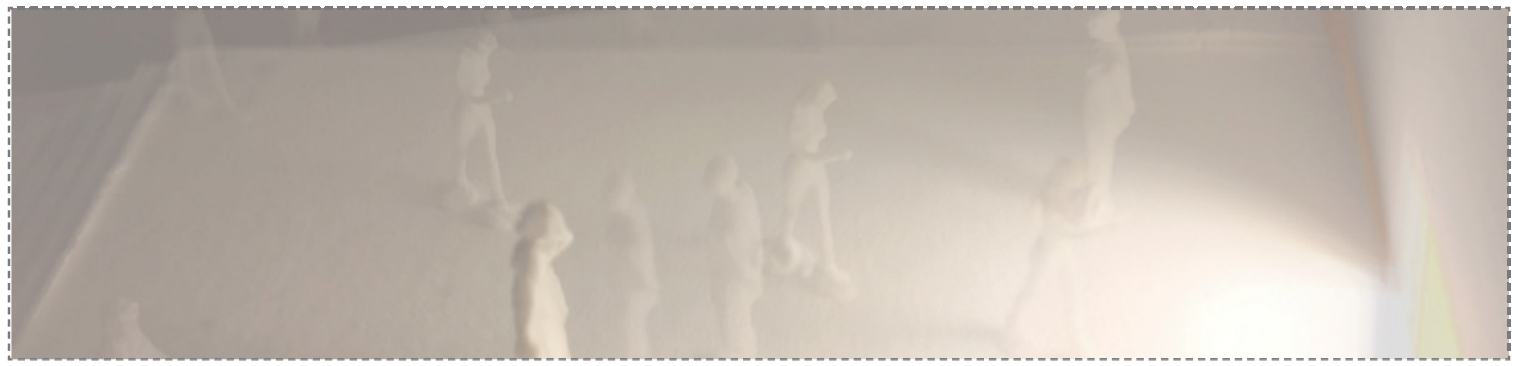

In addition, large street lamps aimed at lighting up the intersections are located at the corner of each block, and at one or two locations in between. They tower about six meters above street level. This lighting strategy continues on the side streets, but is usually limited to only one side of the street. Frequently traveled routes such as Gladstone are more thoroughly lit. A tertiary lighting strategy is employed along Preston, bounded by the area defining Little Italy. These sidewalk-scaled fixtures are meant to rhythmically light up the sidewalk and are located on each pole of the larger street lights and also at two or three intervals in between. These lights are more decoratively detailed and located three meters above street level

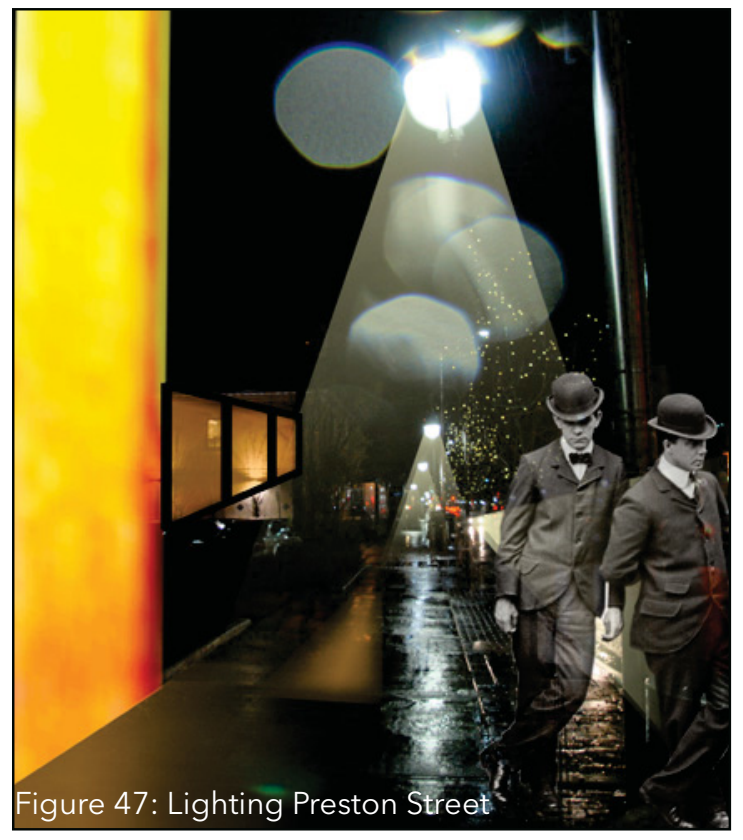

The street lights cast spots onto the sidewalk in front, lighting the way for the those attending the event. Inside the lights are dimmed, the brightest area being towards the back where the cooking demonstration will take place. The space has been cleaned up from the day's activities and a screen is lowered across from the teaching kitchen so that those above can also see what is occurring. 

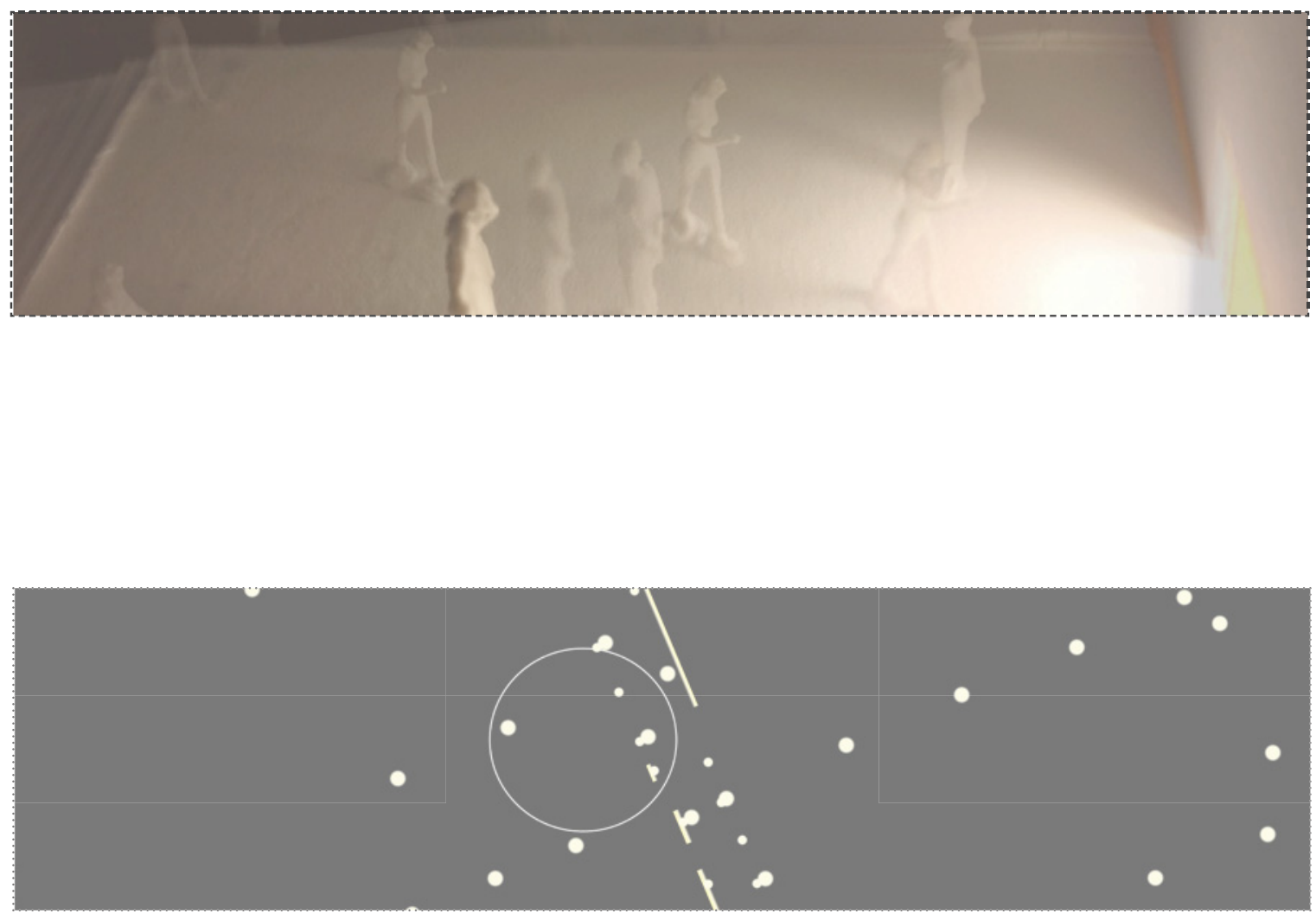

The lounge area is in the same orientation as earlier in the day, but the low lighting and addition of candles transforms the space into a much more sensual one. The basement is set up to discuss wine making and storage. Each room on the second level in the existing house is set up for a different wine; red, white and sparkling. Within the rooms are a series of height-adjustable round tables with white table cloths placed over them.
The room at the back of the house is mainly dark with only tea lights on the tables providing a warm glow. The chairs are pushed to the perimeters to allow for mingling. Below, at the cooking demonstration, the tables will be kept low and extra chairs gathered around them so that people can sit and observe. 


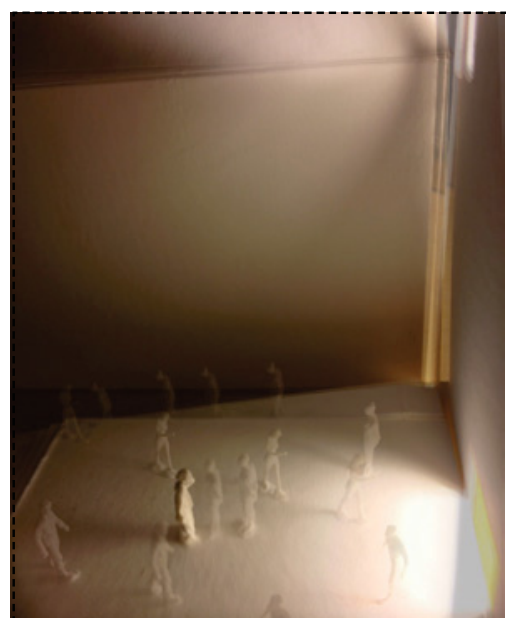

Lighting: 276 Wellington Street examines theatrical illumination, choreography, point of view and the temporality. While this lighting condition is not representative of a realistic situation, it serves to dramatize the shadows cast by the figures and to emphasize their actor-like qualities. The elevated point of view of the spectator makes it difficult to engage with the actor beyond a visual connection.

Figure 48: Lighting: 276 Wellington Street

When actor and spectator were equally lit, as in the Greek theatre, a self-referential feedback loop was generated, equating the reactions of the audience with the gestures and words of the actors. Some spectators saw this as disruptive to the acting and felt that theatre should be made more predictable. In the 18th and 19th centuries, laws were passed that took the unpredictability out of theatre. In 1817, gas lighting was introduced to the Elizabethan theatre, allowing the audience to be placed in darkness, their attention focused on the lit actor on stage.

Translucent curtains are pulled across the middle room and the low lighting in the room creates a play of shadows on it, exaggerating the actions of those in the room for the spectators below. 
Viewers remain distanced and cannot simply step into the scene and become a part of it. By layering images taken from the same vantage point with the use of a spot light, the moving figures appear ghosted. Light is used to create unrealistic effects and allows the viewer's attention to be focused on the bottom right-hand corner of the image.

This disrupted the feedback loop because now the reactions of the audience, unless audible, were imperceptible to the actor. ${ }^{3}$ A lens was eventually added to this light and it evolved into the follow spot. ${ }^{4}$ The upper class chose to frequent the opera house and the concert hall instead, because they felt that the darkening of the auditorium likened the playhouse to the house of Satan. ${ }^{5}$

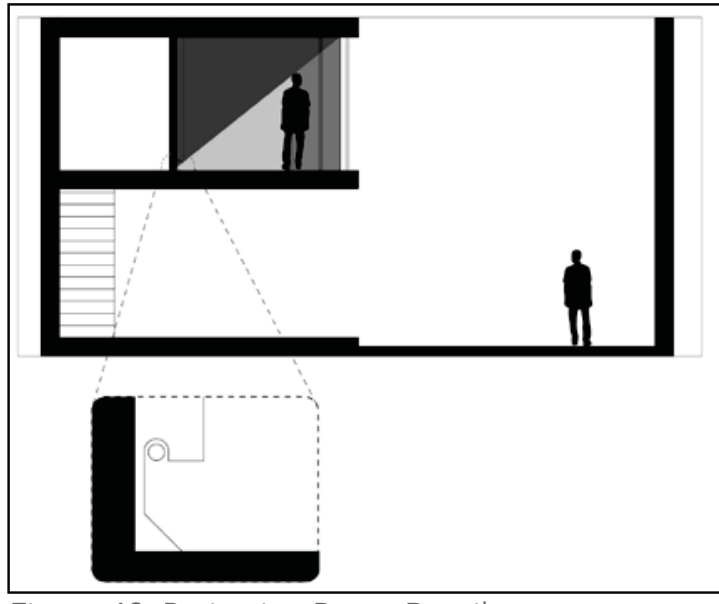

Figure 49: Projection Room Detail

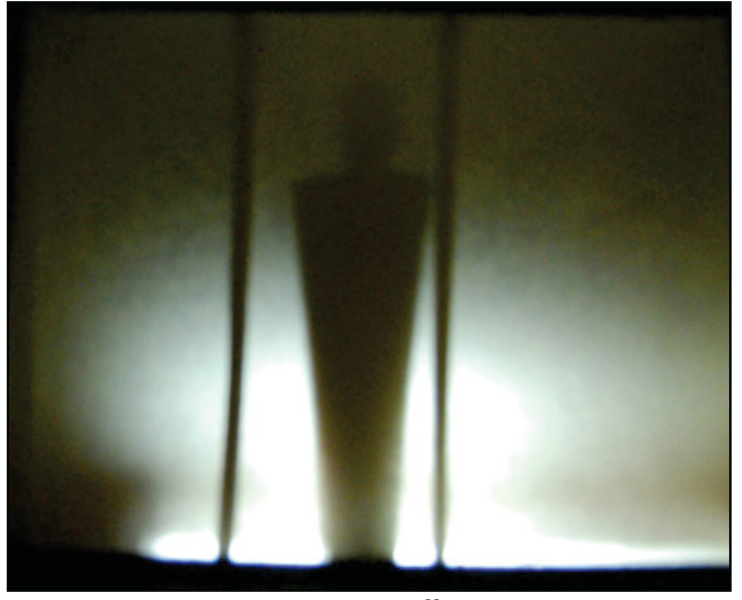

Figure 50: Projection Room Effect 

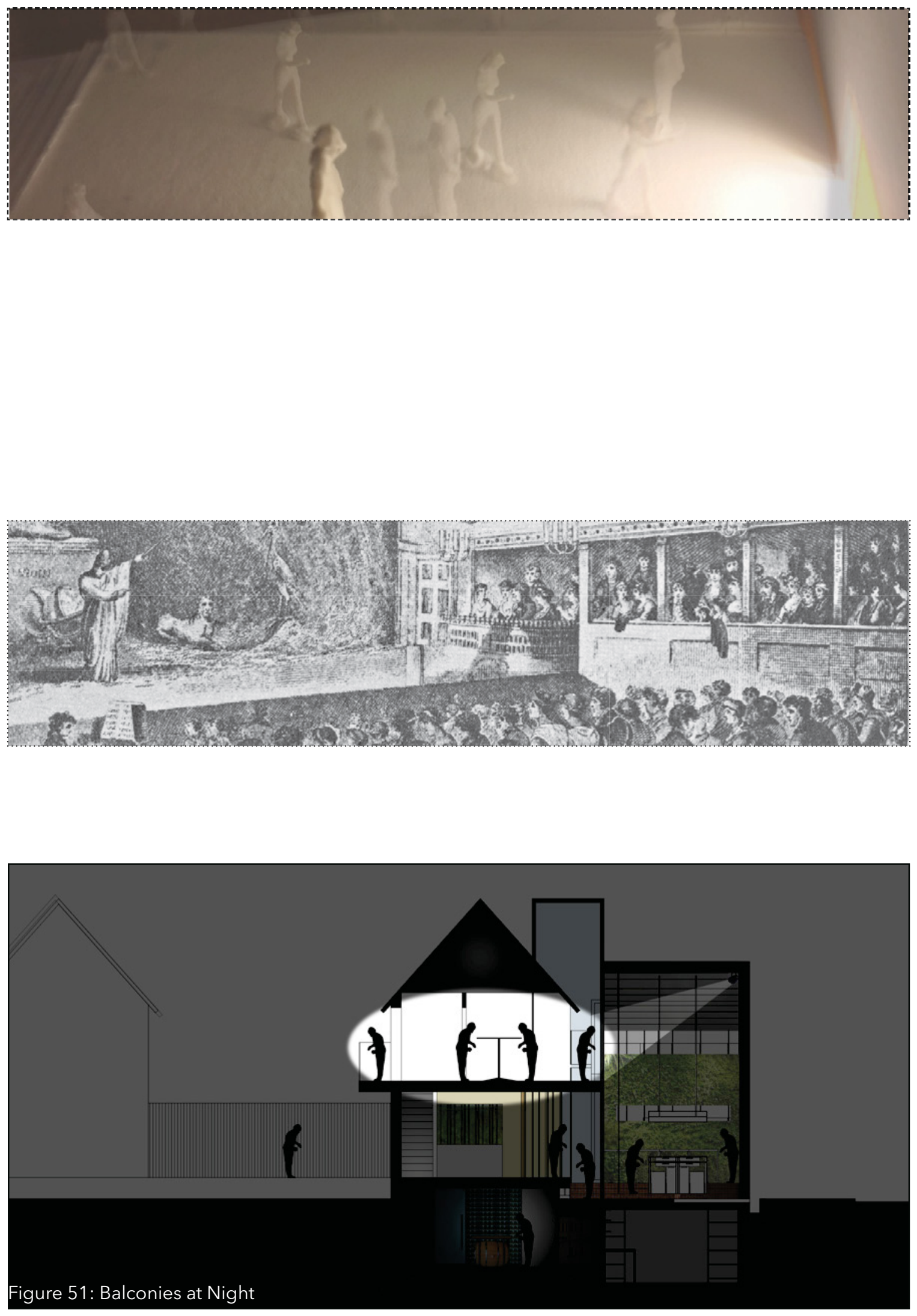

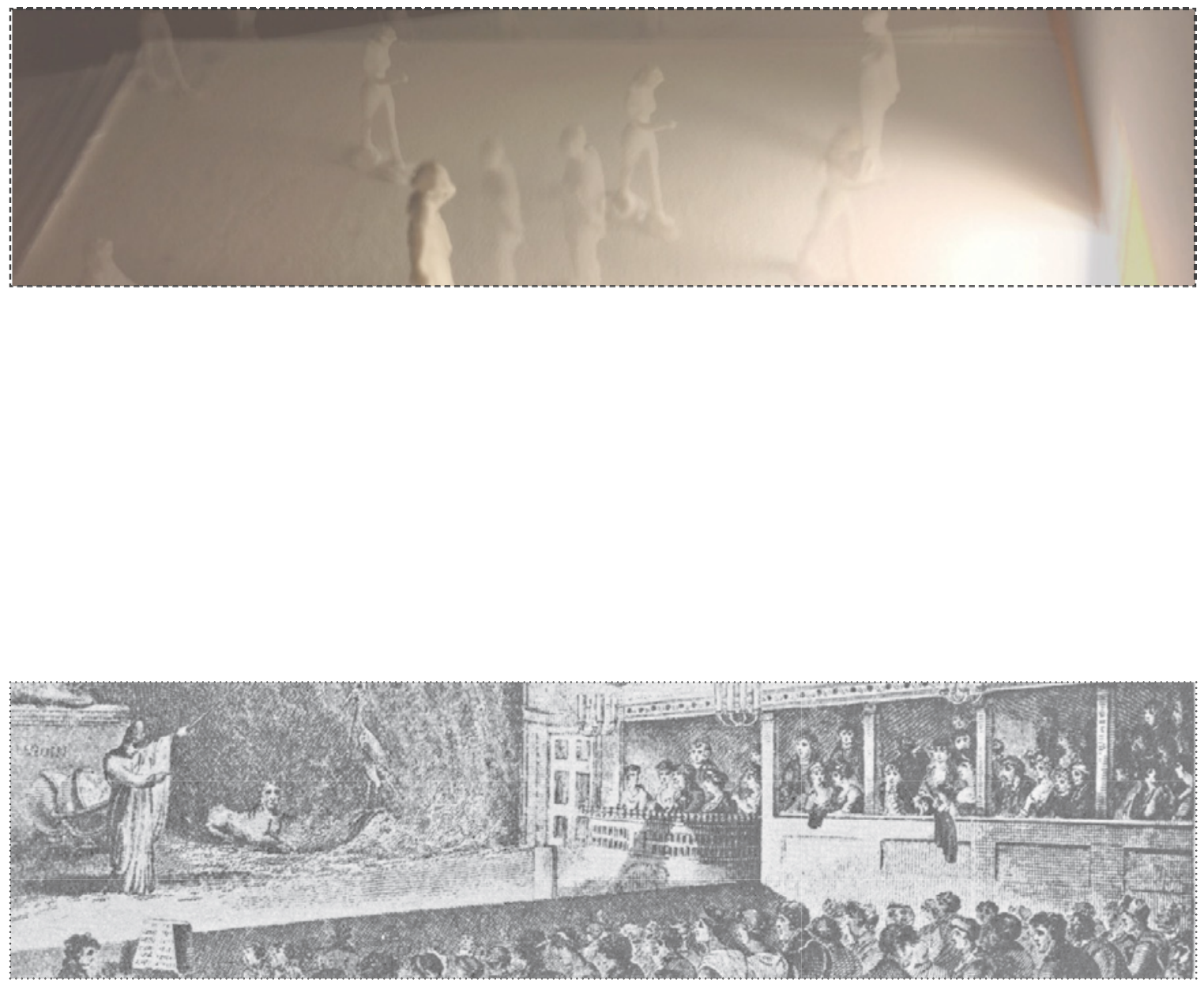

The third room at the front of the house is more brightly lit. There are specific spot lights located on the balconies, lighting up people that step onto them. 

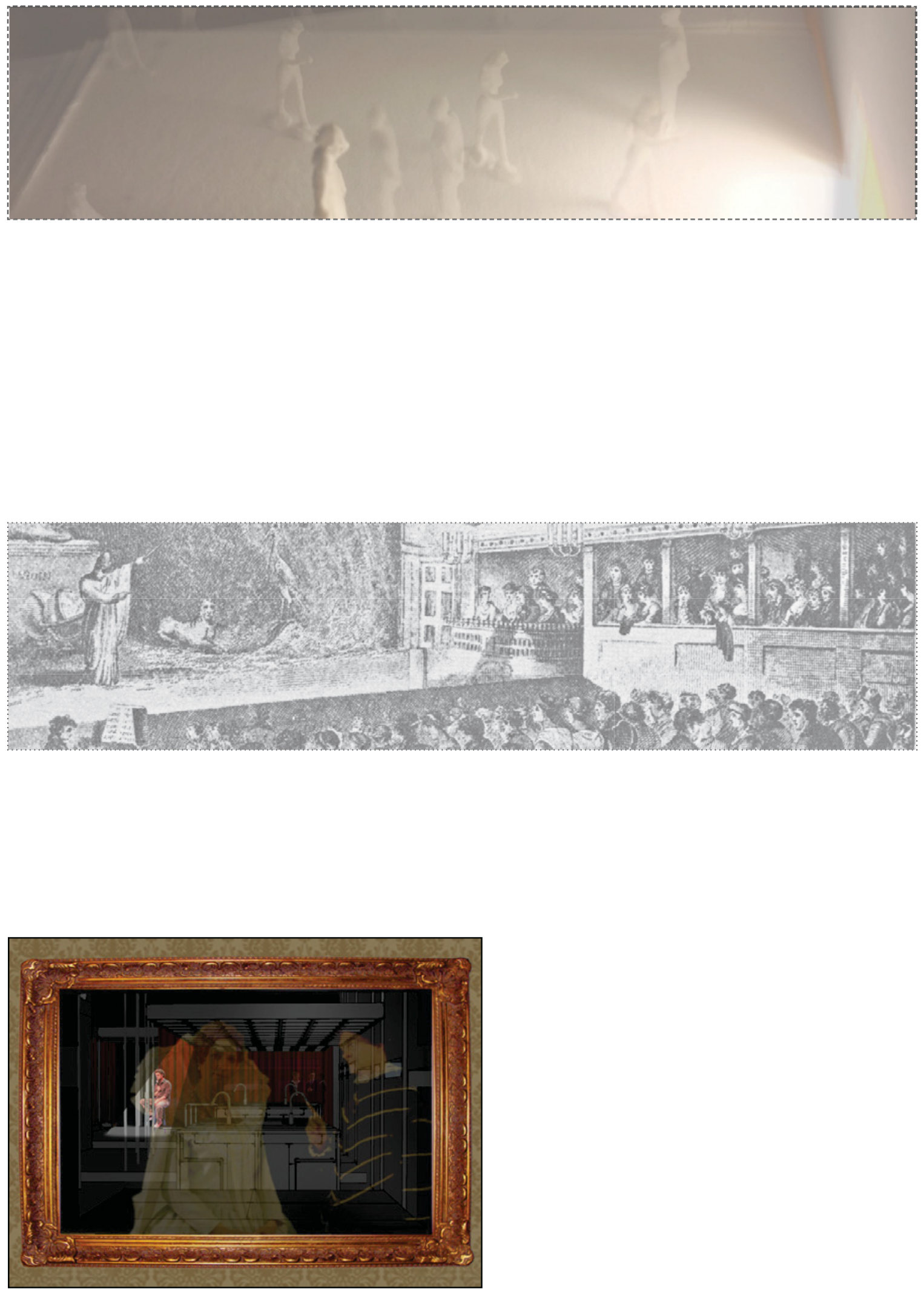

Figure 52: Night Arrival 

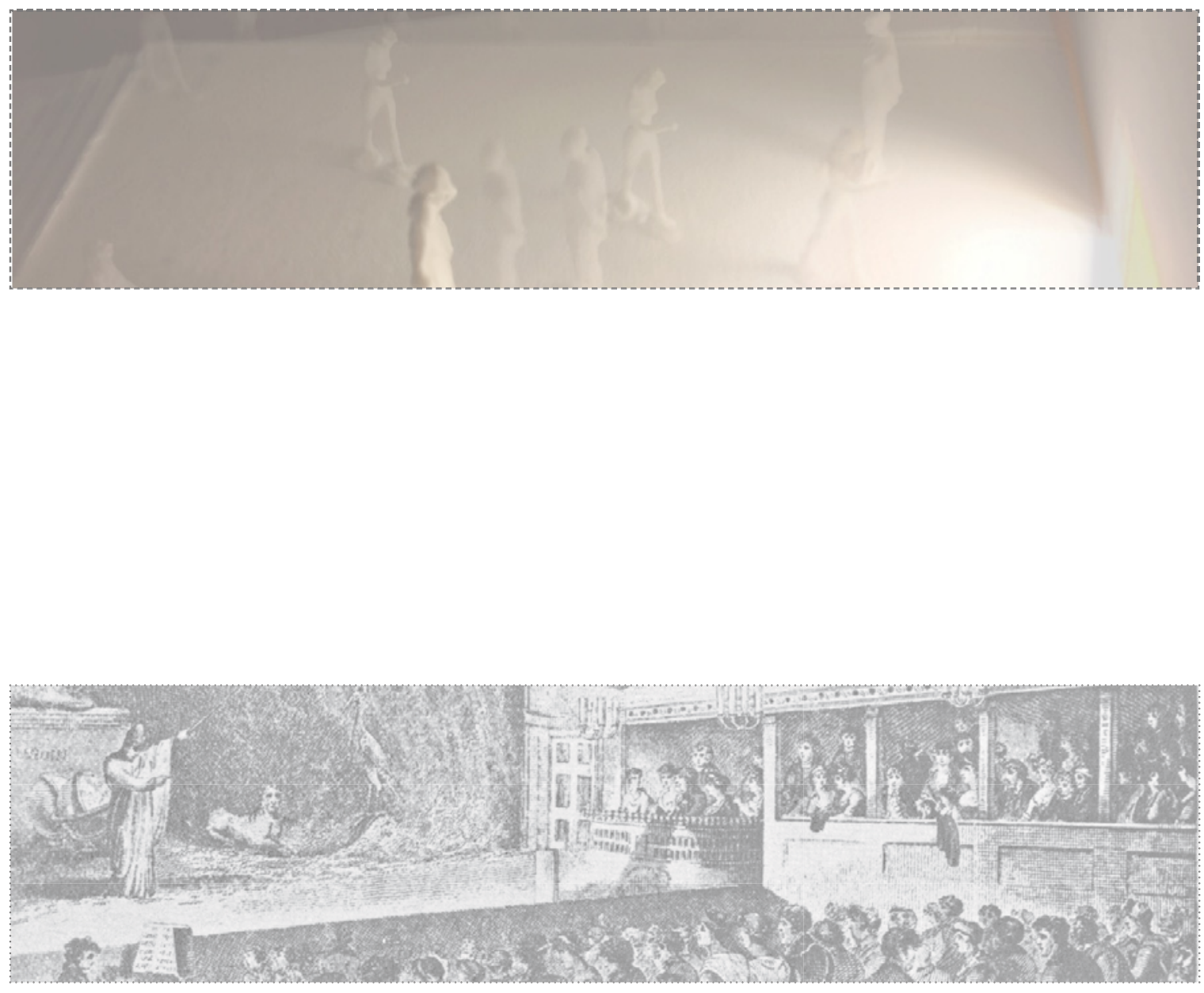

Mike and Beth have purchased tickets for an evening of wine tasting and cooking demonstrations. They enter through the open front door, hang their coats and proceed up the slow set of stairs. The glazed portion of roof above them and the screens of wrought iron on either side guide them toward the back. They observe a lounge space to their left, a working kitchen space to their right and straight ahead an open area with a greenhouse and outdoor garden beyond. They move through to the back and overlook the garden before wandering upstairs as the cooking demonstration is not starting for a while. They go up the stairs and enter the tasting rooms sequentially.

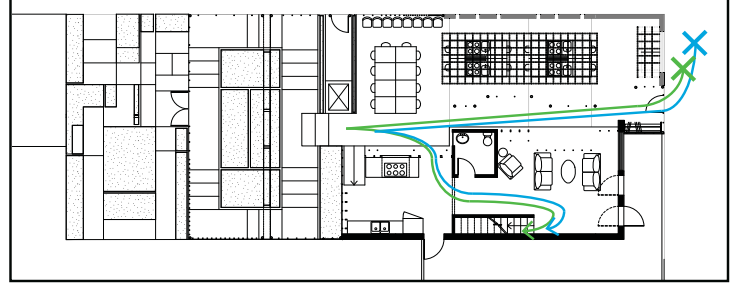



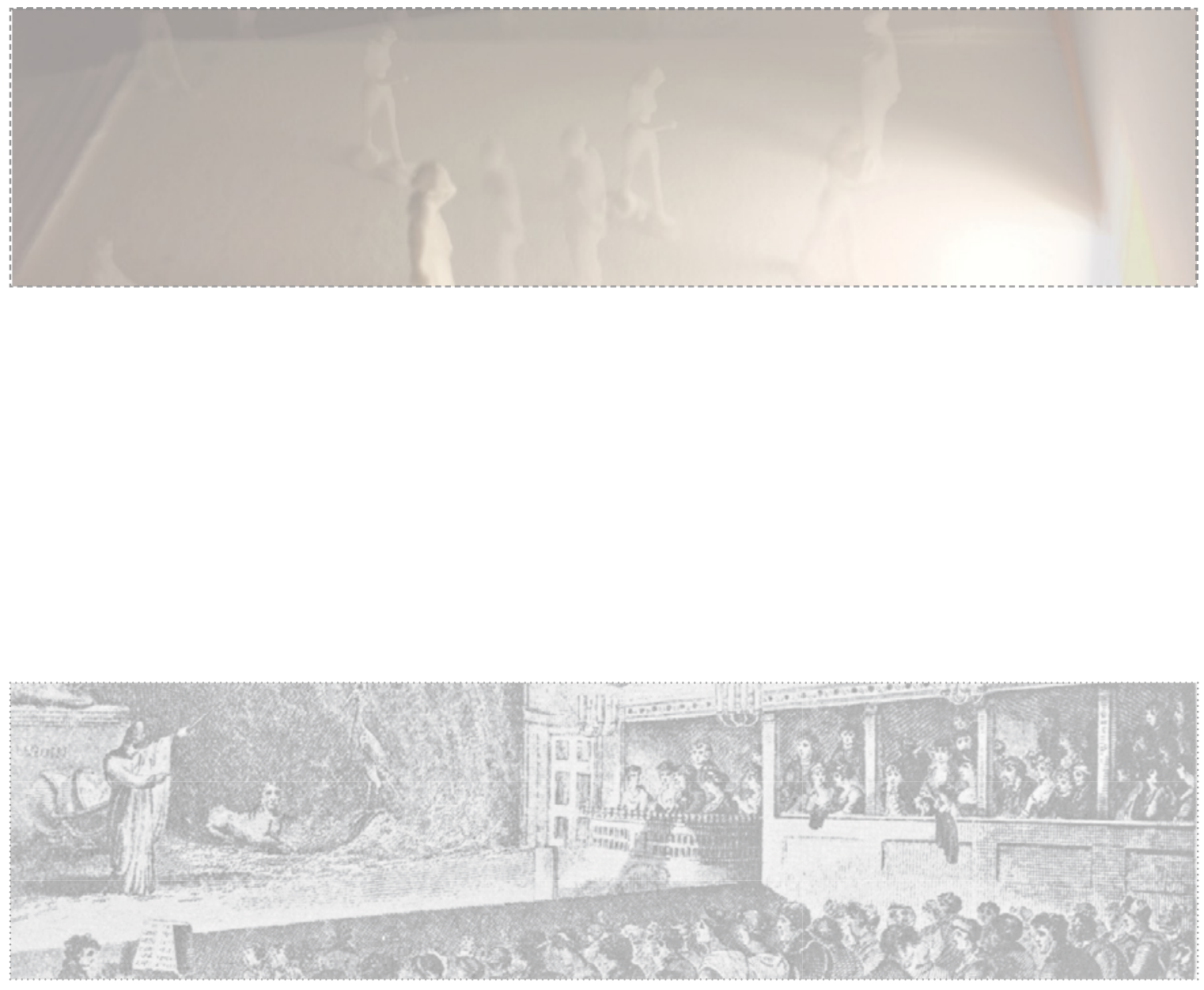

Each room has a unique atmosphere, view and wine associated with it.

After Mike and Beth finish exploring, they descend the stairs to the lounge area which is filled with people sipping wine and conversing. They move down to the basement where a long table is set up to discuss wine making and storage.
There are wine barrels stacked under the stairs and lining two of the walls. The floor is rough stone and the walls are exposed concrete. They go back up as the demonstration is about to begin.

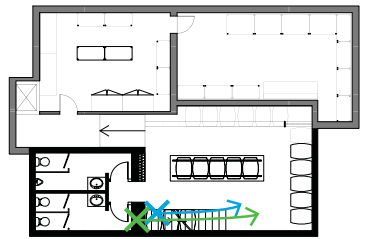



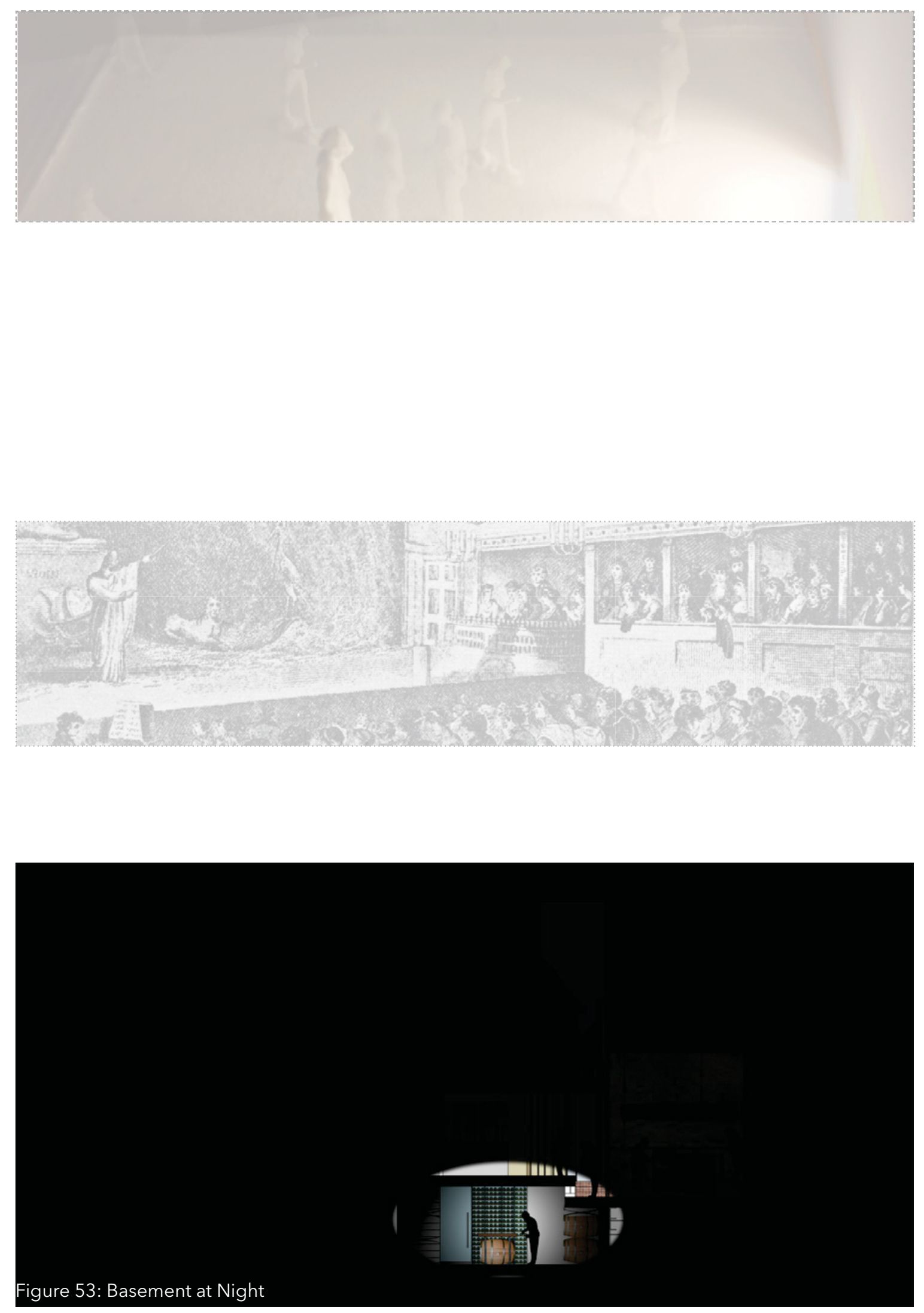

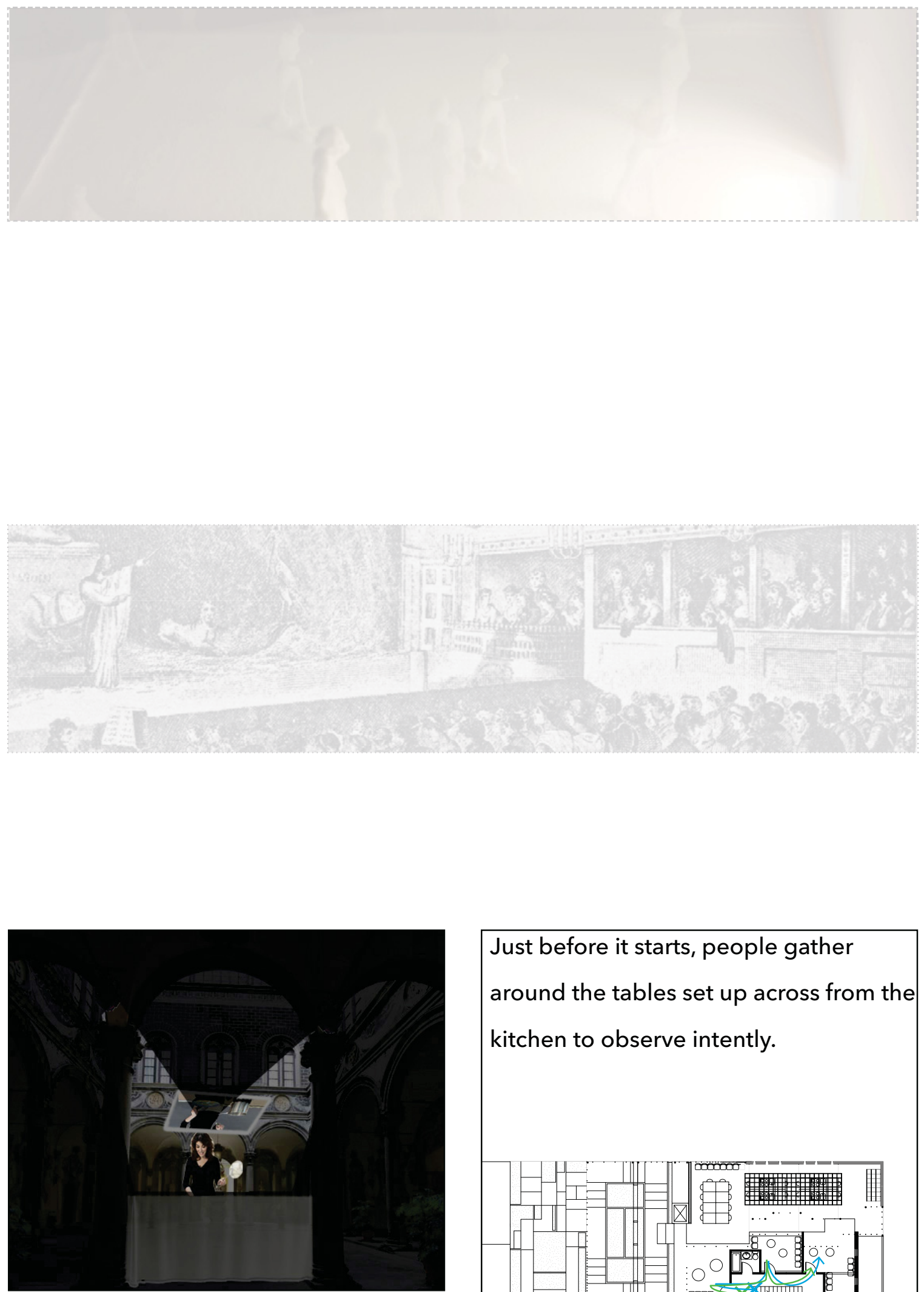

Just before it starts, people gather around the tables set up across from the kitchen to observe intently.

Figure 54: Theatrical View to Kitchen

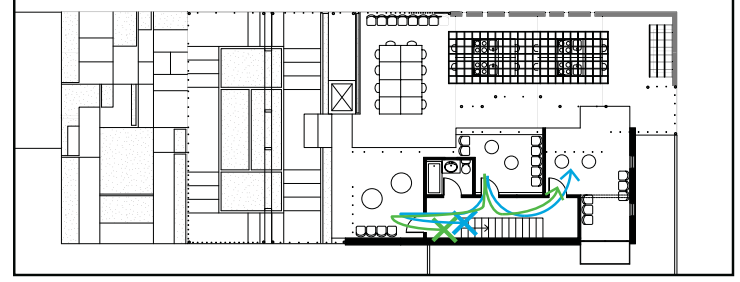


Various people are observing from the level above and the actions of those in the sparkling wine room are put on display, adding to the theatricality.

When the evening comes to a close, Mike and Beth retrieve their coats and exit.
Once all the guests depart, Tom cleans up, lowers all the tables back to their original height and locks up the building.

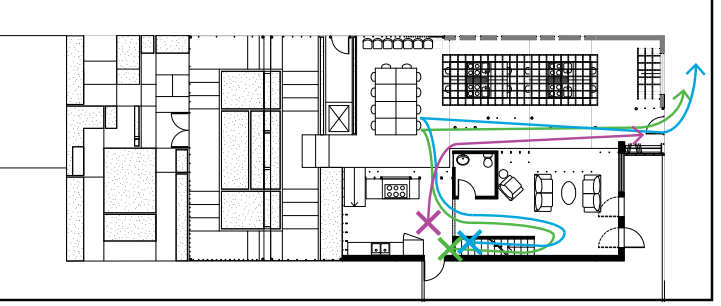




\section{Notes}

1. Erika Fischer-Lichte, The Transformative Power of Performance: A New Aesthetics (New York: Routledge, 2008) 38

2. Iain Mackintosh, Architecture, Actor, and Audience (London: Routledge, 1993) 36.

3. Erika Fischer-Lichte, The Transformative Power of Performance: A New Aesthetics (New York: Routledge, 2008) 39

4. Iain Mackintosh, Architecture, Actor, and Audience (London: Routledge, 1993) 36.

5. Ibid, 37 
ACT 4: PLATES 


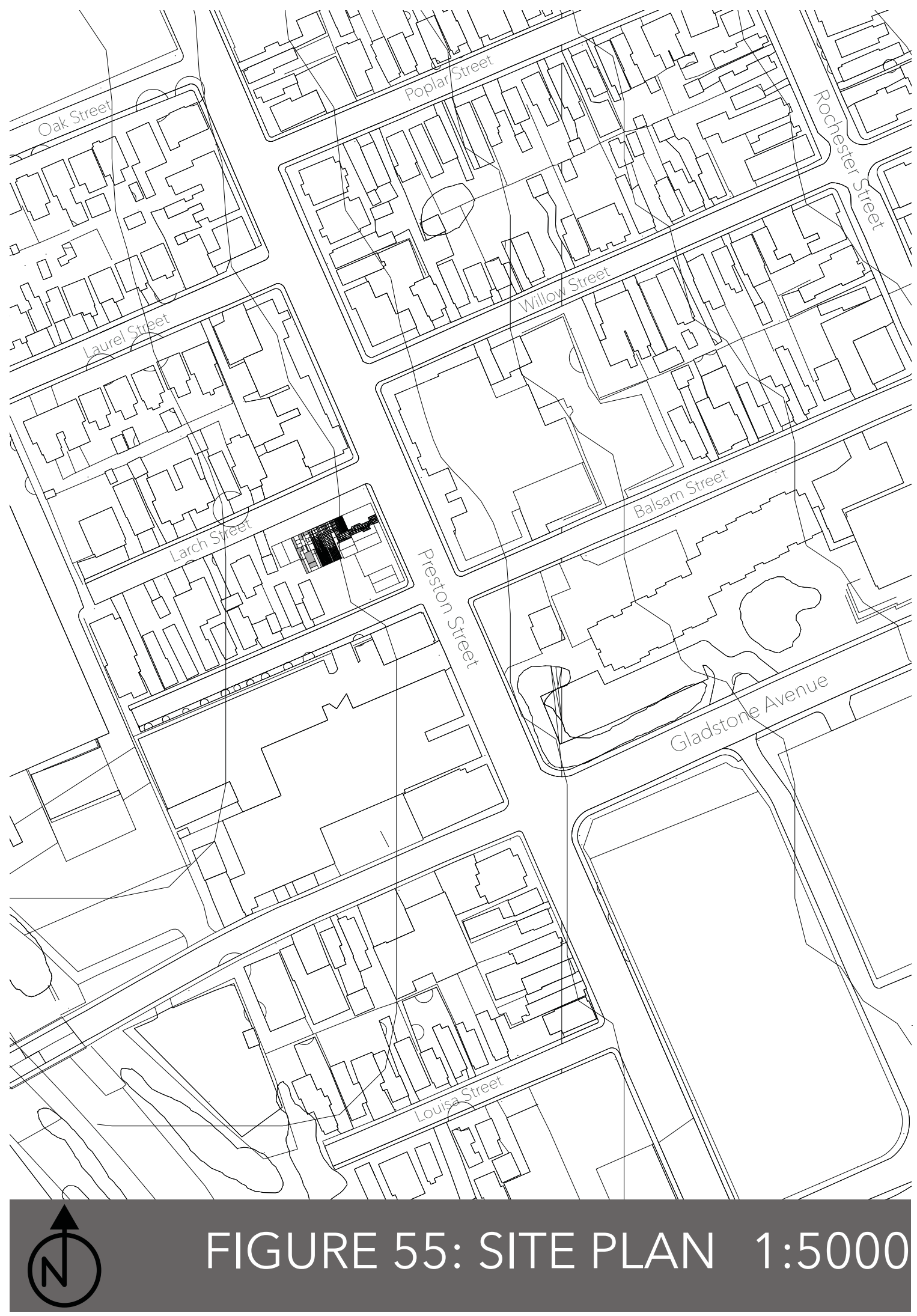




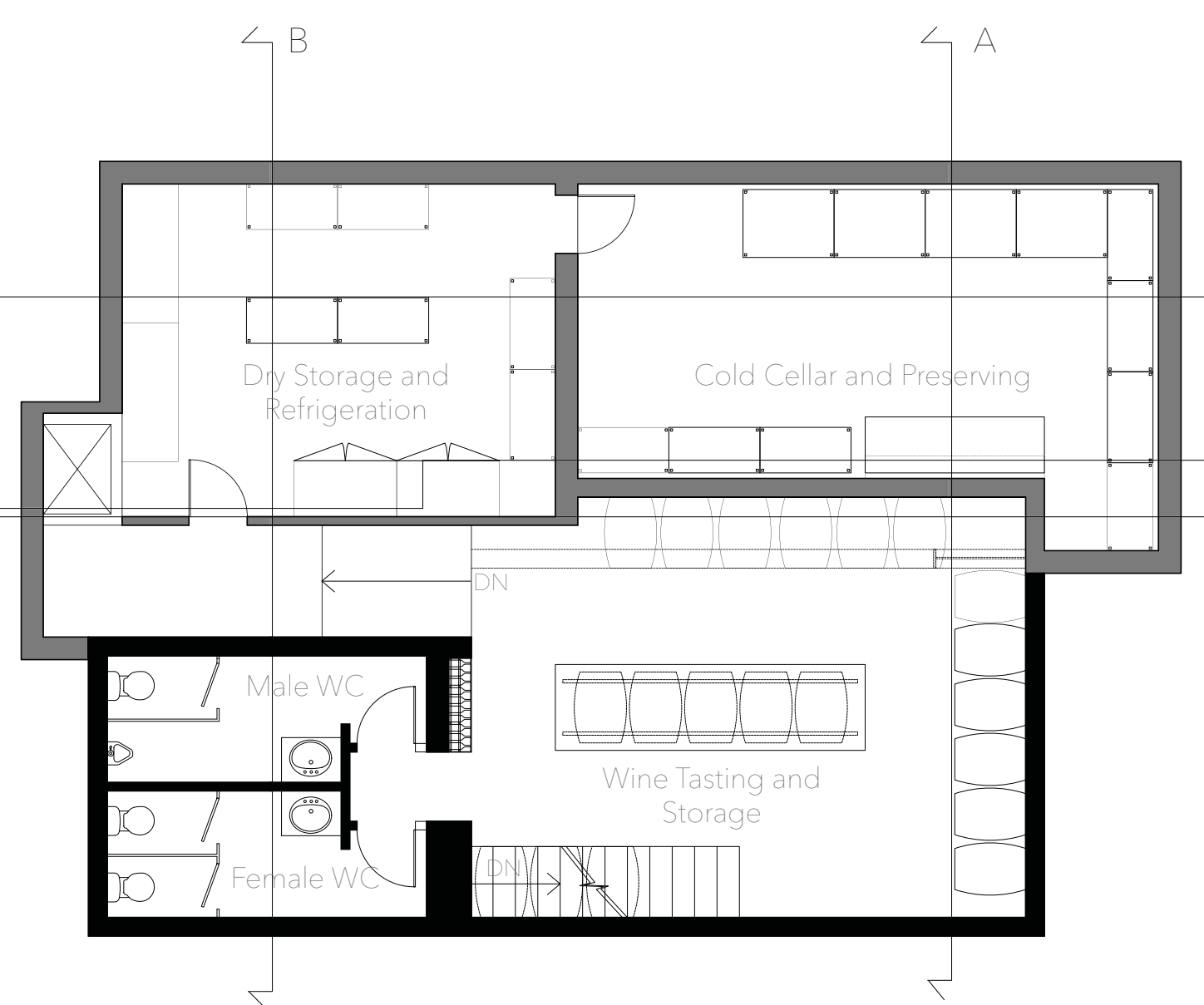




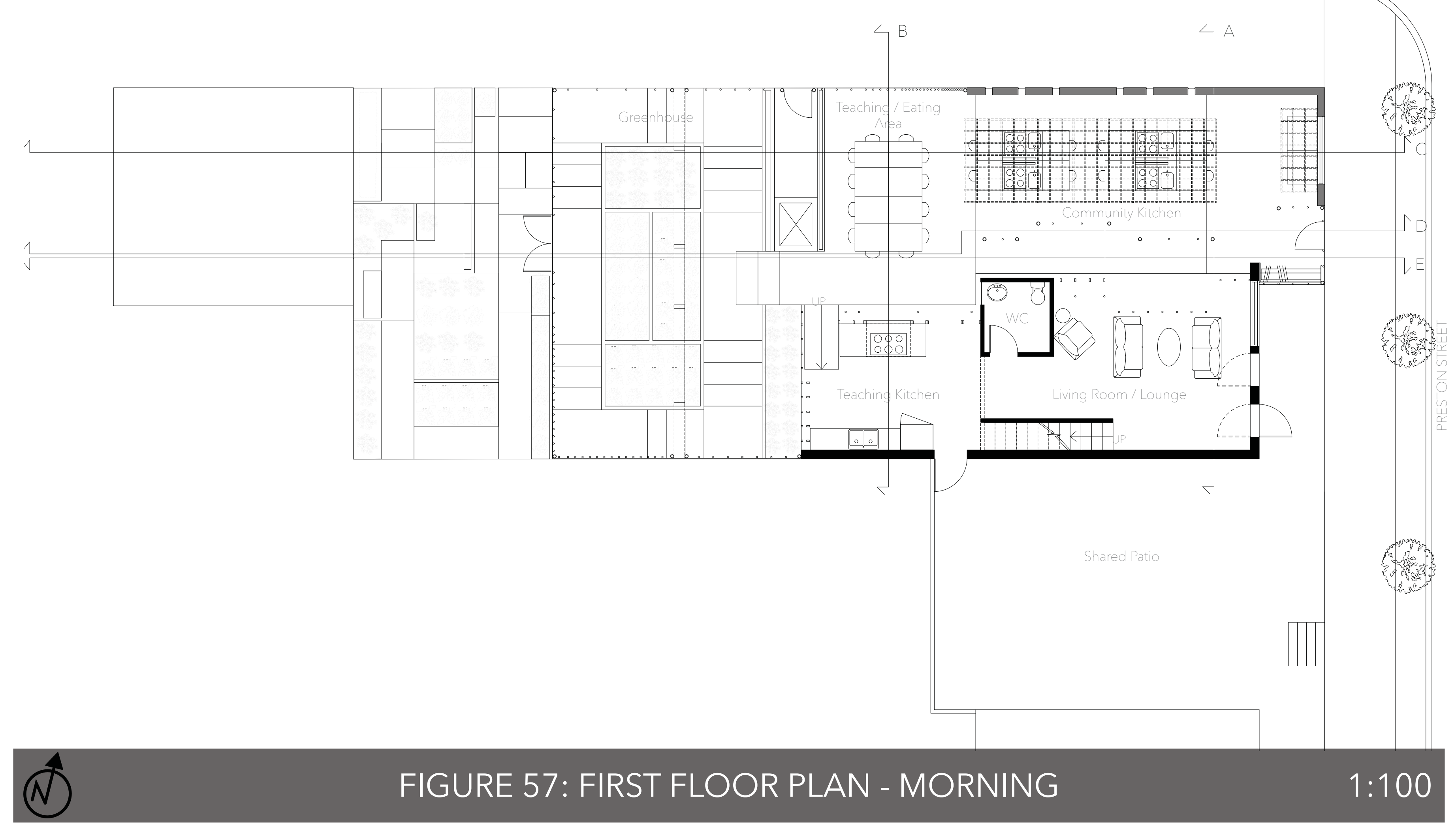




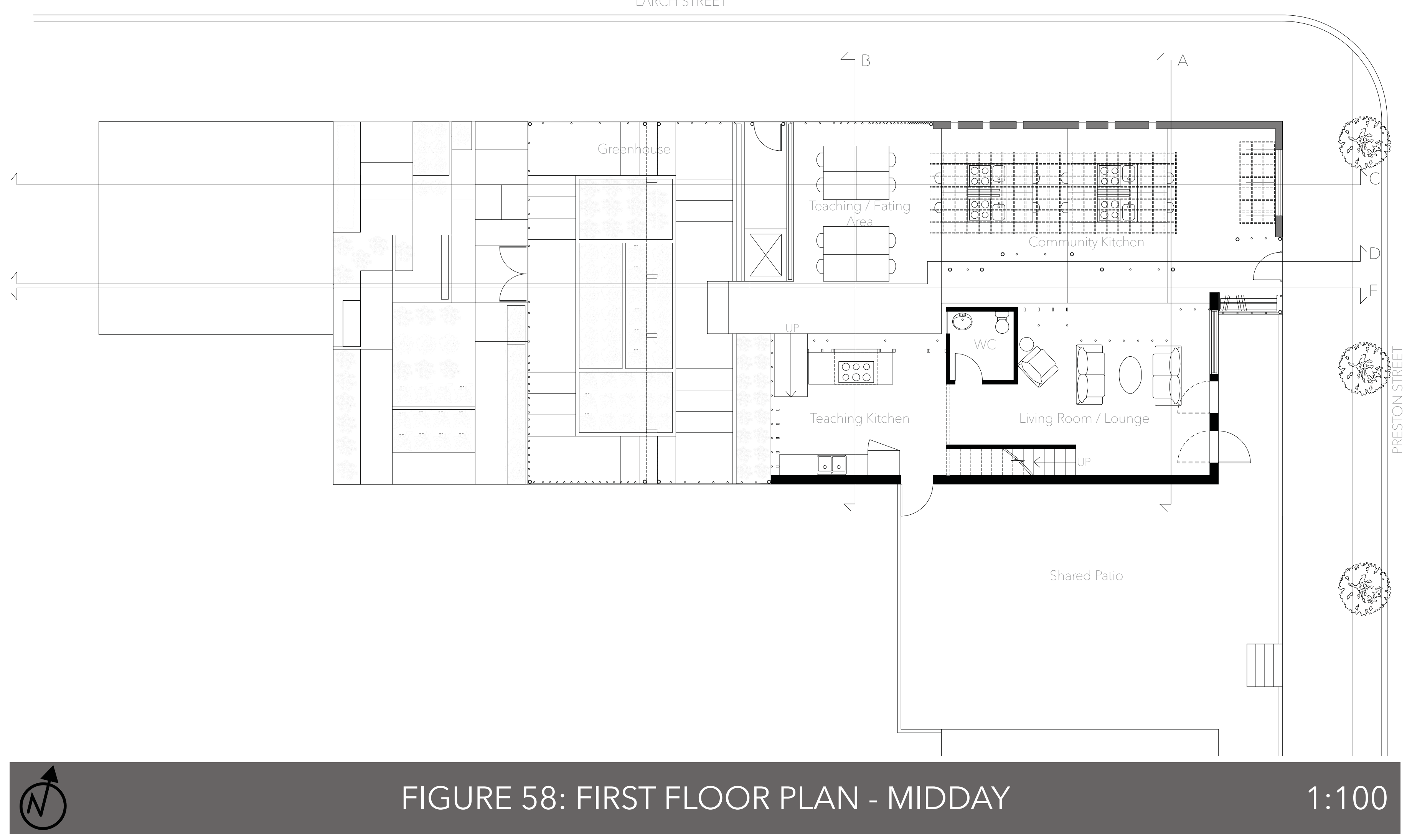




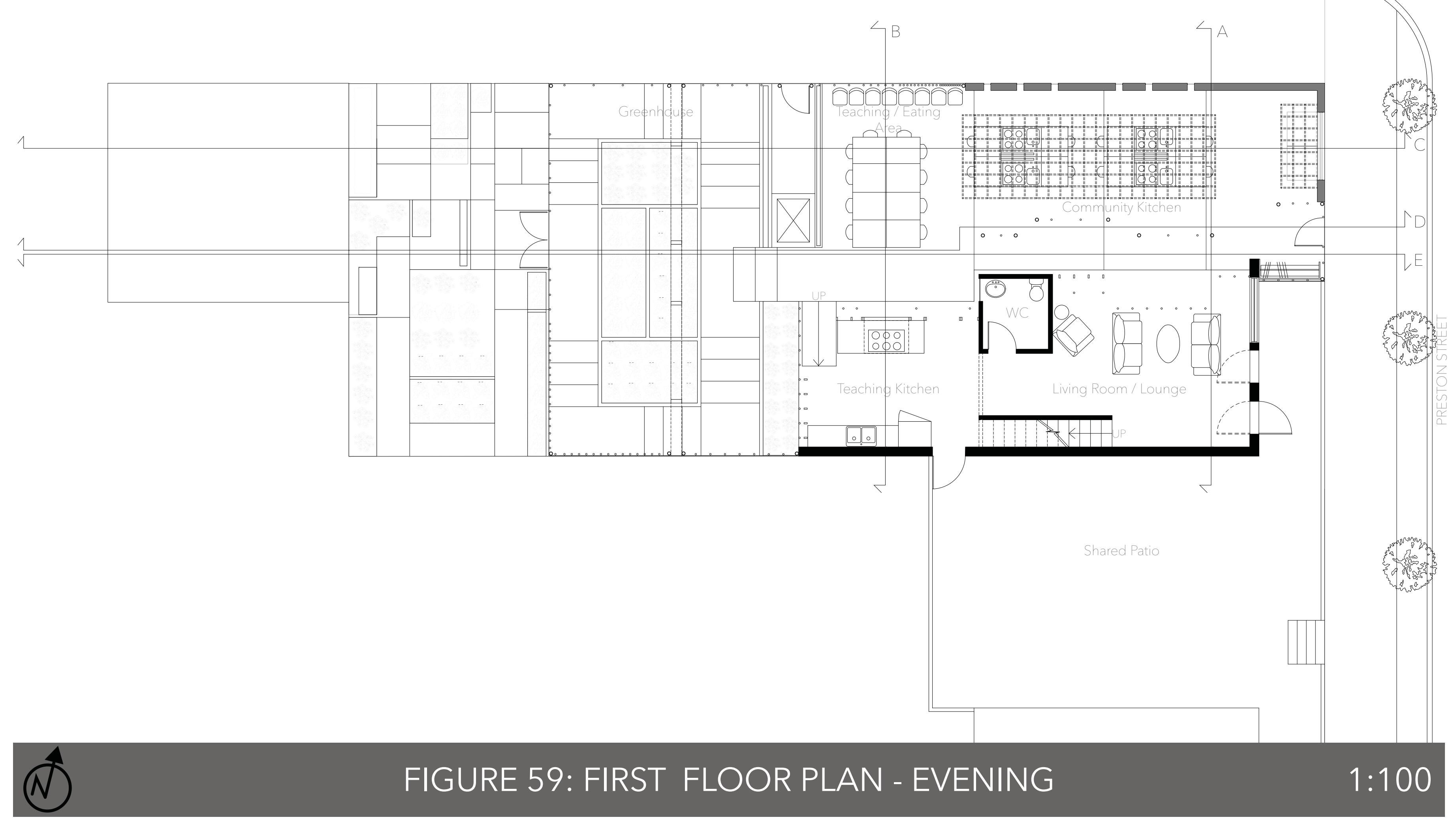




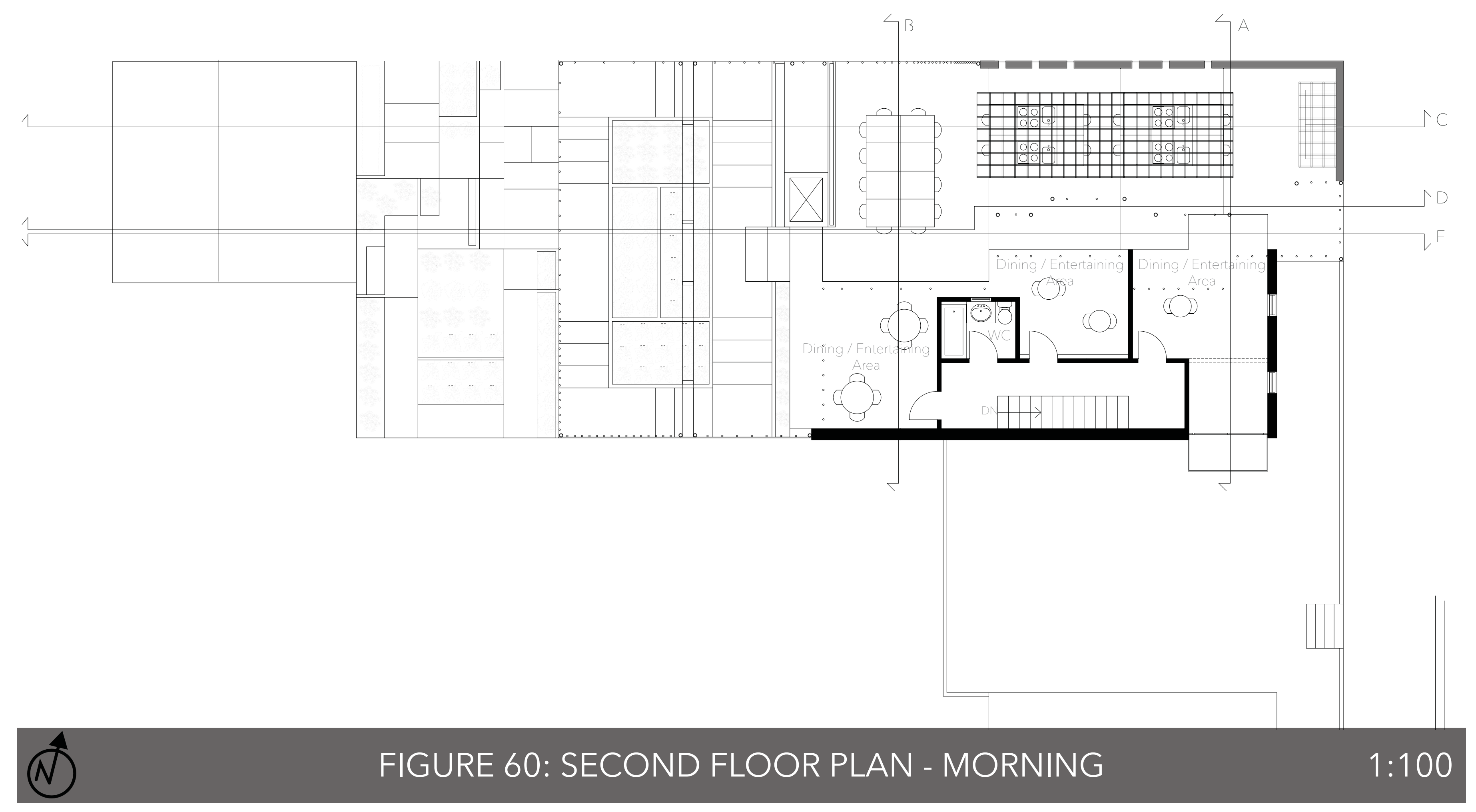




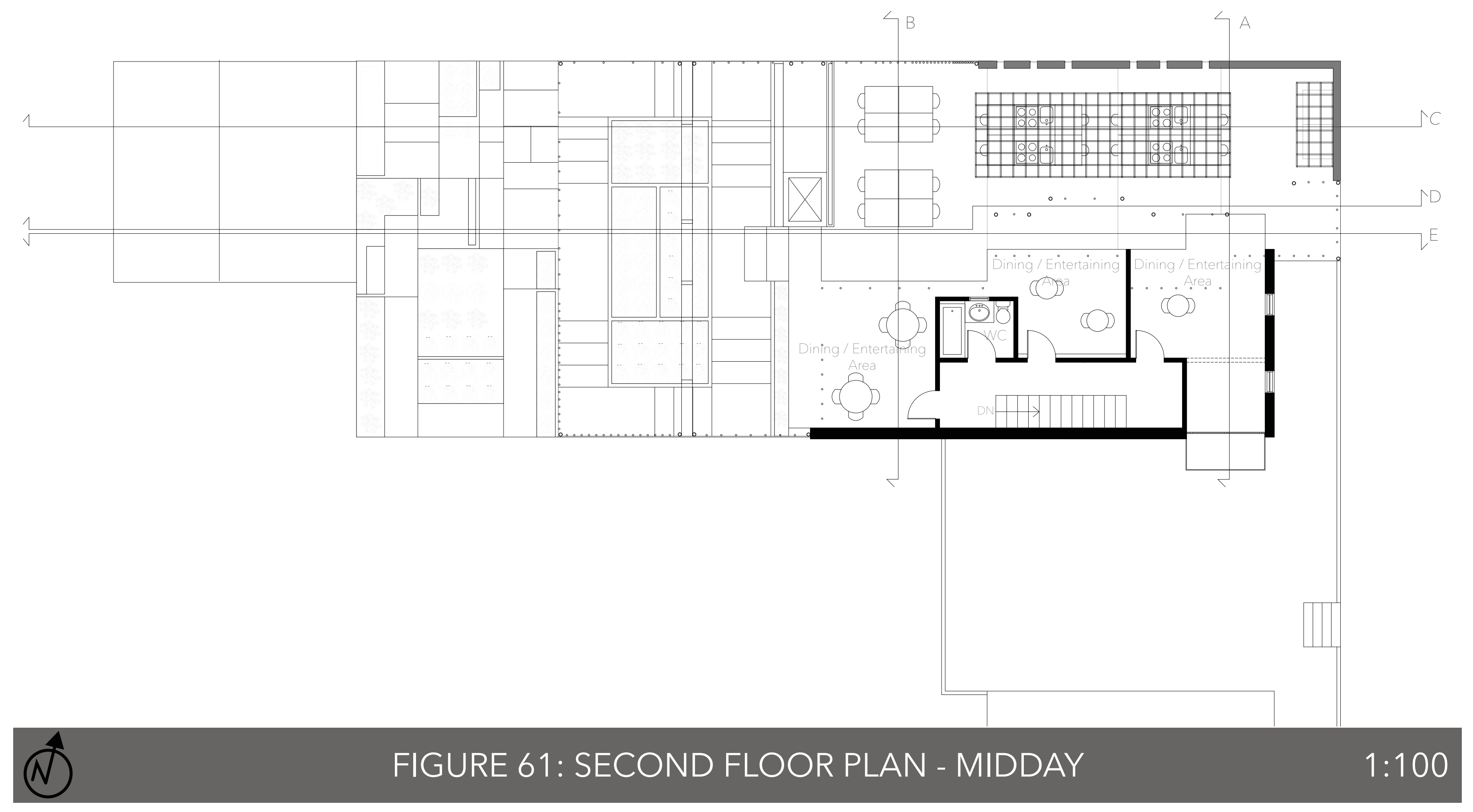




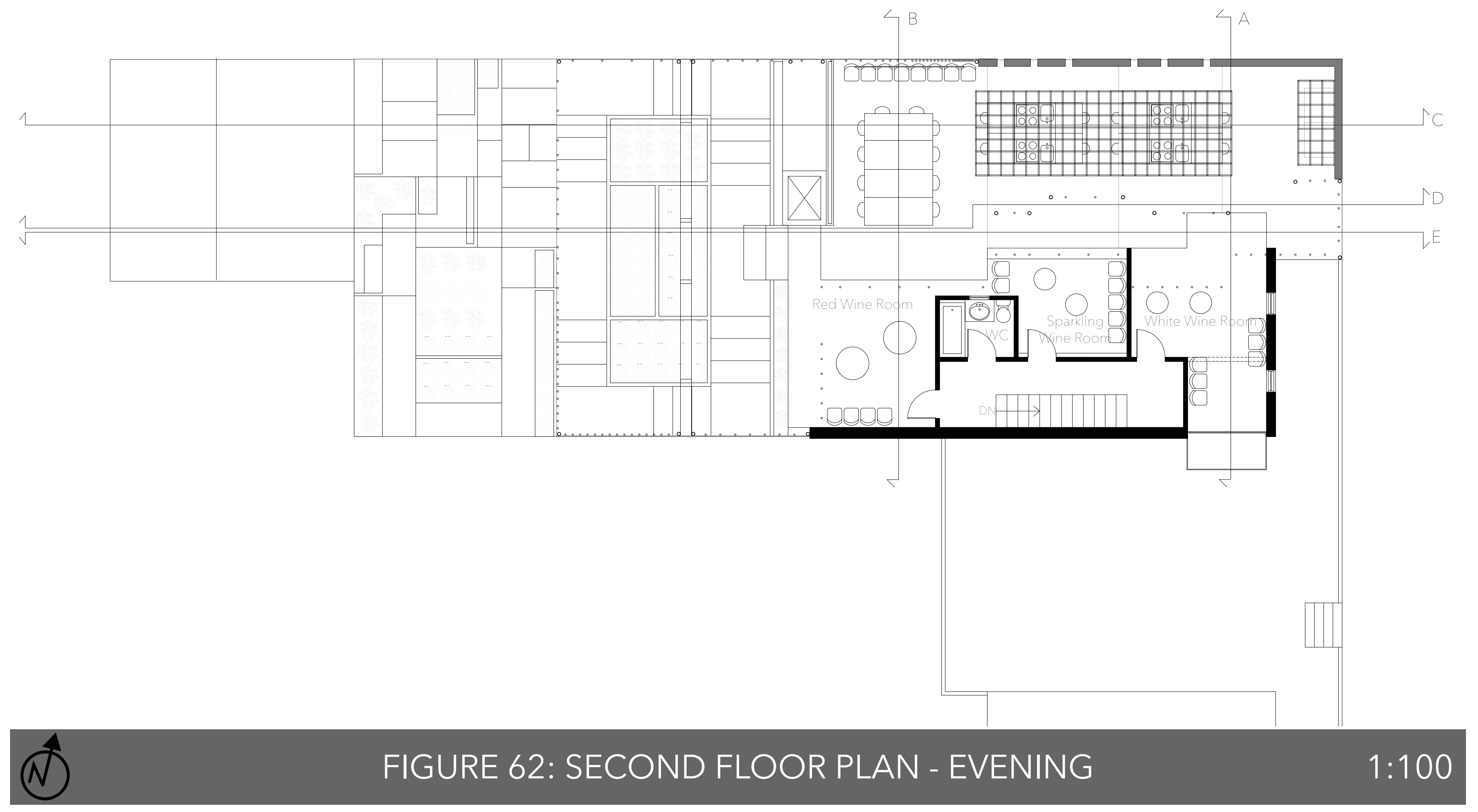




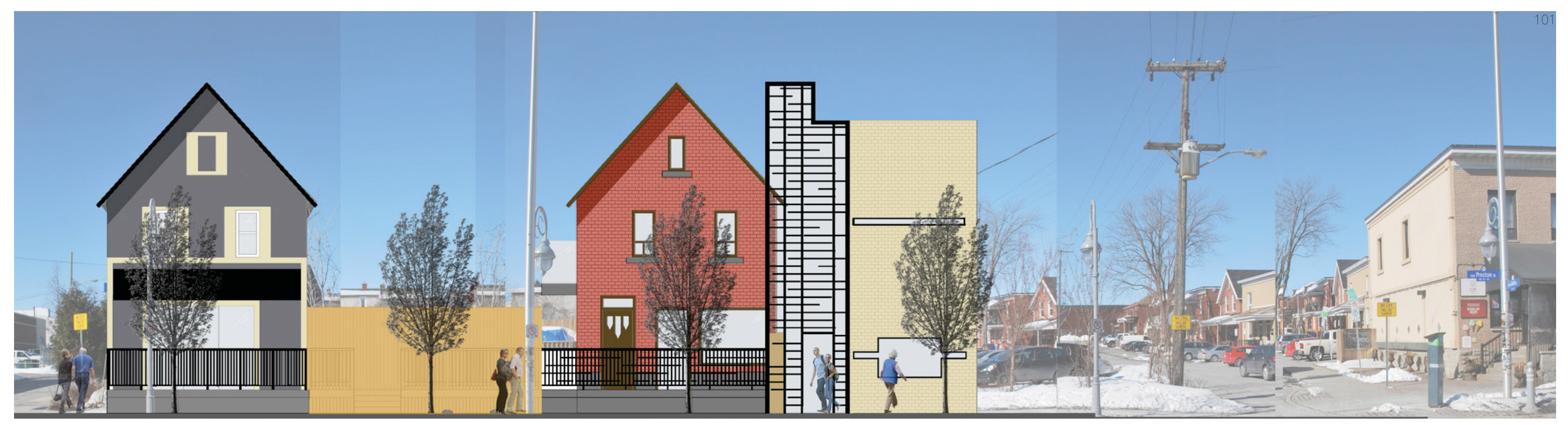

PRESTON STREET

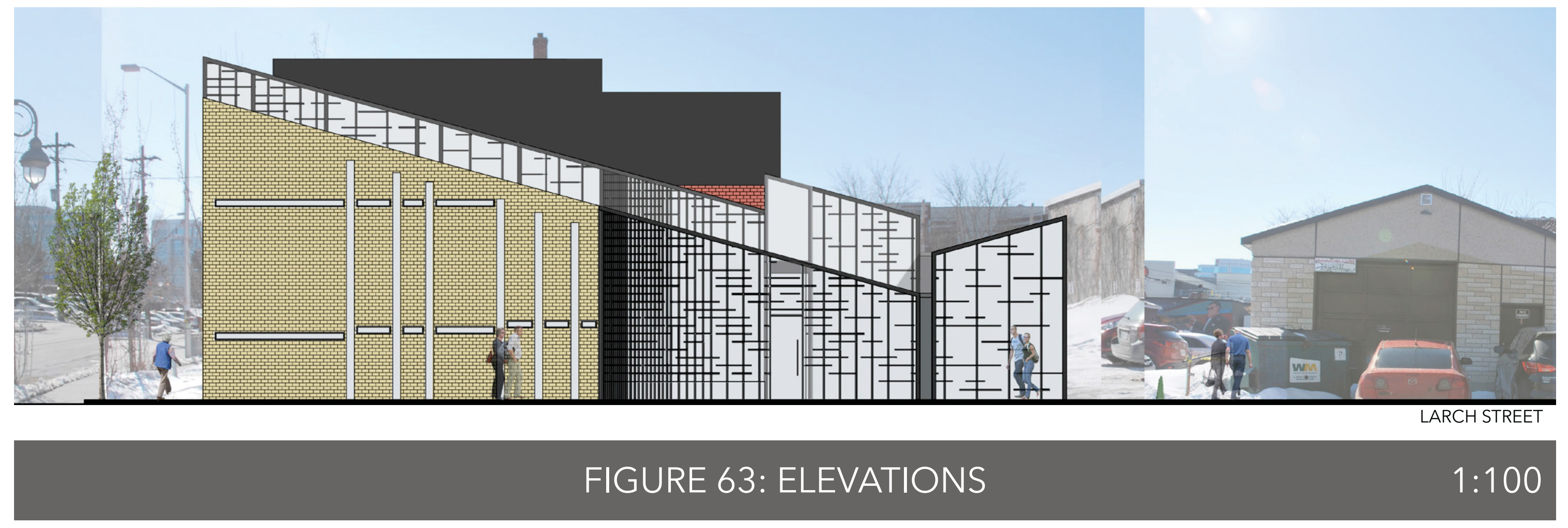




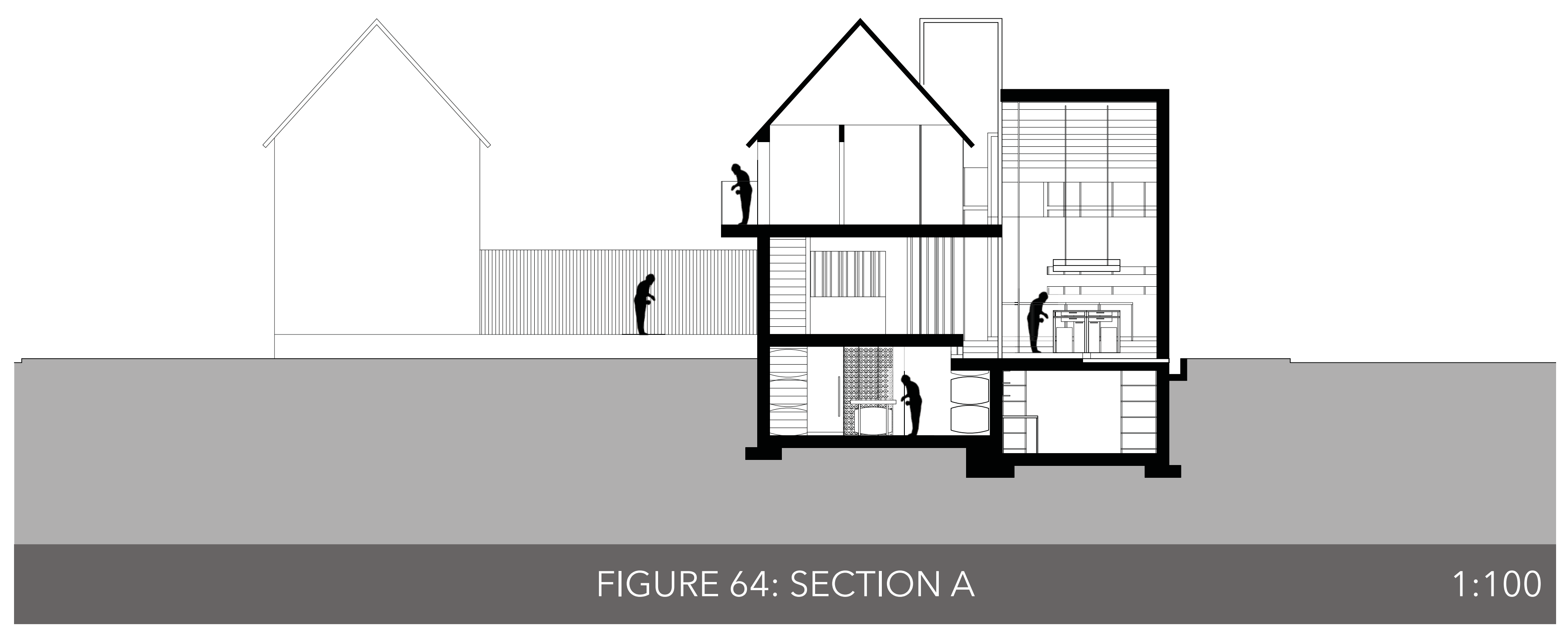




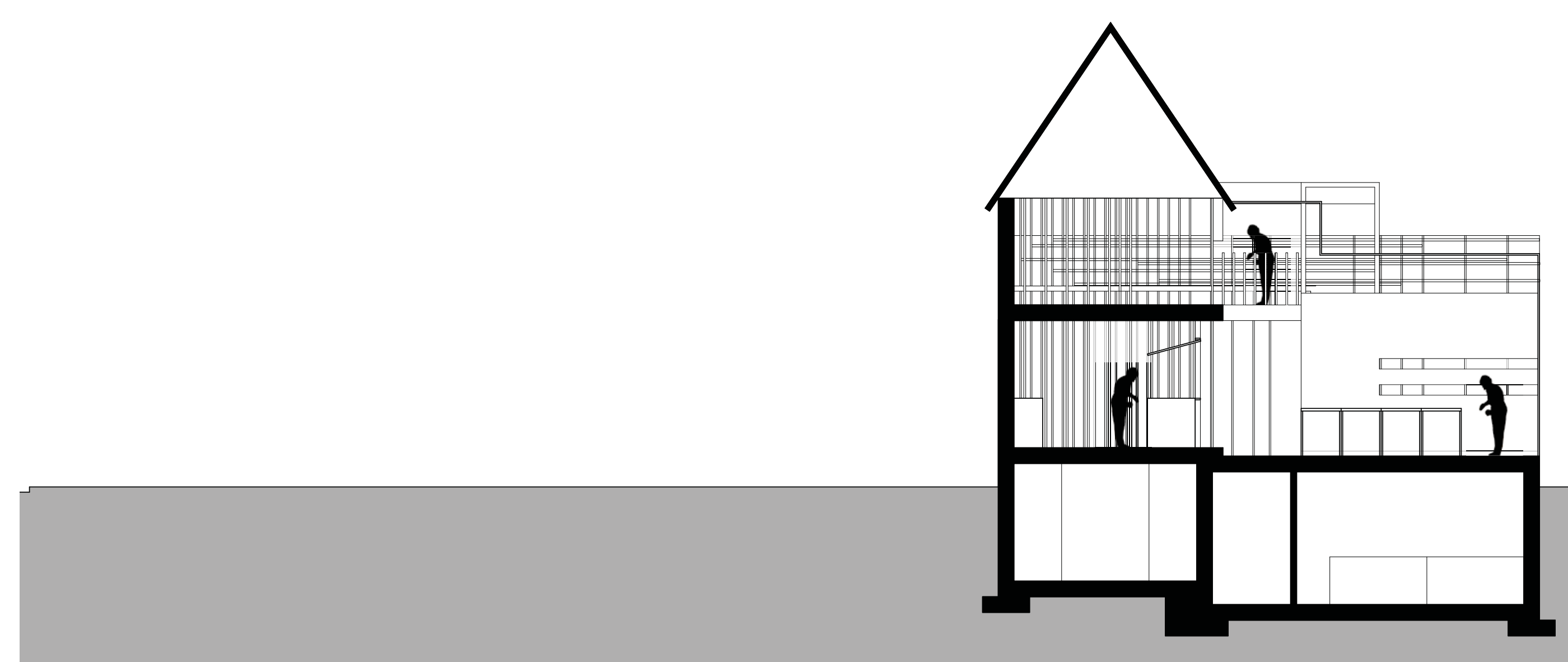




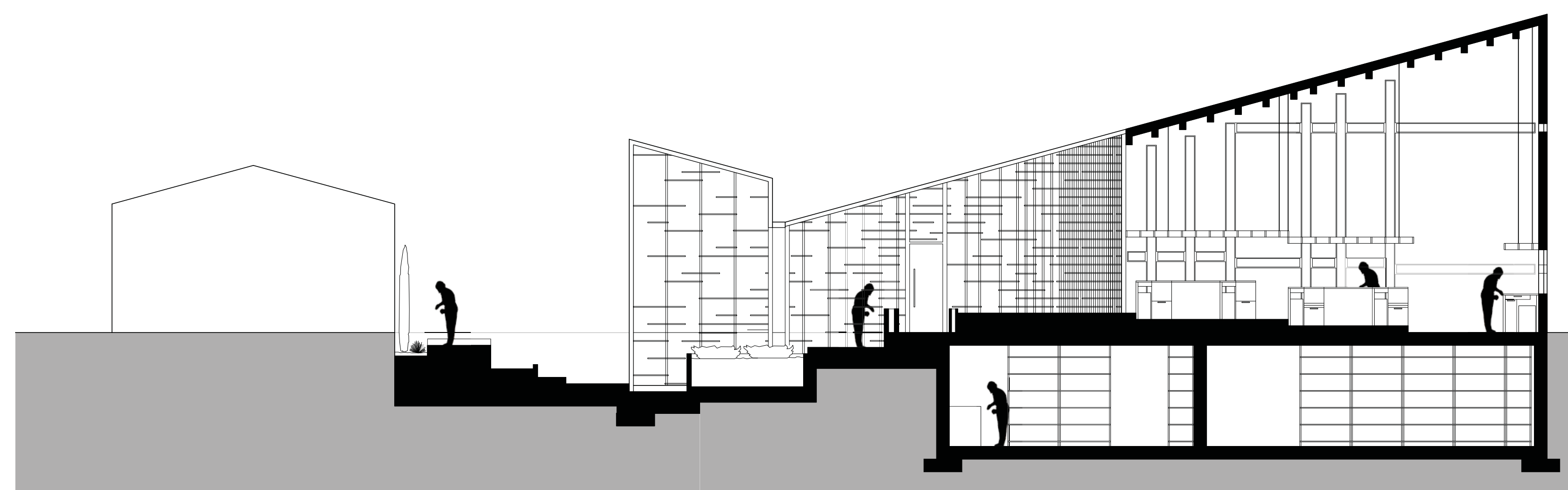

FIGURE 66: SECTION C 


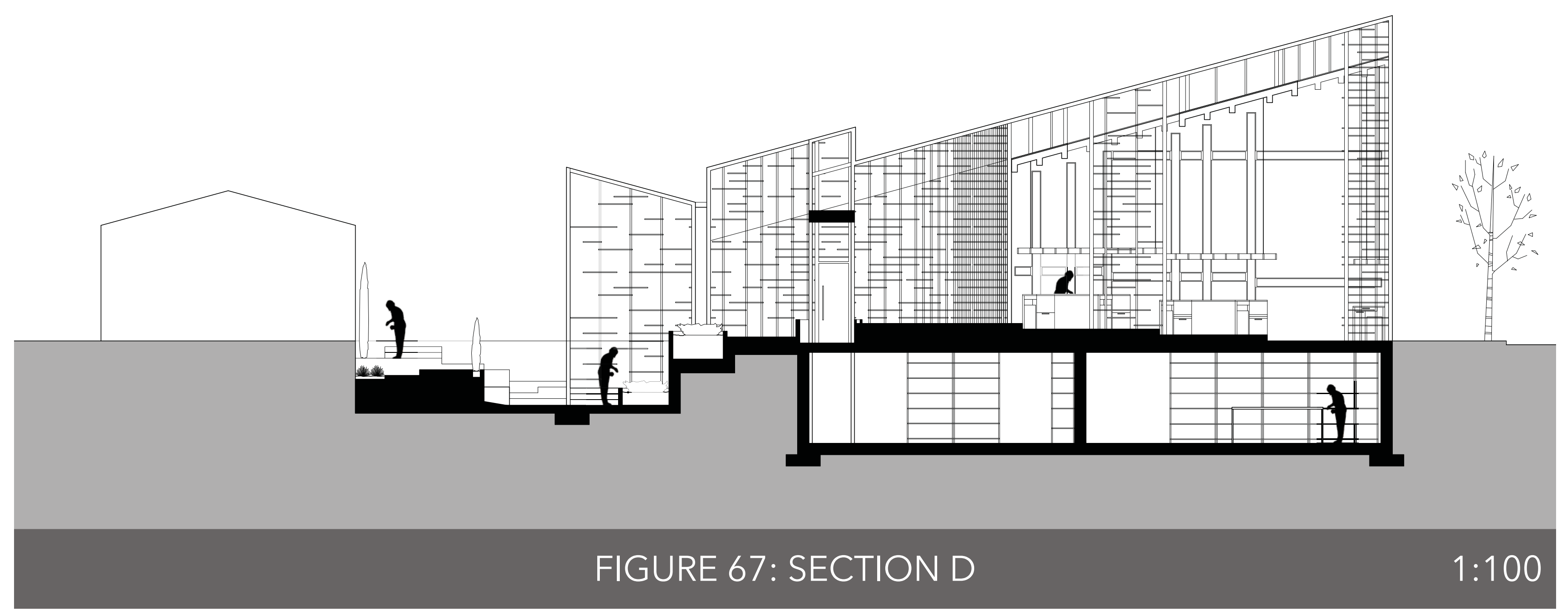




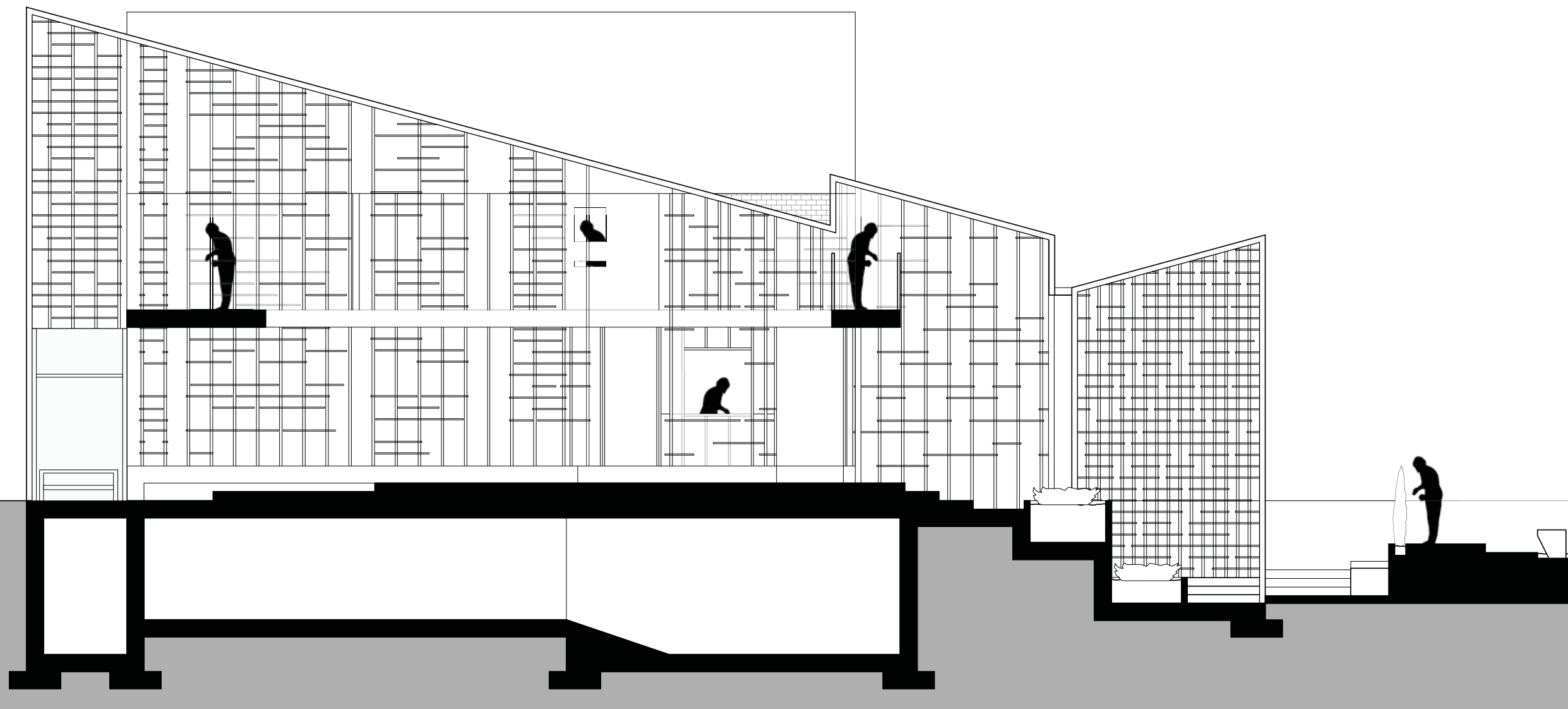

FIGURE 68: SECTION E 


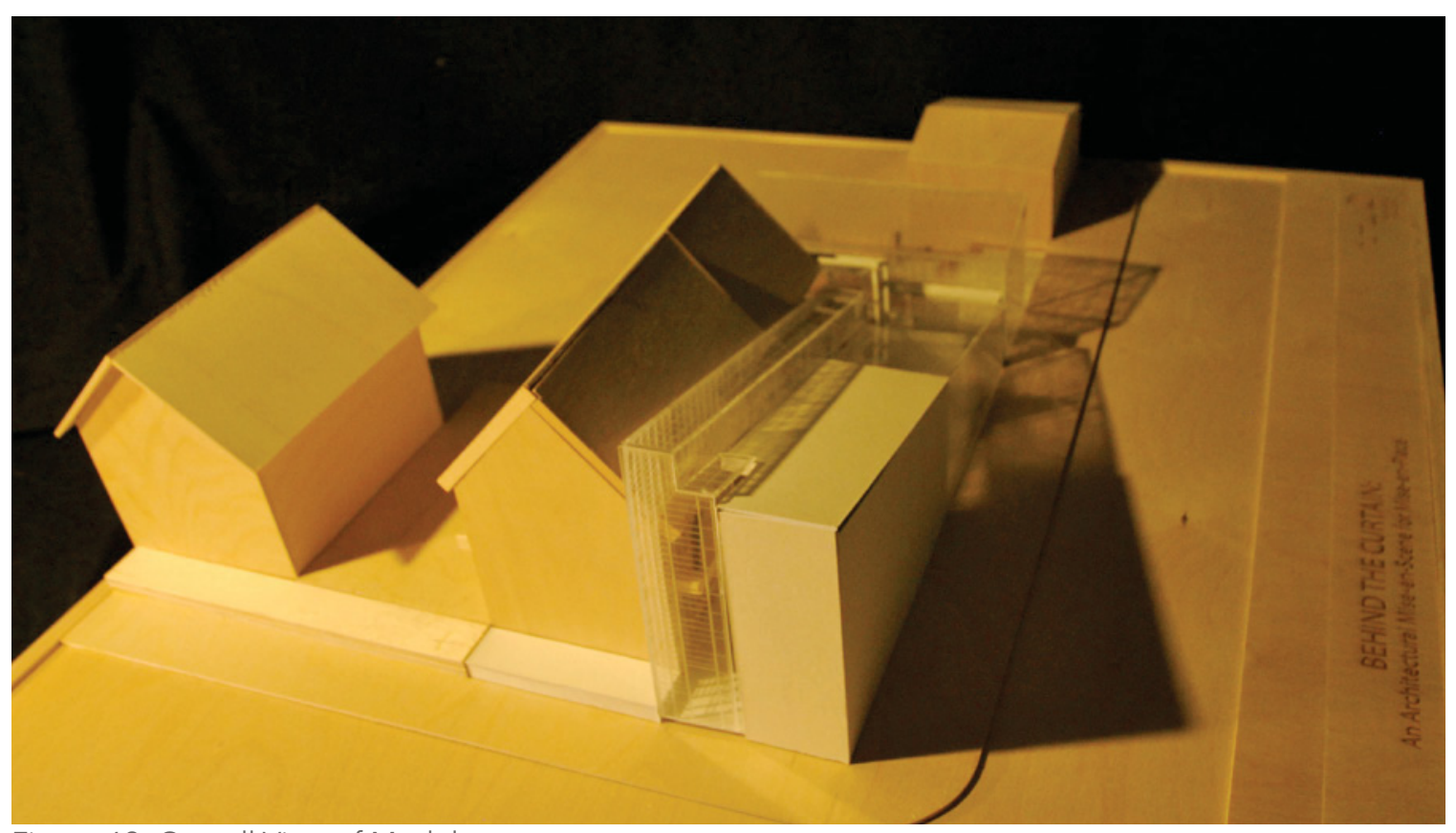

Figure 69: Overall View of Model

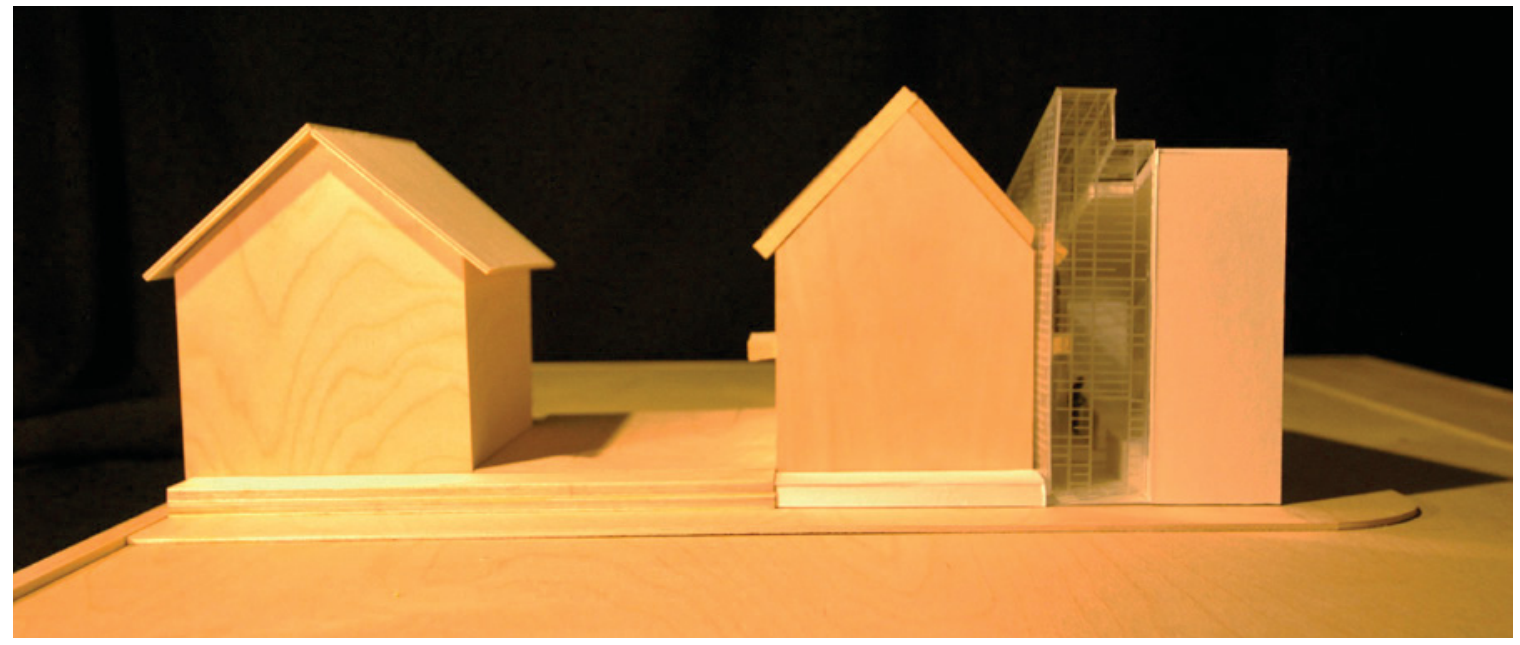

Figure 70: Preston Street Elevation 


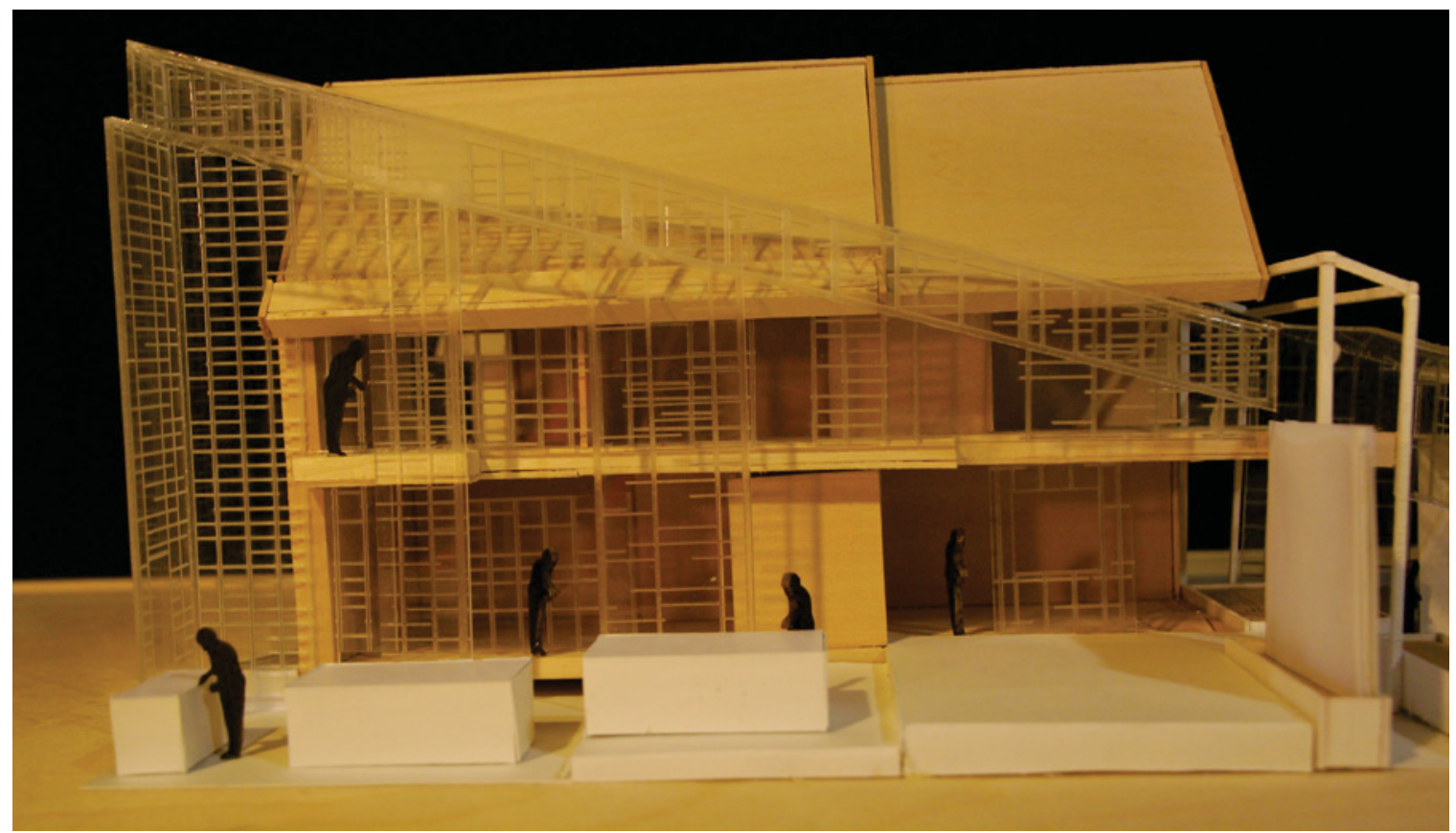

Figure 71: Overall Section

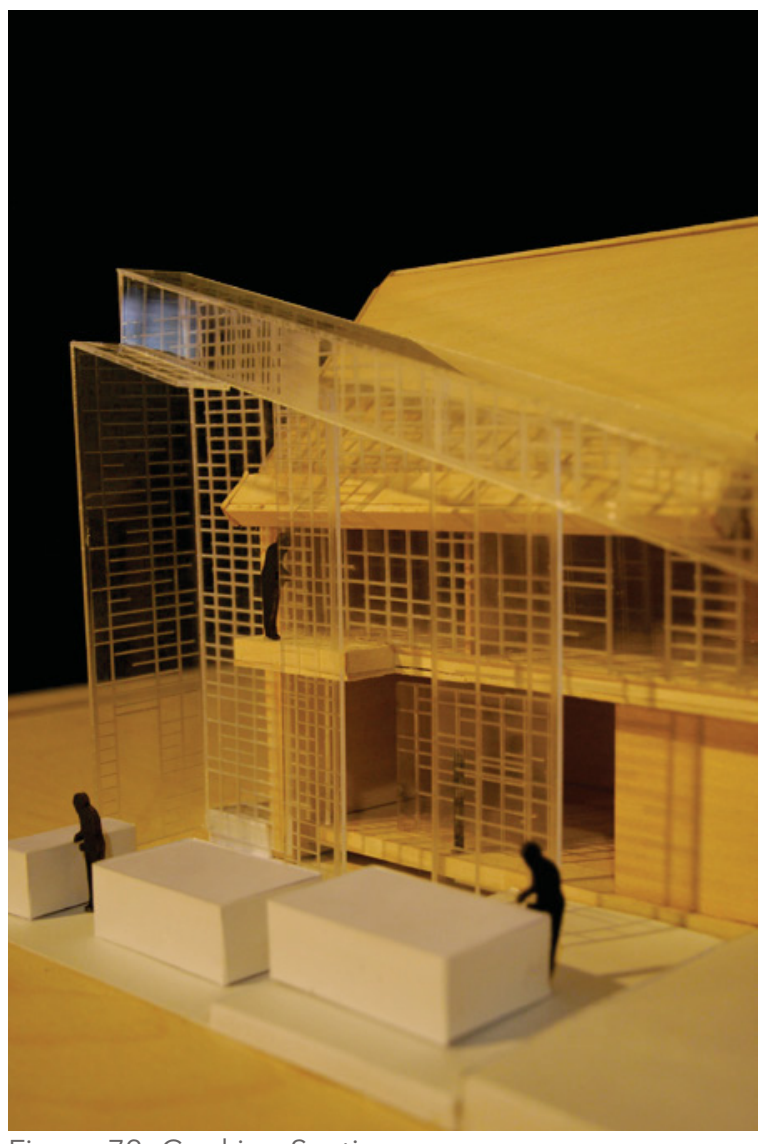

Figure 72: Cooking Section

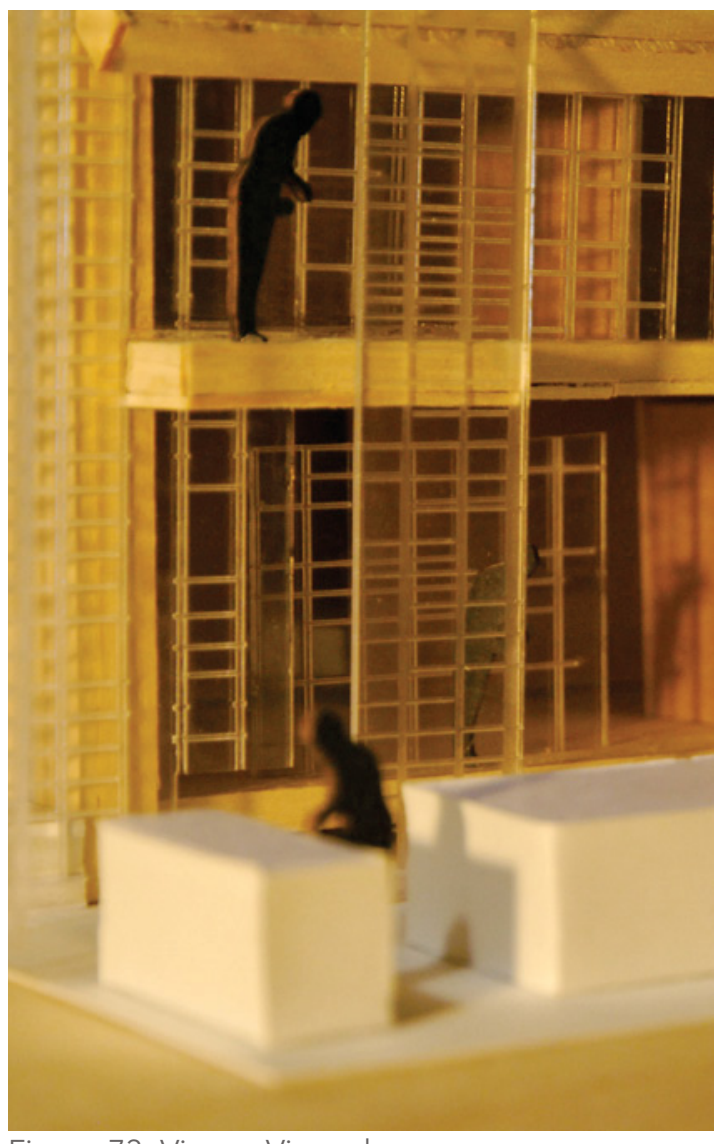

Figure 73: Viewer-Viewed 


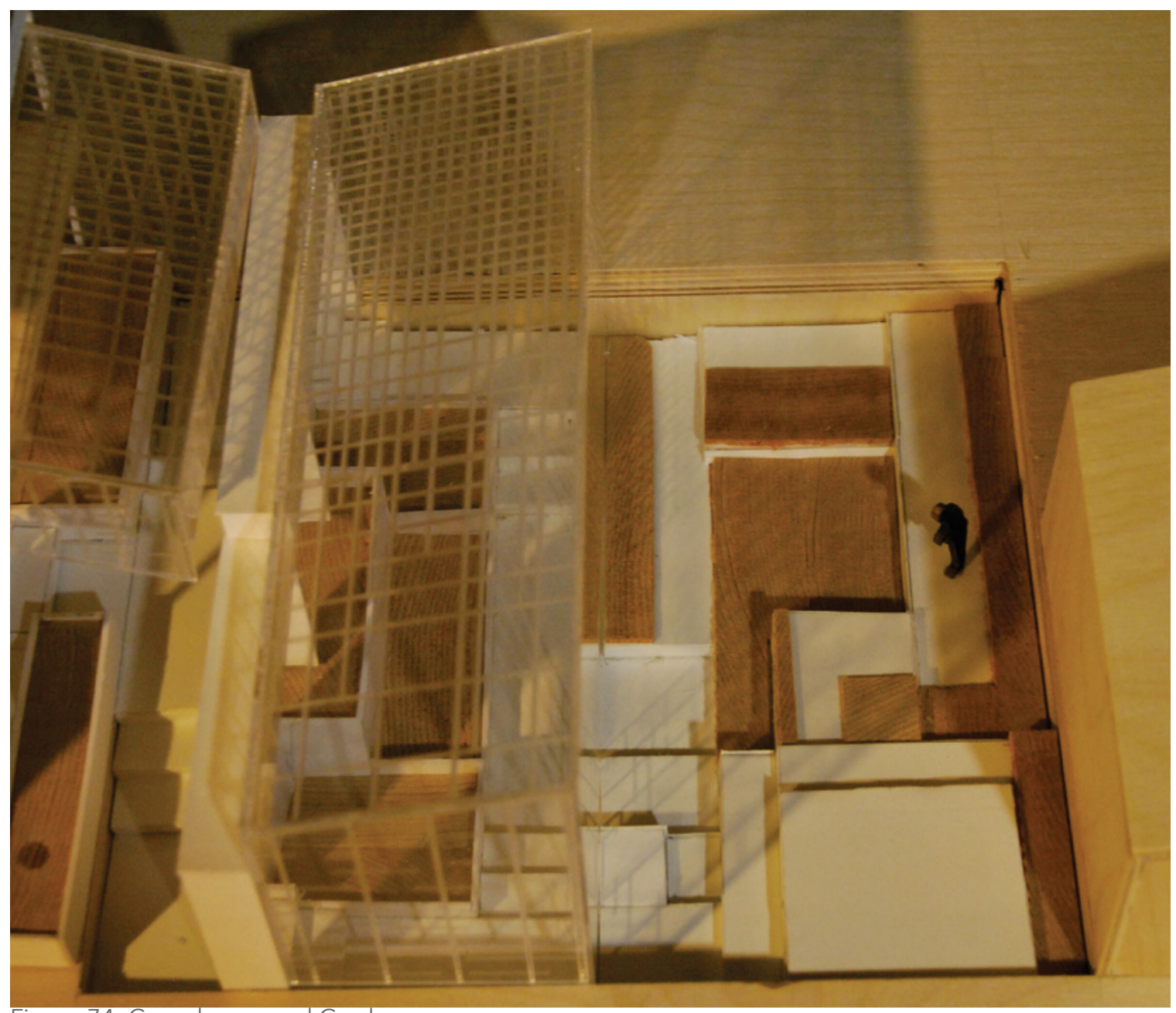

Figure 74: Greenhouse and Garden

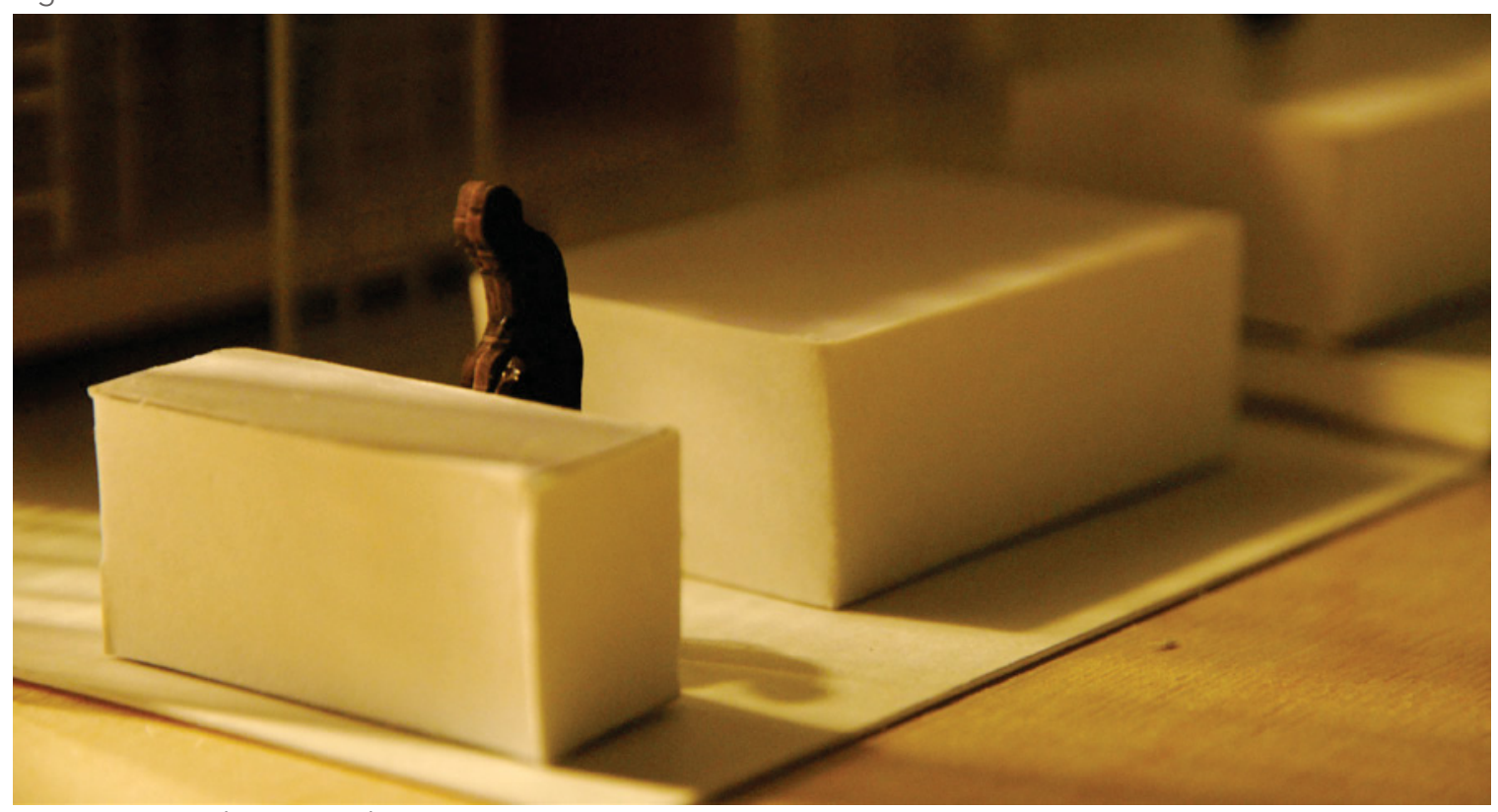

Figure 75: Cooking in Light 
POST SCRIPT 
There is an inherent tension in designing a space for a particular demographic in a specific geographical area. In this case, the space is specifically designed for women of Italian background in Little Italy in Ottawa. The space is designed with a traditional view of gender roles at the crux; women stay home, attend to the household and make meals while men go to work, and once retired, spend the day at their leisure. The woman's place of work is in and around the home, and an active social life is rarely seen as important or necessary for well being. The men adopt the local cafés, such as Giovanni's, as their social gathering places but there is no equivalent provided for the women. The church is one of the only places where these women go to congregate, but it is not seen as a vehicle for social gathering. There are no women to be found in the cafés, unless they are the ones behind the bar making the espressos. Therefore, in response to the tension present in the gender identity of the area, the Culinary Cooperative provides an equal and opposite tension, providing women with a social outlet.

I was raised in Toronto in a traditional Italian family. My mother's parents immigrated from northern Italy in 1952, and my father's parents immigrated from central Italy in 1953. While I never knew my paternal grandfather, I saw evidence of traditional gender roles on my mother's side. My grandfather went to work early in the morning, came home to a fresh plate of pasta for lunch, then returned to work for the rest of the day. In the evening he would come home to dinner on the table and then go outside and tend the garden and chickens or in the winter would watch the Italian news before bed. My grandmother stayed home most of the day performing various domestic tasks. She looked after the house, made clothing and meals, collected ripe produce from the garden, and made sauce and other preserves in the fall. She could drive and was therefore independent, but on my father's side, my grandmother only learned to drive at the age of 60 when my grandfather passed away. Before that she was reliant on him to drive her to her destinations as they lived in an area without public transportation. After he passed, the 
church became her social space and where she met most of her friends and shared common interests.

Sadly, only my paternal grandmother is still alive and I regret not having learned more from my grandparents before they passed. A space like this would allow people like me, second or third generation Canadian-Italians, to go and learn from their grandparents or those of the same generations, the traditions which they can then carry forward. It would also serve to disseminate basic Italian cooking techniques and practices to those outside the culture. This younger generation would also have the opportunity to teach the older generations about topics they are well versed in such as technology or social media. It would become a reciprocal relationship between generations allowing for a smooth transition of guardianship between generations. In this way, the building would always be progressing and new traditions would be formed over time.

There are specific characteristics in the building that are very much tied to Italian culture including; a wine cellar, the use of traditional materials such as venetian plaster, masonry and wrought iron, and references to growing grape vines and the use of pergolas. While these features are primarily identified with Italian culture and are inherent to the building, many of the spaces could be reappropriated if elderly Italians were to leave the area and another culture were to assume it. That is not to say that women would not travel from other areas of the city to use the space, but as the older generations pass away, the younger women may not identify with a traditional view of Italian culture and may therefore not see a significant need for this space. My mother and her generation would appropriate the space, but modify its use to complement the needs of their generation. The project therefore embraces change and allows for modified programming while keeping to its theatrical and communal qualities. 


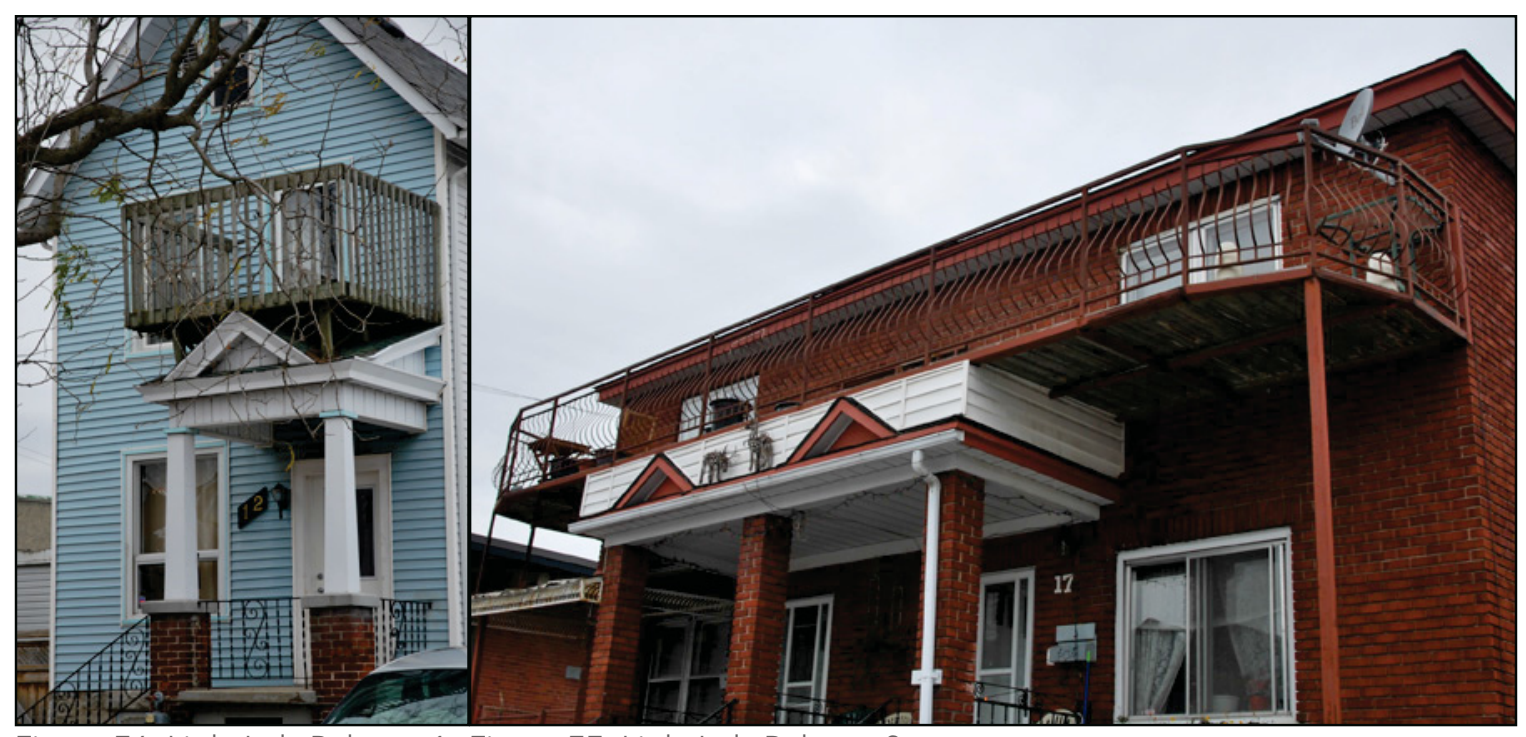

Figure 76: Little Italy Balcony 1 Figure 77: Little Italy Balcony 2

In the area there is evidence of Italian immigrants having reappropriated the existing early 20th century housing, adding wrought iron railings, small second floor balconies, using brick and poured concrete in new constructions, and opening shops and cafés dedicated to promoting the Italian culture and importing products. They utilized what they found in the area to create micro climates in order to grow culture specific vegetables and fruits including tomatoes and grapes. These adjustments and adaptations are part of the changing dynamics of any community and there is no doubt that in the next hundred years the dynamics will change again as other cultures become established in the area. Each culture builds upon what the previous group left behind and appropriates what they find to make what they know and are familiar with.

Food is a necessity for life and thus every culture has it's own traditional dishes. Each culture requires different ingredients and growing conditions for them but there is an inherent ability within human beings to adapt. All cultures have traditions of growing, storing, and preserving food. For this reason, a building dedicated to food could be used by any cultural group as Little Italy changes. The recipes and methods being taught and passed on would be different, but the spirit of the building would be the same. The individual spaces such as the cold cellar, dry storage, cooking stations and teaching 
kitchens could each be adapted to fit the specific needs of various groups in the future.

There is a need to instruct and pass on traditions as cultures try to stay alive in a society that readily dissolves and dilutes them. Among my friends whose families are also of Italian decent, very few speak Italian, make the traditional recipes of their grandparents or know how to tend a garden. There is no urgency to pass on cultural traditions resulting in fragmented cultures and homogenized societies. Culture can be a part of our identity, though, and for this reason there is a need to stay connected to our past and to our roots. The preparation and sharing of food provides this connection.

There is also a need within cultural groups to gather, especially in times of celebration or loss. Food is frequently a component of this gathering, and in the Italian culture, it commonly takes place in or near the kitchen. Thus the largest open area was placed opposite the teaching kitchen to reinforce this connection. This phenomenon is shared by many cultures as is the need for belonging and community. Humans are ultimately social beings and find comfort in interacting with those with which they have shared experiences. For these reasons, spaces to congregate outside the home are increasingly important as a support for a sense of community and a culture of togetherness. 
APPENDIX 

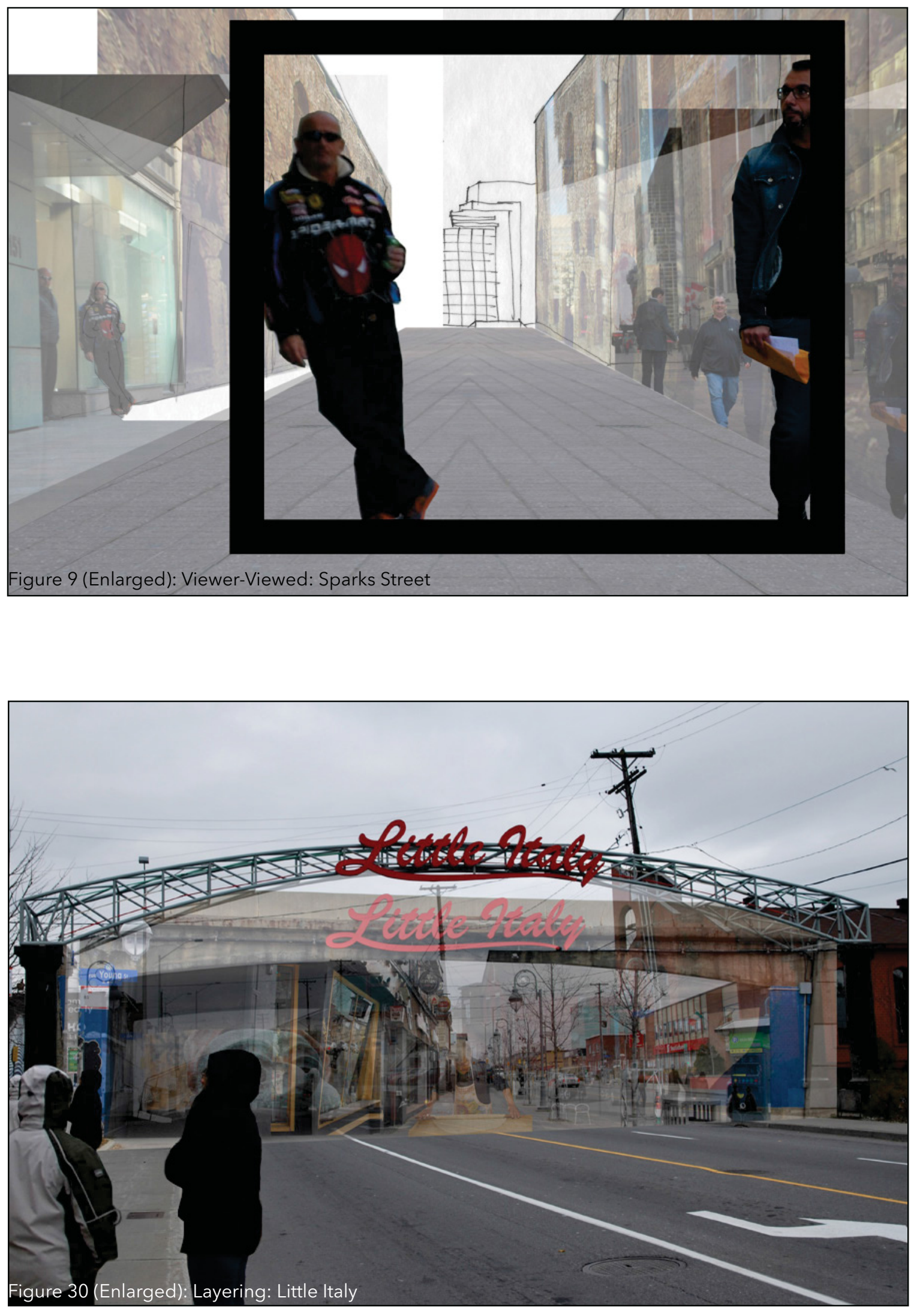

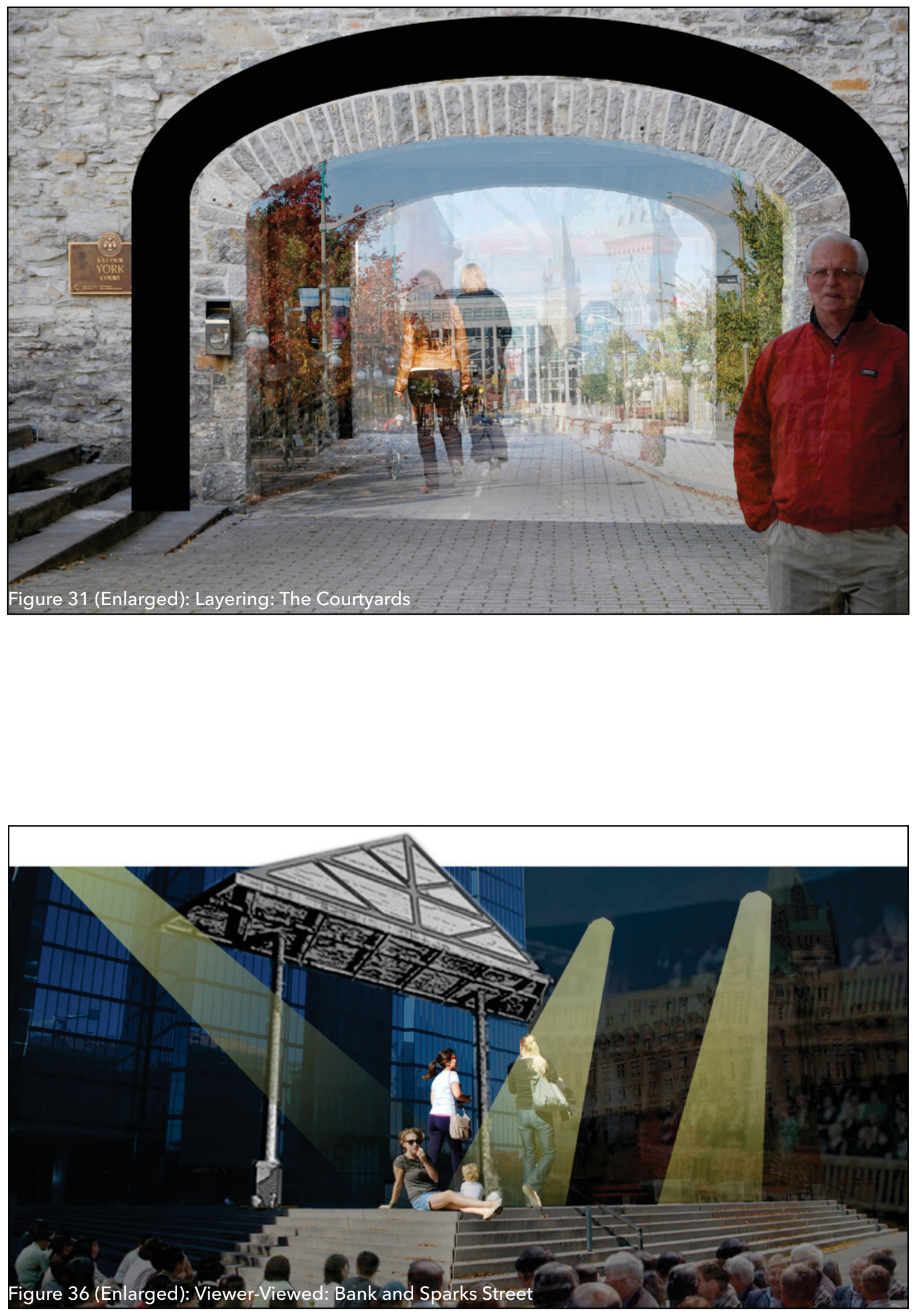


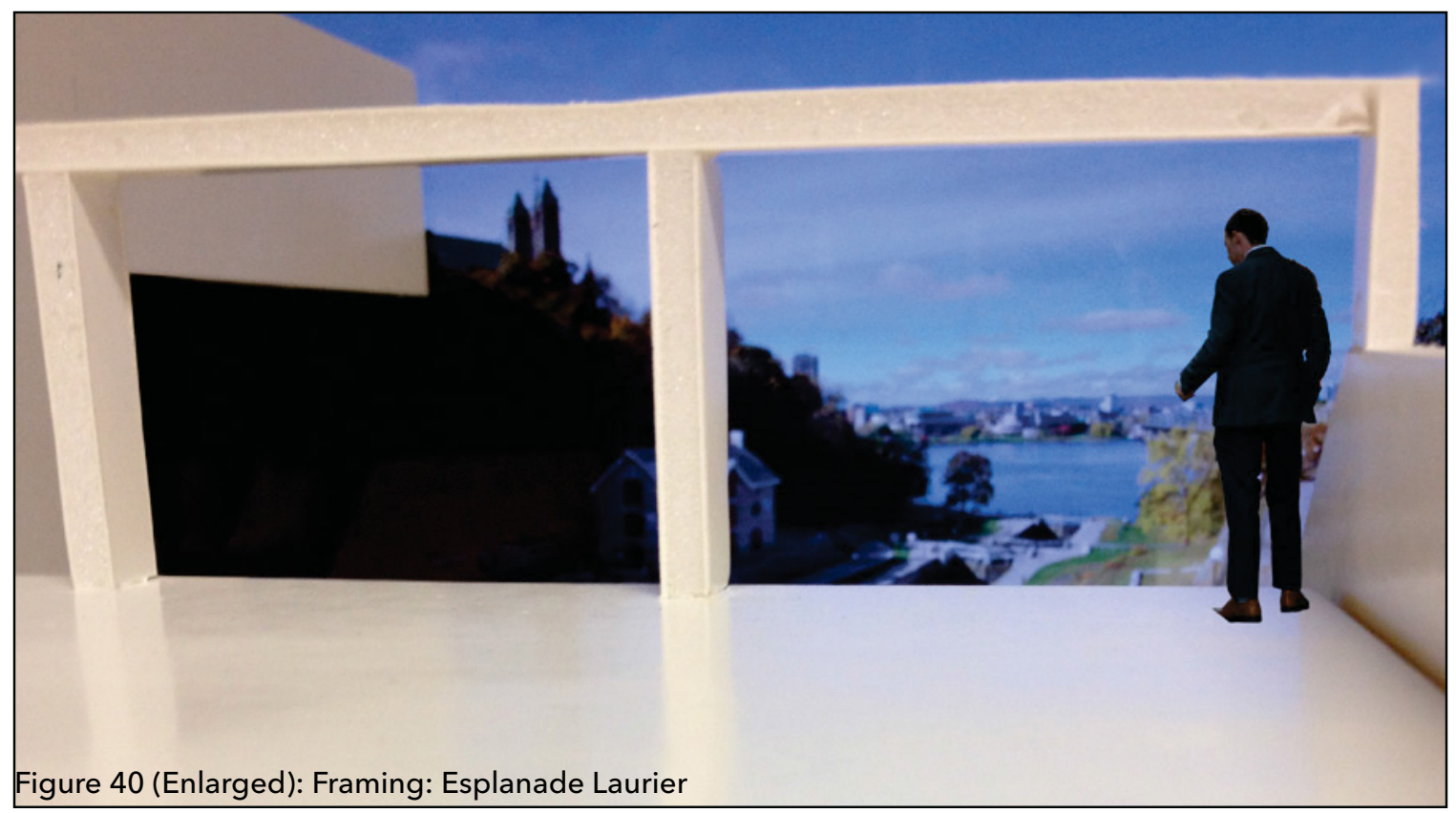




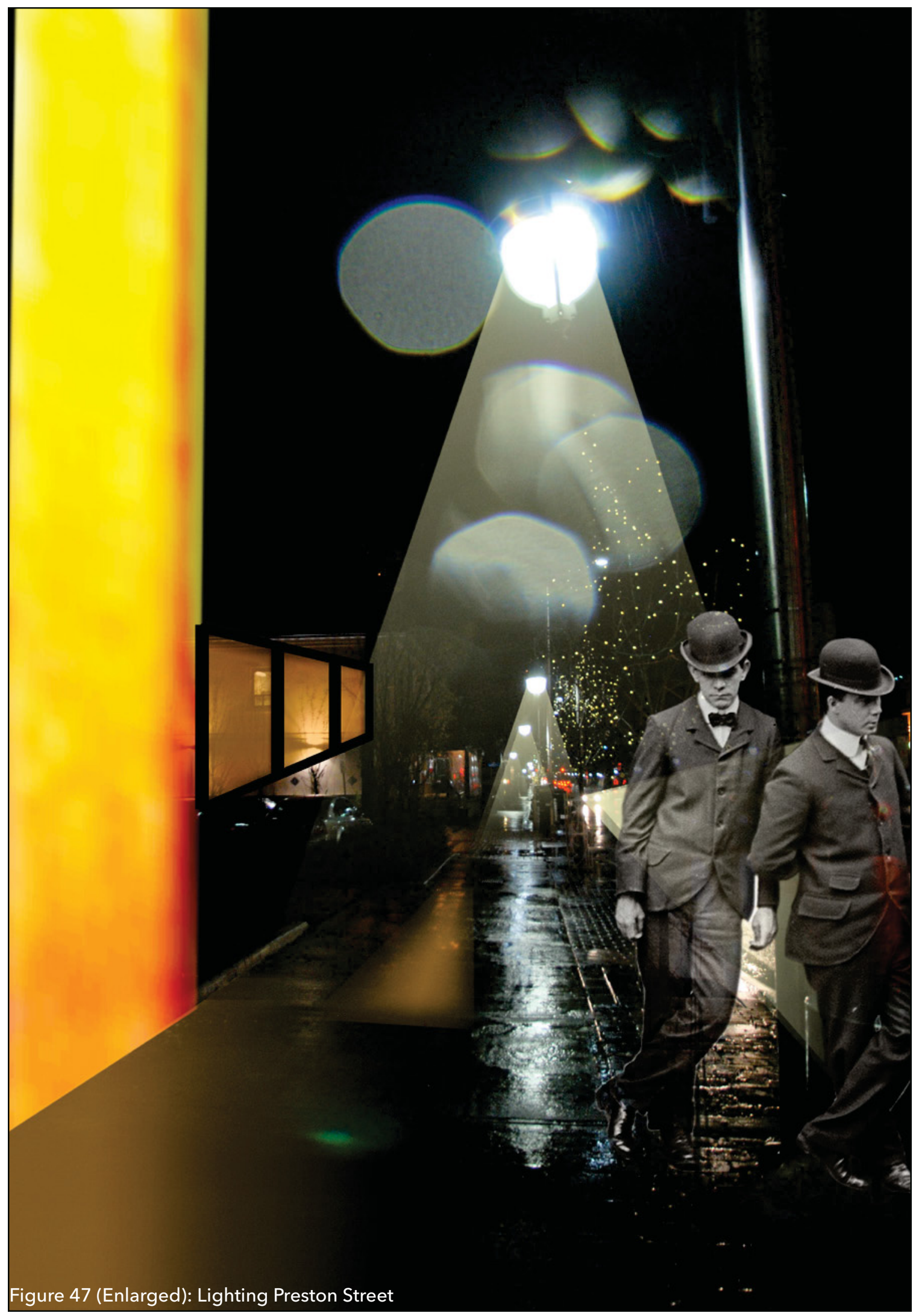




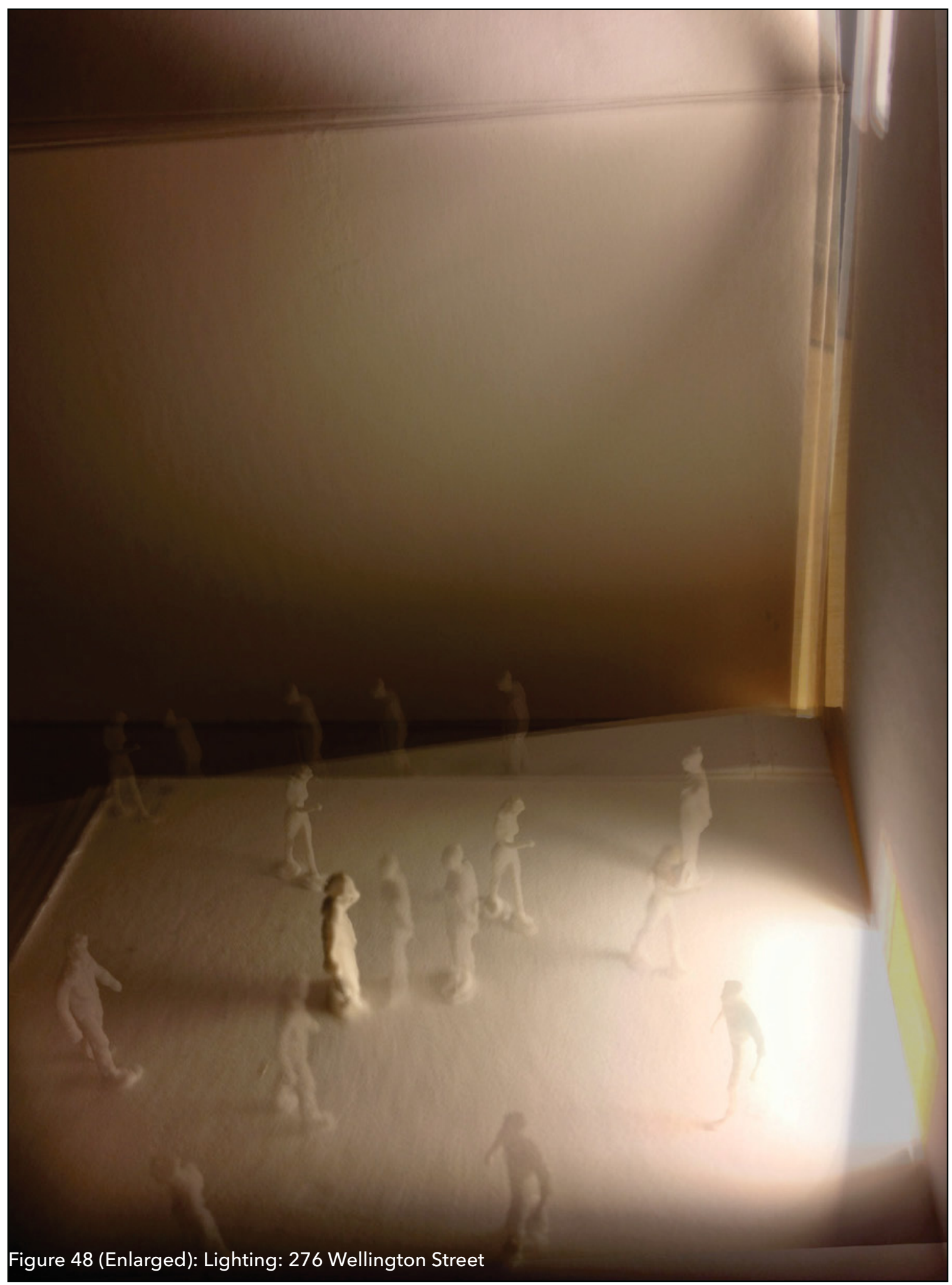



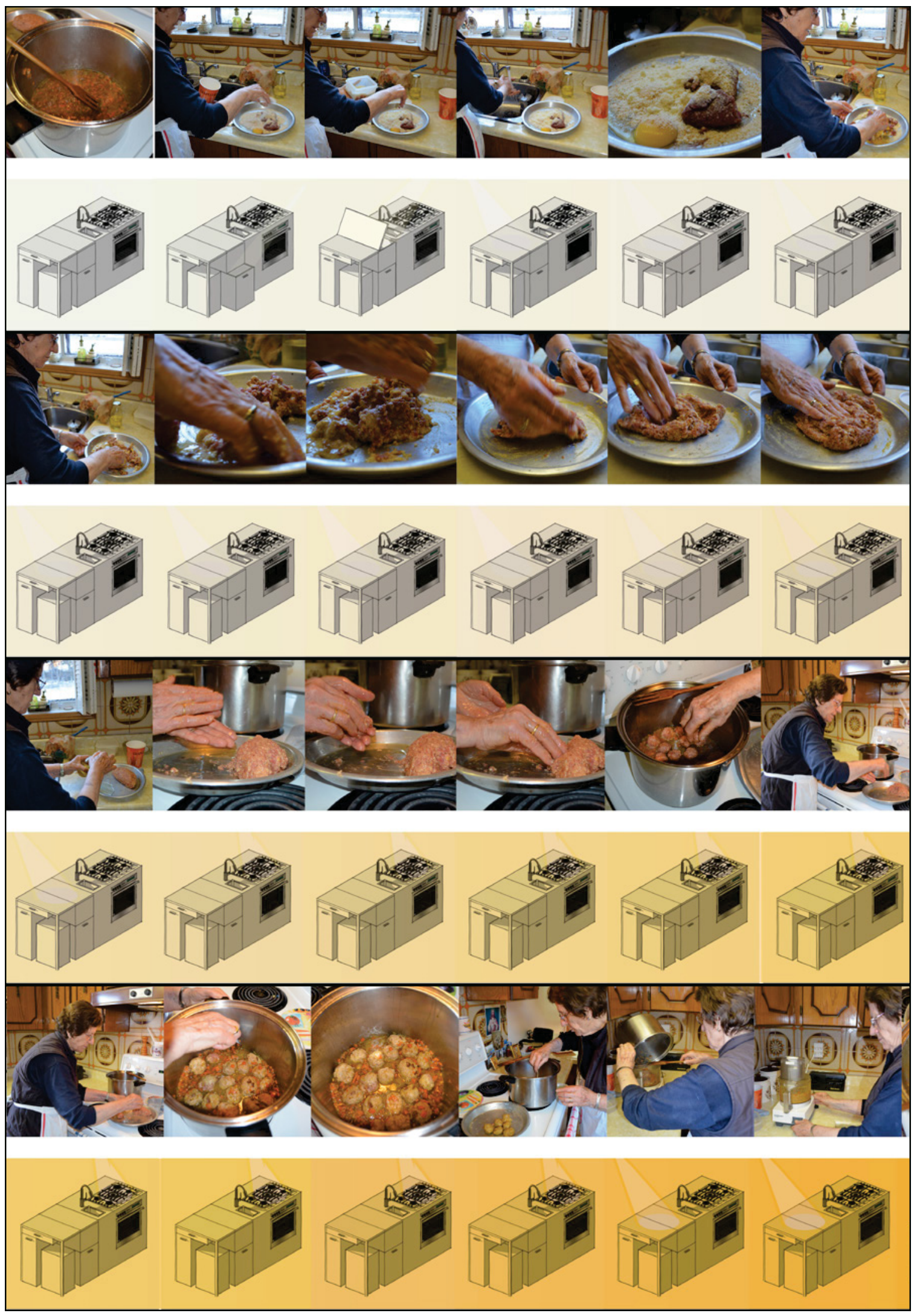


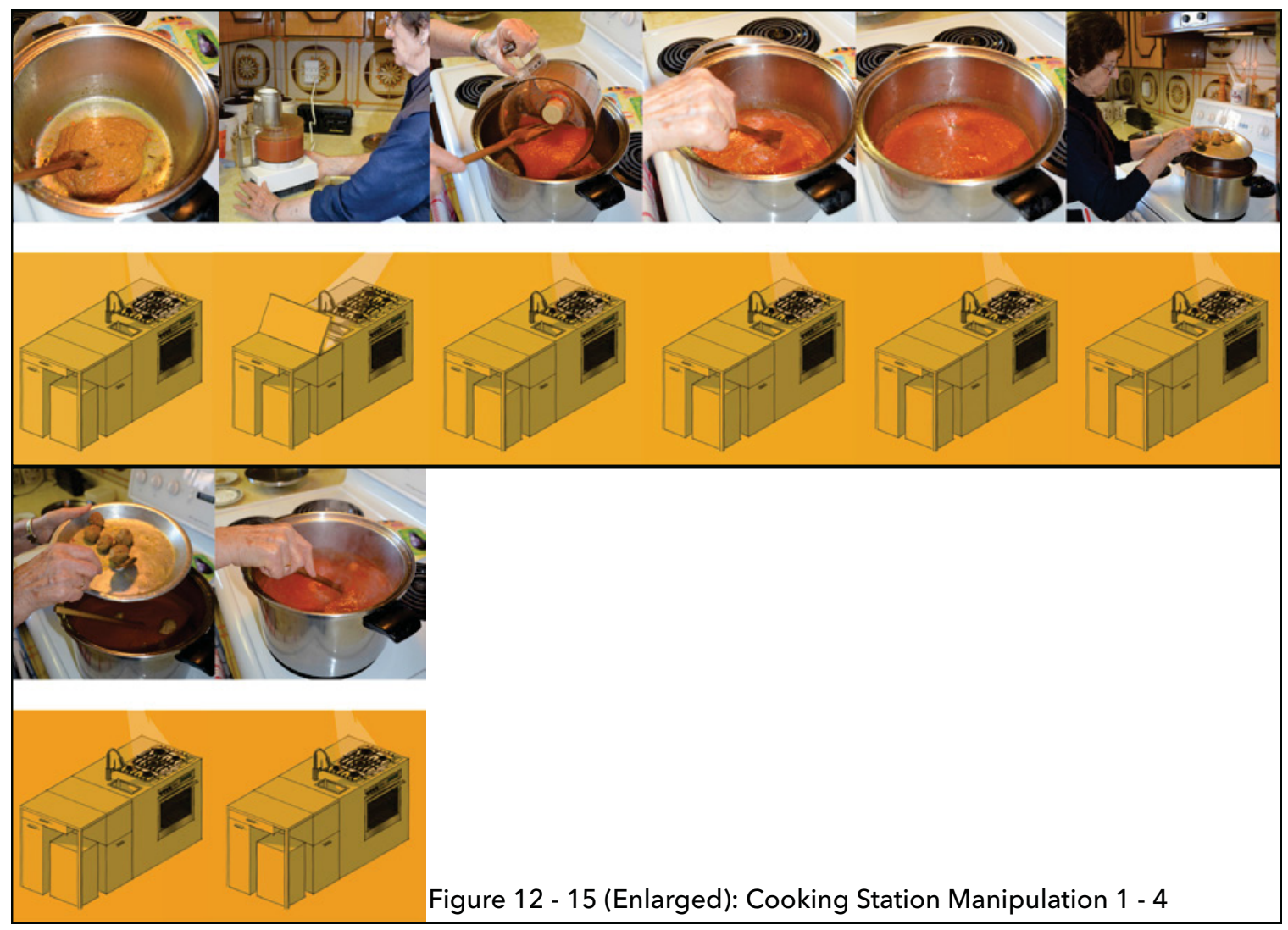



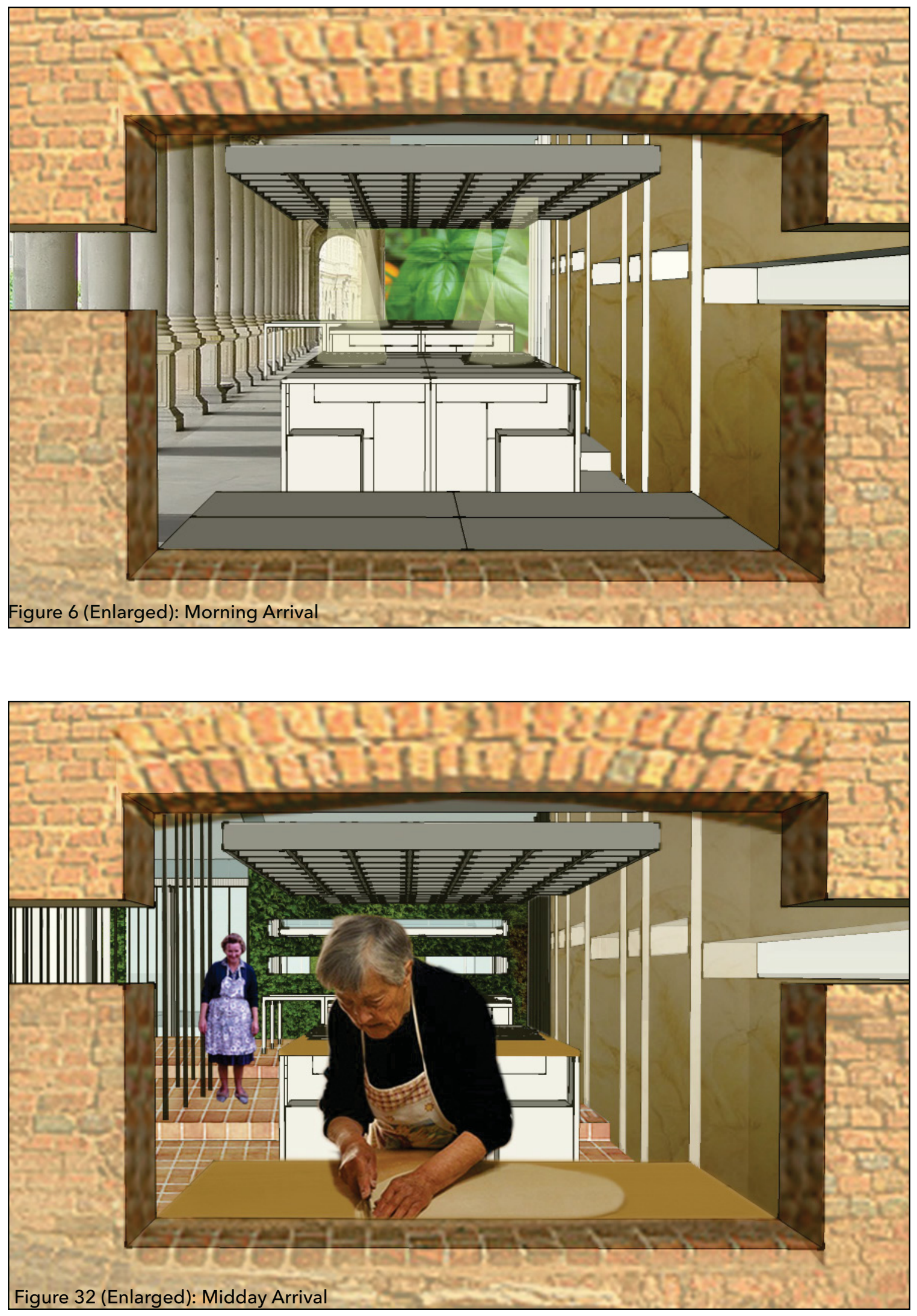

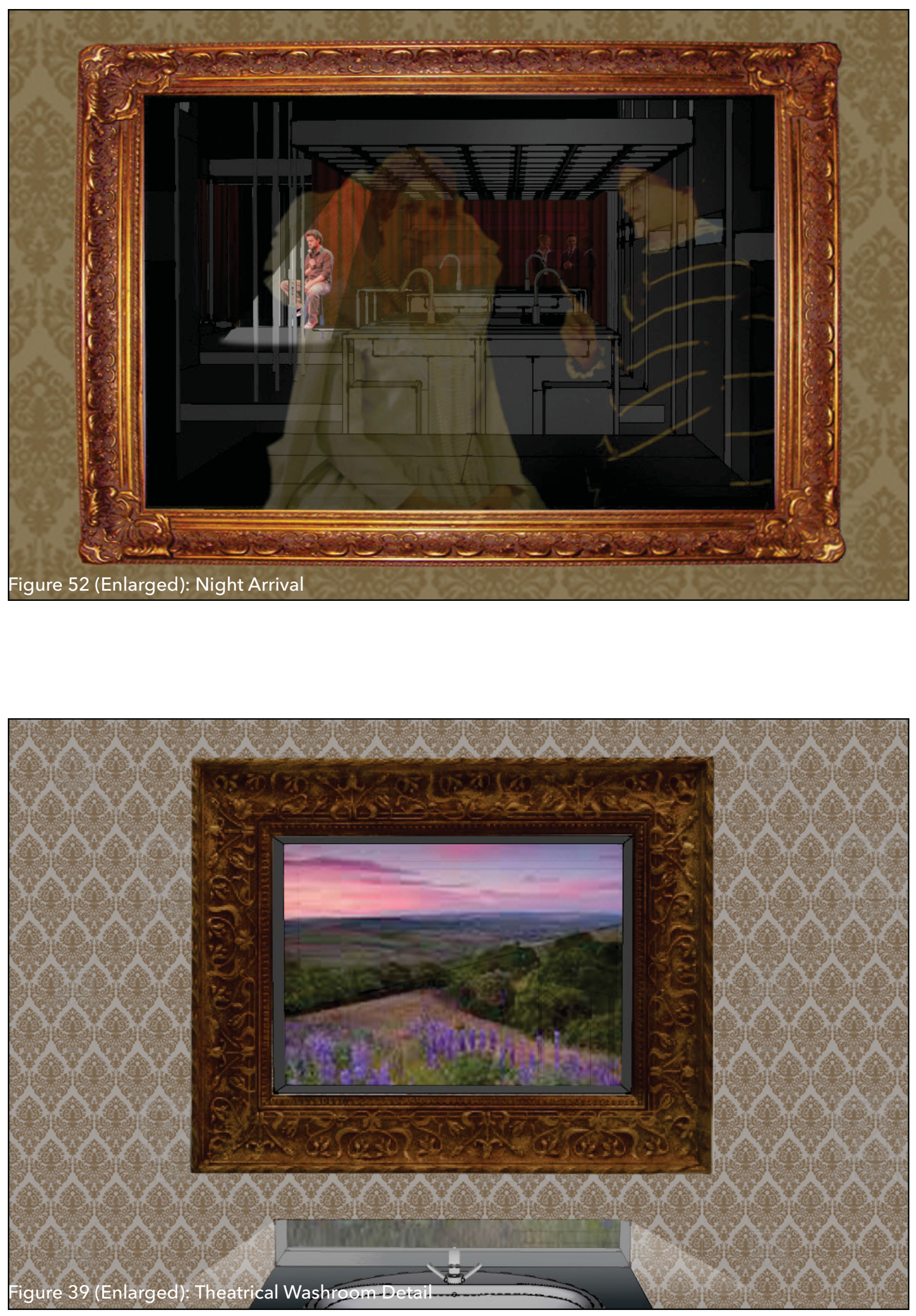

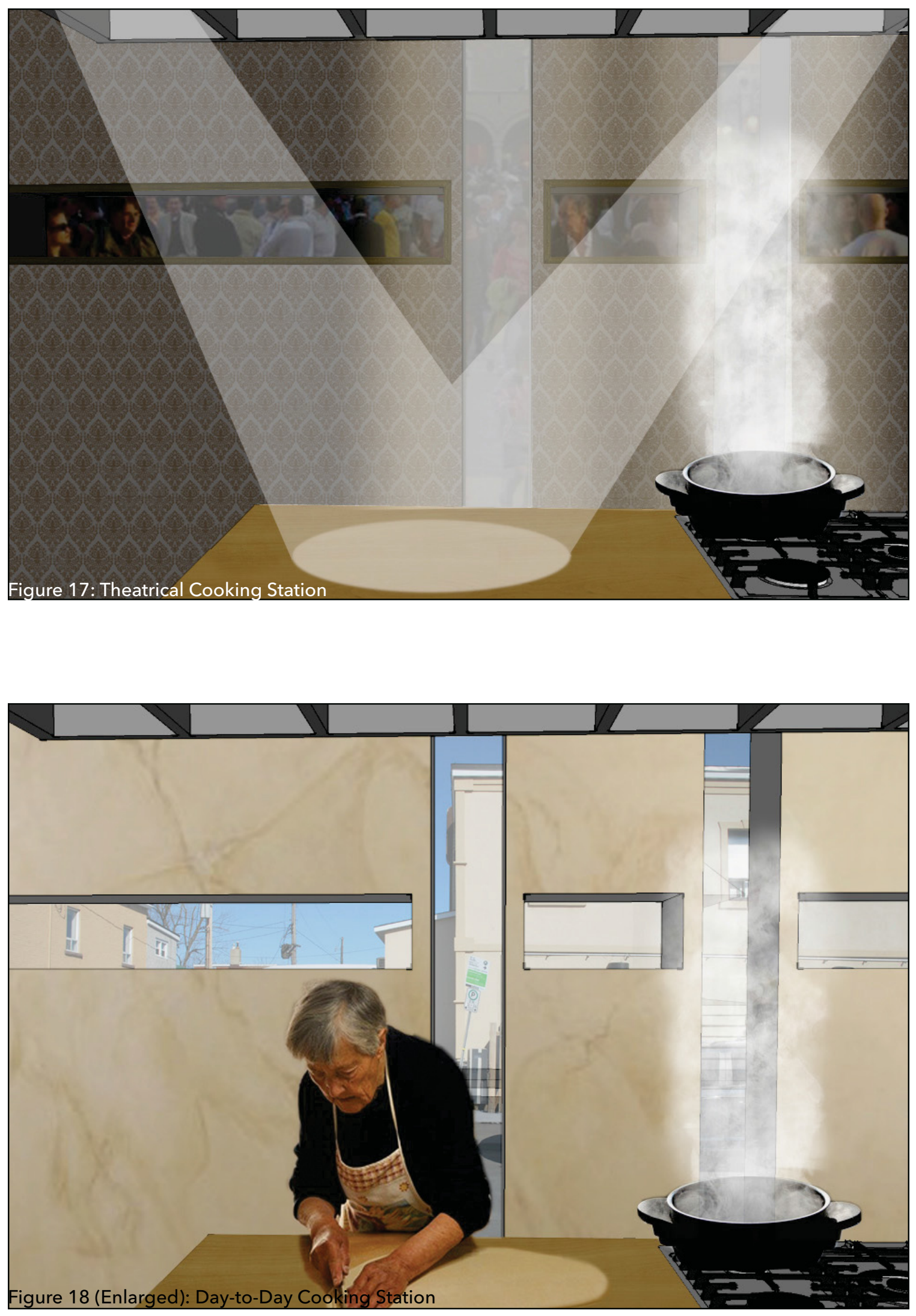

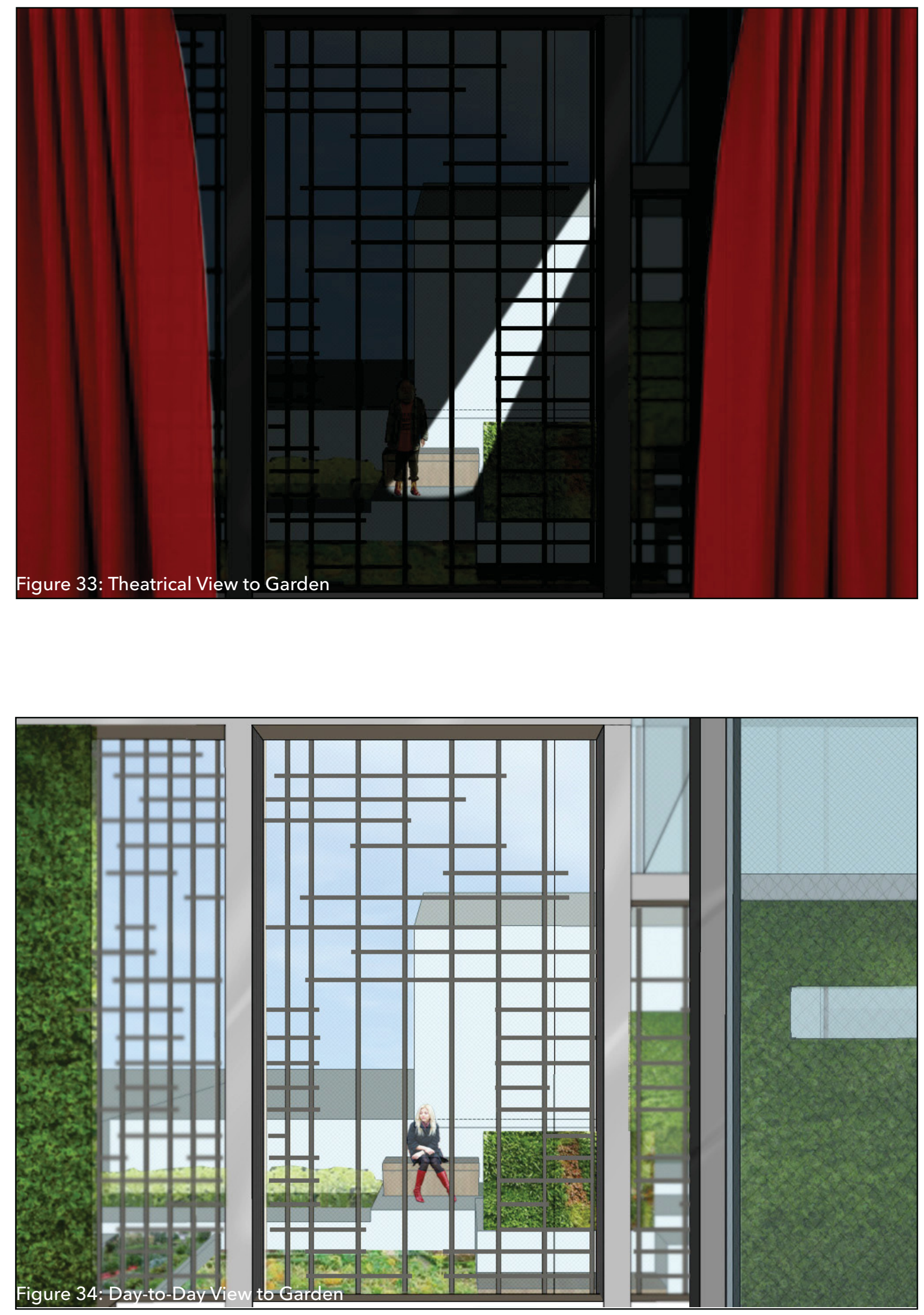

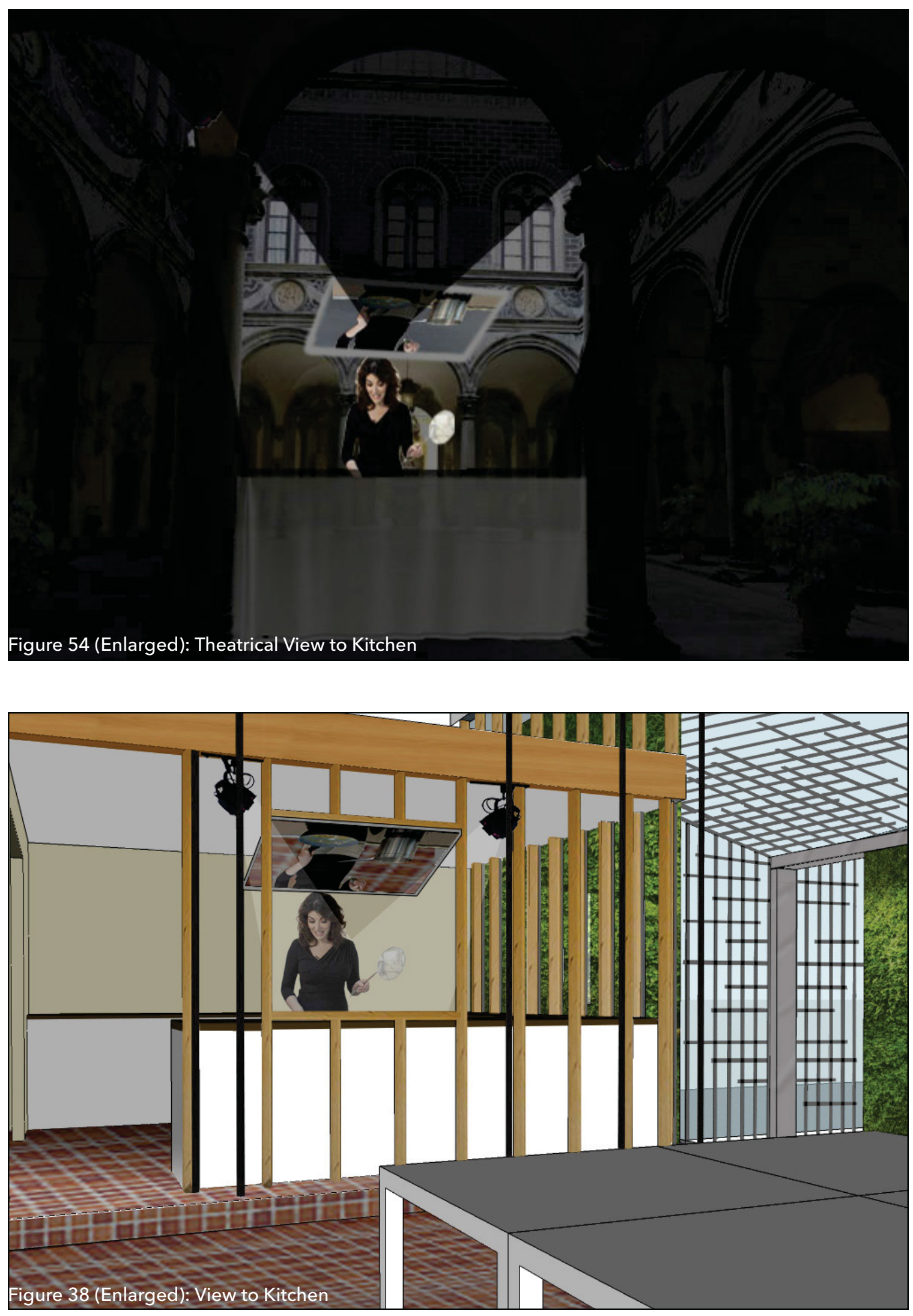

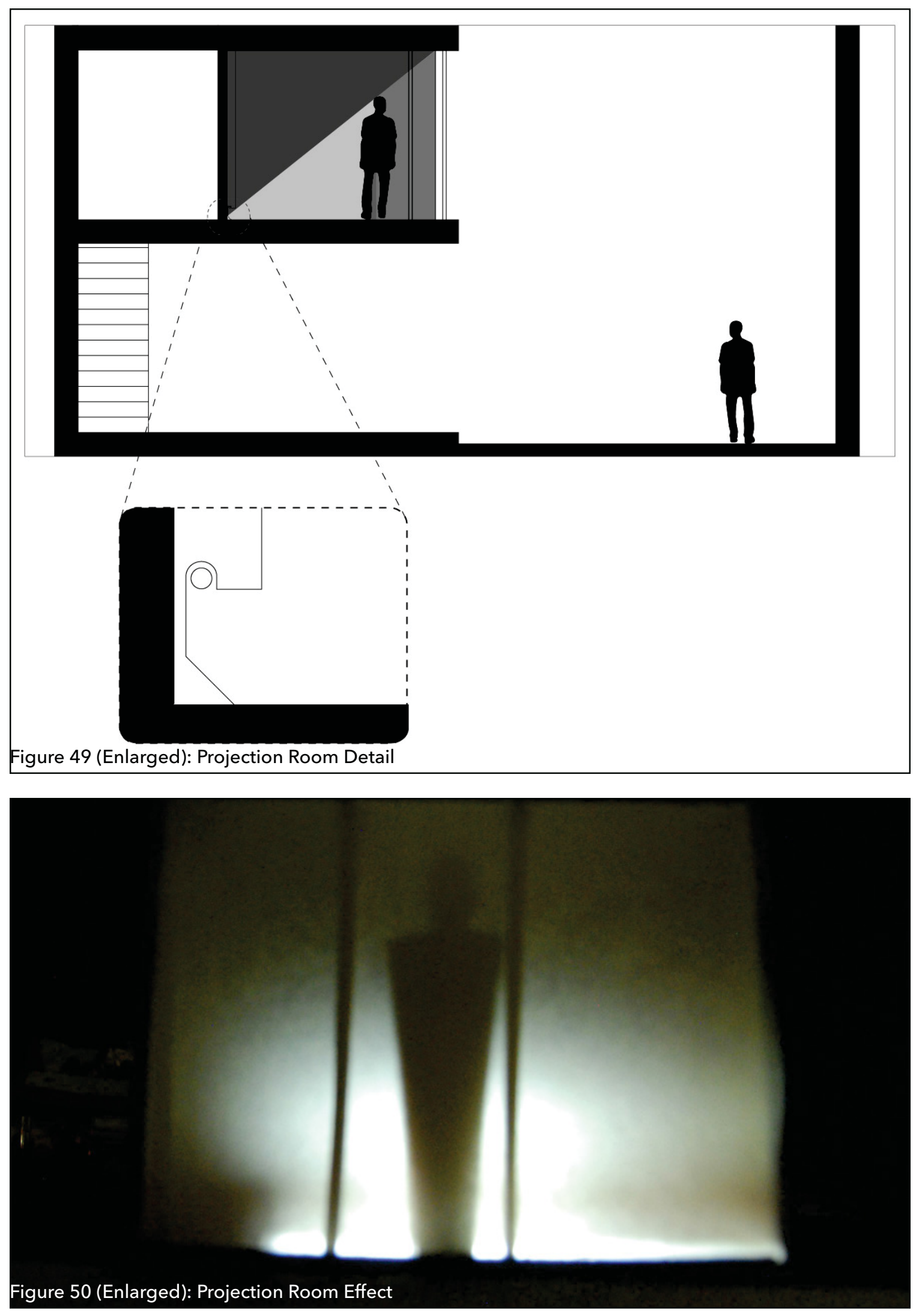


\section{LIST OF ILLUSTRATIONS}

Figure 1: Existing Preston Elevation. Page 9. Petricca, Natalie. Ottawa, Ontario. 2013.

Figure 2: Network Map. Page 10. Petricca, Natalie. Ottawa, Ontario. 2014.

Figure 3: Existing Larch Elevation. Page 13. Petricca, Natalie. Ottawa, Ontario. 2013.

Figure 4: Existing House Reminder. Page 14. Petricca, Natalie. Ottawa, Ontario. 2014.

Figure 5: Arrival Reminder. Page 17. Petricca, Natalie. Ottawa, Ontario. 2014.

Figure 6: Morning Arrival. Page 17, 123. Petricca, Natalie. Ottawa, Ontario. 2014.

Figure 7: Ladies Having Coffee. Page 18. Coffee Klatsch. 2012. Eatocracy. Web. 20 Jan. 2014. <http://eatocracy.cnn.com/2012/10/02/coffee-klatsch-467/>

Figure 8: Ancient Greek Theatre. Page 20. The Greek Theatre at Ephesus. N.d. Primary History - Ancient Greeks. Web. 27 Nov. 2013. <http://www.bbc.co.uk/schools/ primaryhistory/ancient_greeks/arts_and_theatre/teachers_resources.shtml>.

Figure 9: Viewer-Viewed: Sparks Street. Page 21, 116. Petricca, Natalie. Ottawa, Ontario. 2013.

Figure 10: Chatting on the Balcony with Lucy. Page 22. Petricca, Natalie. Ottawa, Ontario. 2013.

Figure 11: Hand Picking Basil. Page 27. Jennifer. Harvesting Basil. 2013. Cambridge. Harvesting Herbs 101. Web. 20 Feb. 2014. <http://www.homegrown.org/forum/topics/ harvesting-herbs-101-basil-chives-cilantro-coriander-mint-parsley>.

Figure 12: Cooking Station Manipulation 1. Page 28, 122. Petricca, Natalie. Woodbridge, Ontario and Ottawa, Ontario. 2014.

Figure 13: Cooking Station Manipulation 2. Page 29, 122. Petricca, Natalie. Woodbridge, Ontario and Ottawa, Ontario. 2014.

Figure 14: Cooking Station Manipulation 3. Page 30, 122. Petricca, Natalie. Woodbridge, Ontario and Ottawa, Ontario. 2014.

Figure 15: Cooking Station Manipulation 4. Page 31, 122. Petricca, Natalie. Woodbridge, Ontario and Ottawa, Ontario. 2014.

Figure 16: Culinary Map. Page 32. Petricca, Natalie. Ottawa, Ontario. 2014

Figure 17: Theatrical Cooking Station. Page 33, 125. Petricca, Natalie. Ottawa, Ontario. 2014.

Figure 18: Day-to-Day Cooking Station. Page 33, 125. Petricca, Natalie. Ottawa, Ontario. 2014.

Figure 19: Views Reminder. Page 34. Petricca, Natalie. Ottawa, Ontario. 2014.

Figure 20: Choreography: Confederation Park. Page 35. Petricca, Natalie. Ottawa, Ontario. 2013. 
Figure 21: Women Making Pasta. Page 39. Eb. Cooking Lessons with Nonna. 2011. Bombo E Motta. Web. 7 Feb. 2014. <http://gypsygazelle.blogspot.ca/2011/07/cookinglessons-with-nonna.html>.

Figure 22: Vertical Herb Gardens. Page 43. Petricca, Natalie. Ottawa, Ontario. 2014

Figure 23: Vertical Herb Garden Reminder. Page 43. Petricca, Natalie. Ottawa, Ontario. 2014.

Figure 24: Pasta Page 44. Petricca, Natalie. Woodbridge, Ontario. 2014.

Figure 25: "Italianamerica" Video Stills 1. Page 45. Italianamerica. Dir. Martin Scorsese. Perf. Charlie Scorsese and Catherine Scorsese. National Communications Foundation, 1974. Film. YouTube. 12 Aug. 2008. Web. 20 Feb. 2014. <http://www.youtube.com/ watch?v=2tzKAILb4iM>.

Figure 26: "Italianamerica" Video Stills 2. Page 46. Italianamerica. Dir. Martin Scorsese. Perf. Charlie Scorsese and Catherine Scorsese. National Communications Foundation, 1974. Film. YouTube. 12 Aug. 2008. Web. 20 Feb. 2014. <http://www.youtube.com/ watch?v=2tzKAlLb4iM>.

Figure 27: "Italianamerica" Video Stills 3. Page 47. Italianamerica. Dir. Martin Scorsese. Perf. Charlie Scorsese and Catherine Scorsese. National Communications Foundation, 1974. Film. YouTube. 12 Aug. 2008. Web. 20 Feb. 2014. <http://www.youtube.com/ watch? $v=2$ tzKAlLb4iM>.

Figure 28: "Italianamerica" Video Stills 4. Page 48. Italianamerica. Dir. Martin Scorsese. Perf. Charlie Scorsese and Catherine Scorsese. National Communications Foundation, 1974. Film. YouTube. 12 Aug. 2008. Web. 20 Feb. 2014. <http://www.youtube.com/ watch?v=2tzKAlLb4iM>.

Figure 29: Pasta Ingredients. Page 50. Hunter, Benjamin. Making Pasta 1. 2013. Life \& Thyme. Web. 20 Feb. 2014. <http://lifeandthyme.com/recipe/making-homemadepasta/>.

Figure 30: Layering: Little Italy. Page 54, 116. Petricca, Natalie. Ottawa, Ontario. 2013.

Figure 31: Layering: The Courtyards. Page 55, 117. Petricca, Natalie. Ottawa, Ontario. 2013.

Figure 32: Midday Arrival. Page 55, 123. Petricca, Natalie. Ottawa, Ontario. 2014.

Figure 33: Theatrical View to Garden. Page 57, 126. Petricca, Natalie. Ottawa, Ontario. 2014.

Figure 34: Day-to-Day View to Garden. Page 57, 126. Petricca, Natalie. Ottawa, Ontario. 2014.

Figure 35: Espalier Reminder. Page 58. Petricca, Natalie. Ottawa, Ontario. 2014.

Figure 36: Viewer-Viewed: Bank and Sparks Street. Page 59, 117. Petricca, Natalie Ottawa, Ontario. 2013.

Figure 37: Elizabethan Theatre. Page 60. Monir Tayeb, and Michel Austin. Interior of the Theatre Royal Haymarket in 1815. N.d. The Hector Berlioz Website. Web. 27 Nov. 2013.

<http://www.hberlioz.com/London/BLHaymarket.htmls. 
Figure 38: View to Kitchen. Page 61, 127. Petricca, Natalie. Ottawa, Ontario. 2014.

Figure 39: Theatrical Washroom Detail. Page 63, 124. Petricca, Natalie. Ottawa, Ontario. 2014.

Figure 40: Framing: Esplanade Laurier. Page 64, 118. Petricca, Natalie. Ottawa, Ontario. 2013.

Figure 41: Balconies Map. Page 67. Petricca, Natalie. Ottawa, Ontario. 2014.

Figure 42: Balconies Overlooking Kitchen and Preston. Page 67. Petricca, Natalie. Ottawa, Ontario. 2014

Figure 43: View to Cook-top. Page 69. Petricca, Natalie. Ottawa, Ontario. 2014.

Figure 44: Gathering Reminder. Page 70. Petricca, Natalie. Ottawa, Ontario. 2014.

Figure 45: Focus Reminder. Page 76. Petricca, Natalie. Ottawa, Ontario. 2014.

Figure 46: Lighting Map. Page 78. Petricca, Natalie. Ottawa, Ontario. 2013.

Figure 47: Lighting Preston Street. Page 79, 119. Petricca, Natalie. Ottawa, Ontario. 2013.

Figure 48: Lighting: 276 Wellington Street. Page 81, 120. Petricca, Natalie. Ottawa, Ontario. 2013.

Figure 49: Projection Room Detail. Page 82, 128. Petricca, Natalie. Ottawa, Ontario. 2014.

Figure 50: Projection Room Effect. Page 82, 128. Petricca, Natalie. Ottawa, Ontario. 2014.

Figure 51: Balconies at Night. Page 83. Petricca, Natalie. Ottawa, Ontario. 2014.

Figure 52: Night Arrival. Page 85, 124. Petricca, Natalie. Ottawa, Ontario. 2014.

Figure 53: Basement at Night. Page 88. Petricca, Natalie. Ottawa, Ontario. 2014.

Figure 54: Theatrical View to Kitchen. Page 89, 127. Petricca, Natalie. Ottawa, Ontario. 2014.

Figure 55: Site Plan. Page 93. Petricca, Natalie. Ottawa, Ontario. 2014.

Figure 56: Basement Plan. Page 94. Petricca, Natalie. Ottawa, Ontario. 2014.

Figure 57: First Floor Plan - Morning. Page 95. Petricca, Natalie. Ottawa, Ontario. 2014. Figure 58: First Floor Plan - Midday. Page 96. Petricca, Natalie. Ottawa, Ontario. 2014.

Figure 59: First Floor Plan - Evening. Page 97. Petricca, Natalie. Ottawa, Ontario. 2014.

Figure 60: Second Floor Plan - Morning. Page 98. Petricca, Natalie. Ottawa, Ontario. 2014. 
Figure 61: Second Floor Plan - Midday. Page 99. Petricca, Natalie. Ottawa, Ontario. 2014.

Figure 62: Second Floor Plan - Evening. Page 100. Petricca, Natalie. Ottawa, Ontario. 2014.

Figure 63: Elevations. Page 101. Petricca, Natalie. Ottawa, Ontario. 2014.

Figure 64: Section A. Page 102. Petricca, Natalie. Ottawa, Ontario. 2014.

Figure 65: Section B. Page 103. Petricca, Natalie. Ottawa, Ontario. 2014.

Figure 66: Section C. Page 104. Petricca, Natalie. Ottawa, Ontario. 2014.

Figure 67: Section D. Page 105. Petricca, Natalie. Ottawa, Ontario. 2014.

Figure 68: Section E. Page 106. Petricca, Natalie. Ottawa, Ontario. 2014.

Figure 69: Overall View of Model. Page 107. Petricca, Natalie. Ottawa, Ontario. 2014.

Figure 70: Preston Street Elevation. Page 107. Petricca, Natalie. Ottawa, Ontario. 2014.

Figure 71: Overall Section. Page 108. Petricca, Natalie. Ottawa, Ontario. 2014.

Figure 72: Cooking Section. Page 108. Petricca, Natalie. Ottawa, Ontario. 2014.

Figure 73: Viewer-Viewed. Page 108. Petricca, Natalie. Ottawa, Ontario. 2014.

Figure 74: Greenhouse and Garden. Page 109. Petricca, Natalie. Ottawa, Ontario. 2014.

Figure 75: Cooking in Light. Page 109. Petricca, Natalie. Ottawa, Ontario. 2014.

Figure 76: Little Italy Balconies 1. Page 110. Petricca, Natalie. Ottawa, Ontario. 2013.

Figure 77: Little Italy Balconies 2. Page 110. Petricca, Natalie. Ottawa, Ontario. 2013. 
REFERENCES

Abramovic, Marina. "Interview Pt. 1." Interview by Paula Cohen. YouTube. TimesTalks,

5 Apr. 2013. Web. 9 Oct. 2013. <http://www.youtube.com/

watch?v=ZcWSeXO3khM>

Allen, James Turney. Greek Theatre of the Fifth Century before Christ. New York: Haskell House, 1966. Print.

Arnott, Peter D. Public and Performance in the Greek Theatre. London: Routledge, 1989.

Print.

Artaud, Antonin. "The Theatre of Cruelty (First Manifesto)." Antonin Artaud, Selected

Writings. New York: Farrar, Straus and Giroux, 1976. 242-50. Print.

Brecht, Bertolt, and John Willett. Brecht on Theatre; the Development of an Aesthetic.

New York: Hill and Wang, 1964. Print.

Brook, Peter. The Empty Space. New York: Atheneum, 1968. Print.

Carlson, Marvin A. Places of Performance: The Semiotics of Theatre Architecture. Ithaca, NY: Cornell UP, 1989. Print.

De, Marinis Marco. The Semiotics of Performance. Bloomington: Indiana UP, 1993.

Dundjerović, Aleksandar Saša. The Theatricality of Robert Lepage. Montreal: McGill-

Queen's UP, 2007. Print.

Eat Pray Love. Dir. Ryan Murphy. Perf. Julia Roberts and Javier Bardem. Sony, 2010

Fischer-Lichte, Erika. The Transformative Power of Performance: A New Aesthetics. New

York: Routledge, 2008. Print.

Frascari, Marco. "Semiotica Ab Edendo, Taste in Architecture." Eating Architecture.

Cambridge, MA: MIT, 2004. 191-202. Print.

Gadamer, Hans-Georg, and Robert Bernasconi. The Relevance of the Beautiful and Other Essays. Cambridge (Cambridgeshire: Cambridge UP, 1986).

Gadamer, Hans-Georg. "The Ontology of the Work of Art and Its Hermeneutic Significance." Truth and Method. New York: Crossroad, 1989. N. pag. 
Garner, Stanton B. Bodied Spaces: Phenomenology and Performance in Contemporary Drama. Ithaca, NY: Cornell UP, 1994.

Gratza, Agnieszka. "Open House - The Evolution of Performance Architecture." Frieze Magazine. Sept. 2013: n. pag. Freize. Sept. 2013. Web. 16 Oct. 2013. <http:// www.frieze.com/issue/article/open-house/>.

Harris, Max. Theatre and Incarnation. New York: St. Martin's, 1990.

Henderson, Brian. "The Long Take". Movies and Methods: An Anthology, ed. Bill Nichols. Berkeley: University of California Press, 1976.

Homan, Sidney. The Audience as Actor and Character: The Modern Theatre of Beckett, Brecht, Genet, Ionesco, Pinter, Stoppard, and Williams. Lewisburg [Pa.: Bucknell UP, 1989

Italianamerica. Dir. Martin Scorsese. Perf. Charlie Scorsese and Catherine Scorsese. National Communications Foundation, 1974. Film. YouTube. 12 Aug. 2008. Web. 20 Feb. 2014. <http://www.youtube.com/watch?v=2tzKAlLb4iM>.

Leatherbarrow, David. Architecture Oriented Otherwise. New York: Princeton Architectural, 2009. Print.

Montagné, Prosper. Larousse Gastronomique, ed: Jennifer Harvey Lang. New York: Crown, 1988. Second English edition.

Mullin, Donald C. The Development of the Playhouse; a Survey of Theatre Architecture from the Renaissance to the Present. Berkeley: University of California, 1970. Print. Pérez-Gómez, A., S. Parcell, and Graduate Program. Chora 1: Intervals in the Philosophy of Architecture. Montreal: McGill-Queen's UP, 1994.

Popow, W. Bro. Victor G. "A Report on Psychology and Architecture." December 2000. October 22,2012. http://www.grandlodge.mb.ca/mrc_docs/Psychology\%20 of\%20Architecture.pdf.

Sennett, Richard. The Fall of Public Man. New York: Knopf, 1977. Print.

Soufas, C. Christopher. Audience and Authority in the Modernist Theatre of Federico García Lorca. Tuscaloosa: University of Alabama, 1996. 
Stone, Deborah, "Architecture and the Environment." Psychological Musings (web log), August 7, 2011. October 22, 2012. http://psychological-musings.blogspot. ca/2011/08/architecture-and-environment.html.

Ubersfeld, Anne, Frank Collins, Paul Perron, and Patrick Debbèche. Reading Theatre. Toronto: University of Toronto, 1999. 